SANDIA REPORT

SAND96-2133 - UC-721 2000

Unlimited Release

Printed December 1996
RECEIVED

JAN 171997

OSTI

\title{
The Role of Regional Groundwater Flow in the Hydrogeology of the Culebra Member of the Rustler Formation at the Waste Isolation Pilot Plant (WIPP), Southeastern New Mexico.
}

T. F. Corbet, P. M. Knupp

Prepared by

Sandia National Laboratories

Albuquerque, New Mexico 87185 and Livermore, California 94550

for the United States Department of Energy

under Contract DE-AC04-94AL85000

Approved for public release; distribution is unlimited.

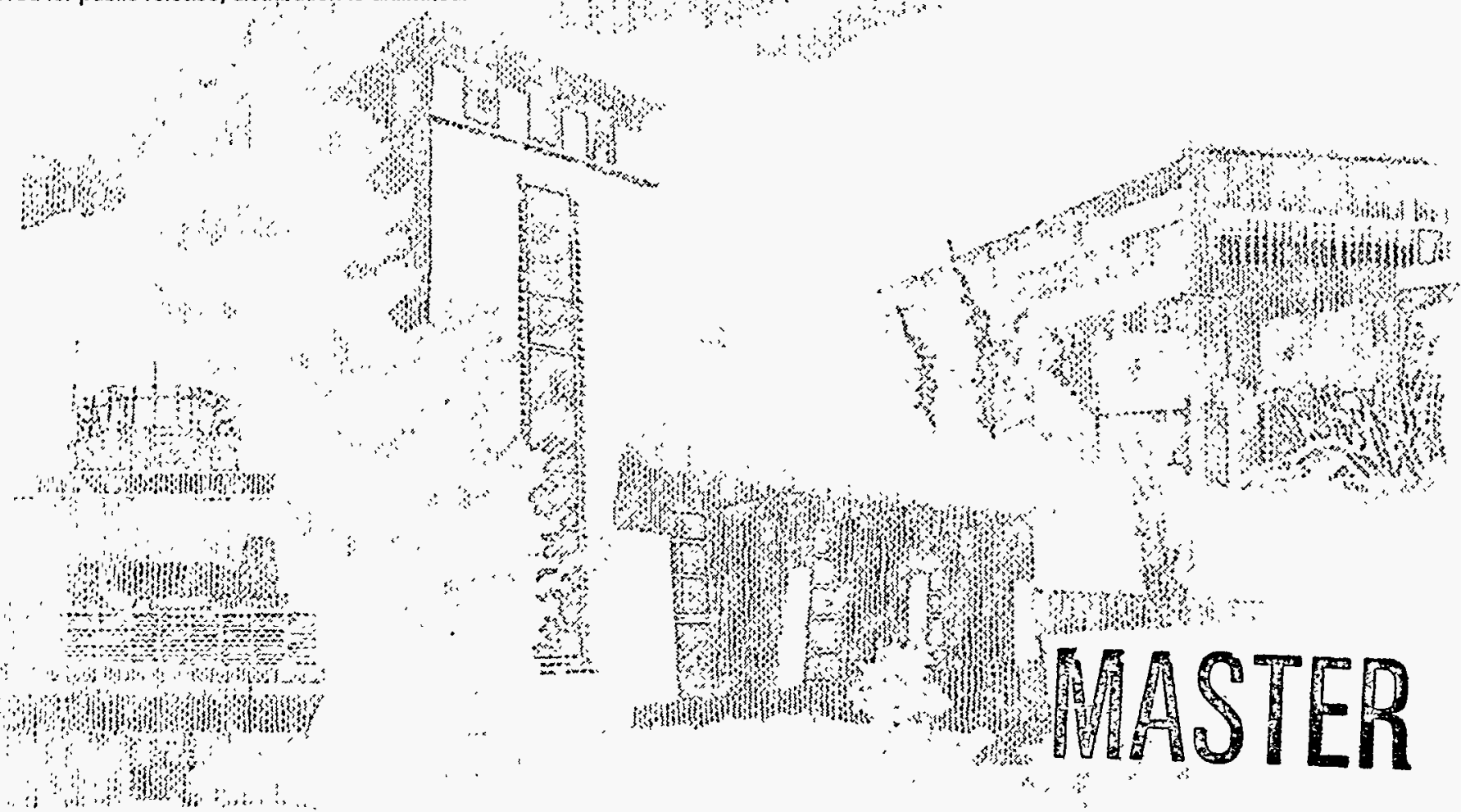


Issued by Sandia National Laboratories, operated for the United States Department of Energy by Sandia Corporation.

NOTICE: This report was prepared as an account of work sponsored by an agency of the United States Government. Neither the United States Government nor any agency thereof, nor any of their employees, nor any of their contractors, subcontractors, or their employees, makes any warranty, express or implied, or assumes any legal liablity or responsibility for the accuracy, completeness, or usefulness of any information, apparatus, product, or process disclosed, or represents that its use would not infringe privately owned rights. Reference herein to any specific commercial product, process, or service by trade name, trademark, manufacturer, or otherwise, does not necessarily constitute or imply its endorsement, recommendation, or favoring by the United States Government, any agency thereof or any of their contractors or subcontractors. The views and opinions expressed herein do not necessarily state or reflect those of the United States Government, any agency thereof or any of their contractors.

Printed in the United States of America. This report has been reproduced directly from the best available copy.

Available to DOE and DOE contractors from

Office of Scientific and Technical Information

PO Box 62

Oak Ridge, TN 37831

Prices available from (615) 576-8401, FTS 626-8401

Available to the public from

National Technical Information Service

US Department of Commerce

5285 Port Royal RD

Springfield, VA 22161

NTIS price codes

Printed copy: A04

Microfiche copy:A01 
SAND96-2133

Unlimited Release

Printed December 1996

Distribution

Category UC-721-2000

\title{
The Role of Regional Groundwater Flow in the Hydrogeology of the Culebra Member of the Rustler Formation at the Waste Isolation Pilot Plant (WIPP), Southeastern New Mexico.
}

\author{
T.F. Corbet \\ Geohydrology Department \\ Sandia National Laboratories \\ Albuquerque, NM 87185 \\ P.M. Knupp \\ Ecodynamics Research Associates \\ PO Box 9229 \\ Albuquerque, NM 87119
}

\begin{abstract}
Niumerical simulation has been used to enhance conceptual understanding of the hydrogeology of the Culebra Dolomite in the context of regional groundwater flow. The hydrogeology of the Culebra is of interest because this unit is a possible pathway for offsite migration of radionuclides from a proposed repository for defense-generated transuranic wastes (the Waste Isolation Pilot Plant). The numerical model used for these simulations is three-dimensional, extends laterally to topographic features that form the actual boundaries of a regional groundwater system, and uses a free-surface upper boundary condition to simulate the effect of change in the rate of recharge on groundwater flow. Steady-state simulations were performed to examine the sensitivity of simulation results to assumed values for hydraulic conductivity and recharge rate. Transient simulations, covering the time period from 14,000 years in the past to 10,000 years in the future, provided insight into how pattems of groundwater flow respond to changes in climate. Simulation results suggest that rates and directions of groundwater flow in the Culebra change with time due to interaction between recharge, movement of the water table, and the topography of the land surface. A cooler and wetter climate in southeastern New Mexico during the late Pleistocene resulted in a groundwater flow system in which the water table was near the land surface and flow directions in the Culebra were controlled by local-scale features of the land-surface topography. The gentle east-to-west slope of the land surface in the vicinity of the WIPP caused groundwater in the Culebra to flow toward and discharge into Nash Draw, a topographic depression. The water table dropped to a lower elevation and became smoother in response to a decrease in recharge that occurred over the period from 14,000 to 8,000 years ago. Consequently, modern-day flow directions in the Culebra reflect regional rather than local features of the topography. Changes in groundwater flow,
\end{abstract}


however, lagged behind changes in the rate of recharge. The present-day position of the water table is still adjusting to the decrease in recharge that ended 8,000 years ago. Groundwater inflow to the portion of the Culebra within the WIPP-site boundary is by a combination of lateral flow within the Culebra and extremely slow vertical leakage from overlying units. Nearly all of the outflow from this portion of the Culebra is by lateral flow. Therefore, contaminants introduced into the Culebra will travel toward the accessible environment along the Culebra rather than by leaking upward or downward into other units. Natural changes in flow in the Culebra over the next 10,000 years will be small and will mainly reflect future short-term wet periods such as have occurred over the past 8,000 years. Maximum future flow rates in the Culebra are expected to be less than two times greater than present-day rates. 


\section{DISCLAMMER}

Portions of this document may be illegible in electronic image products. Images are produced from the best available original document. 


\section{Acknowledgments}

The efforts of a number of people made this work possible. Peter Davies provided initial encouragement for this project and helpful suggestions during its completion. Mike Wallace helped perform and interpret earlier generations of simulations, discretized the hydrostratigraphy and participated in many helpful discussions. Peter Swift provided valuable suggestions on appropriate recharge distributions to represent climate change, contributed text to Section 2.4 conceming the climate history in southeastern New Mexico, and compiled and mapped geologic and geographic information. Lucy Meigs performed simulations to examine the effects of spatially varying recharge and provided valuable insight into simulation results. Bob Holt developed the conceptual model of how geologic processes have effected hydraulic properties and mapped the regions effected by these processes (Figure 2-6). He also constructed structure contour maps on the tops of the hydrostratigraphic units. Roy Courtright helped construct structure contour maps, constructed geologic cross-sections, and checked stratigraphic data for accuracy. Ken Brinster helped compile stratigraphic data. Steve Askew assisted with code development, programmed the software to perform simulations and provide configuration control, ran simulations, and produced graphical output. Ellen Dombrowski assisted with code development and programmed input/output routines. Rebecca Blaine generated the programs used to interactively visualize simulation results. Bruce Baker helped generate graphs of simulation results.

The manuscript was much improved by careful technical reviews by Kurt Larson, Peter Swift, Peter Davies, and Margaret Chu. In addition, Al Lappin provided helpful comments and discussion on the conceptual model of regional flow near the WIPP, Bob Holt reviewed the hydrostratigraphy section, and David Bullock provided a QA review. Tina Johnson and Bob Jones designed and prepared figures. Merlyn Liberty was the technical editor and Carol Crawford was the reference librarian.

We especially want to thank Steve Askew. In addition to being the heart of our day-to-day computational capabilities, Steve contributed to scientific interpretation and remained cheerful and helpful no matter how many times we repeated the simulations. His value to the project was particularly evident as we struggled to complete the work without him. He was a good friend and we are saddened by his passing. 
This Page Intentionally Left Blank 


\section{CONTENTS}

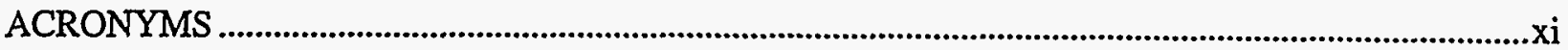

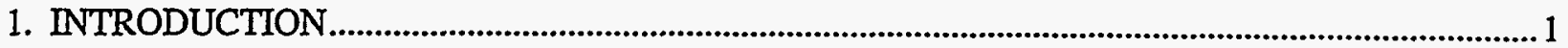

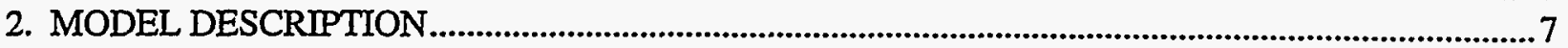

2.1 Groundwater Basin Conceptual Model .................................................................................... 7

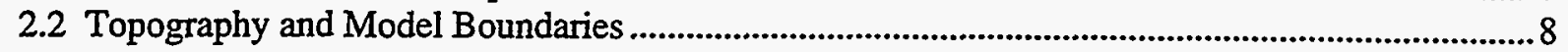

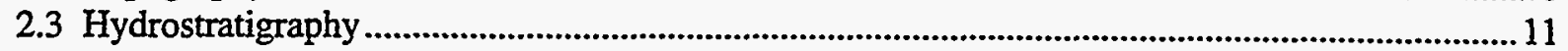

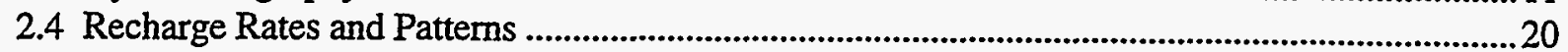

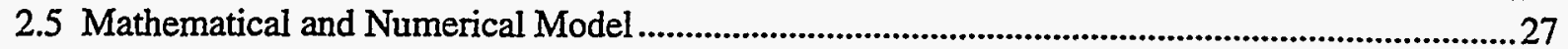

2.5.1 The Free Surface Groundwater Flow Equations: Mathematical Model ..............................229

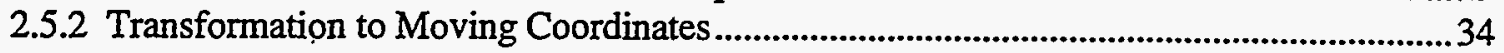

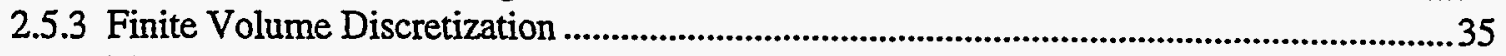

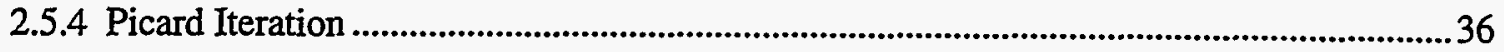

2.5.4.1 FREE-SURFACE BOUNDARY CONDITION FOR THE LINEARIZED

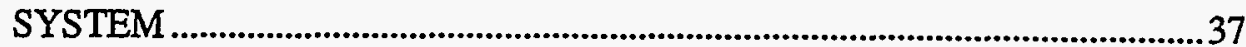

2.5.4.2 UPDATING THE WATER TABLE AND MOVING GRID ..............................40

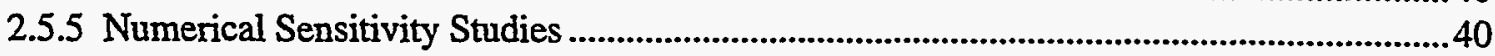

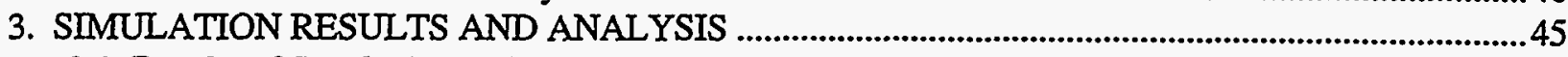

3.1 Results of Steady-State Simulations............................................................................................48

3.1.1 Sensitivity of the Elevation of the Water Table and Hydraulic Head to Model

Parameters........................................................................................................................51

3.1.2 Sensitivity of Lateral Flow Rates in the Culebra to Model Parameters...............................61

3.1.3 Sensitivity of Lateral Flow Directions in the Culebra to Model Parameters ......................8 80

3.1.4 Sensitivity of Mass Balance over the Culebra Reference Volume to Model Parameters..81

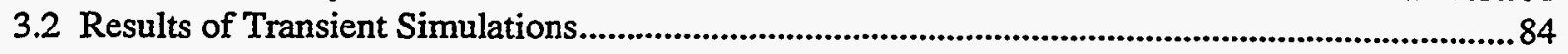

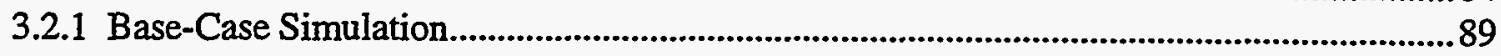

3.2.1.1 RESULTS AT THE SCALE OF THE MODEL DOMAIN .................................89

3.2.1.2 RESULTS AT THE SCALE OF THE WIPP SITE..............................................98

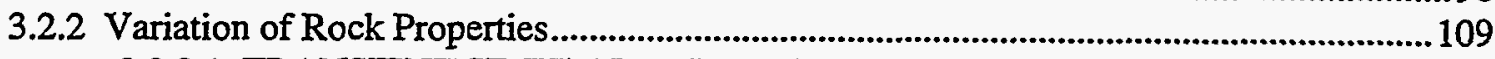

3.2.2.1 TRANSIENT SIMULATION 1: REDUCED ANHYDRITE CONDUCTIVITY .......................................................................................109

3.2.2.2 TRANSIENT SIMULATION 2: INCREASED DISRUPTED ZONE CONDUCTIVITY .....................................................................................111

3.2.2.3 TRANSIENT SIMULATION 3: INCREASED DEWEY LAKE/TRIASSIC ROCKS CONDUCTIVITY.........................................................................113

3.2.2.4 TRANSIENT SIMULATION 4: INCREASED CULEBRA

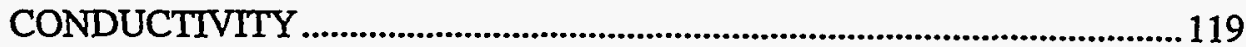

3.2.2.5 TRANSIENT SIMULATION 5: INCREASED MAGENTA

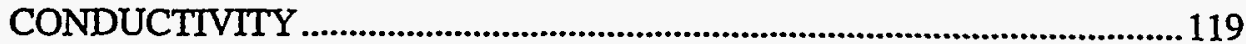

3.2.2.6 TRANSIENT SIMULATION 6: INCREASED SPECIFIC YIELD...................121

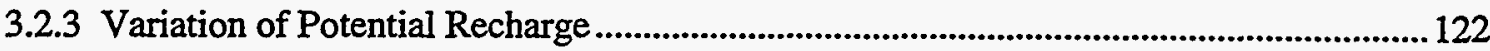

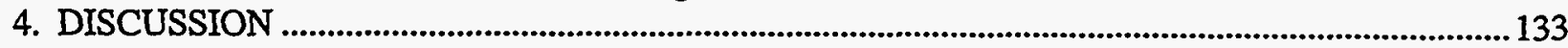

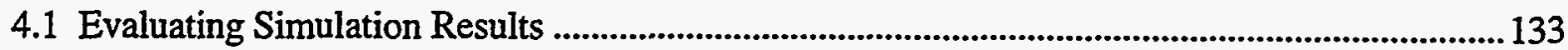

4.2 Conceptual Model of Groundwater Flow in the Culebra .......................................................... 137

4.3 Implications for Flow in the Culebra in the Vicinity of WIPP .................................................. 140

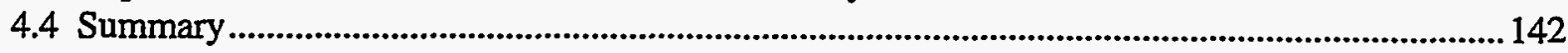

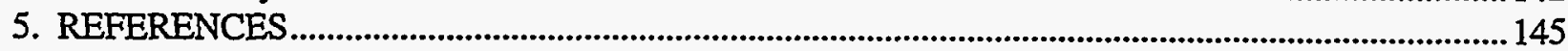

APPENDIX A: A Simplified Derivation of the Steady-State Kinematic Boundary Condition:.................A-1 
APPENDIX B: Existence and Uniqueness of Solutions: A ID Model Problem..................................... B-1 APPENDIX C: Selected Results from Steady-State Simulations........................................................... C-1 APPENDIX D: Selected Results from Transient Simulations .................................................................... D-1 


\section{Figures}

1-1 Boundary of the numerical model....................................................................................................4

2-1 Idealized cross-section of a groundwater basin for a hot, dry climate (a) and a cool, wet climate (b) 4

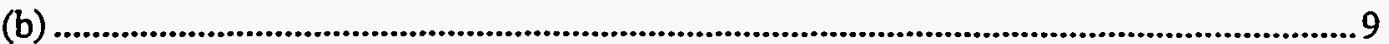

2-2 Outline of the numerical model on a topographic map..................................................................... 10

2-3 Hydrostratigraphic units used in the numerical model .................................................................12

2-4 Geologic cross-section along line B - B' (Figure 2-2)................................................................... 13

2-5 Structure contour map on the top of the Culebra Dolomite Member of the Rustler Formation.... 15

2-6 Regions in which hydraulic conductivity has been affected by post-depositional geological

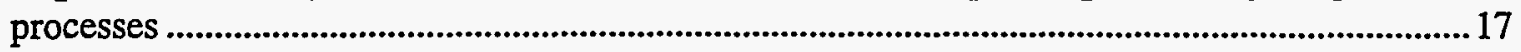

2-7 Zonation approach used to represent the effects of depositional setting and post-depositional processes ................................................................................................................................................. 18

2-8 Distribution of hydraulic conductivity $(\mathrm{m} / \mathrm{s})$ used for the Culebra hydrostratigraphic unit for steady-state simulations 14 and 41 (Table 3-1) ...............................................................................21

2-9 Distribution of hydraulic conductivity $(\mathrm{m} / \mathrm{s})$ used for the anhydrite hydrostratigraphic units for steady-state simulations 14 and 41 (Table 3-1)..........................................................................21

2-10 Distribution of hydraulic conductivity $(\mathrm{m} / \mathrm{s})$ used for the mudstone/halite hydrostratigraphic units for steady-state simulations 14 and 41 (Table 3-1) .............................................................22

2-11 Distribution of hydraulic conductivity $(\mathrm{m} / \mathrm{s})$ used for the Dewey Lake/Triassic hydrostratigraphic unit for steady-state simulations 14 and 41 (Table 3-1)..................................22

2-12 Estimated mean annual precipitation at the WIPP during the late Pleistocene and Holocene......23

2-13 Assumed functions for potential recharge for the transient simulations. ......................................26

2-14 Nomenclature used for the mathematical model of the free surface ............................................32

3-1 Simulated steady-state elevation of the water table (upper point), Magenta head, and Culebra head (lower point) near the center of the WIPP site versus the conductivity of intact

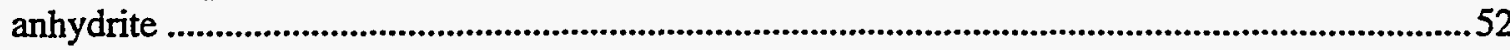

3-2 Simulated steady-state elevation of the water table (upper point), Magenta head, and Culebra head (lower point) near the center of the WIPP site versus the conductivity of intact anhydrite.

3-3 Simulated steady-state elevation of the water table (upper point), Magenta head, and Culebra head (lower point) near the center of the WIPP site versus the conductivity of the disrupted region. .

3-4 Simulated steady-state elevation of the water table (upper point), Magenta head, and Culebra head (lower point) near the center of the WIPP site versus the conductivity of the disrupted region ...

3-5 Simulated steady-state elevation of the water table (upper point), Magenta head, and Culebra head (lower point) near the center of the WIPP site versus the conductivity of the Dewey Lake/Triassic rocks

3-6 Simulated steady-state elevation of the water table (upper point), Magenta head, and Culebra head (lower point) near the center of the WIPP site versus the conductivity of the Dewey Lake/Triassic rocks.

3-7 Simulated steady-state elevation of the water table (upper point), Magenta head, and Culebra head (lower point) near the center of the WIPP site versus the rate of potential recharge.............58

3-8 Simulated steady-state elevation of the water table (upper point), Magenta head, and Culebra head (lower point) near the center of the WIPP site versus the rate of potential recharge............59

3-9 Simulated steady-state elevation of the water table (upper point), Magenta head, and Culebra head (lower point) near the center of the WIPP site versus the rate of potential recharge.............60 


\section{Figures (continued)}

3-10 Simulated lateral specific discharge $(\mathrm{m} / \mathrm{yr})$ in the Culebra near the center of the WIPP site versus the conductivity of intact anhydrite

3-11 Simulated lateral specific discharge ( $\mathrm{m} / \mathrm{yr})$ in the Culebra near the center of the WIPP site versus the conductivity of intact anhydrite

3-12 Simulated lateral specific discharge $(\mathrm{m} / \mathrm{yr})$ in the Culebra near the center of the WIPP site versus the conductivity of the disrupted region

3-13 Simulated lateral specific discharge $(\mathrm{m} / \mathrm{yr})$ in the Culebra near the center of the WIPP site versus the conductivity of disrupted.

3-14 Simulated lateral specific discharge $(\mathrm{m} / \mathrm{yr})$ in the Culebra near the center of the WIPP site versus the conductivity of the Dewey Lake/Triassic rocks

3-15 Simulated lateral specific discharge ( $\mathrm{m} / \mathrm{yr}$ ) in the Culebra near the center of the WIPP site versus the conductivity of the Dewey Lake/Triassic rocks

3-16 Simulated lateral specific discharge ( $\mathrm{m} / \mathrm{yr})$ in the Culebra near the center of the WIPP site versus the rate of potential recharge

3-17 Simulated lateral specific discharge $(\mathrm{m} / \mathrm{yr})$ in the Culebra near the center of the WIPP site versus the rate of potential recharge.

3-18 Simulated lateral specific discharge $(\mathrm{m} / \mathrm{yr})$ in the Culebra near the center of the WIPP site versus the rate of potential recharge

3-19 Simulated lateral flow direction (degrees east of north) in the Culebra near the center of the WIPP site versus the conductivity of intact anhydrite

3-20 Simulated lateral flow direction (degrees east of north) in the Culebra near the center of the WIPP site versus the conductivity of intact anhydrite .72

3-21 Simulated lateral flow direction (degrees east of north) in the Culebra near the center of the WIPP site versus the conductivity of the disrupted region.

3-22 Simulated lateral flow direction (degrees east of north) in the Culebra near the center of the WIPP site versus the conductivity of disrupted region.

3-23 Simulated lateral flow direction (degrees east of north) in the Culebra near the center of the WIPP site versus the conductivity of the Dewey Lake/Triassic rocks.

3-24 Simulated lateral flow direction (degrees east of north) in the Culebra near the center of the WIPP site versus the conductivity of the Dewey Lake/Triassic rocks

3-25 Simulated lateral flow direction (degrees east of north) in the Culebra near the center of the WIPP site versus the rate of potential recharge.

3-26 Simulated lateral flow direction (degrees east of north) in the Culebra near the center of the WIPP site versus the rate of potential recharge.

3-27 Simulated lateral flow direction (degrees east of north) in the Culebra near the center of the WIPP site versus the rate of potential recharge.

3-28 Percent of total inflow to the Culebra reference volume that leaks across the upper surface of the Culebra versus the conductivity of intact anhydrite.

3-29 Percent of total inflow to the Culebra reference volume that leaks across the upper surface of the Culebra versus the conductivity of the disrupted region.

3-30 Percent of total inflow to the Culebra reference volume that leaks across the upper surface of the Culebra versus the conductivity of the Dewey Lake/Triassic rocks.

3-31 Total lateral outflow from Culebra reference volume versus the conductivity of intact anhydrite.

3-32 Total lateral outflow from Culebra reference volume versus the conductivity of the disrupted region.

3-33 Total lateral outflow from Culebra reference volume versus the Dewey Lake/Triassic rocks. .... 88 


\section{Figures (continued)}

3-34 Elevation of the water table at 14,000 years in the past for the base-case simulation....................90

3-35 Depth to the water table at 14,000 years in the past for the base-case simulation ........................91

3-36 Vertical cross-sections showing the land surface and the water table at 14,000 years in the past for the base-case simulation ................................................................................................92

3-37 Head distribution in the Culebra at 14,000 years in the past for the base-case simulation ...........94

3-38 Lateral flow velocity in the Culebra at 14,000 years in the past for the base-case simulation......95

3-39 Vertical cross-sections showing the land surface and the water table at the present time for

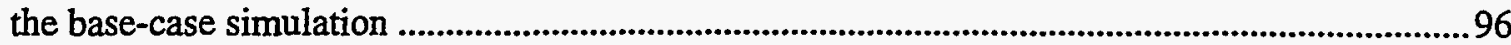

3-40 Head distribution in the Culebra at the present time for the base-case simulation.........................97

3-41 Lateral flow velocity in the Culebra at the present time for the base-case simulation..................99

3-42 Vertical cross-sections showing the land surface and the water table at 10,000 years in the

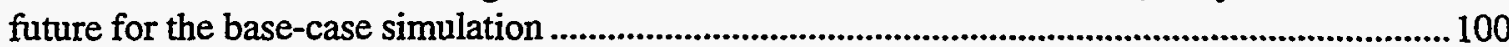

3-43 Head distribution in the Culebra at 10,000 years in the future for the base-case simulation ...... 101

3-44 Lateral flow velocity in the Culebra at 10,000 years in the future for the base-case simulation.

3-45 Elevation of the water table and head in each hydrostratigraphic unit near the center of the WIPP site versus time for the base-case simulation

3-46 Mass balance for the Dewey Lake/Triassic reference volume versus time for the base-case simulation.

3-47 Mass balance for the Magenta reference volume versus time for the base-case simulation ........ 106

3-48 Mass balance for the Culebra reference volume versus time for the base-case simulation.......... 107

3-49 Lateral specific discharge $(\mathrm{m} / \mathrm{yr})$ in the Culebra versus time for the base-case simulation. ....... 108

3-50 Lateral flow direction (degrees east of north) in the Culebra versus time for the base-case simulation.

3-51 Elevation of the water table (WT) and head in each hydrostratigraphic unit versus time for transient simulation 1 .

3-52 Lateral specific discharge $(\mathrm{m} / \mathrm{yr})$ in the Culebra versus time for transient simulation $1 \ldots . . . . . . . . .110$

3-53 Lateral flow direction (degrees east of north) in the Culebra versus time for transient simulation 1

3-54 Elevation of the water table (WT) and head in each hydrostratigraphic unit near the center of the WIPP site (insert) versus time for transient simulation 2 .

3-55 Lateral specific discharge $(\mathrm{m} / \mathrm{yr})$ in the Culebra versus time for transient simulation 2............112

3-56 Lateral flow direction (degrees east of north) in the Culebra versus time for transient simulation 2 .

3-57 Elevation of the water table (WT) and head in each hydrostratigraphic unit near the center of the WIPP site (insert) versus time for transient simulation 3.

3-58 Lateral specific discharge $(\mathrm{m} / \mathrm{yr})$ in the Culebra versus time for transient simulation 3..............115

3-59 Lateral flow direction (degrees east of north) in the Culebra versus time for transient simulation 3 .

3-60 Elevation of the water table (WT) and head in each hydrostratigraphic unit near the center of the WIPP site (insert) versus time for transient simulation 4.

3-61 Lateral specific discharge $(\mathrm{m} / \mathrm{yr})$ in the Culebra versus time for transient simulation 4..............117

3-62 Lateral flow direction (degrees east of north) in the Culebra versus time for transient simulation 4.

3-63 Elevation of the water table (WT) and head in each hydrostratigraphic unit near the center of the WIPP site (insert) versus time for transient simulation 5 .

3-64 Lateral specific discharge ( $\mathrm{m} / \mathrm{yr}$ ) in the Culebra versus time for transient simulation 5............. 120 


\section{Figures (continued)}

3-65 Lateral flow direction (degrees east of north) in the Culebra versus time for transient simulation 5

3-66 Elevation of the water table (WT) and head in each hydrostratigraphic unit near the center of the WIPP site (insert) versus time for transient simulation 6.

3-67 Lateral specific discharge $(\mathrm{m} / \mathrm{yr})$ in the Culebra versus time for transient simulation 6 .............. 123

3-68 Lateral flow direction (degrees east of north) in the Culebra versus time for transient simulation 6 .

3-69 Elevation of the water table (WT) and head in each hydrostratigraphic unit (a) and lateral specific discharge (b) in the Culebra near the center of the WIPP site (insert) versus time for transient simulation 11 .

3-70 Elevation of the water table (WT) and head in each hydrostratigraphic unit versus near the center of the WIPP site time for the step pattern of recharge (transient simulation 7, (a)) and the Holocene pattern of recharge (transient simulation 12, (b))

3-71 Elevation of the water table (WT) and head in each hydrostratigraphic unit versus time near the center of the WIPP site for the step pattern of recharge (transient simulation 8, (a)) and the Holocene pattern of recharge (transient simulation 13, (b)).

3-72 Elevation of the water table (WT) and head in each hydrostratigraphic unit versus time near the center of the WIPP site for transient simulation 14

3-73 Elevation of the water table (WT) and head in each hydrostratigraphic unit versus time for transient simulations 9 (a) and 15 (b)

3-74 Elevation of the water table (WT) and head in each hydrostratigraphic unit versus time for transient simulations 10 (a) and 16 (b)

3-75 Lateral specific discharge in the Culebra versus time for transient simulation 16 at nine locations within the WIPP-site boundary (insert).

\section{Tables}

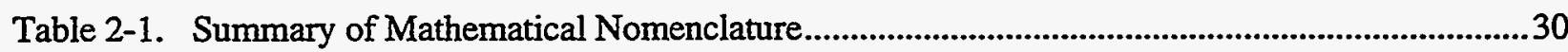

Table 2-2. Solution Sensitivity to Numerical Parameters.......................................................................42

Table 3-1. Values of Intact Hydraulic Conductivity $(\mathrm{K}$ in $\mathrm{m} / \mathrm{s})$ for the Steady-State Simulations ...........46

Table 3-2. Values of Hydraulic Conductivity ( $\mathrm{K}$ in $\mathrm{m} / \mathrm{s}$ ) and Specific Yield for the Transient Simulations

Table 3-3. Rates of Potential Recharge and Recharge Pattern Used for the Transient Simulations ........49

Table 3-4. Lateral-Flow Ratios for the Steady-State Simulations 


\section{ACRONYMS}

$\begin{array}{ll}\text { CPU } & \text { central processing unit } \\ \mathrm{km} & \text { kilometer } \\ \mathrm{m} & \text { meter } \\ \mathrm{mm} & \text { millimeter } \\ \mathrm{MSL} & \text { mean sea level } \\ \mathrm{s} & \text { second } \\ \text { USGS } & \text { United States Geological Survey } \\ \text { UTM } & \text { Universal Transverse Mercator } \\ \text { WIPP } & \text { Waste Isolation Pilot Plant } \\ \mathrm{yr} & \text { year }\end{array}$


This page intentionally left blank. 


\section{INTRODUCTION}

This report summarizes a study in which numerical simulation is used to enhance conceptual understanding of the hydrogeology of the Culebra Dolomite in the context of groundwater flow on a regional scale in the vicinity of the Waste Isolation Pilot Plant (WIPP). The WIPP is a potential repository for defense-generated transuranic wastes. The Culebra Dolomite is a member of the Permian age Rustler Formation, a sequence of predominantly evaporate deposits that overlie the Salado Formation. The Salado is a thick bedded salt of Permian age that contains the WIPP and provides the primary containment for the repository. The groundwater flow system in the overlying Permian and Triassic deposits forms a secondary barrier to releases from the repository in the event of a breach of the primary containment. Consequently, an important requirement of the performance assessment of the repository is to characterize long-term groundwater flow in the shallow system. We consider the possibility that patterns of groundwater flow in the shallow system change over thousands of years in response to change in climate. Although groundwater flow is simulated in all of the strata above the Salado, this report focuses primarily on flow in the Culebra Dolomite because it is thought to be the most likely pathway for lateral migration of radionuclides to the accessible environment.

We use simulation as the instrument to study regional groundwater flow because it is impossible to directly observe how large hydrologic systems behave over long periods of time. The purpose of the numerical model is to integrate, challenge, and constrain our conceptual understanding of the natural system. The fundamental aspect of this approach is that we attempt to represent the real physical boundaries of the groundwater system and the actual driving forces for groundwater flow in the numerical model. We therefore base the numerical model on the well-developed concept of regional groundwater flow in a groundwater basin (Hubbert, 1940; Tóth, 1963; Freeze and Witherspoon, 1967).

Since 1977, a number of modeling studies have been performed to examine groundwater flow in the Culebra in the vicinity of the WIPP. Most of these used an arbitrary rectangular domain, assumed no flow across their upper and lower boundaries, and assigned fixed hydraulic heads or pressures along lateral boundaries to represent observed conditions. (See LaVenue et al., (1988); Davies (1989), and LaVenue and RamaRao (1992) for summaries of these studies.) Studies of this type are essential in characterizing the distribution of hydraulic conductivity and the present-day flow field at the scale of performance assessment calculations. However, they provide little insight into the hydrogeologic processes and conditions that determine the natural patterns of groundwater flow and consequently how those patterns might change with time. Future flow patterns may differ from those of today because of 
either natural processes, such as climate change, or human activities such as drilling or mining. A different modeling approach that recognizes the need to explicitly represent natural hydrologic boundaries is required to obtain this additional information about the groundwater system. Davies (1989) first applied this approach to characterize the regional groundwater flow near the WIPP; this study builds on that work.

Davies (1989) selected boundaries to coincide with hydrologic features and used geologic data to infer hydraulic conductivity values for areas in which conductivity measurements were not available. Recognizing the three-dimensional nature of the regional groundwater system, Davies orientated twodimensional simulations in both vertical and horizontal planes. The vertically orientated simulations were performed because it was recognized that the transient nature of the system is related to movement of the water table and the consequent change in the amount of water stored in the rocks. Davies confirmed that the hypothesis that the modern-day flow system might be a transient response to recharge during the last glacial pluvial period (Lambert, 1987; Lambert and Carter, 1987; Lambert and Harvey, 1987 ) is physically possible. He also concluded that as much as $25 \%$ of the total inflow to the Culebra could be entering as vertical flux, and that fluid pressures in the Culebra are less than hydrostatic because the Culebra is well connected to its discharge area and poorly connected to the source of recharge. He suggested that the results of his study could be expanded by, among other things, using a fully threedimensional approach and additional study of the role of long-term transient changes in flow.

As a first step in extending the work of Davies, Corbet and Wallace (1993) developed a fully three-dimensional model with an adaptive upper boundary condition to approximately simulate movement of the water table. That model was a predecessor to the one used for the simulations described in this report and covered the same geographic area. The earlier simulations were performed using a version of the U.S. Geological Survey code MODFLOW (McDonald and Harbaugh, 1988) that was modified to include seepage faces. A seepage face is the hydrologic condition that occurs where the water table is at, or close to, the land surface. That model was limited in its capabilities in that it only calculated the approximate position of the water table and did not account for lateral variations in hydraulic conductivity. Nonetheless, the simulation results provided the first information about possible recharge rates at a regional scale and the sensitivity of groundwater flow patterns to changes in recharge. Specifically, the results suggested that rates of recharge to the saturated zone do not exceed several millimeters per year and that flow patterns in confined units are sensitive to small changes, perhaps only a few tenths of a millimeter per year, in rates of recharge. 
Our intent, in this study, was to develop the simplest numerical model that could realistically represent the hydrologic behavior of the natural system over long periods of time. A main concern in developing the model was that over the period of time simulated it is possible that change in the elevation of the water table could have a profound effect on groundwater flow. Specifically, the regional groundwater system could range from the type of system associated with humid climates in which the water table is a subdued replica of the land surface to the type of system associated with arid climates in which the water table is at depth and is sloped along the regional gradients of the land surface. The model had to simulate flow for each of these end member cases as well as the transition from one to another. To accomplish this, we choose to use a free-surface formulation in which flow is maintained by recharge to the saturated zone and seepage faces develop where the water table intersects the land surface. We use the term "free surface" to indicate that the position of the water table changes to maintain a balance at the water table between recharge to and flow within the saturated zone.

We developed a new numerical code called SECOFL3D, to perform the simulations. The algorithm implements a rigorous treatment of the free-surface and seepage-face boundary conditions (Bear and Verruijt, 1987; Dagan, 1989; de Marsily, 1986) and is designed to be robust even if extremely large contrasts in hydraulic conductivity are present within the model domain. A moving mesh that adaptively deforms so that its upper surface conforms to the moving water table is used to ensure that the entire computational domain remains saturated.

Lateral boundaries of groundwater basins are sub-vertical flow divides that typically coincide with depressions and highs on the land surface. Flow over a region much larger than the WIPP site (Figure 1-1) was simulated in order to have the model boundary coincide with topographic features that are likely to act as groundwater divides over a range of climatic conditions. A series of steady-state simulations was performed to examine the sensitivity of simulation results to assumed values for hydraulic conductivity and recharge rate. Transient simulations provided insight into how patterns of groundwater flow respond to long-term changes in climate. These simulations covered the time period from late in the Pleistocene (14,000 years ago) to 10,000 years in the future.

The simulation results suggest that patterns of groundwater flow in the Culebra in the vicinity of the WIPP are influenced by the hydrology of the entire groundwater basin. Flow rates and directions depend on the position of the water table and heterogeneity in hydraulic conductivity at the basin-scale. Groundwater flow changes with time due to interaction among recharge, movement of the water table, and topography of the land surface. 

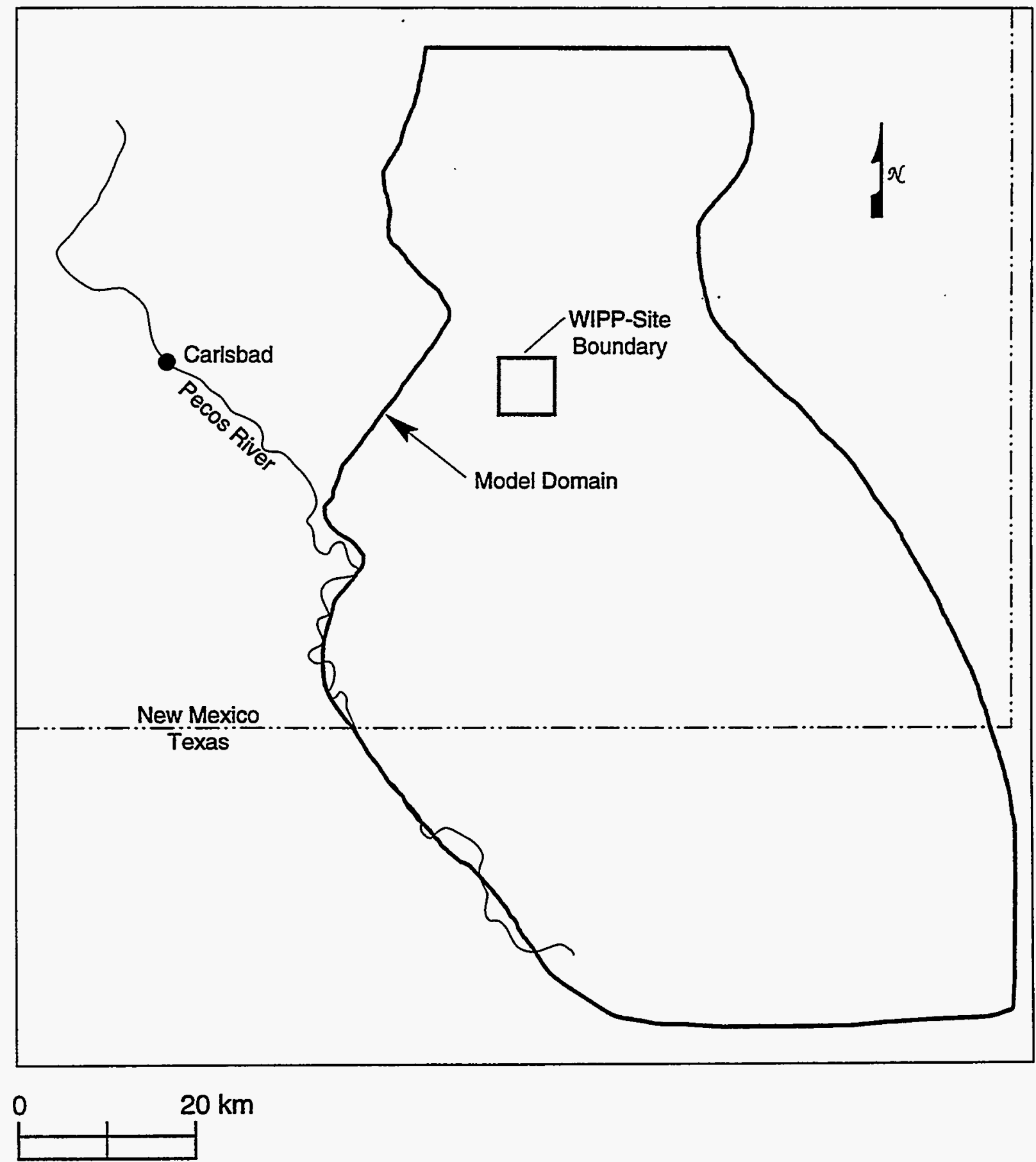

TR1-6115-389-0

Figure 1-1. Boundary of the numerical model. 
The simulations again confirm that slow equilibration to long-term changes in climate could be an important aspect of the hydrology of this region. In our transient calculations, the modern-day water table is still adjusting to a post-Pleistocene drying of the climate that was completed by 8,000 years ago. However, it is likely that natural changes in flow in the Culebra over the next 10,000 years will be small and will mainly reflect future short-term wet periods such as have occurred over the past 8,000 years.

The simulations also provide information about how flow in the Culebra in the vicinity of the WIPP is coupled with flow in adjacent strata. Vertical leakage across the top of the Culebra is directed downward. The amount of vertical leakage into the Culebra cannot be estimated with confidence because the vertical conductivity of the confining units is not well constrained. Vertical leakage may contribute as little as $5 \%$ or more than $50 \%$ of the total inflow to the portion of the Culebra that lies within the WIPP-site boundary. All of the outflow from this portion of the Culebra is lateral flow. Therefore, contaminants introduced into the Culebra will travel toward the accessible environment along the Culebra rather than by migrating upward or downward into other units. 
This Page Intentionally Left Blank 


\section{MODEL DESCRIPTION}

In this section we describe the model used to perform the simulations. The model consists of its conceptual basis, the specified boundary conditions, the distribution of assumed values for hydraulic properties, the mathematical description of the physical processes, and the numerical algorithm used to solve the flow equations.

\subsection{Groundwater Basin Conceptual Model}

The numerical simulations in this study are based on well-developed concepts of regional groundwater flow in groundwater basins (Hubbert, 1940; Tóth, 1963; Freeze and Witherspoon, 1967). A groundwater basin is a three-dimensional closed hydrologic unit bounded on the bottom by an "impermeable" rock unit (actually a hydrostratigraphic unit with much smaller permeability than the units above), on the top by the ground surface and on the sides by groundwater divides. The upper boundary of the region of saturated flow is the water table. All rocks in the basin have finite non-zero permeability, i.e., hydraulic continuity exists throughout the basin. All recharge to the basin is by percolation of precipitation to the water table and all discharge from the basin is by flow across the water table to the land surface. Here, the term recharge is used as defined by Freeze and Cherry (1979) to mean the entry into the saturated zone of water made available at the water-table surface, together with the associated flow away from the water table within the saturated zone.

Differences in the elevation of the water table across the basin provide the driving force for groundwater flow. The pattern of groundwater flow depends on the lateral extent of the basin, shape of the water table, and heterogeneity of rock permeability within the basin. Water flows along gradients of hydraulic head from regions of high head to regions of low head. The highest and lowest heads in the basin occur at the water table at its highest and lowest points respectively. Therefore groundwater generally flows from the elevated regions of the water table, downward across confining units (units with relatively low permeability), then laterally along more conductive units, and finally upward to exit the basin in regions where the water table (and by association, the land surface) is at low elevations.

The position of the water table moves up and down in response to changes in recharge. The water table cannot rise higher than the land surface or the surface of lakes at any location. Seepage faces develop in areas where recharge is sufficient to maintain the water table at the land surface. It is through the development of seepage faces that the topography of the land surface impacts patterns of groundwater 
flow. Seepage faces occur only in topographically low areas if recharge is low (Figure 2-1, (a)). In this case, groundwater flow is toward the seepage faces and directions of groundwater flow are controlled by the regional slope of the land surface. The portion of a basin that is covered by seepage faces increases as recharge increases. Given a sufficiently humid climate, much of the surface of a groundwater basin is covered by seepage faces. That is, the water table is everywhere at or close to the land surface (Figure 2-1, (b)). Flow directions, in this case reflect both the regional slope of the land surface and the local topographic features. We note that the presence of a seepage face means only that the hydraulic head at the water table is equal to the elevation of the land surface at that location (Section 2.5.1). Recharge ${ }^{1}$ or discharge can occur across a seepage face depending on whether hydraulic head increases or decreases with depth below the water table. Recharge can occur in regions where a seepage face is at a relatively high elevation in a groundwater basin. Discharge occurs in regions of low elevation as flow to lakes or streams or as widely distributed evapotranspiration.

The process by which precipitation reaches the saturated zone can be divided into three parts, infiltration, percolation in the unsaturated zone, and recharge to the saturated zone. Evapotranspiration potential greatly exceeds annual precipitation in semi-arid regions such as southeastern New Mexico and only a small portion of precipitation infiltrates below the root zone. The relationship between the rate and spatial distribution of infiltration and climatic factors is complex. Infiltration depends, for example, on the temporal and spatial pattern of precipitation, soil and plant types, land surface slopes, surface drainage, wind speeds, air temperature, and humidity. After infiltration, moisture is available to percolate downward toward the water table. The pattern of flow during percolation is complex because the unsaturated hydraulic properties of the rocks are highly heterogeneous and variable in time. Where the water table is at depth, the net movement of water is downward, but the lateral components of flow are such that the spatial pattern of percolation at the water table is different than the pattern of infiltration at the land surface.

\subsection{Topography and Model Boundaries}

The lateral boundary of the numerical model for the WIPP region (Figure 2-2) coincides with selected topographic depressions and highs. The boundary follows Nash Draw and the Pecos River valley to the west and south and the San Simon Swale to the east. The boundary continues up drainages

1 Recharge, of course, also occurs in regions where the water table is below the land surface (i.e., it is a free surface) and percolation reaches the water table. 


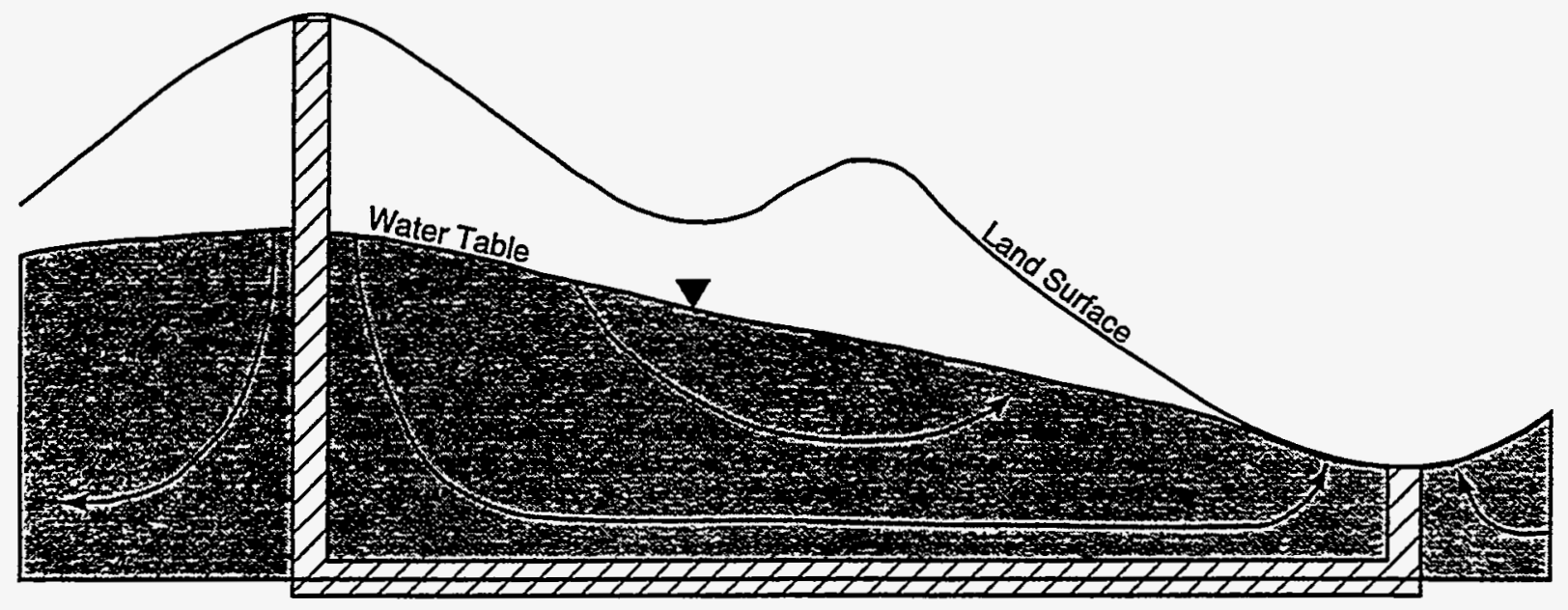

TA1-6115-390-0

(a)

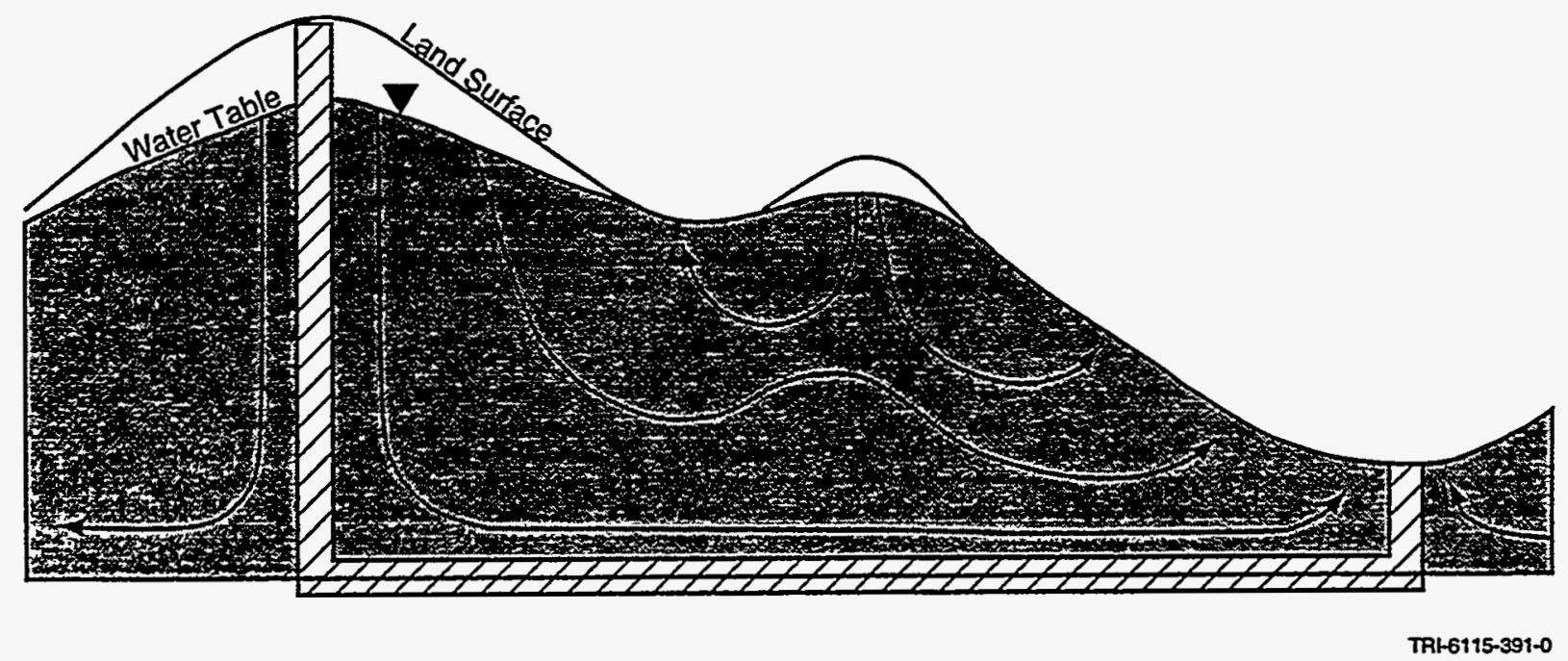

(b)

Figure 2-1. Idealized cross-section of a groundwater basin for a hot, dry climate (a) and a cool, wet climate (b). The cross-hatched lines are boundaries of the groundwater basin. 


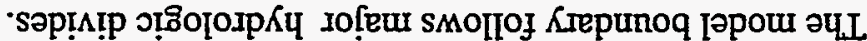

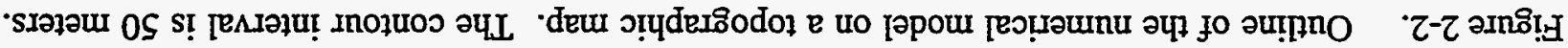

OLLOSLIT-IUL

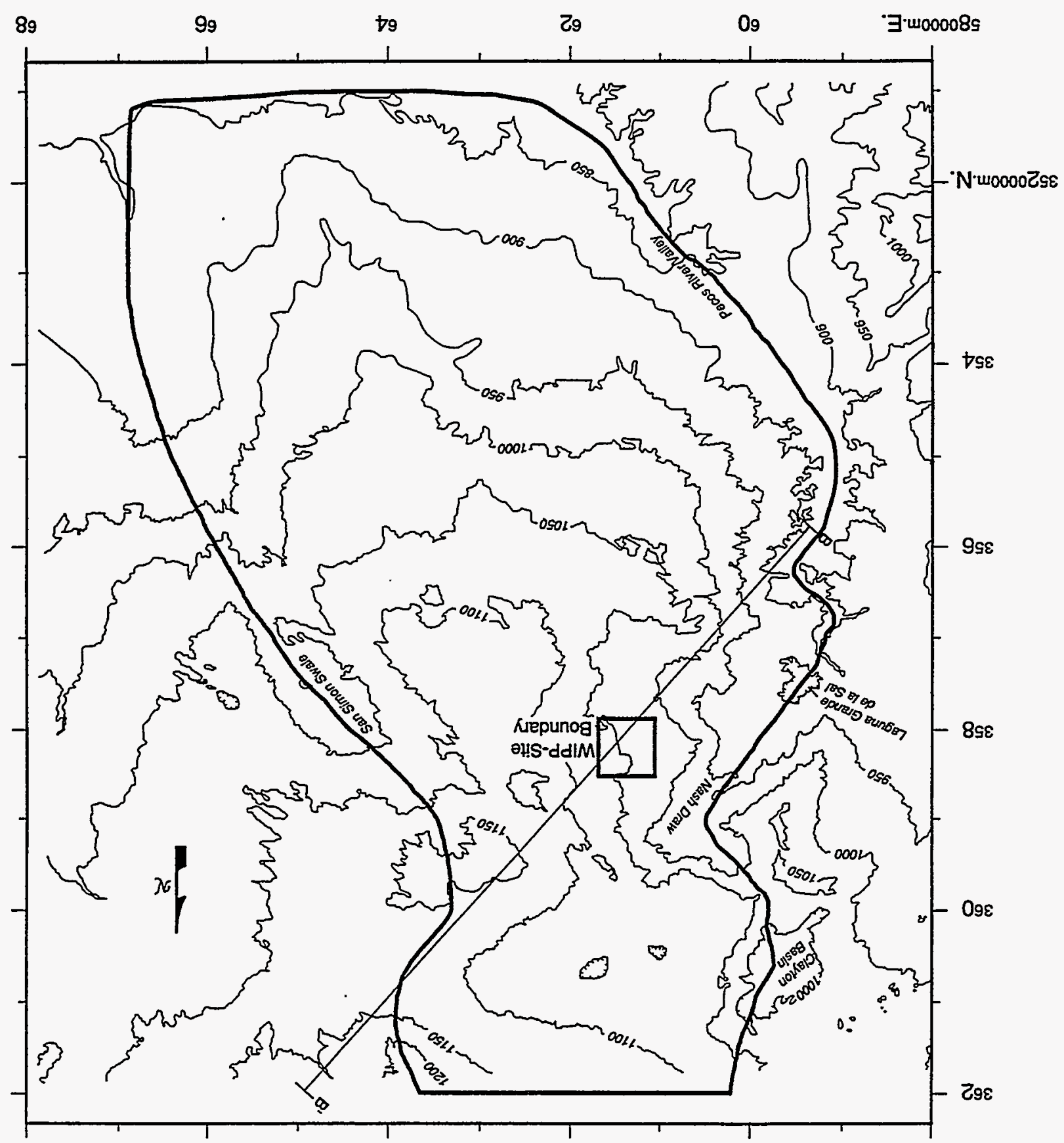


and then follows topographic highs along the northern part of its east side. It is assumed that these boundaries represent groundwater divides whose position remains fixed over the range of past and future climates. There are other groundwater divides within this boundary. The positions of these additional divides may change with time and, in some cases, even their existence might be intermittent. The lower boundary over most of the model domain is the top of the Salado Formation. In a region in which subsidence due to dissolution of halite in the upper Salado has fractured and disrupted overlying strata (Zone 1 of Figure 2-6), the lower boundary along each row of model grid cells is equal to the elevation of the top of the Salado at the eastern edge of Zone 1. This simplification was made because the top surface of the Salado is irregular and not well known in this region. The position of the lower model boundary in the disrupted zone has little effect on model results because, in this region, all of the stratigraphic layers are combined into a single hydrostratigraphic unit with relatively high hydraulic conductivity. The upper boundary of the model coincides with the land surface.

\subsection{Hydrostratigraphy}

Measurements of rock hydraulic properties are available for only a tiny fraction of model area because this area is much larger (it covers approximately 6000 square kilometers) than the area covered by WIPP-site characterization. Values for these properties are inferred from geologic observations and conceptual models of how geologic processes have altered hydraulic properties.

The strata above the Salado are layered and there are large differences in the ease with which water can flow through the individual layers. We conceptualize the effect of the layering on groundwater flow in terms of the hydrostratigraphic units (Figure 2-3) defined by Holt and Powers (1988). A hydrostratigraphic unit comprises one or more adjacent rock layers with similar hydrologic characteristics. The Holt and Powers classification divides the Rustler Formation into 13 hydrostratigraphic units (middle column of Figure 2-3). Those units that are relatively more permeable are referred to here as conductive units and those with very small permeability are called confining units. The confining units consist of anhydrite, halite, and mudstone. Dolomite layers form the conductive units. The confining units are perhaps five orders of magnitude less conductive than the dolomite units. For these simulations, we have combined the four units in the unnamed lower member into one unit and added an additional hydrostratigraphic unit to represent the Dewey Lake Formation and the overlying Triassic rocks. The resulting 10 stratigraphic units are sufficient to represent vertical heterogeneity at the scale of these simulations. A detailed examination, however, would show that each of these units is also vertically heterogeneous. 
Hydrostratigraphic Units

Triassic Rocks and Dewey Lake Formation

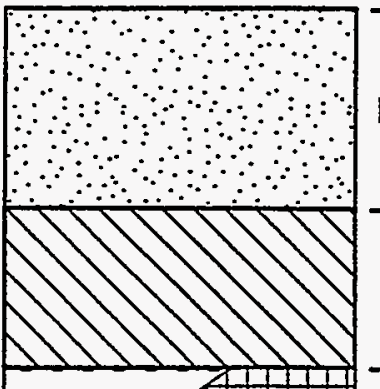

Forty-Niner Member

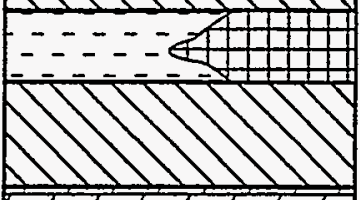

Magenta Dolomite
Member

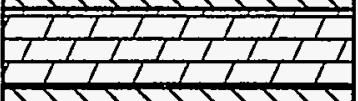

Dewey Lake/Triassic

Anhydrite 5

Muḋstone/Halite 4

Anhydrite 4

Magenta Dolomite

\begin{tabular}{c} 
Tamarisk Member \\
\hline $\begin{array}{c}\text { Culebra Dolomite } \\
\text { Member }\end{array}$ \\
Unnamed \\
lower member \\
\end{tabular}

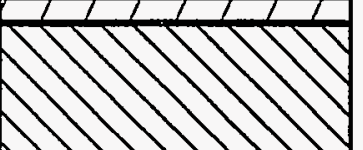

r

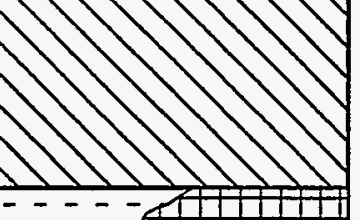

Anhydrite 3
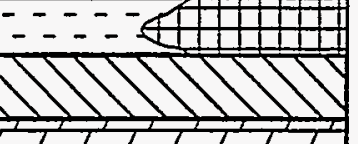

Mudstone/Halite 3

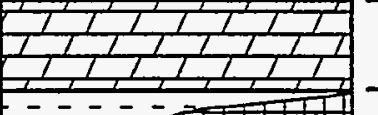

Anhydrite 2

Culebra Dolomite

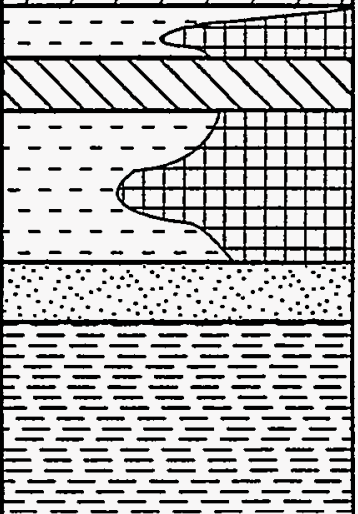

Salado Formation

TRI-6119-327-0

Unnamed

lower member

Figure 2-3. Hydrostratigraphic units used in the numerical model. Modified from Powers and Holt (1990). 


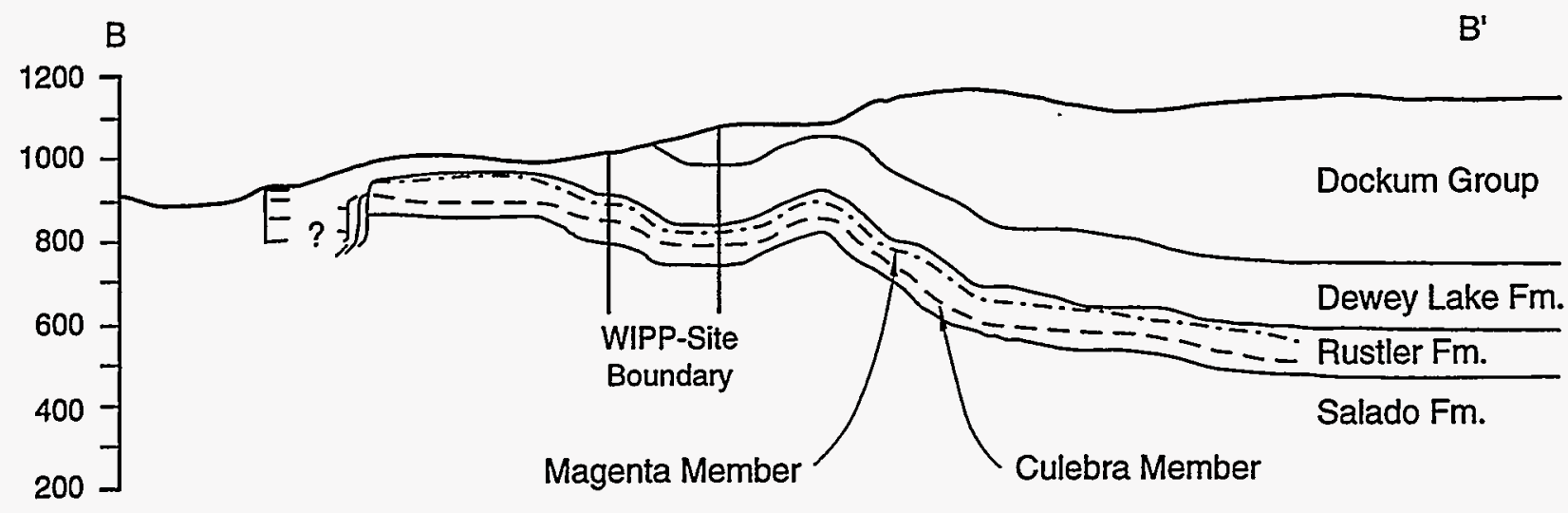

TRI-6115-478-0

Figure 2-4. Geologic cross-section along line B - B' (Figure 2-2). The vertical exaggeration is 24 to 1.

In order to discretize the hydrostratigraphy, the model domain is divided into twelve layers of 1,493 cells for a total of 17,916 model cells. In map view, the model cells are squares, two kilometers on a side, that are aligned with the Universal Transverse Mercator (UTM) grid. The thickness of cells in the vertical direction varies with the thickness of hydrostratigraphic units. We represent each of the lower nine hydrostratigraphic units as a single model layer. The Dewey Lake/Triassic rocks are represented as three model layers.

As the first step in representing the hydrostratigraphic units in our model, we constructed structure contour maps on the tops of the Salado Formation, the unnamed lower member, the Culebra, the Tamarisk, the Magenta, and the Forty-niner. These maps cover a rectangular region extending from UTM coordinate $3510000 \mathrm{~m}$ north to $3620000 \mathrm{~m}$ north, and from $560000 \mathrm{~m}$ east to $680000 \mathrm{~m}$ east. The scale of these maps is $1: 128000$ and the contour interval is $50 \mathrm{~m}$. In addition, a metric topographic map of the land surface was compiled at the same scale. We used elevations of unit tops interpreted from geophysical logs, mainly from oil and gas drill holes, to construct these maps. Three data sets of unittop elevations were used: existing sets from Holt and Powers (1988) and Richey (1987), and a new 
supplementary set based on interpretations of more than 100 additional geophysical logs. Together, the data sets contained elevations at about 1020 locations. All contouring was done manually in order to allow for subjective geologic interpretation in the maps.

The structure of the Rustler Formation is well represented by the structure on the top of the Culebra (Figure 2-5). This surface has over $600 \mathrm{~m}$ of relief, ranging from 300 to 900 meters above mean sea level (MSL). Two prominent structural features are apparent: a broad depression east of the WIPP site and a deep graben bounded by north-northwest trending faults southeast of WIPP. Regions in which the Tamarisk and the Forty-niner reach their maximum thickness correlate to the broad depression on the structure maps, indicating that this structural feature was present in Rustler time. This depression is important to the regional hydrogeology of the area because thick beds of halite were deposited in salt pans that formed in it (Holt and Powers, 1988).

The floor of the graben has dropped as much as $250 \mathrm{~m}$ relative to surrounding strata. This faulting occurred after the Rustler Formation was deposited. The graben plays a large role in the regional distribution of hydraulic properties in that it truncates Rustler strata and places them adjacent to sediments, probably similar to those of the Dewey Lake Formation, that filled the graben as it formed.

We used the topographic map and four of the structure maps, the Salado, unnamed lower member, Tamarisk, and the Forty-niner, to discretize the hydrostratigraphic units. The Culebra and Magenta structure maps were not used directly in this process because the spatial variation of the thicknesses of these units was small enough that they could be treated as constants for the purpose of our simulations. The structure and the landsurface topography maps were manually discretized by assigning an elevation value at the center of each model cell. We did not construct structure maps for four of the hydrostratigraphic units, anhydrites units 2 and 4, and mudstone/halite units 3 and 4 (Figure 2-3). In order to assign values for the tops of these units, we made use of the observation (Holt and Powers, 1988) that the thickness of each anhydrite unit does not vary much in the vicinity of the WIPP. Nearly all of the thickness variation of the Tamarisk and Forty-niner members occurs in the mudstone/halite units. We therefore used the following approach to discretize the three Rustler hydrostratigraphic units immediately above the Tamarisk Member. Using the elevations of the tops of the Tamarisk and the Forty- 


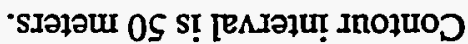

'uop̣euro

0-6ட6-9แ9-181
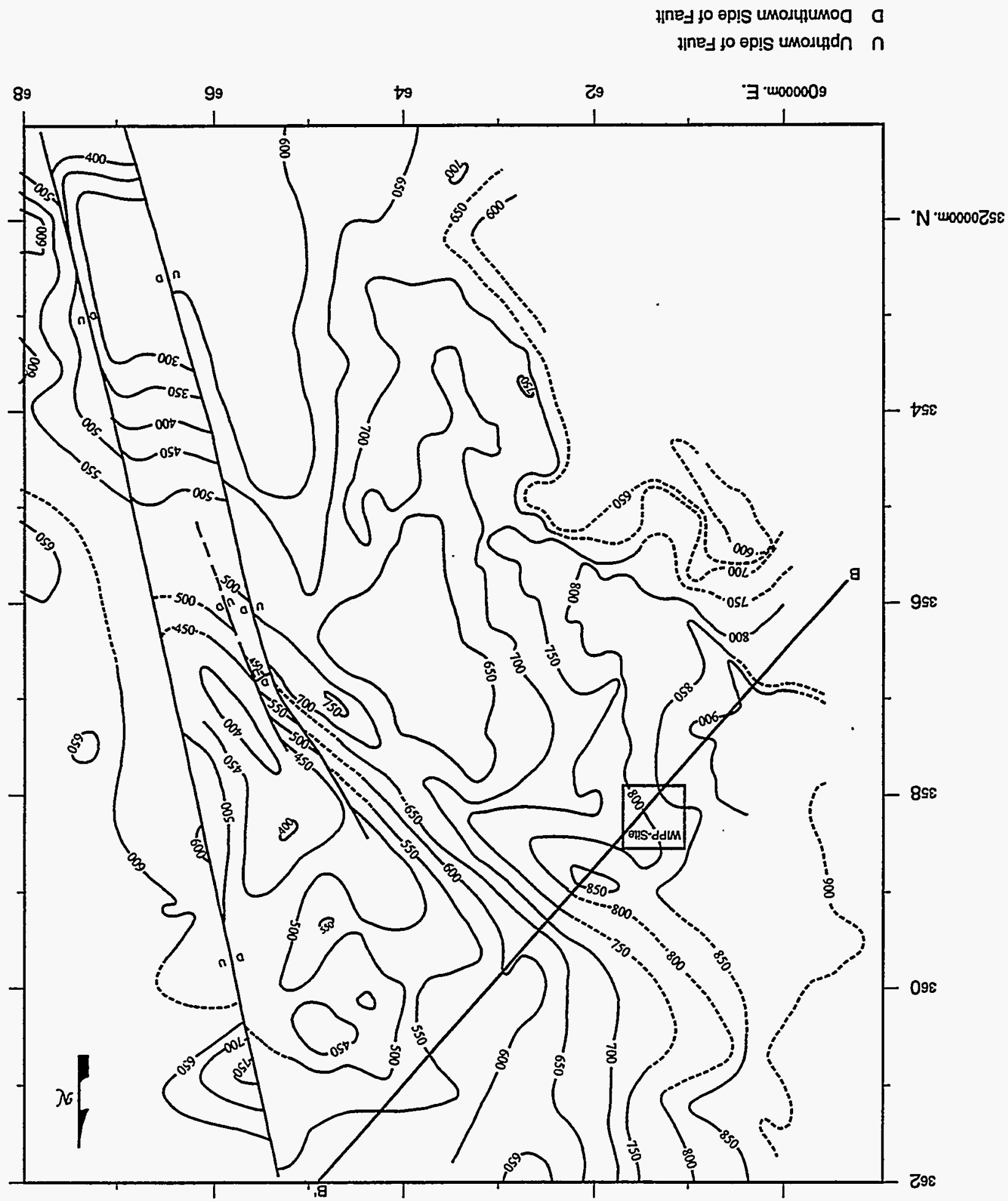
niner members from the structure maps as reference values, we assumed thickness of 6,5 , and $9.5 \mathrm{~m}$ for the Magenta, Anhydrite 4 and Anhydrite 5 to assign top elevations for these units and the Mudstone/ Halite 4. The Mudstone/Halite 4 consists of the thickness between the top of the Tamarisk to the top of the Forty-niner that is not taken up by the other units. In a few locations in which this method would have resulted in a thickness of the Mudstone/Halite 4 unit less than $2 \mathrm{~m}$, the Mudstone/Halite 4 was assigned a thickness of $2 \mathrm{~m}$ and Anhydrites 4 and 5 were assigned thickness of $35 \%$ and $65 \%$, respectively, of the remaining thickness between the top of the Magenta and the top of the Forty-niner. The interval between the top of the Tamarisk and the top of the unnamed member was divided in a similar way. Constant thicknesses of 7, 7.5, and $16 \mathrm{~m}$ were assumed for the Culebra, Anhydrite 2 and Anhydrite 3. If this method would have resulted in a thickness of the Mudstone/Halite 3 unit less than $2 \mathrm{~m}$, the Mudstone/Halite 3 was assigned a thickness of $2 \mathrm{~m}$ and Anhydrites 2 and 3 were assigned thicknesses of $30 \%$ and $70 \%$ of the remaining thickness between the top of the Culebra and the top of the Tamarisk.

The hydrostratigraphic units account for vertical differences in hydraulic properties. Such differences are due to the sedimentary processes that were active as these rocks were deposited. However, the hydrologic properties of these rocks also vary laterally. It is thought that post-depositional geologic processes caused the lateral variations. Those processes that were accounted for in our assignment of hydraulic conductivity values are summarized below. The regions affected by these processes are shown in Figures 2-6 and 2-7.

Salado Dissolution. The top of the Salado Formation has been dissolved over large areas. This dissolution disrupts and fractures Rustler strata and consequently increases their hydraulic conductivity to varying degrees (Beauheim and Holt, 1990). In the most extreme case, the Rustler breaks into blocks which rotate and are collapsed downward. In these regions, stratigraphic continuity is disrupted and vertical hydraulic conductivity increases to the extent that the Rustler does not behave hydrologically as a layered system. In other regions in which Salado dissolution is less extensive, stratigraphic continuity is maintained but fracturing increases the hydraulic conductivity of the more brittle carbonate and anhydrite units.

Dissolution of Pore- and Fracture-Filling Minerals. Evaporite minerals (halite, gypsum, or anhydrite) fill much of the pore space and fractures in intact Rustler units (Holt and Powers, 1988; Beauheim and Holt, 1990). Over portions of the map area, moving groundwaters have dissolved these minerals and have thereby locally increased hydraulic conductivity. For example, past dissolution of cements and fracture fillings is thought to be an important control on the pattern of hydraulic conductivity of the Culebra in the vicinity of WIPP. 


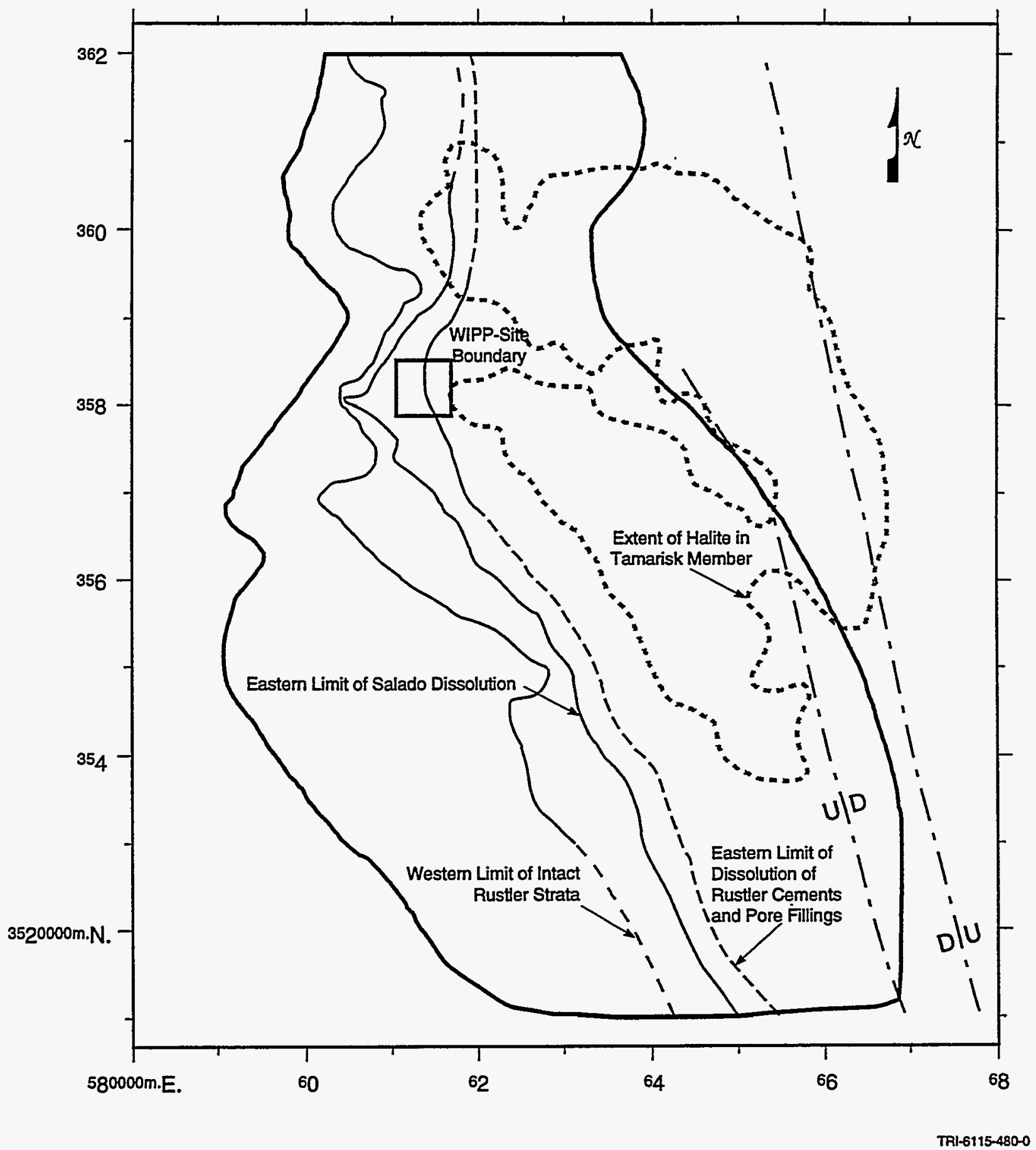

Figure 2-6. Regions in which hydraulic conductivity has been affected by post-depositional geological processes. 


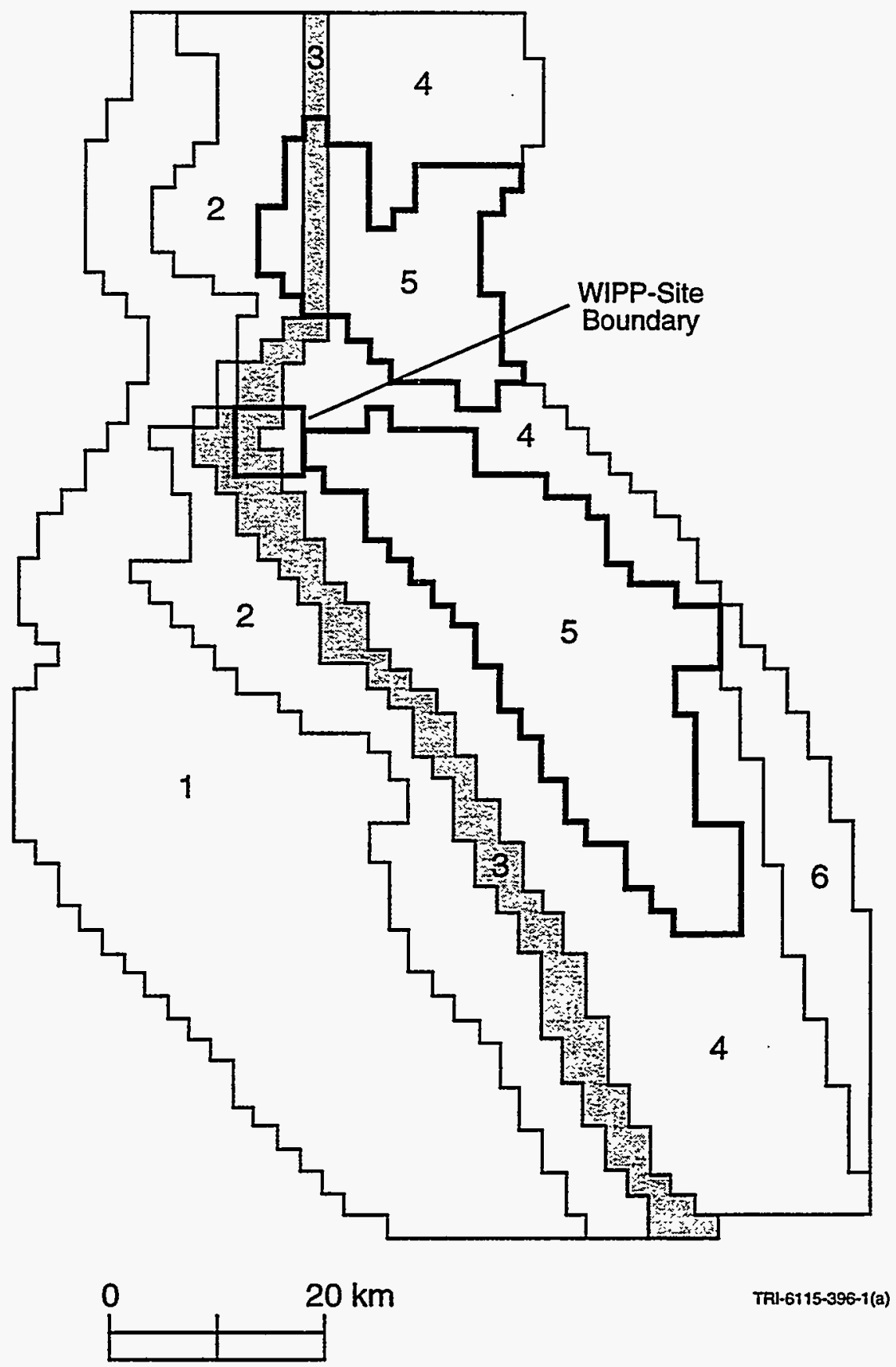

Figure 2-7. Zonation approach used to represent the effects of depositional setting and postdepositional processes. Zone 1 is a region in which dissolution of the upper Salado has fractured and disrupted overlying strata to the extent that stratigraphic layering is not preserved over long distances. In Zone 2, dissolution of the upper Salado is thought to have fractured the Rustler, but did not disrupt layering. Fractures that predate dissolution of the upper Salado are mostly filled with gypsum. These fracture fillings have been removed in Zones 2 and 3 . Zone 4 represents intact strata. The region occupied by the halite facies of the mudstone/halite layers is indicated by Zone 5 . A graben structure is shown as Zone 6. 
Proximity to Halite Deposits. In regions where halite deposits are present in the Rustler, halite replaces gypsum in the rock matrix and fills fractures in units that underlie or overlie the halite deposits (e.g., Holt and Powers, 1988). The hydraulic conductivity in units affected by gypsum replacement and fracture filling is possibly as low as that of the halite deposits.

The regions affected by the various geologic processes have been mapped (Figure 2-6) and approximated by zones for modeling (Figure 2-7). The boundaries of these regions have been inferred from geologic observations and mapping. The eastern boundary of region disrupted by dissolution of the upper Salado was delineated during construction of the structure contour maps. West of this line, the elevation data for the top of each hydrostratigraphic unit could not be contoured as a smooth surface. Isopach maps of the upper Salado were used to infer the eastern boundary of Salado dissolution. The upper Salado thins more than is characteristic for depositional variations west of this line. The Salado isopach maps did not cover our entire map area; professional judgment was used to extend this boundary into the Texas portion and over the northern $10 \mathrm{~km}$ of Figure 2-6. The eastern margin of dissolution of evaporite cement in the Culebra coincides with the line of $20 \%$ filling of fractures with gypsum (Figure 21, Beauheim and Holt, 1990) near the WIPP site. More than $20 \%$ of fractures to the east of this line are filled with gypsum. This line was extrapolated to the north and south based on the thickness of rock above the Culebra and the Salado dissolution line. As the thickness increased, the cement dissolution line was moved closer to the Salado dissolution line. The extent of region occupied by the halite facies of mudstone/halite units coincides with the region in which the thickness of the Tamarisk is greater than $40 \mathrm{~m}$. This cutoff thickness is based on the extent of the halite facies in the vicinity of WIPP as mapped by Holt and Powers (1988).

We use a two-step approach to assign hydraulic conductivity values to cells within the numerical model. First, an "intact" conductivity.value is assigned to each hydrostratigraphic unit or, in the case in the mudstone/halite units, to each of the two rock types in the unit. These values represent the hydraulic conductivity of that unit or rock type before the effect of post-depositional processes. A range of values for the intact hydraulic conductivities was estimated using published values measured for similar rock types as a guide. The intact values assigned changed from simulation to simulation to account for uncertainty; the values used are given in Tables 3-1 and 3-2. Second, intact values are adjusted to reflect the impact of the post-depositional process in the zones shown in Figure 2-6. The amount of adjustment is based on the average of measured values of hydraulic conductivity in each of these zones in the Culebra in the vicinity of the WIPP site. The following adjustments, in units of the logarithm of conductivity $(\mathrm{m} / \mathrm{s})$, are applied: 
- upper Salado dissolution (Zone 2), applied to dolomites and anhydrites: $\quad+1.0$

- dissolution of fracture fillings (Zones 2 and 3), applied to dolomites: +1.5

- presence of halite in adjacent layers (Zone 5), applied to the Culebra: $\quad-2.0$

Figures 2-8 through 2-11, for example, are the distributions of hydraulic conductivity of the Culebra, the anhydrite layers, the mudstone/halite layers, and the Dewey Lake/Triassic rocks assuming the intact conductivities for the base-case transient simulation (Table 3-2). Zone 6 is assumed to have the same conductivity as the Dewey Lake/Triassic rocks. The Magenta conductivity distribution is the same as that for the Culebra; however, its conductivity is everywhere one order of magnitude less. The unnamed lower member is assumed to consist of mudstone where it is in the disrupted region (Zone 1) or in the graben (Zone 6).

\subsection{Recharge Rates and Patterns}

Geologic data from southeastern New Mexico and the surrounding region show repeated altemations of wetter and drier climates throughout the Pleistocene and correspond to global cycles of glaciation and deglaciation. Data from plant and animal remains and paleo-lake levels permit quantitative climate reconstructions for the region only for the last glacial cycle, and confirm the interpretation that conditions were coolest and wettest during glacial maxima (Swift, 1993). The hottest and driest conditions since the last glaciation have been similar to those of the present. Modeling of global circulation patterns suggests that these changes resulted from the disruption and southward displacement of the winter jet stream by the ice sheet, causing an increase in the frequency and intensity of winter storms throughout the American Southwest (COHMAP Members, 1988). Mean annual precipitation 22,000 to 18,000 years ago, when the last North American ice sheet reached its southern limit roughly $1500 \mathrm{~km}$ north of the WIPP, was approximately twice that of the present (Figure 2-12). Mean annual temperatures may have been as much as $5^{\circ} \mathrm{C}$ colder than at present.

Relatively short-term climatic fluctuations in southeastern New Mexico have occurred throughout the Pleistocene and Holocene with periodicities on the scale of thousands of years (Figure 2-12). The causes of these nonglacial fluctuations are, in general, unknown, but paleoclimatic data indicate that precipitation may have approached glacial highs for relatively short periods at some times during the Holocene (Swift, 1993). Based on the past record, fluctuations of this sort are possible and perhaps likely during the next 10,000 years. 


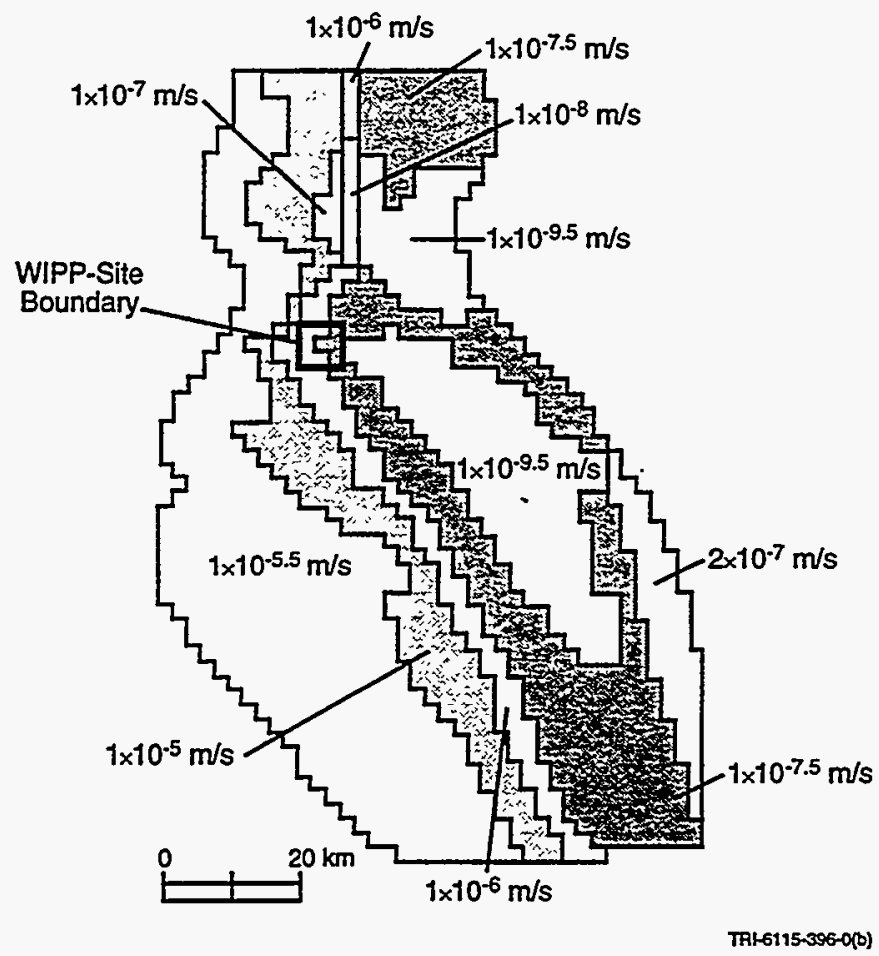

Figure 2-8. Distribution of hydraulic conductivity $(\mathrm{m} / \mathrm{s})$ used for the Culebra hydrostratigraphic unit for the base-case transient simulation (Table 3-2).

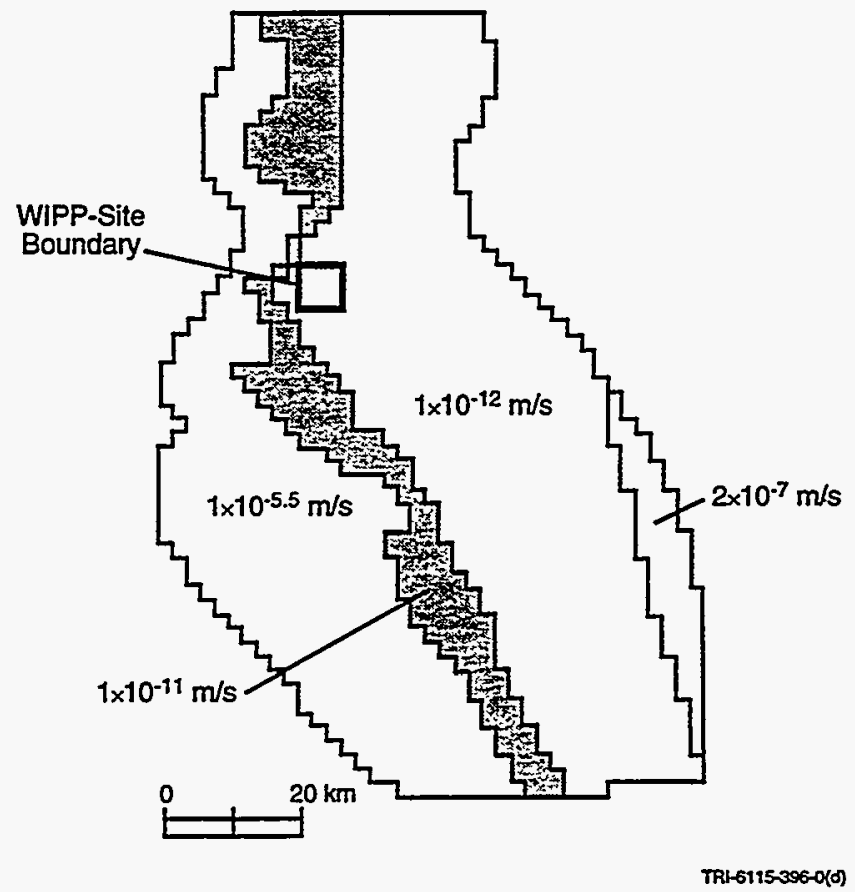

Figure 2-9. Distribution of hydraulic conductivity $(\mathrm{m} / \mathrm{s})$ used for the anhydrite hydrostratigraphic units for the base-case transient simulation (Table 3-2). 


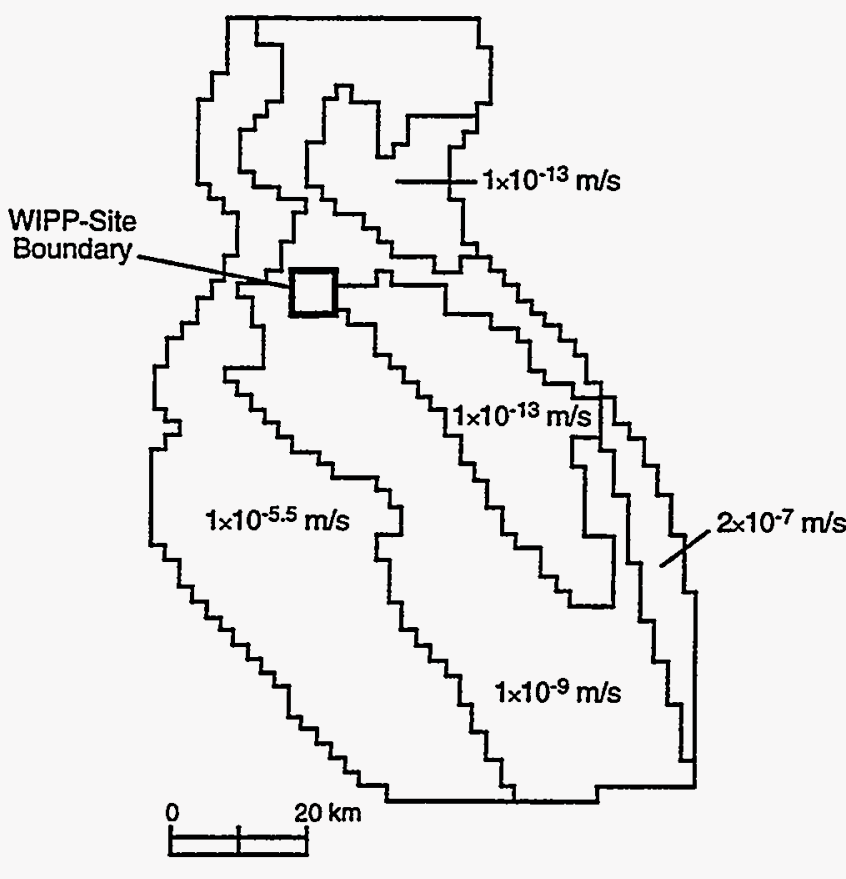

TA16115-396-O(c)

Figure 2-10. Distribution of hydraulic conductivity $(\mathrm{m} / \mathrm{s})$ used for the mudstone/halite hydrostratigraphic units for the base-case transient simulation (Table 3-2).

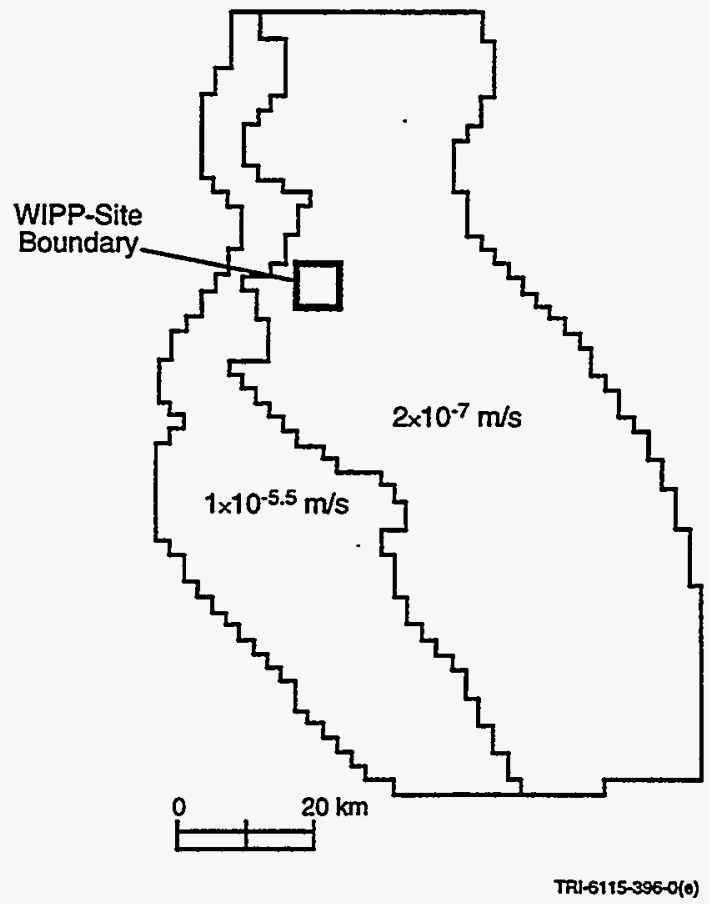

Figure 2-11. Distribution of hydraulic conductivity $(\mathrm{m} / \mathrm{s})$ used for the Dewey Lake/Triassic hydrostratigraphic unit for the base-case transient simulation (Table 3-2). 


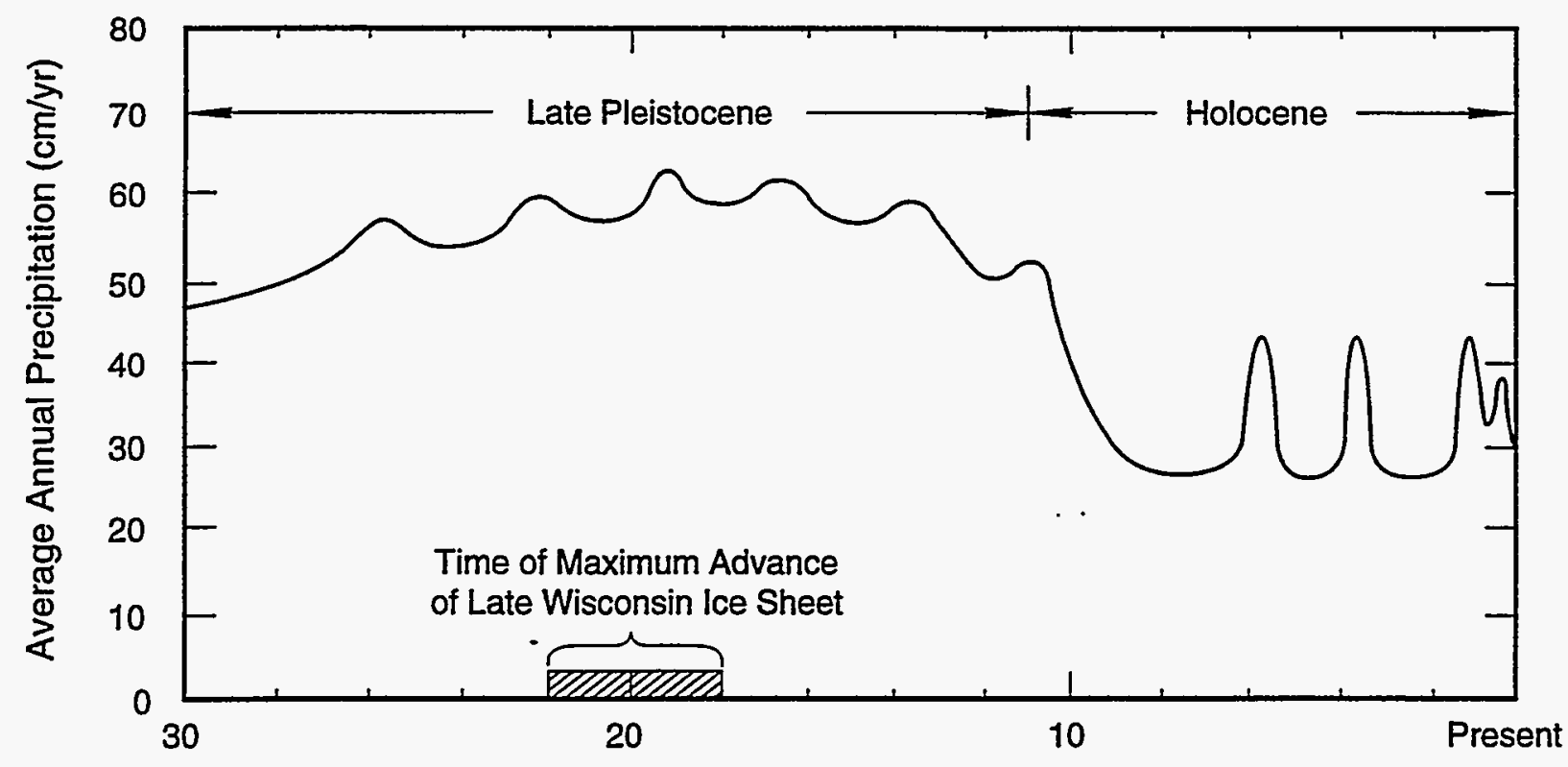

Thousands of Years from Present

TR1-6342-299-5

Figure 2-12. Estimated mean annual precipitation at the WIPP during the late Pleistocene and Holocene. (Swift, 1993).

We represent the link between climate and groundwater flow in our mathematical model by varying the amount of water available to recharge to the saturated zone. This approach is a simplification of the conceptual model discussed above in that it does not consider the complex processes that determine infiltration rates or flow in the unsaturated zone. We make this simplification because 1) the additional model-development effort and computational time required to implement a more complex model is not warranted given the lack of detailed information about past and future climatic conditions and the hydraulic properties of the unsaturated zone, and 2) a more complex model is not required to meet our objectives of using the numerical model to get a better conceptual understanding of how changes in climate effect groundwater flow in the vicinity of the WIPP. In order to implement the simplified model, we assume that maximum recharge occurs during cool wet periods. This assumption is consistent with geologic evidence that the water table was at a higher elevation in the Pleistocene (Davies, 1989). The evidence includes the presence of middle-Pleistocene stream-gravel deposits (Bachman, 1985) and the existence of late-Pleistocene calcium-sulfate deposits on the eastern margin of Nash Draw. The calcium-sulfate deposits are at an elevation above the present-day water table and have been interpreted to be spring deposits (Bachman, 1981; Bachman, 1985). 
We make a distinction between potential recharge (rate specified as model input) and simulated actual recharge (a model result). Potential recharge is the maximum amount of moisture available to recharge the saturated zone. Actual recharge is equal to potential recharge in areas where the water table is at depth, but can be less than potential recharge if the water table is near the land surface and a seepage face forms.

We assume that potential recharge varies in time but is spatially uniform over the model domain because of the large uncertainty in its spatial distribution and the relative insensitivity of model results to spatially-varying recharge. The rate of potential recharge used in these simulations should be thought of as the water available to recharge the water table as averaged over the area of a model cell (4 square kilometers) and long periods of time (hundreds of years). This conceptual averaging is consistent with the resolution in modeling natural systems at this scale.

We selected minimum and maximum values of potential recharge so that the simulated hydraulic conditions range from conditions that are similar to those of today (water table at depth) to the limiting conditions that could occur in times of greater recharge (water table near the land surface). The values used for potential recharge are model specific in that they were selected to simulate this range of possible hydrologic conditions. The validity of the results does not rest on demonstrating that these values are the same as past or future actual values. However, the values used are certainly reasonable. The rates used in these calculations ranged from 0.0 to $2.0 \mathrm{~mm} / \mathrm{year}$. A similar range, from 0.2 to $2.0 \mathrm{~mm} / \mathrm{yr}$, was determined by Campbell et al., (1996) using a chloride mass balance method to estimate localized infiltration rates at the WIPP site. They noted that these estimates are in agreement with studies in other similar geologic environments. In addition, we believe that these calculations provide the best possible estimates of the upper limit of recharge over large areas and long periods of time.

We make two assumptions about past recharge conditions: 1) that times of maximum precipitation are also times of maximum recharge, and 2) recharge in the late Pleistocene was sufficient to raise the water table to near the land surface. Therefore, recharge sufficient to raise the water table to the land surface was assumed at the start of the transient simulations (i.e., at 14,000 years before present). We refer to this recharge rate as the late Pleistocene recharge rate. The potential recharge was assumed to decrease to zero (the Holocene minimum recharge rate) over 6,000 years. This portion of the recharge function represents the first-order feature of the precipitation record: that the average annual precipitation decreased starting about 14,000 years ago and reached a minimum about 8,000 years ago (Swift, 1993). 
The remainder of the recharge function (Figure 2-13), covering the period from 8,000 years ago until 10,000 years in the future, represents the historical short-term wet periods as well as uncertainty about future precipitation rates and temporal patterns. The historical wet periods are represented by spikes in the recharge function that reach maximum recharge rates (maximum Holocene recharge rates) at $6,000,4,000$, and 2,000 years ago. Each spike has a duration of 1,000 years. We use different rates for the maximum Holocene recharge rate to represent uncertainty in that value but, within a single simulation, we assume the same maximum rate for each wet period.

Because of uncertainty about the magnitude and duration of future climatic change, we use two patterns for future recharge. Either pattern is possible, given the present state of knowledge about future climates, but neither is presented here as a prediction of the future state. Rather, the two patterns, and the parameterization of potential recharge within each pattern, provide a distribution that reasonably represents our uncertainty about the effects of possible future climatic change on recharge. Both recharge patterns assume that recharge will be greater at some time in the future than it is at present, and that present recharge is the same as its minimum Holocene value (zero for this analysis, as discussed below). Both recharge patterns also assume that the dominant effects on climate change during the next 10,000 years will be natural, rather than anthropogenic.

The first recharge pattern considered in the analysis assumes that recharge will increase from its minimum value at the present to its maximum Holocene value 500 years in the future. Recharge is then held constant after this "step" increase, and this pattern is therefore referred to as the "step pattern" of future recharge. As discussed below, the maximum Holocene value is varied between simulations to characterize uncertainty about. the magnitude of the maximum value. Conceptually, the step pattern corresponds to a future in which the climatic patterns of the Holocene are disrupted, and the climate either becomes continuously wetter or the frequency of alternations between wetter and drier climates becomes sufficiently high that the hydrologic response is indistinguishable from that of a continuously wetter climate.

The second recharge pattern used in this analysis is simply a continuation of the observed pattern of the Holocene, with an oscillatory recharge function with peaks occurring 500, 2,000, 4,000, 6,000, 8,000 , and 10,000 years in the future. We refer to this pattern as the Holocene pattern of future recharge. Conceptually, this pattern corresponds to a continuation of the variability of the Holocene, with alternations of wetter and drier climates, and without major, first-order disruptions to the climatic cycles. 

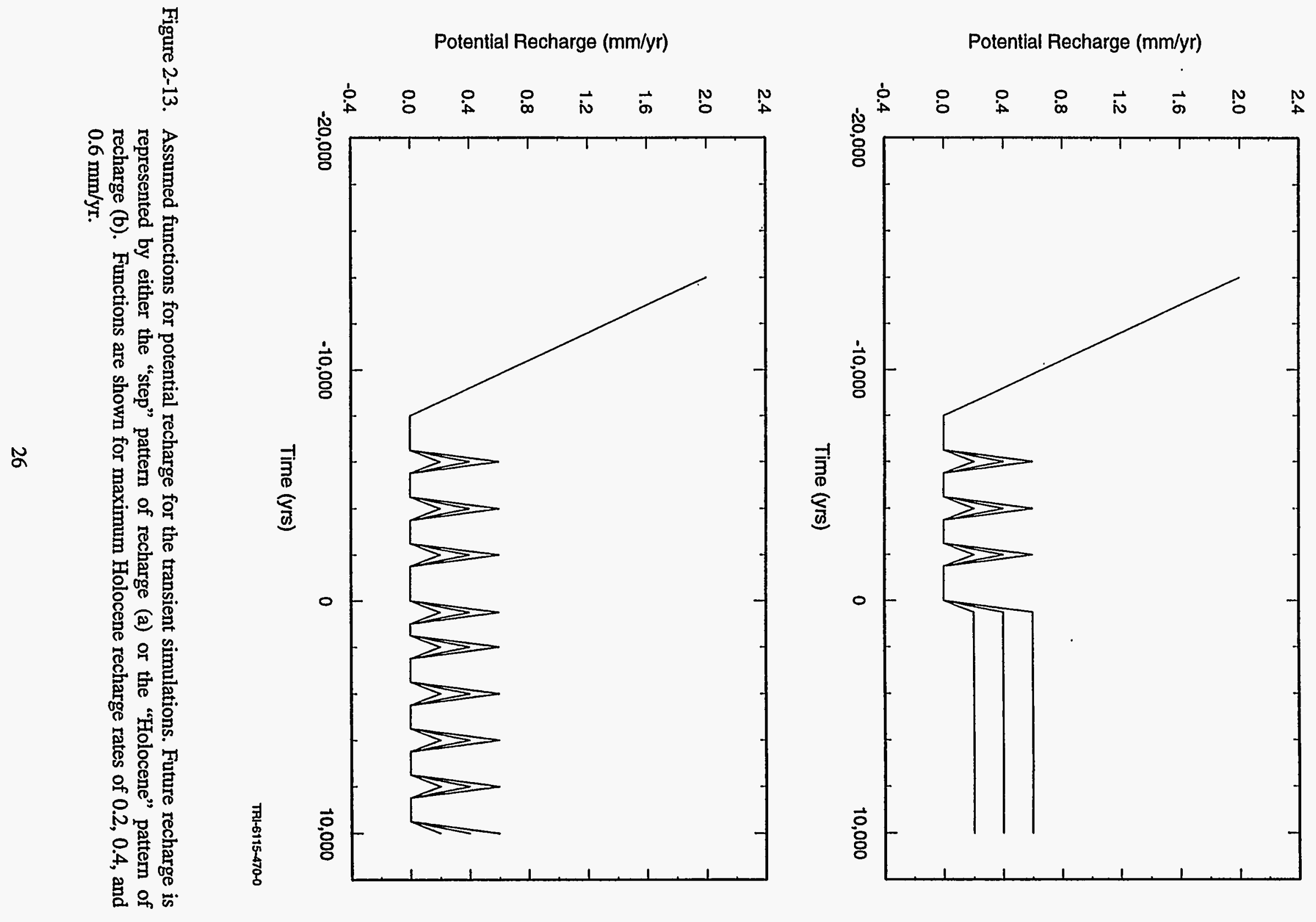
The values used for the late Pleistocene, Holocene minimum, and Holocene maximum recharge rates for the transient simulations are shown in Table 3-3. We assume as an initial condition at 14,000 years ago a flow field that had equilibrated to a late Pleistocene recharge rate of $2.0 \mathrm{~mm} / \mathrm{yr}$ for all the transient simulations. This is a somewhat arbitrary rate that was selected to be large enough to maintain the water table near the land surface for all of the distributions of hydraulic conductivity considered.

Values used for the maximum Holocene rates of potential recharge are $0.2,0.4$, or $0.6 \mathrm{~mm} / \mathrm{yr}$. This range is limited to those values that are not so large that they result in unrealistically high simulated heads for the present time. The largest value also results in future conditions similar to those assumed for the late Pleistocene if the step recharge function is used.

The choice to use a value of $0.0 \mathrm{~mm} / \mathrm{yr}$ for the minimum Holocene recharge rate is also somewhat arbitrary, and is not intended to imply that the actual present recharge rate is zero. For modeling purposes, the only requirement imposed on the minimum Holocene recharge rate is that it is a non-negative number that is sufficiently less than the lowest maximum Holocene value used $(0.2 \mathrm{~mm} / \mathrm{yr})$. Flow in the transient simulations does not reach equilibration with the minimum Holocene recharge rate. Choosing a value of zero for this rate makes the sloped portions of the recharge function steeper, and consequently, maximizes the simulated impact of climate change for a given value of the maximum Holocene recharge rate.

\subsection{Mathematical and Numerical Model}

We considered two candidate mathematical models, the saturated-unsaturated model (i.e., Richard's equation) and the fully saturated, free-surface model. Using the saturated-unsaturated model would not have provided additional information because the data required to characterize the unsaturated zone (Neuman and Witherspoon, 1971) are not available. We chose the saturated model because it met the objectives of this study without requiring data for the unsaturated zone.

The equations governing free-surface flows in porous media are non-linear. The non-linearity of the equations foils attempts to derive exact solutions except under extreme simplifying assumptions (Polubarinova-Kochina, 1962). Another approach in this situation is to derive approximate solutions to the linearized equations (see, for example, Dagan (1967)). A modern alternative is to numerically solve discrete approximations to the non-linear equations on a high-speed digital computer. Fewer simplifying assumptions need to be made and one can include as much heterogeneity and other detail in the model as can be justified by the data. 
In the computational arena the most frequently studied problem in free-surface flow through porous media has been that of seepage through a dam. A lengthy list of computer codes that have been written to address this problem can be given: Borja and Kishnani (1991), Dassargues et al., (1988), Durbin and Berenbrock (1985), France et al. (1971), Lacy and Prevost (1987), Liggett (1977), Neuman and Witherspoon (1970), Potter and Gburek (1987), and Wang and Bruch (1989). Most of these codes are based on finite element methods derived from a series of elegant mathematical results developed using the theory of variational inequalities (Alt, 1980; Bruch, 1980; Crank, 1984; and Liggett and Liu, 1983)

The motivation for the present free-surface simulations is not the 'seepage-through-a-dam' problem, but rather that of regional groundwater flow near WIPP. There are some important differences between the dam problem and the regional flow problem. Because a dam involves an engineered porous medium, there is less heterogeneity than in the regional flow problem. The shape of the regional land surface is more complex than that possessed by a dam. These factors lead one to expect generally more complicated seepage face geometry and flow patterns in the regional flow problem. In addition, the regional flow problem possesses different spatial and temporal scales than does the dam problem.

There are already a number of widely used computer codes that treat the free-surface flow problem in a non-rigorous manner (Kipp, 1987; McDonald and Harbaugh, 1988; and Reeves et al., 1986). By using the term "non-rigorous," we mean that the equations of free-surface flow in porous media, involving the kinematic boundary condition, are not solved. MODFLOW, for example, uses a nonordered approximation to the free-surface boundary conditions in which partially saturated cells at the water-table approximate the free surface phenomena (McDonald et al., 1991). By non-ordered we mean that no set of continuum partial differential equations (derived from a statement of conservation of mass) are solved in the 'free-surface' option of these codes. Instead, heuristic procedures are relied upon to approximate the physical behavior of such a system. The danger of such an approach is that it is not always clear when such procedures are valid approximations of the phenomena that one is attempting to model, particularly when heterogeneous formations are involved.

The alternative to the non-rigorous approach is to solve the groundwater flow equations with free-surface and seepage-face boundary conditions. This alternative is implemented in the SECOFL3D code. One of the decisions that must be made in designing a free-surface algorithm is whether or not to use a fixed or a moving grid. For reasons noted below, we opted to use a moving coordinate system that conforms to the motion of the free surface. Such a grid can be considered adaptive in the sense that it 
moves in response to changes in the solution. Since a logically rectangular grid is used, and the number of nodes does not vary, the adaptivity can be considered of the type $\mathbf{R}$ (see Hawken et al., (1991) for a discussion of the various types of adaptivity). The adaptivity used here is less common than that used in most R-type adaptive schemes in that we do not adapt to solution gradients or curvature in the interior of the domain, but instead adapt to the changing position of the water table.

A summary of the mathematical symbols used in this report is given in Table 2-1.

\subsubsection{The Free Surface Groundwater Flow Equations: Mathematical Model}

There are two domains of importance in these simulations: a stratigraphic domain $\Omega_{s}$ on which spatially-varying material properties such as conductivity are defined and the saturated domain $\Omega$ on which the groundwater-flow equations are solved. The latter is a subset of the former and can vary in time. No equations are solved on the stratigraphic domain, but properties must be defined on the entire stratigraphic unit. The SECOFL3D code presently assumes that $\Omega$ is an irregularly-shaped "box" with unknown moving top surface given by the water-table elevation $Z_{W T}$ :

$$
\Omega=\left\{(x, y, z, t) \mid x_{m} \leq x \leq x_{M}, y_{m} \leq y \leq y_{M}, z_{B} \leq z \leq z_{W T}, t_{s} \leq t \leq t_{e}\right\}
$$

The bottom of the model domain, $Z_{B}$, is a function of $x$ and $y$. The water-table elevation $Z_{W r}$ is a function of $x, y$, and $t$. The interior equation for the domain $\Omega$ is

$$
\nabla \cdot \kappa \nabla h=S_{s} \frac{\partial h}{\partial t}
$$

with $\mathrm{K}$ a spatially-dependent conductivity tensor, $S_{s}$ the specific storage coefficient. 
Table 2-1. Summary of Mathematical Nomenclature

\begin{tabular}{|c|c|c|}
\hline Symbol & Parameter & Dimensions \\
\hline $\mathrm{U}$ & Logical Space Domain & none \\
\hline$\xi, \eta, \zeta$ & Logical Space Coordinates & none \\
\hline$\Omega$ & Physical Domain & $\mathrm{L}, \mathrm{T}$ \\
\hline$x, y, z$ & Physical Space Coordinates & $\mathrm{L}$ \\
\hline$t$ & Time Coordinate & $\mathrm{T}$ \\
\hline$\nabla$ & Divergence Operator, $\left(\frac{\partial}{\partial x}, \frac{\partial}{\partial y}\right)$ & $L^{-1}$ \\
\hline$\kappa$ & Hydraulic Conductivity Tensor & $\mathrm{L} / \mathrm{T}$ \\
\hline $\mathbf{N}$ & surface normal flux & $T^{-1}$ \\
\hline$\left.\frac{\partial h}{\partial t}\right|_{\varepsilon}$ & Eulerian Time Derivative of Head & $\mathrm{L} / \mathrm{T}$ \\
\hline$\left.\frac{\partial h}{\partial t}\right|_{L}$ & Lagrangian Time Derivative of Head & $\mathrm{L} / \mathrm{T}$ \\
\hline$x_{t}$ & Grid Speed & $\mathrm{L} / \mathrm{T}$ \\
\hline$\nabla_{\xi}$ & Divergence Operator, $\left(\frac{\partial}{\partial \xi}, \frac{\partial}{\partial \eta}\right)$ & none \\
\hline $\operatorname{res}_{i, j}$ & local scaled residual & none \\
\hline$h_{i, j, k}$ & Discrete head variable at grid node $(i, j, k)$ & $\mathrm{L}$ \\
\hline$\Delta t$ & Time-step size & $\mathrm{T}$ \\
\hline$z_{W T}^{n}$ & Water-table elevation at discrete time level $n$ & $\mathrm{~L}$ \\
\hline$c 5, c 5 b, c 10$ & finite volume stencil coefficients & none \\
\hline
\end{tabular}


General boundary conditions can be imposed with SECOFL3D on the sides and bottom of the domain, but in the present application zero-gradient boundary conditions are assumed for this portion of the domain. On the top portion of $\Omega$ free-surface (or phreatic) boundary conditions are imposed, based on Bear and Verruijt (1987), Dagan (1989), and de Marsily (1986). Because the location of the water-table is not known à priori, two boundary conditions must be imposed at the water-table:

$$
h\left(x, y, z_{W T}, t\right)=z_{W T}(x, y, t)
$$

and

$$
(\kappa \cdot \nabla h+N) \cdot \nabla(h-z)=\omega \frac{\partial h}{\partial t}
$$

with $\mathbf{N}=-\mathbf{R} \nabla z$ being the vertical infiltration rate. The first boundary condition is a statement that the pressure at the water-table surface is atmospheric. A derivation of the second condition, sometimes referred to as the kinematic boundary condition (Figure 2-14), follows. This derivation is based primarily on Bear and Verruijt (1987). A simplified derivation of the steady-state kinematic condition is given in Appendix A. The guiding physical observation is that the flux normal to the surface must be continuous. If $v$ is a unit outward normal to the surface, and $\mathbf{F}_{\text {sal }}, \mathbf{F}_{\text {unsat }}$ are the saturated and unsaturated fluxes at the same point on the surface,

$$
\mathbf{F}_{\text {sat }} \cdot \mathrm{v}=\mathbf{F}_{\text {unsat }} \cdot \mathrm{V}
$$

If the free surface were stationary, then the saturated flux would be simply $-\kappa \nabla h$ (Darcy's Law). To correct for the motion of the water table, one subtracts the term $\omega u$, the velocity of the water-table in a porous medium, giving

$$
\mathbf{F}_{\text {sat }}=-\kappa \nabla h-\omega \mathbf{u} \text {. }
$$

The unsaturated flux is assumed to be strictly vertical,

$$
\mathbf{F}_{\text {unsat }}=-\mathbf{R} \nabla z
$$




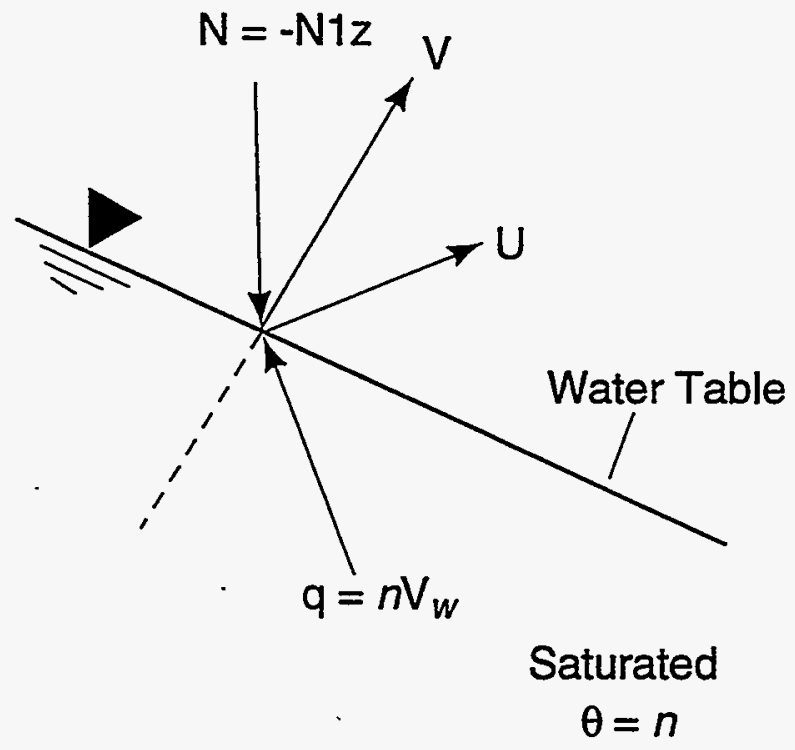

TRI-6115-393-0

Figure 2-14. Nomenclature used for the mathematical model of the free surface. Modified from (Bear and Verruijt, 1987).

where positive $\mathbf{R}$ denotes recharge and negative $\mathbf{R}$ corresponds to a net loss of fluid across the interface due to evapotranspiration. In these simulations, $\mathbf{R} \geq 0$ was always used. If the equation of the surface is implicitly defined by the relation $F(x, y, z, t)=0$, and the pressure at all points on the free surface is taken to be zero, one has from the relation $h=z+p / p g$ that

$$
F(x, y, z, t)=h(x, y, t)-z
$$

Because the vector $\nabla F$ is an outward normal to the surface $F=0$, one can represent the unit normal $v$ by

$$
v=\nabla F /|\nabla F|
$$

with $\nabla F=\nabla(h-z)$. From (6), (7), and (9), equation (5) becomes

$$
(\kappa \nabla h+\omega \mathbf{u}) \cdot \nabla F=\mathbf{R} \nabla z \cdot \nabla F
$$

Because $F$ is a quantity that is conserved as the surface moves, the material derivative of $F$ must vanish

$$
\frac{\partial F^{\cdot}}{\partial t}+\mathbf{u} \cdot \nabla F=0
$$


The kinematic condition (10) thus becomes

$$
(\kappa \nabla h-R \nabla z) \cdot \nabla F=\omega \frac{\partial F}{\partial t}
$$

that is,

$$
(\kappa \nabla h-R \nabla z) \cdot \nabla(h-z)=\omega \frac{\partial h}{\partial t}
$$

If the conductivity tensor is assumed to be diagonal, one obtains the form of the kinematic boundary condition solved by the SECOFL3D code:

$$
K_{11}\left(\frac{\partial h}{\partial x}\right)^{2}+K_{22}\left(\frac{\partial h}{\partial y}\right)^{2}+K_{33}\left(\frac{\partial h}{\partial z}\right)^{2}=\omega \frac{\partial h}{\partial t}+\left(K_{33}+R\right) \frac{\partial h}{\partial z}-R
$$

We emphasize that the kinematic condition is a non-linear boundary condition and that this creates a difficult problem to solve numerically. Even if the quadratic terms in the kinematic condition were not present, the boundary condition would remain non-linear when the conductivity is heterogeneous. Because the equations are non-linear, it is likely that multiple solutions to these equations may exist, or in some cases, no solution may exist. This possibility is discussed further in Appendix B.

The specific yield $\omega$ appears in the kinematic boundary condition as part of an accumulation term. According to Dagan (1989), the accumulation term in (2) can be neglected in the free-surface problem because in most applications $S_{s}\left(z_{W T}-z_{B}\right) \ll \omega$. However, there is no penalty incurred if this term is included in the numerical algorithm, so it is not neglected in SECOFL3D.

If the recharge flux $\mathbf{N}$ is independent of time, an equilibrium or "steady-state" water-table develops. This condition physically represents the case of mass balance between fluid injected into the saturated zone by steady recharge and fluid lost due to the presence of seepage faces. For steady-state the SECOFL3D code uses the interior equation

$$
\nabla \cdot \kappa \nabla h=0
$$

The equilibrium water-table position is embodied in the condition $\partial h / \partial t=0$, which reduces the kinematic boundary condition to

$$
(\nabla \cdot \kappa \nabla h+\mathbf{N}) \cdot \nabla(h-z)=0
$$


This equation shows that, to first-order, the equilibrium position reached in steady-state is due to a balance between surface recharge and vertical flow.

An additional complication in modeling free-surface groundwater flow is the need to simulate seepage flow wherein the water-table interacts with the land surface. The appropriate "seepage" boundary condition is:

$$
h\left(x, y, z_{W T}, t\right)=z_{L S}(x, y)
$$

(Bear and Verruijt, 1987; de Marsily, 1986), which replaces the condition (3). The kinematic condition (4) is not enforced at seepage faces.

The kinematic condition is applied wherever the water-table elevation is below the land surface. If the water-table elevation is the same as the land surface, the kinematic condition may need to be converted to a seepage face. To determine whether the kinematic or the seepage boundary condition should be applied when the elevation of the water-table and the land surface are the same, we compute

$$
U=R-\left(K_{33}+R\right) \partial h / \partial z+\nabla h \cdot \kappa \nabla h
$$

Since $U=\omega \partial h / \partial t$, its algebraic sign indicates whether the water-table is rising or falling at a particular location. If the water table is at the land surface and $U<0$ it is assumed that the water-table is freely falling and thus the kinematic condition is called for. If $U \geq 0$ at the land surface, then the water-table is rising and the seepage condition is enforced as a Dirichlet boundary condition in the linearized system.

\subsubsection{Transformation to Moving Coordinates}

Because the domain $\Omega$ is time-dependent, a moving mesh is a particularly convenient means of solving the equations described in the previous section. In this approach, a boundary-conforming transformation $\mathbf{x}(\xi, \eta, \zeta)$ from a unit logical space $U=\{(\xi, \eta, \zeta) \mid 0 \leq \xi, \eta, \zeta \leq 1\}$ to the saturated domain $\Omega$ is introduced. Such a transformation permits standard second-order accurate central-differencing of the boundary conditions. In the moving mesh approach, there are no unsaturated or partially saturated cells within the computational domain. Since no equation is solved on the unsaturated portion of the domain, no artificial "transfer" stencils (which raise operator symmetry issues) need be introduced. A special equation need not be written for partially saturated cells at the free-surface. All of these factors are difficult to deal with in a fixed mesh approach. 
A moving mesh introduces an extra step in the computation, that of generating a mesh every time the free surface is moved. Usually the stratigraphic mesh is constructed to ensure that coordinate lines follow the principle axes of the conductivity tensor. Moving the mesh can disrupt this alignment if not done carefully. Another disadvantage of the moving mesh approach is that it is necessary to interpolate spatially-varying aquifer properties, such as conductivity, to the correct value within a moving-mesh cell; if done inefficiently, this can entail a significant computational burden. To minimize these problems, the present algorithm permits motion of only the upper portion of the grid and only in the vertical direction, i.e., only the $z$-coordinate is a function of time. This greatly simplifies both the interpolation and grid generation steps. As already noted, a moving mesh algorithm requires a coordinate transformation. Some would count this as an added disadvantage of the method, but techniques for computing in general coordinates are becoming standard (see Knupp and Steinberg (1993), for example). Further details on how the mesh is moved are given in Section 2.5.4.2.

\subsubsection{Finite Volume Discretization}

The transformed equations are discretized using centered differences on a finite volume, staggered mesh. The head variable is cell-centered; fluxes are defined at cell edges. Ghost cells, with unknown head values, are used in the implementation of the boundary conditions. This approach has been documented in McDonald and Harbaugh (1988) and Reeves et al., (1986) for the confined aquifer case and will not be repeated here. A standard backwards-time differencing scheme (1st-order accurate) is used.

It is expected that the grid-speed $z_{t}$ is small, so the gradient in the pseudo-advective term $z_{\imath} \partial h / \partial z$ is discretized with centered differences. The term is lagged by a single step in the intra-timestep iteration to preserve symmetry of the stencils. Backward time differencing of the grid-speed term $z_{t}$ is used; this must be averaged to cell centers.

Discretization of the kinematic boundary condition is straightforward except if "inactive" cells are used. These are cells that are used to alter the box-like shape of the domain $\Omega$ to permit more general shapes. A no-flow condition is imposed at the interface of such cells by setting the hydraulic conductivity of the inactive cell to zero (harmonic averaging then gives zero conductivity at cell edges). If the mesh contains inactive cells, the kinematic boundary condition must be differenced in a particular way to ensure that there is no-flow across the inactive cells at the water-table. The quadratic term 


$$
\nabla h \cdot \kappa \nabla h=K_{11}\left(\frac{\partial h}{\partial x}\right)^{2}+K_{22}\left(\frac{\partial h}{\partial y}\right)^{2}+K_{33}\left(\frac{\partial h}{\partial z}\right)^{2}
$$

in the kinematic condition contains the terms relevant to horizontal flow at the water-table. One can minimize the use of ghost-cell heads in the computation of these lateral gradients by using the fact that

$$
\frac{\partial h}{\partial x}=\left(1-\frac{\partial h}{\partial z}\right) \frac{\partial z_{W T}}{\partial x}
$$

and similarly for the term containing the gradient in the $y$-direction. To prevent lateral flow into inactive cells, the first of the relevant terms is differenced as:

$$
\begin{aligned}
2 K_{11}\left(\frac{\partial z_{W T}}{\partial x}\right)^{2} & \approx\left(K_{11}\right)_{i-1 / 2, j, K L+1 / 2}\left(\frac{\partial z_{W T}}{\partial x}\right)_{i-1 / 2, j}^{2} \\
& +\left(K_{11}\right)_{i+1 / 2, j, K L+1 / 2}\left(\frac{\partial z_{W T}}{\partial x}\right)_{i+1 / 2, j}^{2}
\end{aligned}
$$

The term involving $K_{22}$ is differenced similarly, but the term involving $K_{33}$ does not need special discretization because it is assumed there are no inactive cells within a vertical column.

If an active cell is adjacent to an inactive cell, harmonic averaging of the cell conductivities results in $K_{11}=0$ at the interface between the two cells. Thus, some of the terms in the above differencing scheme drop out in the presence of adjacent inactive cells. It is possible to show that the above scheme has second-order spatial accuracy.

\subsubsection{Picard Iteration}

Because the free-surface flow equations are non-linear, the set of discrete equations must be linearized. This can be done by means of a Picard Iteration. The discretization described in the previous section results in a banded system of equations $\tau h=R$. The equations are non-linear because the matrix $\tau$ depends on the unknown elevation of the water table and on the unknown location of the seepage face. The solution algorithm thus requires an intra-time-step iteration. The solution at time-level $n$, including the location of the water-table, is known. To advance to time-level $n+1$, the solution at the previous time-level is used as the initial provisional solution for the intra-time-step calculation. The intra-time-step iteration then performs the following basic steps: 
- Calculate the elements of $\tau$ using the provisional solution.

- Iterate on the linearized equations until the scaled residual is less than the user-specified convergence criteria "conv."

- Compute the following scaled residual based on boundary condition (3):

$$
\operatorname{res}_{i, j}=1-\frac{h_{i, j, K L}+h_{i, j, K L+1}}{2 z_{W T}}
$$

- Apply convergence test. If the maximum scaled residual is greater than the user-specified convergence criteria "conv_nl," update the water-table position. Otherwise the solution for time level $n+1$ is converged.

\subsubsection{FREE-SURFACE BOUNDARY CONDITION FOR THE LINEARIZED SYSTEM}

The linearized equations include ghost-cells, so the matrix elements depend upon the boundary conditions. It is best to save the fixed head boundary condition for the update step because an unstable algorithm results if the kinematic condition is used. The following approach gives a stable algorithm.

Three relationships between the head and the equation of the surface $z=\eta(x, y, t)$ can be derived in a manner similar to that given in the previous section:

$$
\begin{aligned}
& \frac{\partial h}{\partial x}=\left(1-\frac{\partial h}{\partial z}\right) \frac{\partial \eta}{\partial x}, \\
& \frac{\partial h}{\partial y}=\left(1-\frac{\partial h}{\partial z}\right) \frac{\partial \eta}{\partial y}, \\
& \frac{\partial h}{\partial t}=\left(1-\frac{\partial h}{\partial z}\right) \frac{\partial \eta}{\partial t} .
\end{aligned}
$$

These relations can be used to derive another form of the kinetic boundary condition, which is particularly convenient for computations:

$$
\left(1-\frac{\partial h}{\partial z}\right)\left[K_{11}\left(\frac{\partial \eta}{\partial x}\right)^{2}+K_{22}\left(\frac{\partial \eta}{\partial y}\right)^{2}\right]-K_{33} \frac{\partial h}{\partial z}+R=\omega \frac{\partial \eta}{\partial t}
$$

The reason that this form is best for computation is that, in the finite volume grid, it is better to evaluate $\partial \eta / \partial x$ than $\partial h / \partial x$ (because of ghost-cells and seepage-face boundary conditions). 
The units of the kinematic equation are Length / Time. To non-dimensionalize, we divide by $K_{33}$ (we assume all the conductivities in the problem are positive). We may then write the equation in the following convenient form:

$$
u=(1-s) \varepsilon^{2}+(\rho-s)
$$

with

$$
\begin{gathered}
\varepsilon^{2}=\left(\frac{K_{11}}{K_{33}}\right)\left(\frac{\partial \eta}{\partial x}\right)^{2}+\left(\frac{K_{22}}{K_{33}}\right)\left(\frac{\partial \eta}{\partial y}\right)^{2}, \\
u=\left(\frac{\omega}{K_{33}}\right) \frac{\partial \eta}{\partial t}, \\
s=\frac{\partial h}{\partial z} \\
\rho=\frac{R}{K_{33}}
\end{gathered}
$$

If the water table is below the land surface (so there is no seepage face), the kinematic boundary condition in the form (25) is used to derive stencil coefficients for the ghost-cells of the linearized system. The approach is to re-write the Kinematic Condition as a Mixed boundary condition at time-level $n+1$, and spatial indices $(i, j, k l+1 / 2)$

$$
A_{\ell}\left(\frac{\partial \eta}{\partial t}\right)_{\ell+1}+B_{\ell}\left(\frac{\partial h}{\partial z}\right)_{\ell+1}=C_{\ell}
$$

where $A_{\ell}, B_{\ell}$, and $C_{\ell}$ are coefficients that depend on the solution at the previous non-linear iteration level, $\ell$. It is possible to show that,

$$
\frac{\partial \eta}{\partial t}=\frac{\left(h_{k l+1}^{n+1}-h_{k l+1}^{n}+h_{k l}^{n+1}-h_{k l}^{n}\right)}{2 \Delta t}+O\left[(\Delta z)^{2}, \Delta t\right] .
$$

The two-point stencil derived from (31) takes the form:

$$
c 5 h_{i, j, k l+1}+c 5 b h_{i, j, k l}=c 10
$$


with

$$
\begin{aligned}
& c 5=\left(\frac{A_{\ell}}{2 \Delta t}+\frac{B_{\ell}}{\Delta z}\right), \\
& c 5 b=\left(\frac{A_{\ell}}{2 \Delta t}+\frac{B_{\ell}}{\Delta z}\right), \\
& c 10=C_{\ell}+\frac{A_{\ell}}{\Delta t} z_{W T}^{n} .
\end{aligned}
$$

Rewriting the 'pure-elevation' form (25) of the kinetic boundary condition we have

$$
\begin{aligned}
& A_{\ell}=\frac{\omega}{K_{33}}, \\
& B_{\ell}=1+\varepsilon^{2}, \\
& C_{\ell}=\rho+\varepsilon^{2} .
\end{aligned}
$$

In the limit as $\Delta t \rightarrow 0$, the stencil for the kinematic condition reduces to

$$
h_{K L+1}+h_{K L}=2 z_{W T}^{n}
$$

while the update boundary condition is

$$
h_{K L+1}+h_{K L}=2 z_{W T}
$$

These are two independent conditions consistent with the solution $z_{W T}=z_{W T}^{n}$ expected for this limiting case. On the other hand, if limit $\Delta t \rightarrow \infty$, the mixed stencil (31) becomes the gradient condition

$$
B_{\ell}\left(h_{K L+1}-h_{K L}\right) / \Delta z=C_{\ell} .
$$

The update condition in steady-state remains the Dirichlet condition. 


\subsubsection{UPDATING THE WATER TABLE AND MOVING GRID}

The water-table position is locally updated using boundary condition (3) and the provisional head solution:

$$
\left(z_{W T}\right)_{i, j}=\left(h_{i, j, K L}+h_{i, j, K L+1}\right) / 2
$$

If the updated water-table position exceeds the land surface elevation, the water-table is corrected by setting $\left(z_{W T}\right)_{i j}=\left(z_{L s}\right)_{i j}$.

After the water-table position has been updated, it is necessary to update the z-coordinate of the moving mesh. As far as possible, the computational mesh is constructed to coincide with stratigraphic layers. Cells that lie far below the water table remain fixed while only cells close to the water table are moved. The degree of "closeness" is controlled by a parameter "wt_tol," which gives the fraction of the vertical distance in physical space that contains moving cells. For example, wt_tol $=0.1$ permits only cells lying in the top $10 \%$ of the aquifer to move. Cells below this cutoff distance retain their original gridding. If the water table drops, previously fixed cells may convert to moving cells or vise-versa. Grid movement is done for each vertical column of the mesh and no movement of the $x$ and $y$-coordinates is made. A linear transformation between the elevation of the topmost fixed cell of a column and the elevation of the water table has been found adequate for constructing the elevations of the intermediate cells of the moving mesh. Once the mesh has been updated, the grid speed $z_{t}$ is recalculated for use in the pseudo-advective term. Conductivities, storativities, and specific yield values are interpolated either harmonically or linearly in the vertical direction using the values defined on the stratigraphic domain $\Omega_{s}$ and the location of the center of each cell in the computational mesh. Because the mesh is updated only in the vertical direction the calculations described here are relatively straightforward and not computationally intensive.

\subsubsection{Numerical Sensitivity Studies}

A brief study of the sensitivity of the flow solutions to the numerical parameters was undertaken to determine whether or not the solutions are sensitive to the numerical parameters. It was not possible to do this for every simulation, so a representative steady-state simulation was used. First, the code was run with tight tolerances, giving a solution to which we could compare runs having looser tolerance settings (looser settings are desired in order that the runs are not excessively CPU intensive). The crucial parameters that were varied were the following: 
- conv_nl: the non-linear iteration scaled tolerance.

- conv: the tolerance on the scaled residual for the linear solver,

- $\lim 2:$ the number of solver iterations per water-table update,

- $\quad \mathrm{rf}$ nl: the water-table update under-relaxation parameter.

'Tight' settings for these parameters were: conv_nl=1 $\times 10^{-5}$, conv=1 $\times 10^{-12}, \lim 2=50$, and If_nl=0.5. Run Number 1 used conv_nl $=1.6 \times 10^{-3}$, conv $=1.0 \times 10^{-6}, \lim 2=200$, and $\mathrm{rf} \_\mathrm{nl}=0.1$. Runs 2 through 19 used the same parameters except for the excursions indicated in Table 2-2. We looked at three measures of the differences between the 'tight' tolerance solution and the other nineteen solutions: the average difference in the position of the water table, the maximum difference in the position of the water table, and the average difference in vertical specific discharge at the water table.

The heads themselves were not examined since these tend to track the water-table elevations closely. Table 2-2 shows the runs that were made and gives these three numbers. We observe that, in general, there is not a great sensitivity of the solution to the numerical parameters, provided that excessively loose values (particularly of conv_nl) are not used. We conclude from these results that the settings used in Run Number 1 , conv_ $\mathrm{nl}=1.6 \times 10^{-3}$, conv $=1 \times 10^{-6}, \mathrm{rf} \_\mathrm{nl}=0.1$, and $\lim 2=200$ were adequate to give solutions close to the one obtained using the 'tight' tolerances.

We performed a grid refinement analysis using one steady-state simulation. Grid sizes of $39 \times$ $56 \times 10(1 \mathrm{X})$ and $78 \times 112 \times 20$ cells $(2 \mathrm{X})$ were used. The water-table solutions from these two simulations were compared. For each cell face $(i, j)$ of the $1 \mathrm{X}$ water-table solution, there are four cell faces in the $2 \mathrm{X}$ solution. The water-table solution at each of these four cell faces of the $2 \mathrm{X}$ solution were averaged to obtain a single water-table value for the $2 \mathrm{X}$ solution that could be compared to the $1 \mathrm{X}$ solution. Cell faces that corresponded to dead cells or seepage faces were eliminated from the comparison, leaving 1083 'free-surface' cells over which the differences between the two solutions could be computed. The root-mean-square difference between the $1 \mathrm{X}$ water-table solution and the averaged $2 \mathrm{X}$ solution for 'free-surface' cells was computed to be 1.4 meters. The maximum difference between the $1 \mathrm{X}$ and averaged $2 \mathrm{X}$ water-table solutions was $13.0 \mathrm{~m}$, occurring at cell indices $(7,30)$. The water-table elevation in the refined solution was lower by $13.0 \mathrm{~m}$ at $(7,30)$. In this particular simulation, the water- 
Table 2-2. Solution Sensitivity to Numerical Parameters

\begin{tabular}{|c|c|c|c|c|c|}
\hline $\begin{array}{l}\text { Run } \\
\text { No. }\end{array}$ & Param. & Value & $\operatorname{RMS} \Delta z_{W T}^{*}$ & $\operatorname{Max} \Delta z_{W T} \dagger$ & RMS Vert Sp Dis $\ddagger$ \\
\hline 1 & conv_nl & $1.6 \times 10^{-3}$ & $0.15 \mathrm{~m}$ & $3.8 \mathrm{~m}$ & $2.5 \times 10^{-5} \mathrm{~m} / \mathrm{sec}$ \\
\hline 2 & conv_nl & $1.6 \times 10^{-1}$ & $27 \mathrm{~m}$ & $128 \mathrm{~m}$ & $1.9 \times 10^{-2} \mathrm{~m} / \mathrm{sec}$ \\
\hline 3 & conv_nl & $1.6 \times 10^{-2}$ & $3.0 \mathrm{~m}$ & $1.9 \mathrm{~m}$ & $2.5 \times 10^{-4} \mathrm{~m} / \mathrm{sec}$ \\
\hline 4 & conv_nl & $1.6 \times 10^{-4}$ & $0.16 \mathrm{~m}$ & $5.2 \mathrm{~m}$ & $2.8 \times 10^{-5} \mathrm{~m} / \mathrm{sec}$ \\
\hline 5 & conv_nl & $1.6 \times 10^{-5}$ & $0.16 \mathrm{~m}$ & $5.4 \mathrm{~m}$ & $2.8 \times 10^{-5} \mathrm{~m} / \mathrm{sec}$ \\
\hline 6 & conv & $1.6 \times 10^{-4}$ & $0.16 \mathrm{~m}$ & $4.1 \mathrm{~m}$ & $2.7 \times 10^{-5} \mathrm{~m} / \mathrm{sec}$ \\
\hline 7 & conv & $1 \times 10^{-5}$ & $0.16 \mathrm{~m}$ & $3.9 \mathrm{~m}$ & $2.5 \times 10^{-5} \mathrm{~m} / \mathrm{sec}$ \\
\hline 8 & conv & $1 \times 10^{-7}$ & $0.15 \mathrm{~m}$ & $3.8 \mathrm{~m}$ & $2.5 \times 10^{-5} \mathrm{~m} / \mathrm{sec}$ \\
\hline 9 & conv & $1 \times 10^{-8}$ & $0.15 \mathrm{~m}$ & $3.8 \mathrm{~m}$ & $2.5 \times 10^{-5} \mathrm{~m} / \mathrm{sec}$ \\
\hline 10 & conv & $1 \times 10^{-10}$ & $0.16 \mathrm{~m}$ & $5.4 \mathrm{~m}$ & $2.8 \times 10^{-5} \mathrm{~m} / \mathrm{sec}$ \\
\hline 11 & conv & $1 \times 10^{-12}$ & $0.16 \mathrm{~m}$ & $5.5 \mathrm{~m}$ & $2.8 \times 10^{-5} \mathrm{~m} / \mathrm{sec}$ \\
\hline 12 & $\lim 2$ & 50 & $0.24 \mathrm{~m}$ & $5.2 \mathrm{~m}$ & $5.2 \times 10^{-5} \mathrm{~m} / \mathrm{sec}$ \\
\hline 13 & $\lim 2$ & 100 & $0.15 \mathrm{~m}$ & $3.6 \mathrm{~m}$ & $2.5 \times 10^{-5} \mathrm{~m} / \mathrm{sec}$ \\
\hline 16 & If_nl & 0.5 & $0.11 \mathrm{~m}$ & $2.4 \mathrm{~m}$ & $1.8 \times 10^{-5} \mathrm{~m} / \mathrm{sec}$ \\
\hline 17 & If_nl & 0.25 & $0.18 \mathrm{~m}$ & $5.6 \mathrm{~m}$ & $3.7 \times 10^{-5} \mathrm{~m} / \mathrm{sec}$ \\
\hline 18 & rf_nl & 0.05 & $0.15 \mathrm{~m}$ & $3.6 \mathrm{~m}$ & $2.4 \times 10^{-5} \mathrm{~m} / \mathrm{sec}$ \\
\hline 19 & rf_nl & 0.01 & $0.14 \mathrm{~m}$ & $3.8 \mathrm{~m}$ & $2.4 \times 10^{-5} \mathrm{~m} / \mathrm{sec}$ \\
\hline
\end{tabular}

* RMS $\Delta z_{W T}$, the root-mean-square difference of the water-table elevation over the whole domain,

$\dagger \operatorname{Max} \Delta z_{\mathrm{W} T}$, the maximum difference of the water-table elevation over the whole domain,

$\doteqdot$ RMS Vertical Specific Discharge over the whole domain. 
table solution seems to be no more accurate than one and a half meters, and considerably worse in some local areas. Were the $2 \mathrm{X}$ grid to be refined yet again, it is possible that the water-table solution could change by similar amounts, i.e., it is unknown whether the assymptotic regime has been reached. Consequently, truncation error due to insufficient grid resolution cannot be said to have been eliminated from the uncertainties present in these simulations. 
This Page Intentionally Left Blank 


\section{SIMULATION RESULTS AND ANALYSIS}

We performed 54 steady-state and 17 transient simulations. The main objective of the steadystate simulations was to examine the sensitivity of model results to values of selected model parameters in order to enhance our conceptual understanding of the hydrologic system. The transient simulations provide insight into how the hydrologic system responds as the potential recharge changes with time. This insight is the basis for making predictions about how flow patterns might change in the future.

We used 27 combinations of intact hydraulic conductivity for the steady-state simulations (Table 3-1) and 7 combinations of hydraulic conductivity and specific yield for the transient simulations (Table 3-2). Six hydraulic properties, the intact hydraulic conductivity of anhydrite layers, Dewey Lake/Triassic rocks, the Culebra, and the Magenta, the hydraulic conductivity of the disrupted region (Figure 2-7) and the specific yield were varied. Four of these six hydraulic properties were selected for the sensitivity analysis because we believe that they are most important in determining groundwater flow patterns at the scale of the groundwater basin. Each of these properties plays a distinct role. The conductivity of the anhydrites controls the amount of vertical leakage to the more conductive members of the Rustler Formation. The hydraulic conductivity of the region that has been disrupted by solution of the top of the Salado determines, to a large extent, the absolute elevation of heads in the basin. The conductivity of the Dewey Lake/Triassic rocks plays a critical role in perhaps the most important aspect of the groundwater. basin, the elevation and relief of the water table. And finally, the specific yield of the Dewey Lake/Triassic rocks is the major factor in determining how fast the groundwater basin reacts to changes in recharge. The remaining two hydraulic properties, the conductivity of the Magenta and the Culebra, that are less important at a basin scale, but are relevant to the performance of the WIPP.

A potential recharge rate of $0.2 \mathrm{~mm} / \mathrm{yr}$ was used for steady-state simulations 1 through 27 (Table 3-1). A rate of $2.0 \mathrm{~mm} / \mathrm{yr}$ was used for steady-state simulations 28 through 54 . All of the transient simulations assumed a flow field that had equilibrated to a potential recharge rate of $2.0 \mathrm{~mm} / \mathrm{yr}$ as an initial condition. Table 3-3 shows the value used for the maximum Holocene potential recharge $(0.2,0.4$, or $0.6 \mathrm{~mm} / \mathrm{yr})$ and the future recharge pattern (step or Holocene as discussed in Section 2.4) used for the transient simulations.

The results of the simulations are presented and analyzed at two scales. To obtain insight into the results at the scale of the entire model domain we use a set of map views and vertical cross-sections 
Table 3-1. Values of Intact Hydraulic Conductivity ( $\mathrm{K}$ in $\mathrm{m} / \mathrm{s}$ ) for the Steady-State Simulations

\begin{tabular}{|c|c|c|c|c|c|c|c|}
\hline Simulation & $\begin{array}{c}\mathrm{K} \\
\text { Disrupted } \\
\text { Region }\end{array}$ & $\underset{\text { Anhydrite }}{\mathrm{K}}$ & $\begin{array}{c}\mathbf{K} \\
\text { Dewey } \\
\text { Lake/Triassic }\end{array}$ & $\begin{array}{c}\mathrm{K} \\
\text { Culebra }\end{array}$ & $\begin{array}{c}\mathrm{K} \\
\text { Magenta }\end{array}$ & $\underset{\text { Halite }}{\mathbf{K}}$ & $\underset{\text { Mudstone }}{\mathrm{K}}$ \\
\hline 1,28 & $1 \times 10^{-4.5}$ & $1 \times 10^{-13}$ & $2 \times 10^{-6}$ & $1 \times 10^{-7.5}$ & $1 \times 10^{-8.5}$ & $1 \times 10^{-13}$ & $1 \times 10^{-9}$ \\
\hline 2,29 & $1 \times 10^{-4.5}$ & $1 \times 10^{-13}$ & $2 \times 10^{-7}$ & $1 \times 10^{-7.5}$ & $1 \times 10^{-8.5}$ & $1 \times 10^{-13}$ & $1 \times 10^{-9}$ \\
\hline 3,30 & $1 \times 10^{-4.5}$ & $1 \times 10^{-13}$ & $2 \times 10^{-8}$ & $1 \times 10^{-7.5}$ & $1 \times 10^{-8.5}$ & $1 \times 10^{-13}$ & $1 \times 10^{-9}$ \\
\hline 4,31 & $1 \times 10^{-4.5}$ & $1 \times 10^{-12}$ & $2 \times 10^{-6}$ & $1 \times 10^{-7.5}$ & $1 \times 10^{-8.5}$ & $1 \times 10^{-13}$ & $1 \times 10^{-9}$ \\
\hline 5,32 & $1 \times 10^{-4.5}$ & $1 \times 10^{-12}$ & $2 \times 10^{-7}$ & $1 \times 10^{-7.5}$ & $1 \times 10^{-8.5}$ & $1 \times 10^{-13}$ & $1 \times 10^{-9}$ \\
\hline 6,33 & $1 \times 10^{-4.5}$ & $1 \times 10^{-12}$ & $2 \times 10^{-8}$ & $1 \times 10^{-7.5}$ & $1 \times 10^{-8.5}$ & $1 \times 10^{-13}$ & $1 \times 10^{-9}$ \\
\hline 7,34 & $1 \times 10^{-4.5}$ & $1 \times 10^{-11}$ & $2 \times 10^{-6}$ & $1 \times 10^{-7.5}$ & $1 \times 10^{-8.5}$ & $1 \times 10^{-13}$ & $1 \times 10^{-9}$ \\
\hline 8,35 & $1 \times 10^{-4.5}$ & $1 \times 10^{-11}$ & $2 \times 10^{-7}$ & $1 \times 10^{-7.5}$ & $1 \times 10^{-8.5}$ & $1 \times 10^{-13}$ & $1 \times 10^{-9}$ \\
\hline 9,36 & $1 \times 10^{-4.5}$ & $1 \times 10^{-11}$ & $2 \times 10^{-8}$ & $1 \times 10^{-7.5}$ & $1 \times 10^{-8.5}$ & $1 \times 10^{-13}$ & $1 \times 10^{-9}$ \\
\hline 10,37 & $1 \times 10^{-5.5}$ & $1 \times 10^{-13}$ & $2 \times 10^{-6}$ & $1 \times 10^{-7.5}$ & $1 \times 10^{-8.5}$ & $1 \times 10^{-13}$ & $1 \times 10^{-9}$ \\
\hline 11,38 & $1 \times 10^{-5.5}$ & $1 \times 10^{-13}$ & $2 \times 10^{-7}$ & $1 \times 10^{-7.5}$ & $1 \times 10^{-8.5}$ & $1 \times 10^{-13}$ & $1 \times 10^{-9}$ \\
\hline 12,39 & $1 \times 10^{-5.5}$ & $1 \times 10^{-13}$ & $2 \times 10^{-8}$ & $1 \times 10^{-7.5}$ & $1 \times 10^{-8.5}$ & $1 \times 10^{-13}$ & $1 \times 10^{-9}$ \\
\hline 13,40 & $1 \times 10^{-5.5}$ & $1 \times 10^{-12}$ & $2 \times 10^{-6}$ & $1 \times 10^{-7.5}$ & $1 \times 10^{-8.5}$ & $1 \times 10^{-13}$ & $1 \times 10^{-9}$ \\
\hline 14,41 & $1 \times 10^{-5.5}$ & $1 \times 10^{-12}$ & $2 \times 10^{-7}$ & $1 \times 10^{-7.5}$ & $1 \times 10^{-8.5}$ & $1 \times 10^{-13}$ & $1 \times 10^{-9}$ \\
\hline 15,42 & $1 \times 10^{-5.5}$ & $1 \times 10^{-12}$ & $2 \times 10^{-8}$ & $1 \times 10^{-7.5}$ & $1 \times 10^{-8.5}$ & $1 \times 10^{-13}$ & $1 \times 10^{-9}$ \\
\hline 16,43 & $1 \times 10^{-5.5}$ & $1 \times 10^{-11}$ & $2 \times 10^{-6}$ & $1 \times 10^{-7.5}$ & $1 \times 10^{-8.5}$ & $1 \times 10^{-13}$ & $1 \times 10^{-9}$ \\
\hline 17,44 & $1 \times 10^{-5.5}$ & $1 \times 10^{-11}$ & $2 \times 10^{-7}$ & $1 \times 10^{-7.5}$ & $1 \times 10^{-8.5}$ & $1 \times 10^{-13}$ & $1 \times 10^{-9}$ \\
\hline 18,45 & $1 \times 10^{-5.5}$ & $1 \times 10^{-11}$ & $2 \times 10^{-8}$ & $1 \times .10^{-7.5}$ & $1 \times 10^{-8.5}$ & $1 \times 10^{-13}$ & $1 \times 10^{-9}$ \\
\hline 19,46 & $1 \times 10^{-6.5}$ & $1 \times 10^{-13}$ & $2 \times 10^{-6}$ & $1 \times 10^{-7.5}$ & $1 \times 10^{-8.5}$ & $1 \times 10^{-13}$ & $1 \times 10^{-9}$ \\
\hline 20,47 & $1 \times 10^{-6.5}$ & $1 \times 10^{-13}$ & $2 \times 10^{-7}$ & $1 \times 10^{-7.5}$ & $1 \times 10^{-8.5}$ & $1 \times 10^{-13}$ & $1 \times 10^{-9}$ \\
\hline 21,48 & $1 \times 10^{-6.5}$ & $1 \times 10^{-13}$ & $2 \times 10^{-8}$ & $1 \times 10^{-7.5}$ & $1 \times 10^{-8.5}$ & $1 \times 10^{-13}$ & $1 \times 10^{-9}$ \\
\hline 22,49 & $1 \times 10^{-6.5}$ & $1 \times 10^{-12}$ & $2 \times 10^{-6}$ & $1 \times 10^{-7.5}$ & $1 \times 10^{-8.5}$ & $1 \times 10^{-13}$ & $1 \times 10^{-9}$ \\
\hline 23,50 & $1 \times 10^{-6.5}$ & $1 \times 10^{-12}$ & $2 \times 10^{-7}$ & $1 \times 10^{-7.5}$ & $1 \times 10^{-8.5}$ & $1 \times 10^{-13}$ & $1 \times 10^{-9}$ \\
\hline 24,51 & $1 \times 10^{-6.5}$ & $1 \times 10^{-12}$ & $2 \times 10^{-8}$ & $1 \times 10^{-7.5}$ & $1 \times 10^{-8.5}$ & $1 \times 10^{-13}$ & $1 \times 10^{-9}$ \\
\hline 25,52 & $1 \times 10^{-6.5}$ & $1 \times 10^{-11}$ & $2 \times 10^{-6}$ & $1 \times 10^{-7.5}$ & $1 \times 10^{-8.5}$ & $1 \times 10^{-13}$ & $1 \times 10^{-9}$ \\
\hline 26,53 & $1 \times 10^{-6.5}$ & $1 \times 10^{-11}$ & $2 \times 10^{-7}$ & $1 \times 10^{-7.5}$ & $1 \times 10^{-8.5}$ & $1 \times 10^{-13}$ & $1 \times 10^{-9}$ \\
\hline 27,54 & $1 \times 10^{-6.5}$ & $1 \times 10^{-11}$ & $2 \times 10^{-8}$ & $1 \times 10^{-7.5}$ & $1 \times 10^{-8.5}$ & $1 \times 10^{-13}$ & $1 \times 10^{-9}$ \\
\hline
\end{tabular}


Table 3-2. Values of Intact Hydraulic Conductivity ( $K$ in $\mathrm{m} / \mathrm{s}$ ) and Specific Yield for the Transient Simulations

\begin{tabular}{|c|c|c|c|c|c|c|c|c|}
\hline Simulation & $\begin{array}{c}\mathrm{K} \\
\text { Disrupted } \\
\text { Region }\end{array}$ & $\underset{\text { Anhydrite }}{\mathrm{K}}$ & $\begin{array}{c}\mathrm{K} \\
\text { Dewey } \\
\text { Lake/Triassic }\end{array}$ & $\underset{\text { Culebra }}{\mathrm{K}}$ & $\underset{\text { Magenta }}{\mathrm{K}}$ & $\begin{array}{c}\mathrm{K} \\
\text { Halite }\end{array}$ & $\underset{\text { Mudstone }}{\mathbf{K}}$ & $\begin{array}{l}\text { Specific } \\
\text { Yield }\end{array}$ \\
\hline $\begin{array}{c}b c, 7,8 \\
11,12,13\end{array}$ & $1 \times 10^{-5.5}$ & $1 \times 10^{-12}$ & $2 \times 10^{-7}$ & $1 \times 10^{-7.5}$ & $1 \times 10^{-8.5}$ & $1 \times 10^{-13}$ & $1 \times 10^{-9}$ & 0.01 \\
\hline 1 & $1 \times 10^{-5.5}$ & $1 \times 10^{-13}$ & $2 \times 10^{-7}$ & $1 \times 10^{-7.5}$ & $1 \times 10^{-8.5}$ & $1 \times 10^{-13}$ & $1 \times 10^{-9}$ & 0.01 \\
\hline $\begin{array}{c}2,9,10,14,1 \\
5,16\end{array}$ & $1 \times 10^{-4.5}$ & $1 \times 10^{-12}$ & $2 \times 10^{-7}$ & $1 \times 10^{-7.5}$ & $1 \times 10^{-8.5}$ & $1 \times 10^{-13}$ & $1 \times 10^{-9}$ & 0.01 \\
\hline 3 & $1 \times 10^{-5.5}$ & $1 \times 10^{-12}$ & $2 \times 10^{-6}$ & $1 \times 10^{-7.5}$ & $1 \times 10^{-8.5}$ & $1 \times 10^{-13}$ & $1 \times 10^{-9}$ & 0.01 \\
\hline 4 & $1 \times 10^{-5.5}$ & $1 \times 10^{-12}$ & $2 \times 10^{-7}$ & $1 \times 10^{-6.5}$ & $1 \times 10^{-8.5}$ & $1 \times 10^{-13}$ & $1 \times 10^{-9}$ & 0.01 \\
\hline 5 & $1 \times 10^{-5.5}$ & $1 \times 10^{-12}$ & $2 \times 10^{-7}$ & $1 \times 10^{-7.5}$ & $1 \times 10^{-7.5}$ & $1 \times 10^{-13}$ & $1 \times 10^{-9}$ & 0.01 \\
\hline 6 & $1 \times 10^{-5.5}$ & $1 \times 10^{-12}$ & $2 \times 10^{-7}$ & $1 \times 10^{-7.5}$ & $1 \times 10^{-8.5}$ & $1 \times 10^{-13}$ & $1 \times 10^{-9}$ & 0.05 \\
\hline
\end{tabular}


of model results. These include contour maps of the water table, depth to the water table, and hydraulic head, and vector plots of lateral groundwater velocities. We plotted selected model parameters versus time to get a more detailed view of the model results in the vicinity of the WIPP site. These parameters were selected because of their relevance to the performance of the repository. They include hydraulic head, lateral flow rates, flow directions, and vertical leakage into and out of the Culebra at nine locations within the WIPP-site boundary.

We also found it informative to calculate mass balances for the portions of the more conductive rock units that underlie a $6 \mathrm{~km}$ by $6 \mathrm{~km}$ area that approximately correspond to the WIPP site. These are referred to as the reference volumes for these units. The UTM coordinates of the surface trace of the reference volumes are N3585000E, 611000; N3585000, E617000; N3570000, E617000; and N357000, E611000. The UTM coordinates of the corners of the WIPP site are N3585057, E610496; N3585109, E616941; N3578681, E617015; and N3578612, E610566. We summed the total inflow and outflow, and the flow across the vertical and horizontal faces of each reference volume. These flows are reported in the units of $\mathrm{m}^{3} / \mathrm{yr}$.

We believe that the total lateral outflow from the Culebra reference volume is the best indicator of flow away from an intrusion borehole that these simulations can provide. In analyzing the results of transient simulations, we are concerned with how future rates of total lateral outflow from the Culebra reference volume compare to the simulated present rate. We refer to the ratio of the total lateral-outflow from the Culebra reference volume at a given time in the future to that quantity at the simulated present time as the lateral-flow ratio. For example, Table D-4 shows that for the base-case transient simulation, the rate of lateral outflow from the Culebra reference volume is $3335 \mathrm{~m}^{3} / \mathrm{yr}$ at 10,000 years in the future. Table D-1 shows that the value for this number is $2107 \mathrm{~m}^{3} / \mathrm{yr}$ at the simulated present time. The ratio of these numbers, as indicated in Table D-7, is 1.6. Steady-state simulations, by definition, do not provide the rate of lateral flow at different times. The lateral-flow ratios for steady-state simulations (Table 3-4) are the ratios of total lateral outflow from the Culebra for pairs of calculations that differ only in their recharge rate.

\subsection{Results of Steady-State Simulations}

Analysis of the steady-state simulations focuses on flow conditions at the WIPP site. In particular, we examine how the simulated elevation of the water table, vertical gradients of head, and 
Table 3-3. Rates of Potential Recharge and Recharge Pattern Used for the Transient Simulations

\begin{tabular}{|c|c|c|c|c|}
\hline Simulation & $\begin{array}{c}\text { Late } \\
\text { Pleistocene } \\
\text { Recharge } \\
(\mathrm{mm} / \mathrm{yr})\end{array}$ & $\begin{array}{c}\text { Holocene } \\
\text { Minimum } \\
\text { Recharge } \\
(\mathrm{mm} / \mathrm{yr})\end{array}$ & $\begin{array}{c}\text { Holocene Peak } \\
\text { Recharge } \\
\text { (mm/yr) }\end{array}$ & $\begin{array}{c}\text { Recharge } \\
\text { Pattern }\end{array}$ \\
\hline bc, 1 through 6 & 2.0 & 0.0 & 0.2 & step \\
\hline 11,14 & 2.0 & 0.0 & 0.2 & Holocene \\
\hline 7,9 & 2.0 & 0.0 & 0.4 & step \\
\hline 12,15 & 2.0 & 0.0 & 0.4 & Holocene \\
\hline 8,10 & 2.0 & 0.0 & 0.6 & step \\
\hline 13,16 & 2.0 & 0.0 & 0.6 & Holocene \\
\hline
\end{tabular}


Table 3-4. Lateral-Flow Ratios for the Steady-State Simulations

\begin{tabular}{ccccc}
\hline Simulation Pair & $\begin{array}{c}\text { Lateral-Flow } \\
\text { Ratio }\end{array}$ & & Simulation Pair & $\begin{array}{c}\text { Lateral-Flow } \\
\text { Ratio }\end{array}$ \\
\cline { 1 - 2 } \cline { 4 - 4 } \cline { 4 - 4 } $2 / 28$ & 2.4 & 1.4 & $15 / 42$ & 1.0 \\
$3 / 30$ & 1.5 & $16 / 43$ & 3.3 \\
$4 / 31$ & 2.3 & $17 / 44$ & 1.6 \\
$5 / 32$ & 1.8 & & $18 / 45$ & 1.0 \\
$6 / 33$ & 1.1 & $19 / 46$ & 1.4 \\
$7 / 34$ & 5.5 & $20 / 47$ & 0.9 \\
$8 / 35$ & 2.0 & $21 / 48$ & 0.7 \\
$9 / 36$ & 1.1 & $22 / 49$ & 1.6 \\
$10 / 37$ & 2.1 & $23 / 50$ & 1.0 \\
$11 / 38$ & 1.1 & $24 / 51$ & 0.8 \\
$12 / 39$ & 1.0 & $25 / 52$ & 2.9 \\
$13 / 40$ & 2.2 & $26 / 53$ & 1.3 \\
$14 / 41$ & 1.1 & $27 / 54$ & 0.7 \\
\hline
\end{tabular}


flow velocities in the Culebra depend on assumed values for hydraulic properties and recharge rates. Results for the steady-state simulations are presented for the Dewey Lake/Triassic rocks, Magenta, and Culebra at the centers of nine model cells that are located within the WIPP-site boundary. Tables in Appendix $\mathrm{C}$ contain water table elevations, hydraulic heads, and lateral flow magnitudes and directions at the nine locations. In addition, a mass balance for the reference volumes of these three units is included in Appendix C.

The heart of this section is a series of graphs that show how heads, Culebra flow velocities, and mass balance over the Culebra reference volume vary as a function of the hydraulic conductivity of the Dewey Lake/Triassic rocks, intact anhydrite, and the disrupted region, as well as the recharge rate.

\subsubsection{Sensitivity of the Elevation of the Water Table and Hydraulic Head to Model Parameters}

Figures 3-1 through 3-9 summarize the simulated elevation of the water table and values of hydraulic head in the Magenta and Culebra near the center of the WIPP site. Each graph in these figures presents heads profiles from two or three simulations as a function of one parameter. Anhydrite conductivity, for example, is the independent variable in Figures 3-1 and 3-2. For each value of anhydrite conductivity in each graph, the three data points are the water table (upper point), Magenta head, and Culebra head (lower point).

In each of the steady-state simulations, the difference in head between these units decreases as the conductivity of the anhydrite layers increases. Unless the water table at the WIPP site is fixed at the land surface (i.e., at $1045 \mathrm{~m}$ in this model), the decrease in the total difference in head between the water table and the base of the Rustler is, for most combinations of hydraulic conductivity and recharge, accomplished by both decreasing the elevation of the water table and increasing head in the Culebra. The exceptions are those simulations in which potential recharge is equal to $0.2 \mathrm{~mm} / \mathrm{yr}$ and the conductivity of the Dewey Lake/Triassic rocks is equal to $2 \times 10^{-6} \mathrm{~m} / \mathrm{s}$. In these simulations, the head in the Culebra decreases with increasing anhydrite conductivity.

Figures 3-3 and 3-4 show the variation of heads with the conductivity of the disrupted region. It is clear that the effect of changing this parameter is to raise or lower heads in all three units by approximately a equal amount. This parameter can be thought of as controlling the "base level" of the 

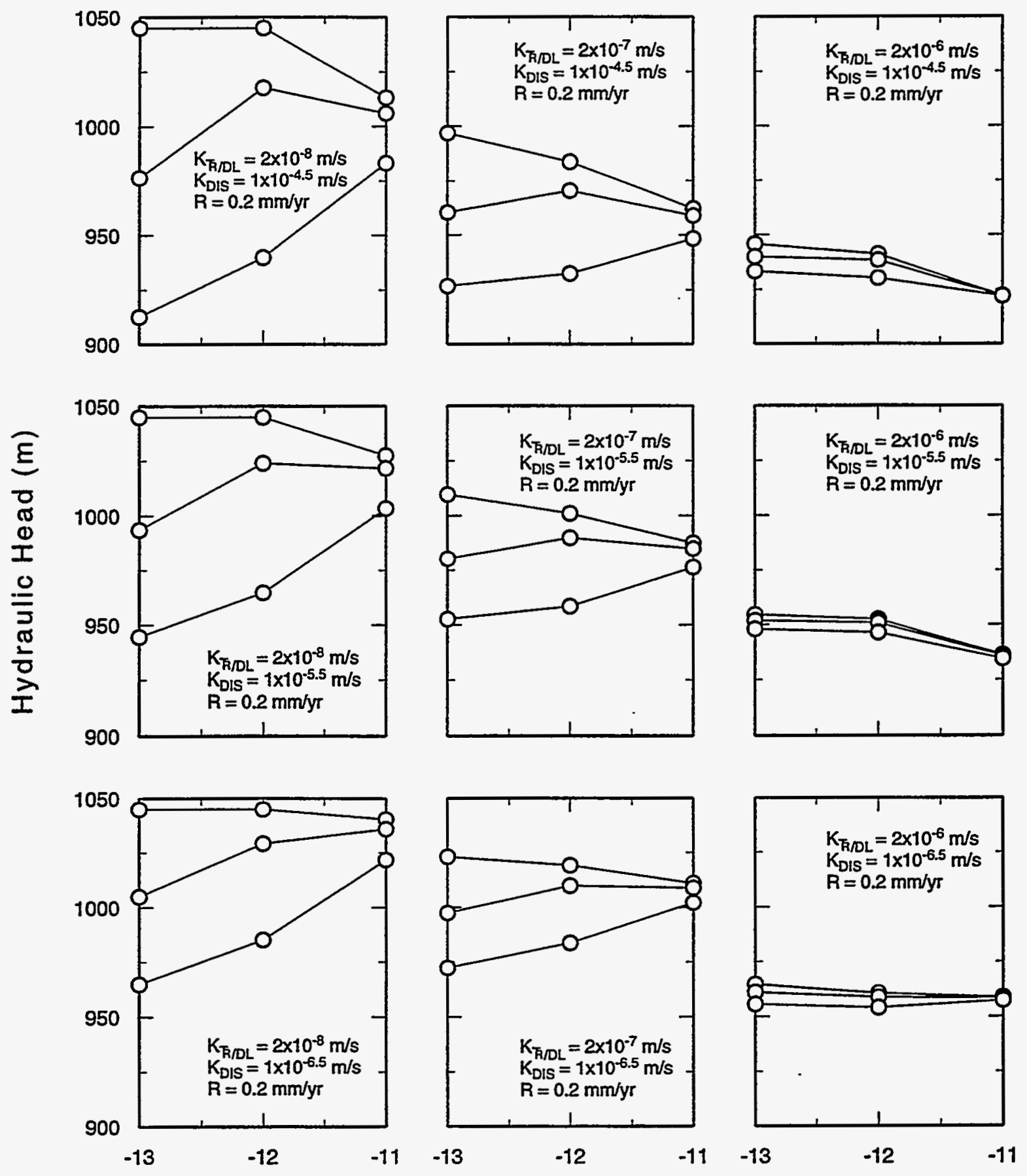

Hydraulic Conductivity of Anhydrite ( $\log \mathrm{m} / \mathrm{s}$ )

TRI-6115-432-0

Figure 3-1. Simulated steady-state elevation of the water table (upper point), Magenta head, and Culebra head (lower point) near the center of the WIPP site versus the conductivity of intact anhydrite. Graphs in each row have the same value of disturbed zone conductivity and graphs in each column have the same value of conductivity of the Dewey Lake/Triassic rocks. Potential recharge is equal to $0.2 \mathrm{~mm} / \mathrm{yr}$. 

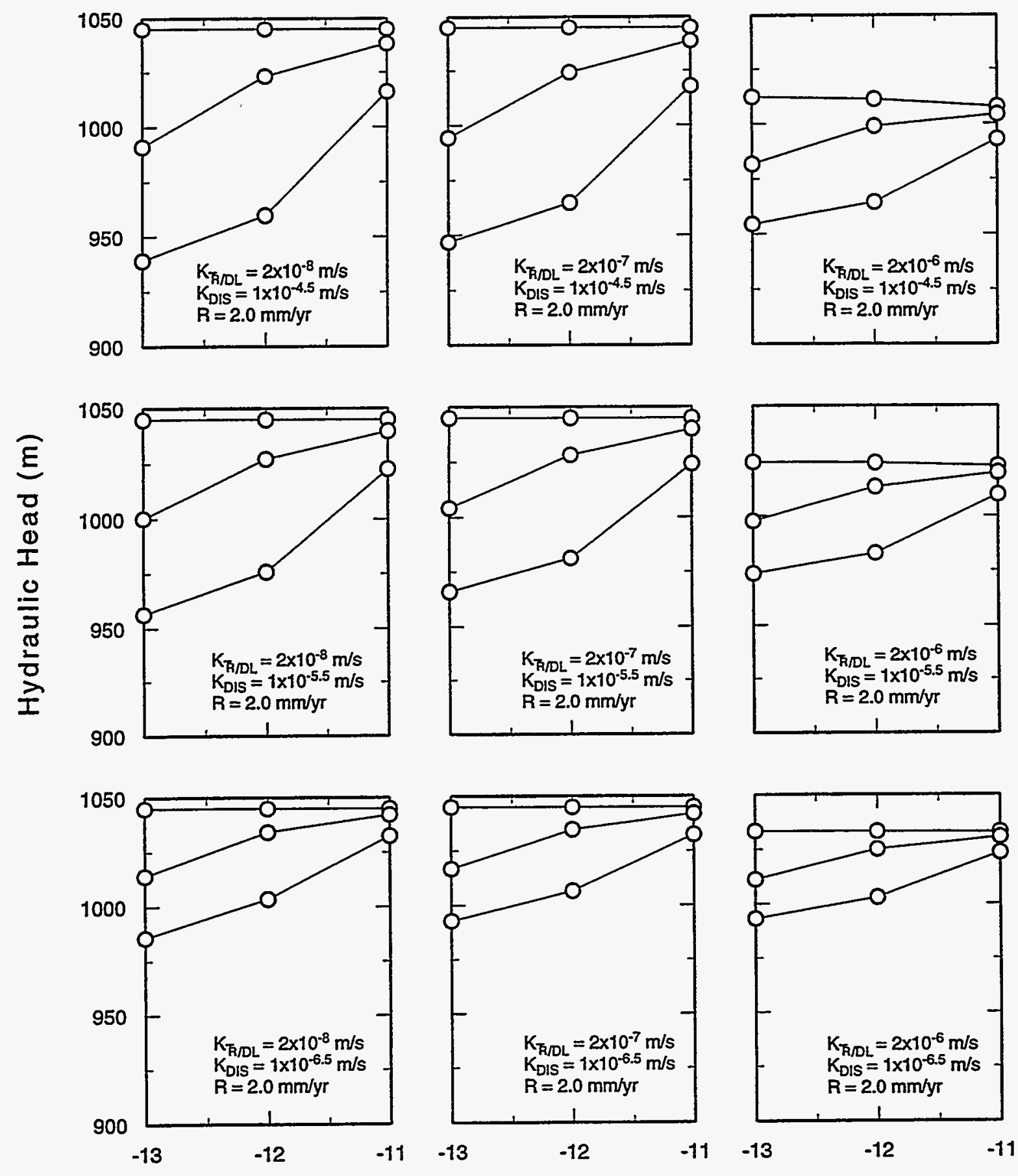

\section{Hydraulic Conductivity of Anhydrite ( $\log \mathrm{m} / \mathrm{s}$ )}

TRI-6115-433-0

Figure 3-2. Simulated steady-state elevation of the water table (upper point), Magenta head, and Culebra head (lower point) near the center of the WIPP site versus the conductivity of intact anhydrite. Potential recharge is equal to $2.0 \mathrm{~mm} / \mathrm{yr}$. 


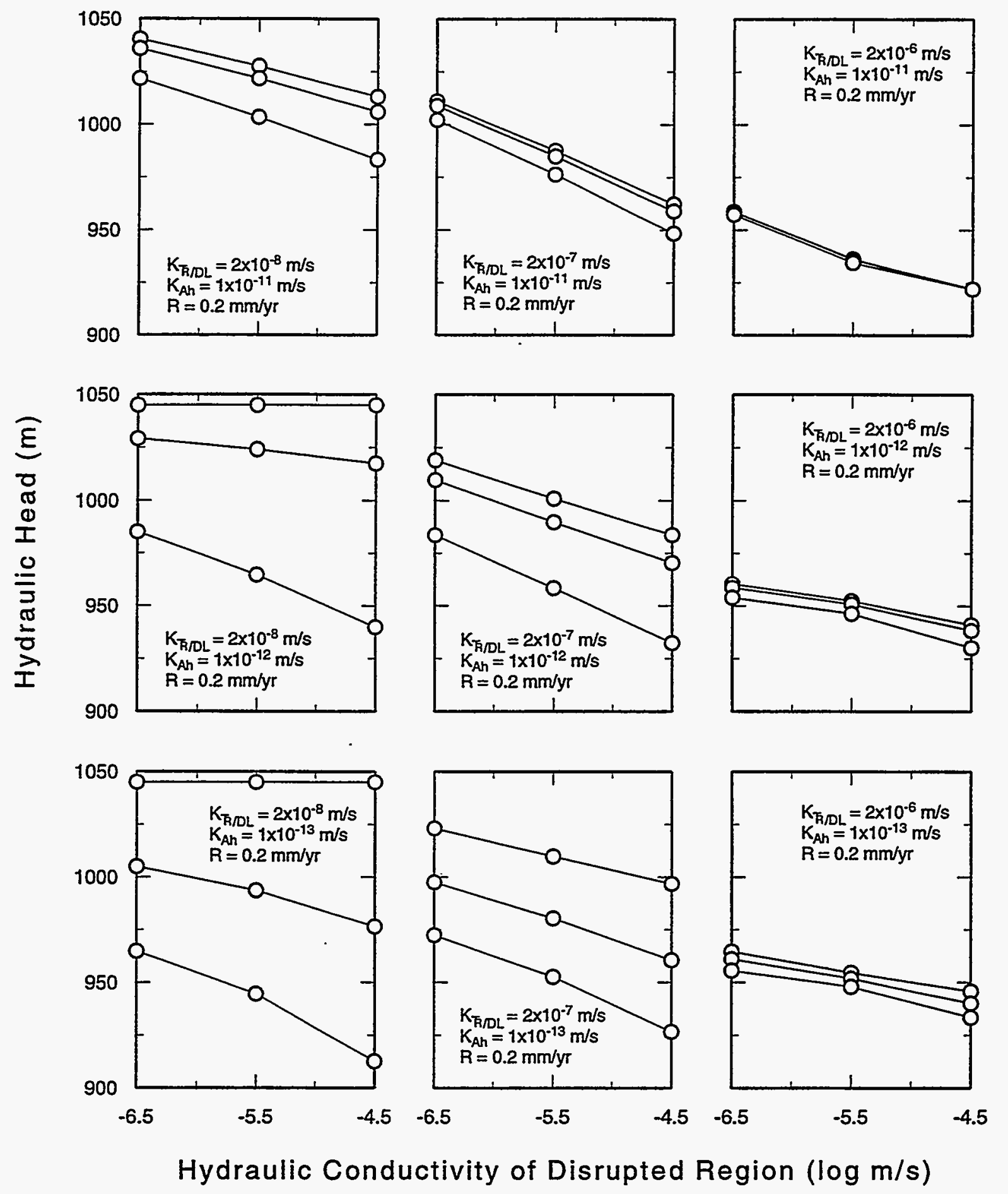

TRI-6115-434-0

Figure 3-3. Simulated steady-state elevation of the water table (upper point), Magenta head, and Culebra head (lower point) near the center of the WIPP site versus the conductivity of the disrupted region. Graphs in each row have the same value of anhydrite conductivity and graphs in each column have the same value of conductivity of the Dewey Lake/Triassic rocks. Potential recharge is equal to $0.2 \mathrm{~mm} / \mathrm{yr}$. 

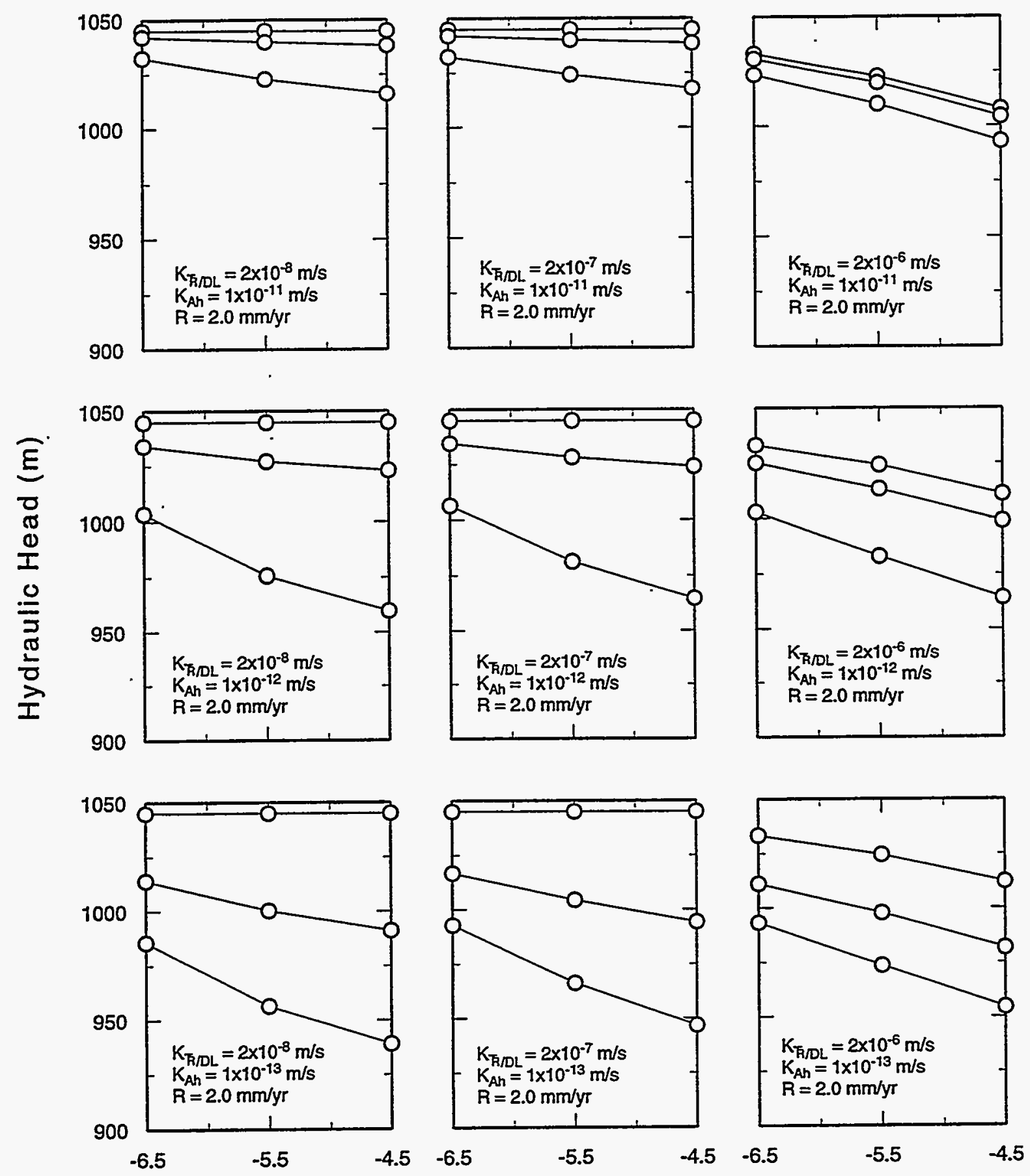

Hydraulic Conductivity of Disrupted Region ( $\log \mathrm{m} / \mathrm{s}$ )

TRI-6115-435-0

Figure 3-4. Simulated steady-state elevation of the water table (upper point), Magenta head, and Culebra head (lower point) near the center of the WIPP site versus the conductivity of the disrupted region. Potential recharge is equal to $2.0 \mathrm{~mm} / \mathrm{yr}$. 

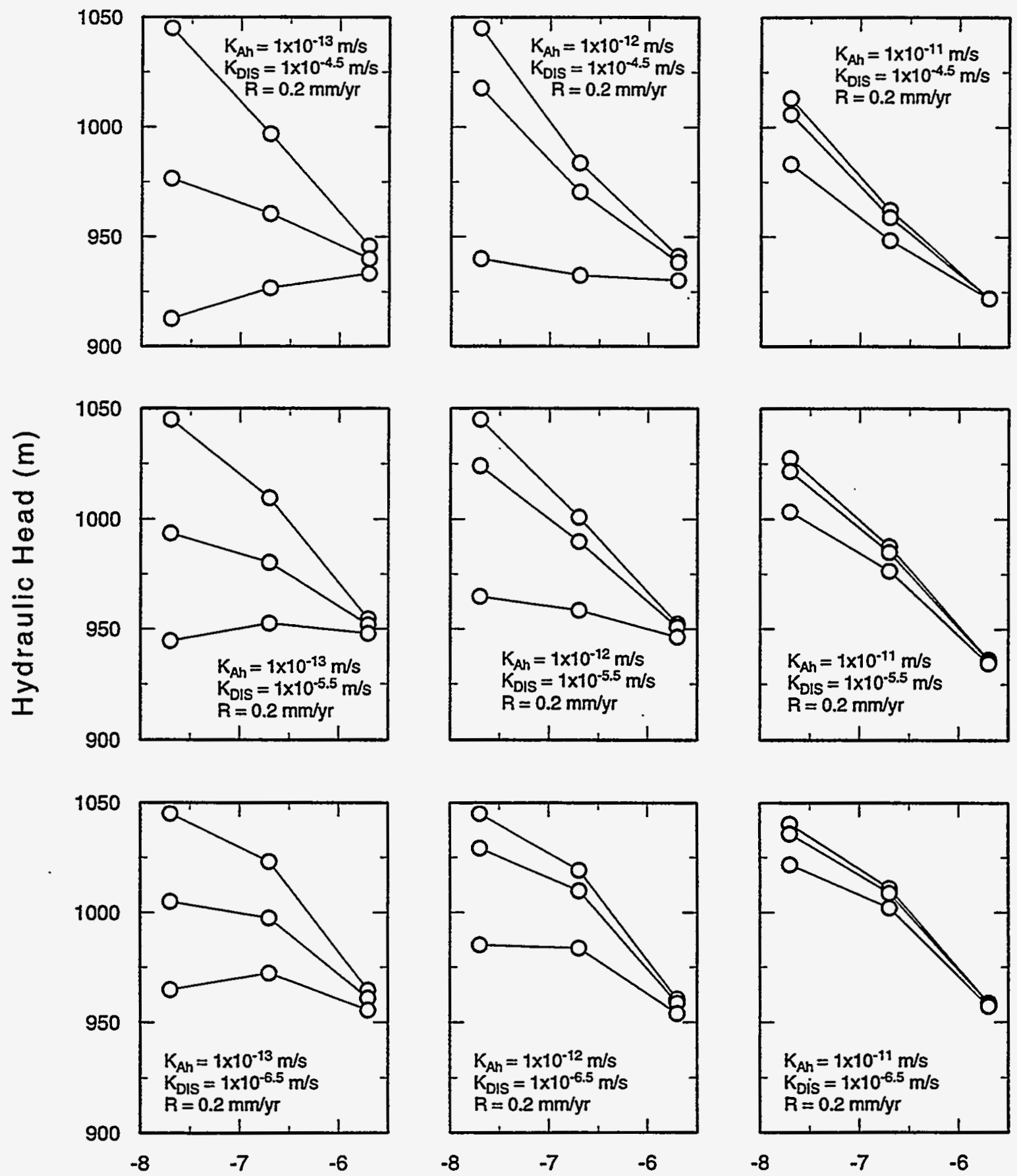

Hydraulic Conductivity of Triassic Rocks/Dewey Lake $(\log \mathrm{m} / \mathrm{s})$

TRI-6115-436-0

Figure 3-5. Simulated steady-state elevation of the water table (upper point), Magenta head, and Culebra head (lower point) near the center of the WIPP site versus the conductivity of the Dewey Lake/Triassic rocks. Graphs in each row have the same value of conductivity of the disrupted region and graphs in each column have the same value of anhydrite conductivity. Potential recharge is equal to $0.2 \mathrm{~mm} / \mathrm{yr}$. 

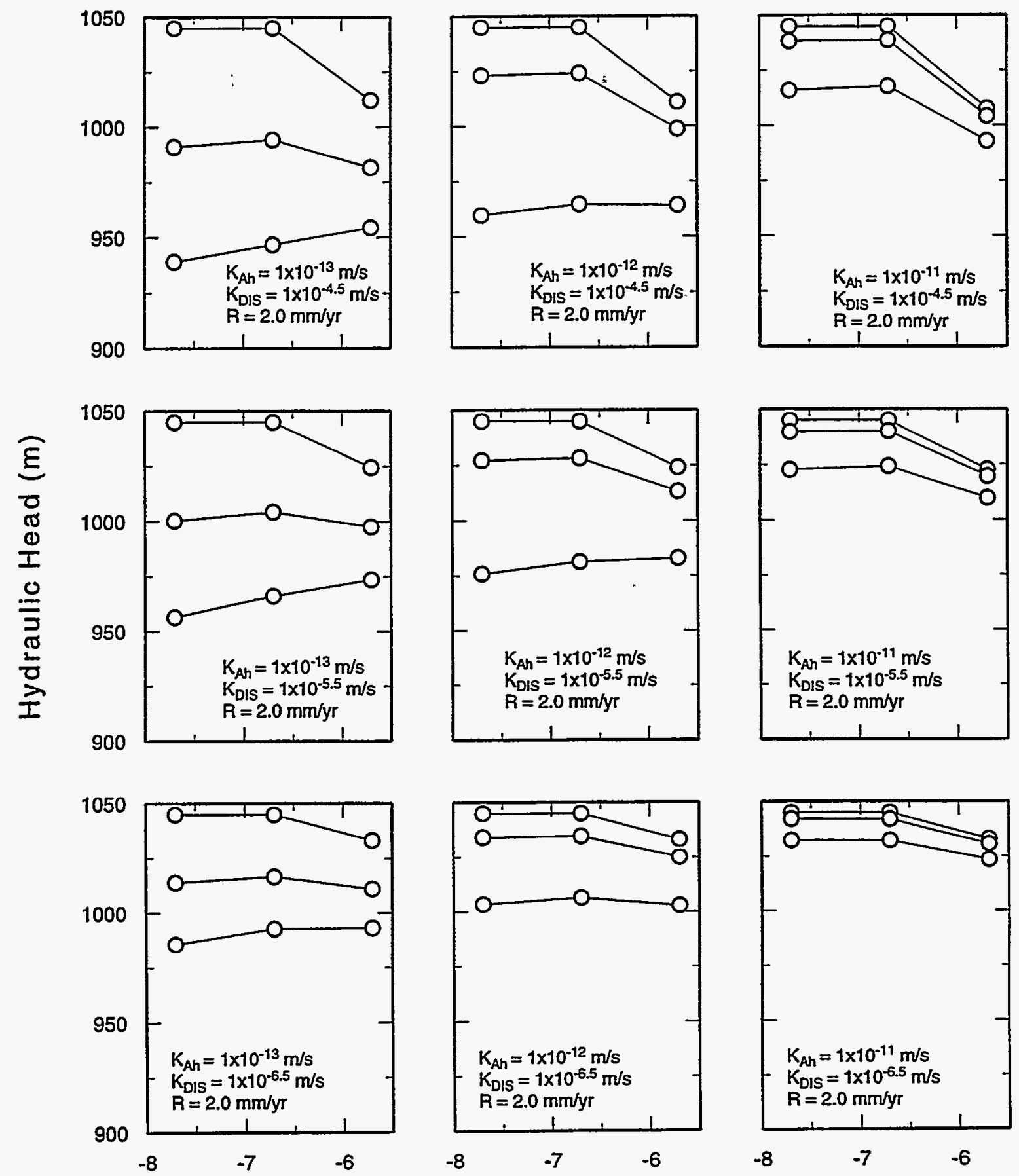

Hydraulic Conductivity of Triassic Rocks/Dewey Lake ( $\log \mathrm{m} / \mathrm{s}$ )

TRI-6115-437-0

Figure 3-6. Simulated steady-state elevation of the water table (upper point), Magenta head, and Culebra head (lower point) near the center of the WIPP site versus the conductivity of the Dewey Lake/Triassic rocks. Potential recharge is equal to $2.0 \mathrm{~mm} / \mathrm{yr}$. 

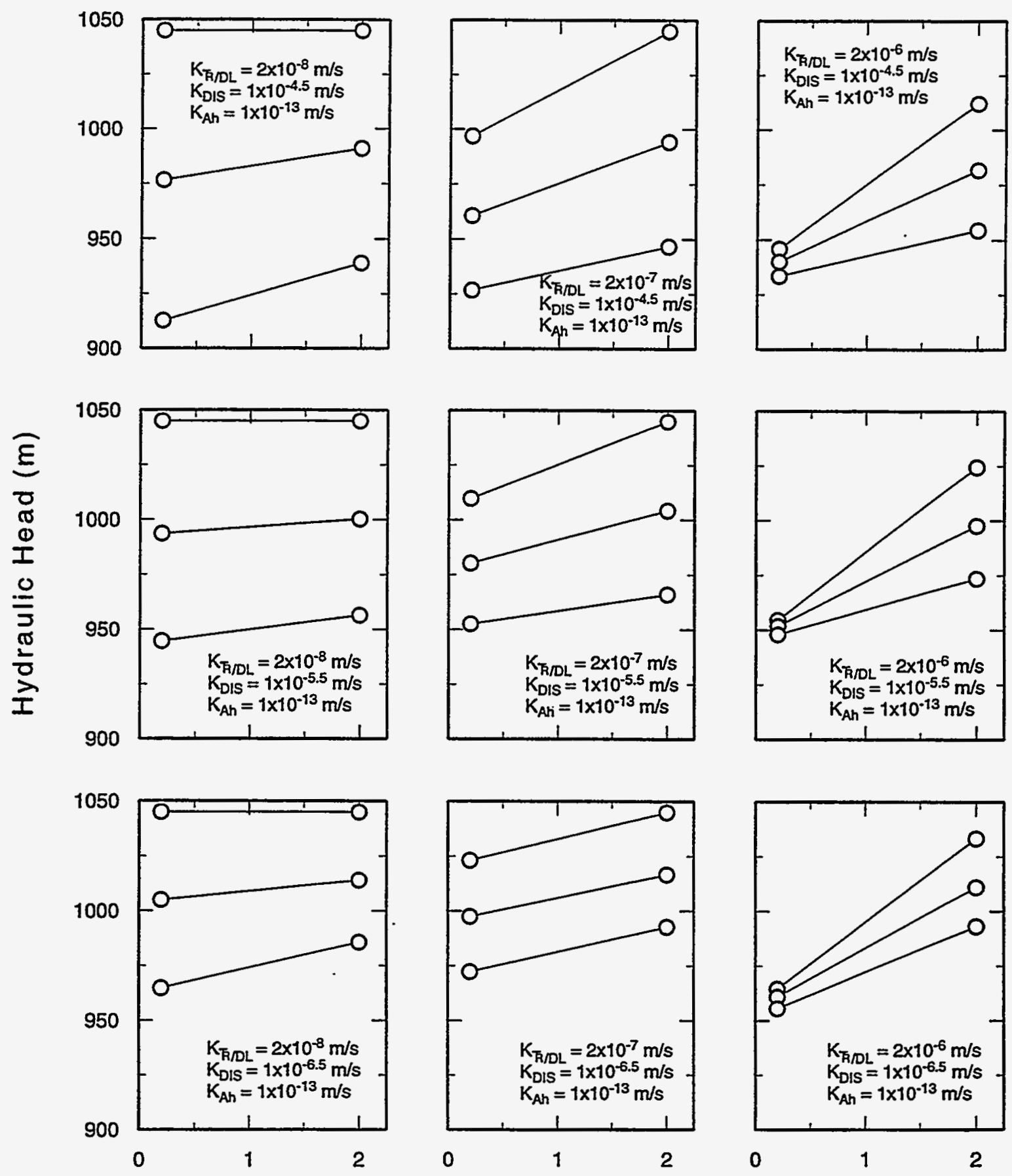

Recharge $(\log \mathrm{mm} / \mathrm{yr})$

TRI-6115-438-0

Figure 3-7. Simulated steady-state elevation of the water table (upper point), Magenta head, and Culebra head (lower point) near the center of the WIPP site versus the rate of potential recharge. Graphs in each row have the same value of conductivity of the disrupted region and graphs in each column have the same value of conductivity of the Dewey Lake/Triassic rocks. The conductivity of intact anhydrite is $1 \times 10^{-13} \mathrm{~m} / \mathrm{s}$. 


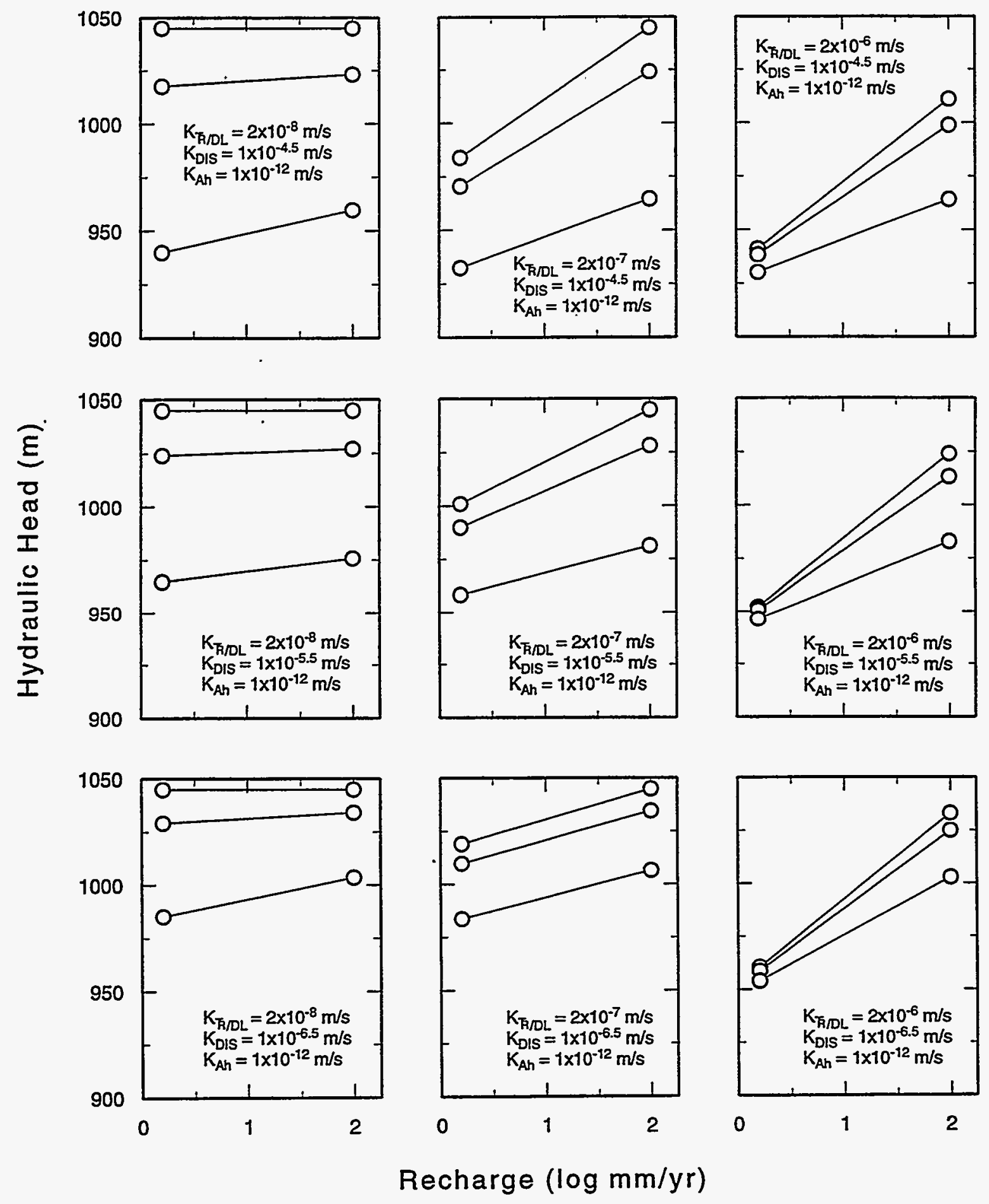

TR1-6115-439-0

Figure 3-8. Simulated steady-state elevation of the water table (upper point), Magenta head, and Culebra head (lower point) near the center of the WIPP site versus the rate of potential recharge. The conductivity of intact anhydrite is $1 \times 10^{-12} \mathrm{~m} / \mathrm{s}$. 

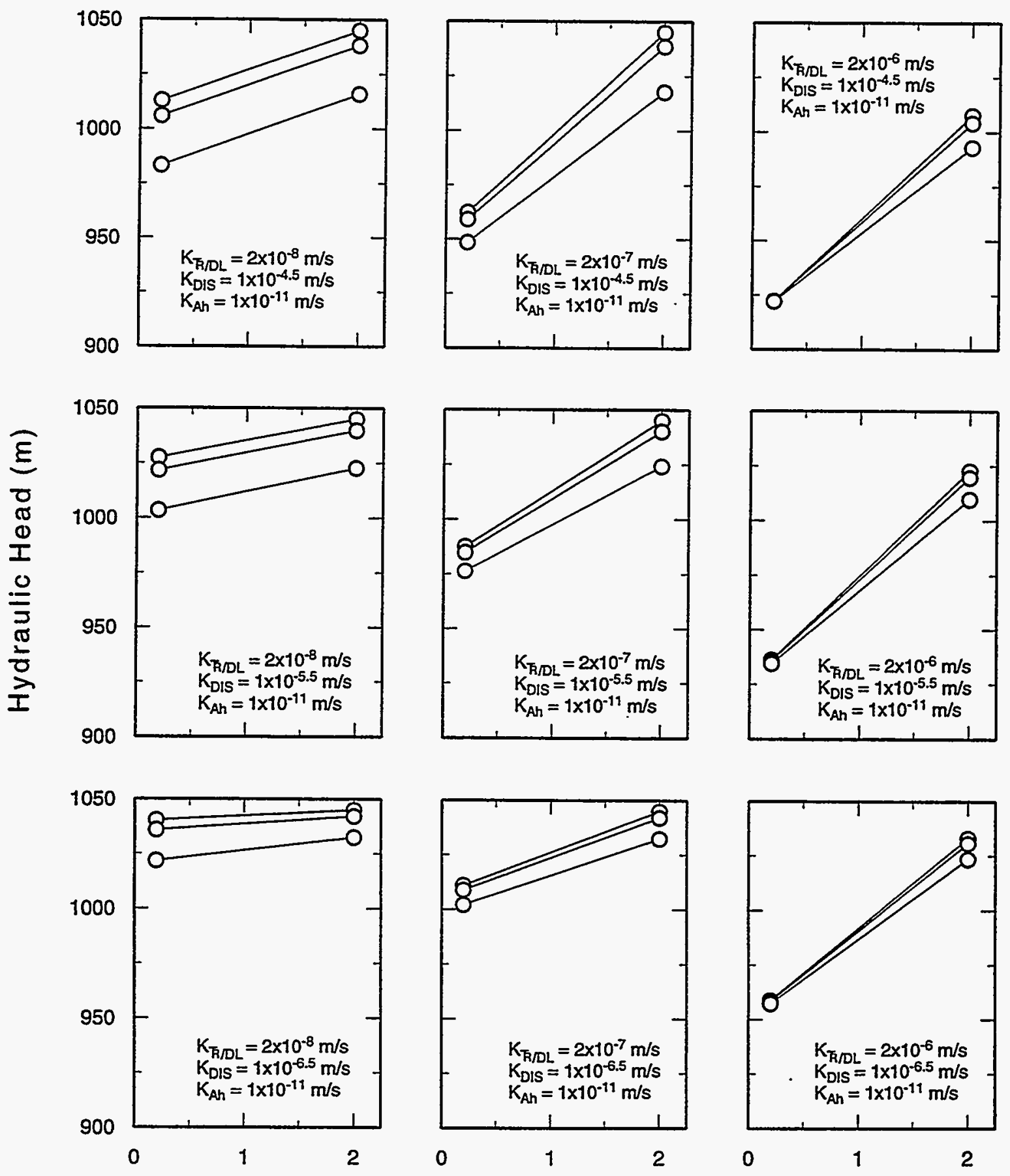

Recharge $(\log \mathrm{mm} / \mathrm{yr})$

$\operatorname{TRI}-6115-440-0$

Figure 3-9. Simulated steady-state elevation of the water table (upper point), Magenta head, and Culebra head (lower point) near the center of the WIPP site versus the rate of potential recharge. The conductivity of intact anhydrite is $1 \times 10^{-11} \mathrm{~m} / \mathrm{s}$. 
groundwater flow system. A low base level exists if the conductivity of the disrupted zone is large. These figures also show that vertical gradients of head increase very slightly as the conductivity of the disrupted region increases.

Figures 3-5 and 3-6 show that larger values of Dewey Lake/Triassic conductivity result in a lower water table and smaller head differences between conductive units. These head differences are as sensitive to the conductivity of the Dewey Lake/Triassic rocks as they are to the conductivity of the confining units that separate the conductive units. Heads in the Culebra can either increase or decrease with increasing Dewey Lake/Triassic conductivity.

The change in head with the rate of potential recharge is shown in Figures 3-7, 3-8, and 3-9. For all parameter combinations, hydraulic heads are greater at larger recharge rates. This is also true for the elevation of the water table unless the water table is at the surface for both recharge rates. The amount that head increases as the rate of potential recharge is changed from 0.2 to $2.0 \mathrm{~mm} / \mathrm{yr}$ scales with the conductivity of the Dewey Lake/Triassic rocks. Larger increases in head occur at larger values of conductivity. The head in the Culebra, for example, is increased by as much as $20 \mathrm{~m}$ if the conductivity of the Dewey Lake/Triassic rocks is $2 \times 10^{-8} \mathrm{~m} / \mathrm{s}$ and up to $70 \mathrm{~m}$ if the conductivity is $2 \times 10^{-6} \mathrm{~m} / \mathrm{s}$.

\subsubsection{Sensitivity of Lateral Flow Rates in the Culebra to Model Parameters}

The variation of lateral flow rates in the Culebra with assumed values of hydraulic conductivity and recharge rate is shown in Figures 3-10 through 3-18. Similar graphs for flow directions are contained in Figures 3-19 through 3-27. Each column of data in the individual graphs shows lateral flow magnitude or direction at nine locations within the WIPP-site boundary for a single simulation. Lines connect data at the same location. The range of the nine points in each column of each graph represents the spatial variation of lateral flow for that simulation.

In analyzing the lateral flow results, we consider two indicators, trend and sensitivity. An example of a trend is that flow magnitude shows either a consistent increase or decrease with change in a model parameter. Sensitivity is a measure of the amount of change in lateral flow. Flow is defined here to be sensitive to a parameter if the variation in flow magnitude or direction with the value of that parameter is large compared to the spatial variation of flow magnitude or direction for a fixed value of that parameter. 
0.2

0.1

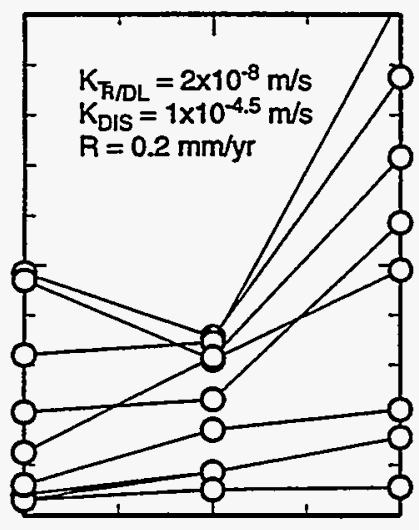

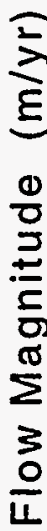

0.0

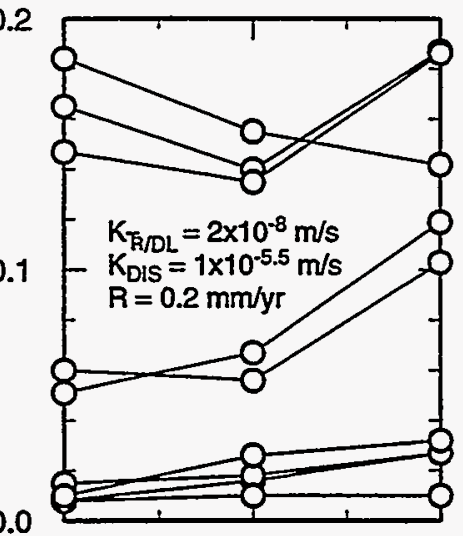

0.2
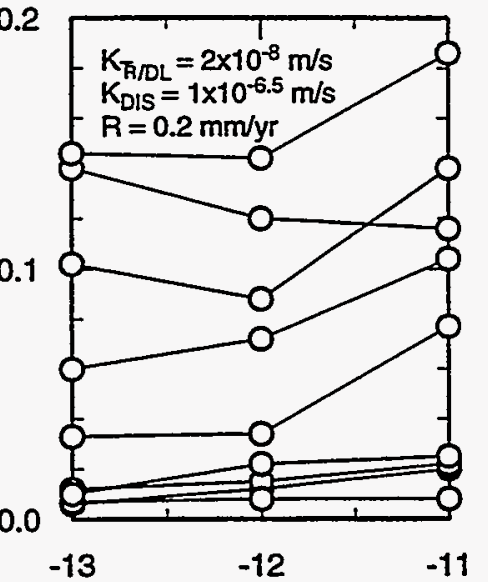
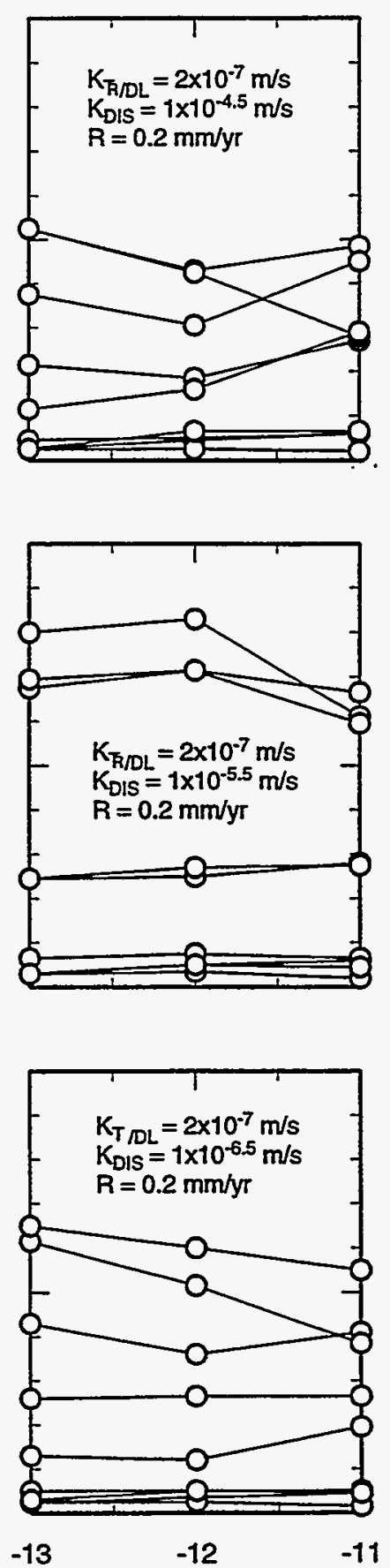
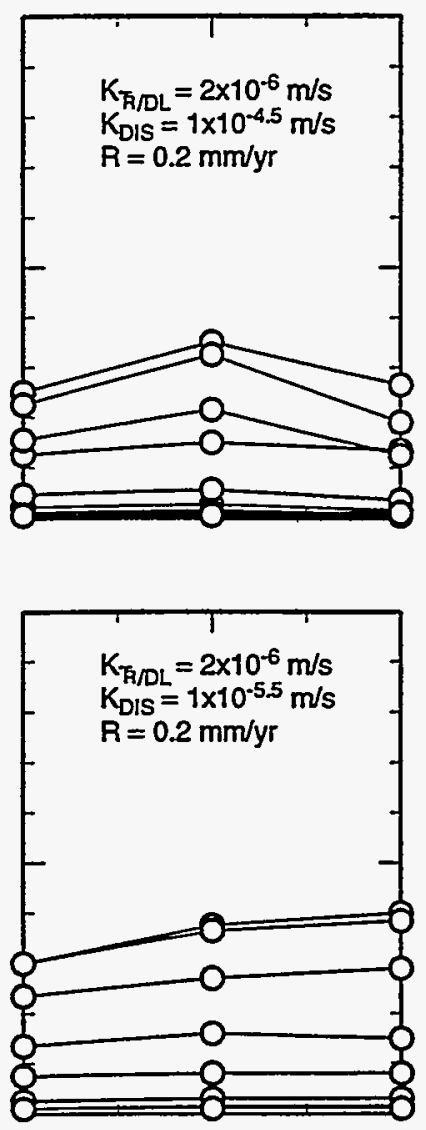

$K_{\text {TR/DL }}=2 \times 10^{-6} \mathrm{~m} / \mathrm{s}$

$K_{\mathrm{DIS}}=1 \times 10^{-5.5} \mathrm{~m} / \mathrm{s}$

$R=0.2 \mathrm{~mm} / \mathrm{yr}$

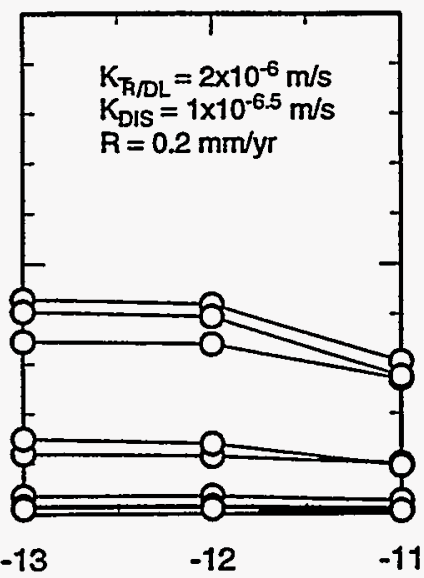

Hydraulic Conductivity of Anhydrite $(\log \mathrm{m} / \mathrm{s})$

TRI-6115-441-0

Figure 3-10. Simulated lateral specific discharge $(\mathrm{m} / \mathrm{yr})$ in the Culebra at nine locations within the WIPP site versus the conductivity of intact anhydrite. Potential recharge is equal to 0.2 $\mathrm{mm} / \mathrm{yr}$. 


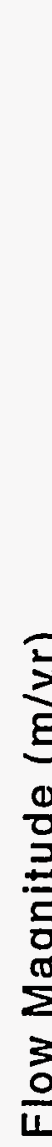

0.2

0.1

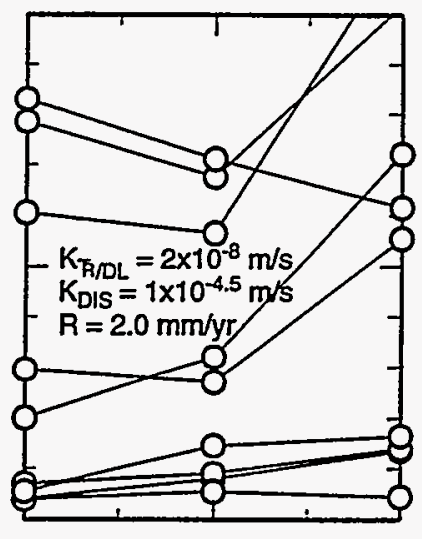

0.0

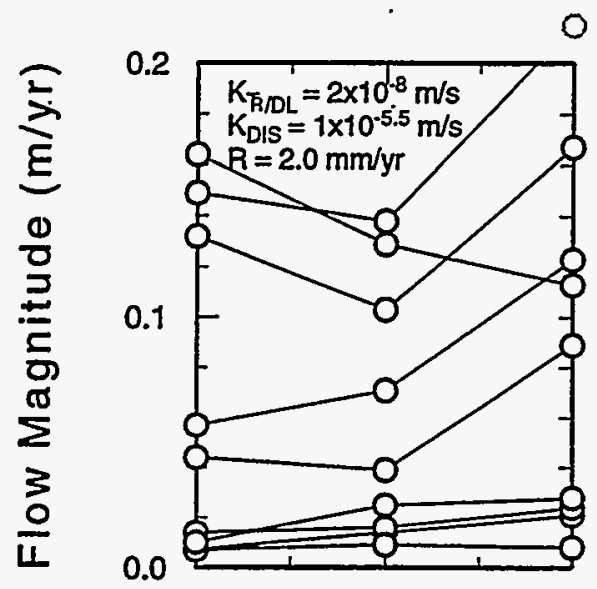

0.2

0.1

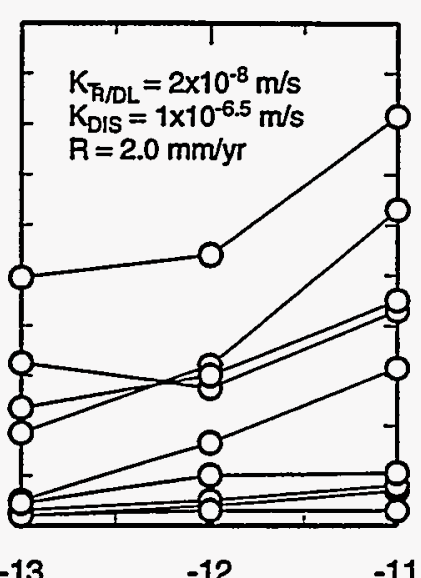

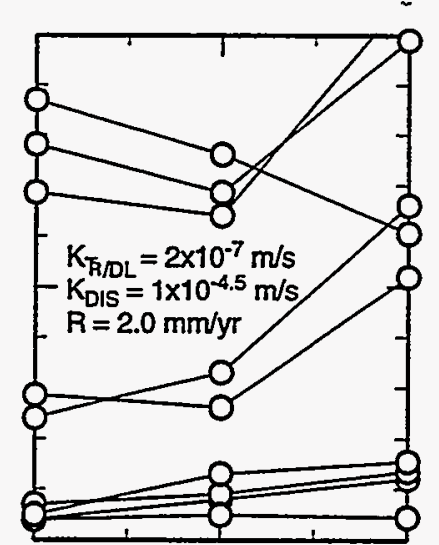
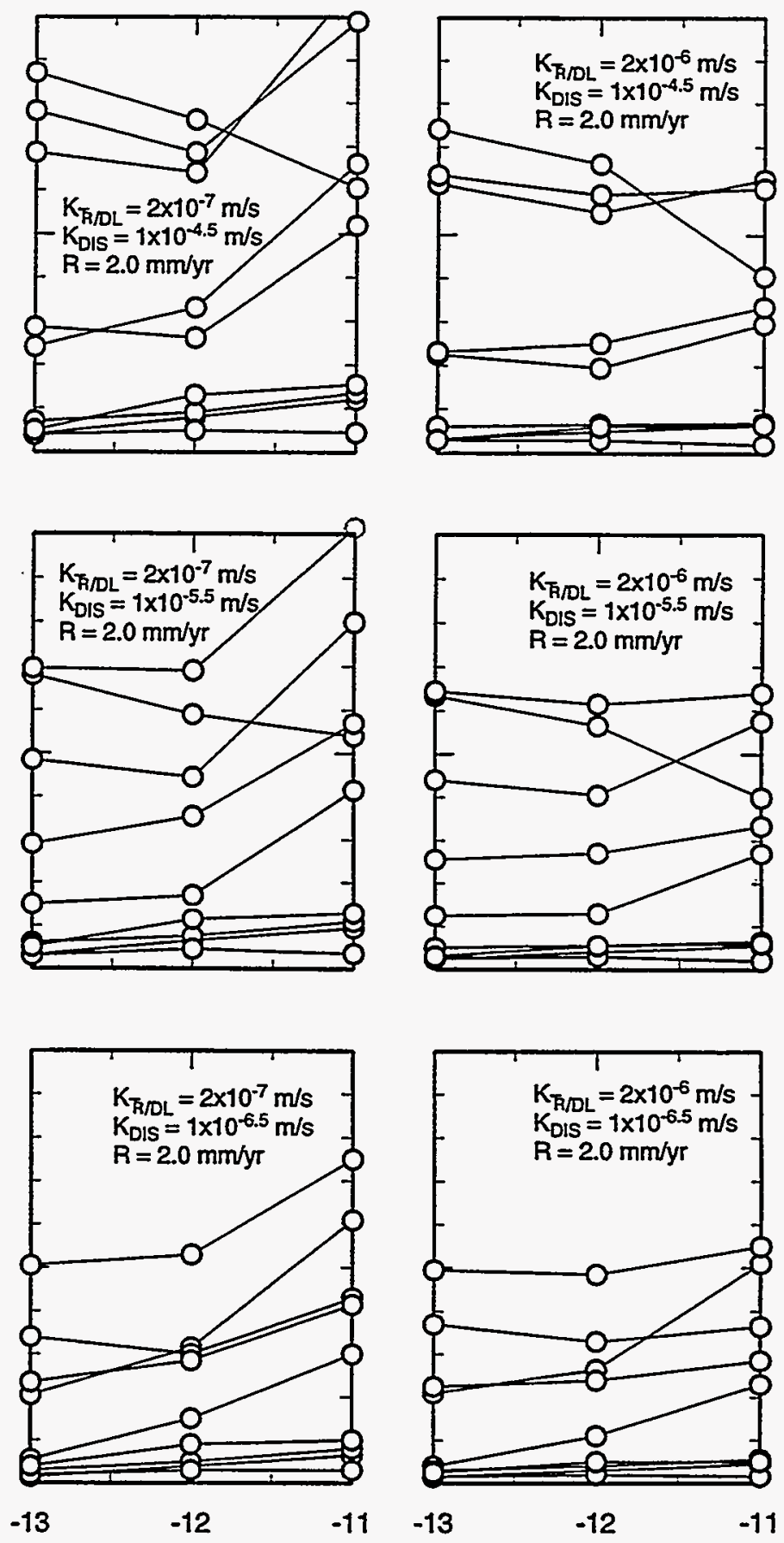

Hydraulic Conductivity of Anhydrite ( $\log \mathrm{m} / \mathrm{s})$

TRI-6115-442-0

Figure 3-11. Simulated lateral specific discharge $(\mathrm{m} / \mathrm{yr})$ in the Culebra at nine locations within the WIPP site versus the conductivity of intact anhydrite. Potential recharge is equal to 2.0 $\mathrm{mm} / \mathrm{yr}$. 
0.2

0.1
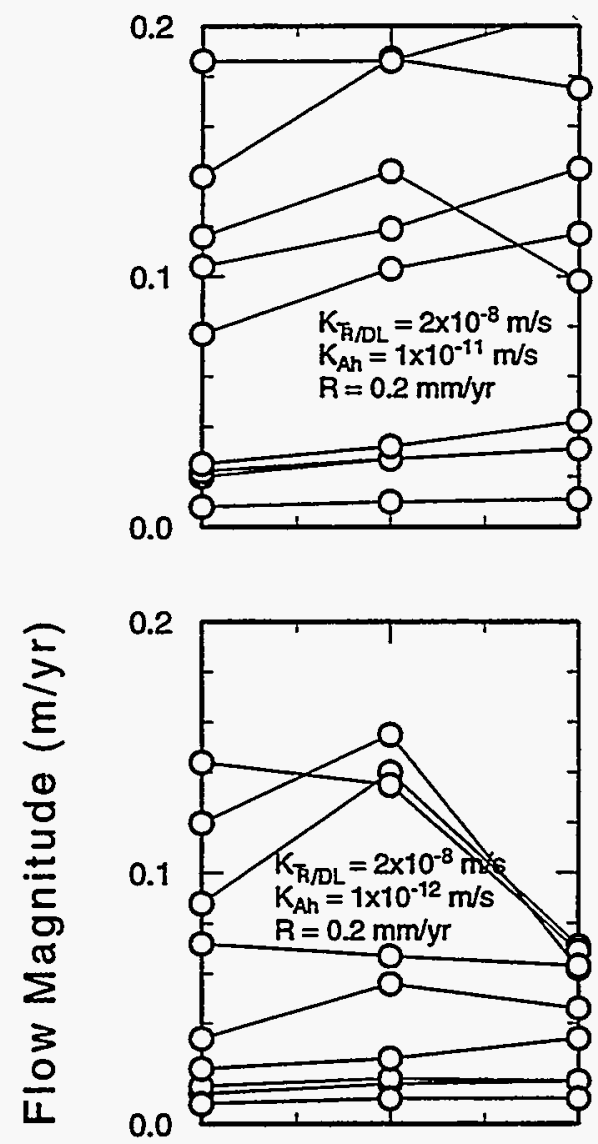

0.2

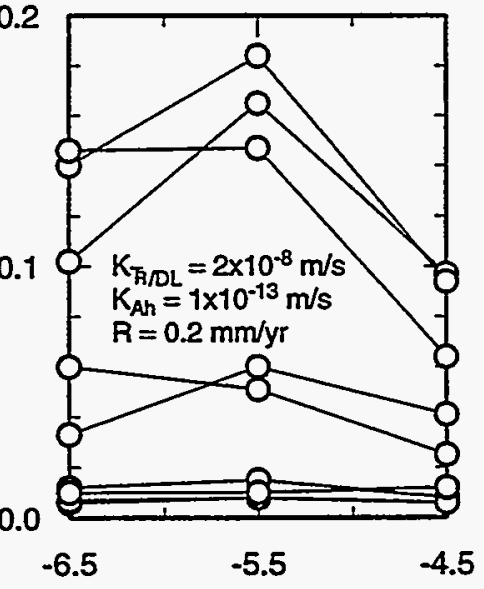

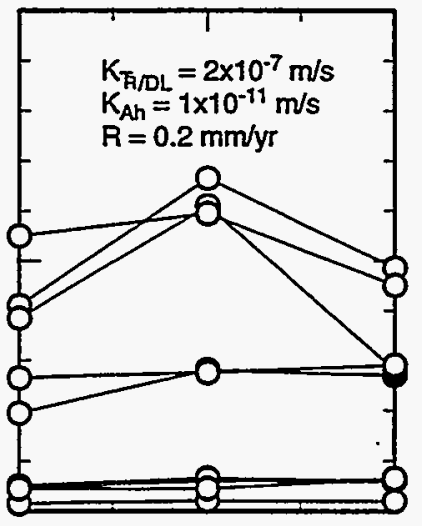
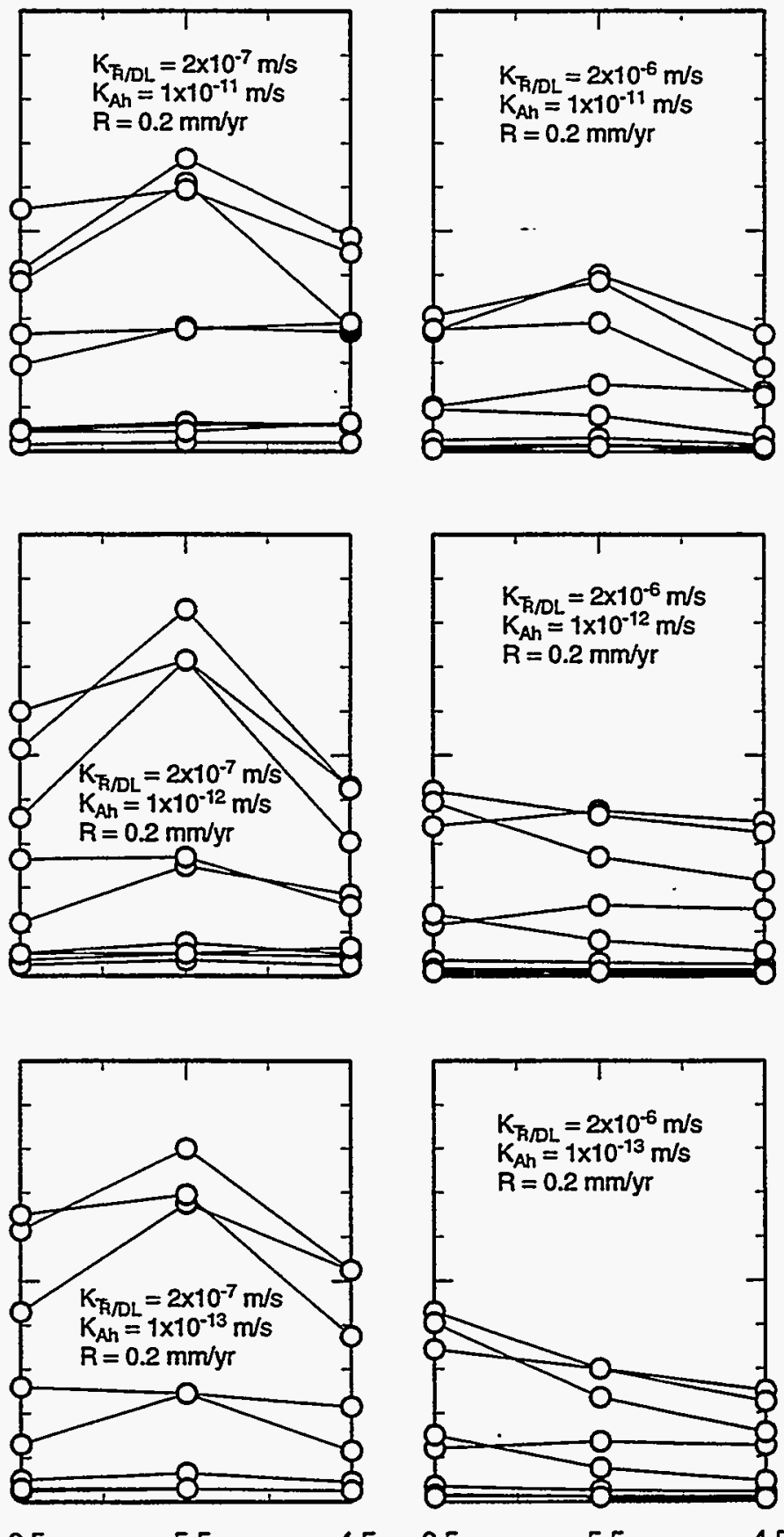

$-6.5$

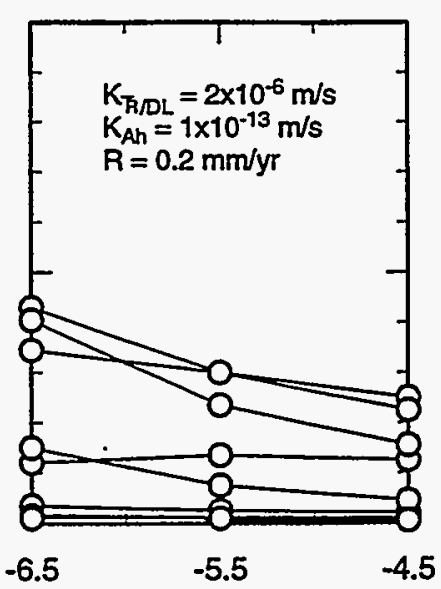

Hydraulic Conductivity of Disrupted Region ( $\log \mathrm{m} / \mathrm{s}$ )

TRI-6115-443-0

Figure 3-12. Simulated lateral specific discharge $(\mathrm{m} / \mathrm{yr})$ in the Culebra at nine locations within the WIPP site versus the conductivity of the disrupted region. Potential recharge is equal to $0.2 \mathrm{~mm} / \mathrm{yr}$. 

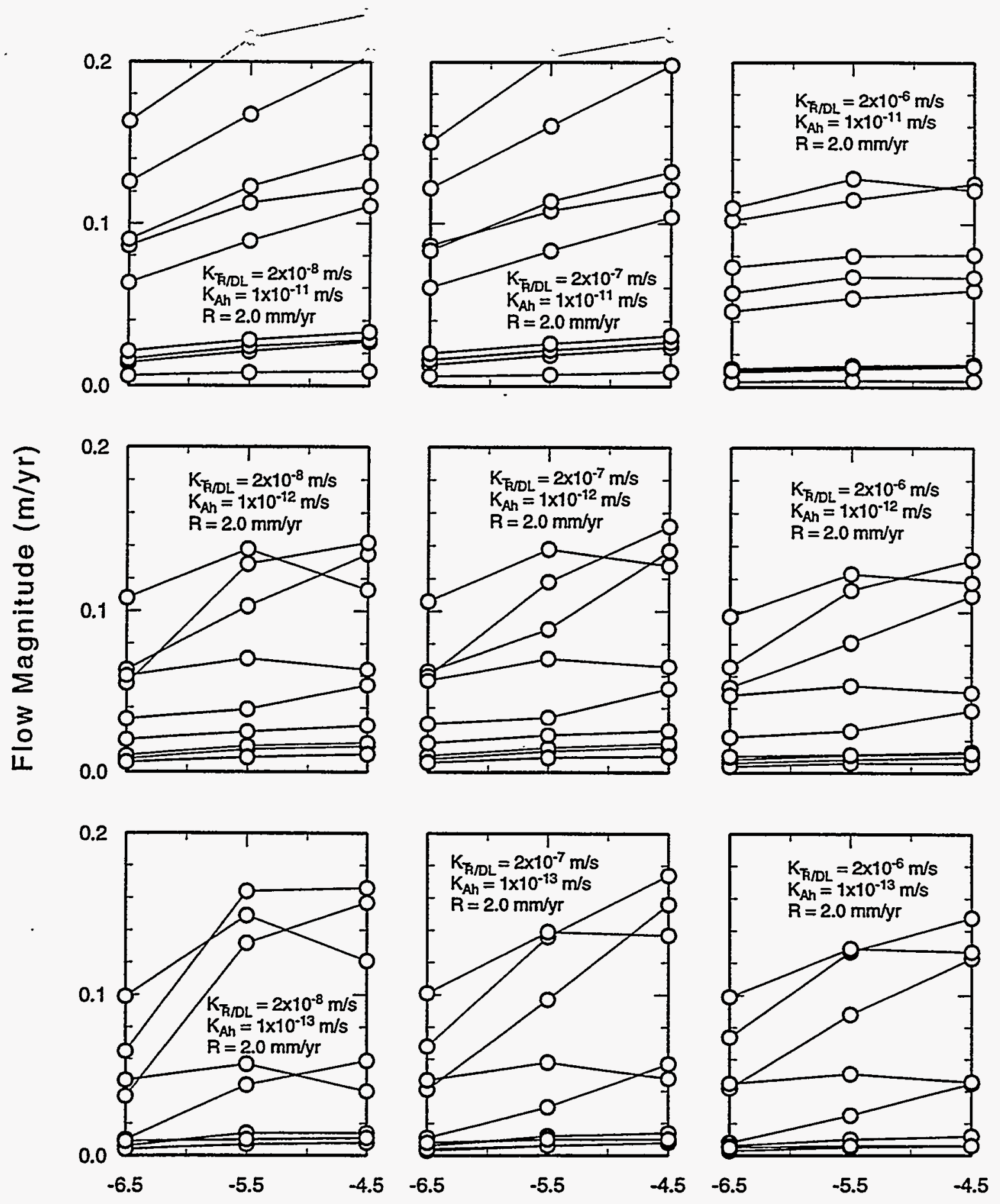

Hydraulic Conductivity of Disrupted Region ( $\log \mathrm{m} / \mathrm{s}$ )

TRI-6115-444-0

Figure 3-13. Simulated lateral specific discharge (m/yr) in the Culebra at nine locations within the WIPP site versus the conductivity of disrupted region. Potential recharge is equal to 2.0 $\mathrm{mm} / \mathrm{yr}$. 

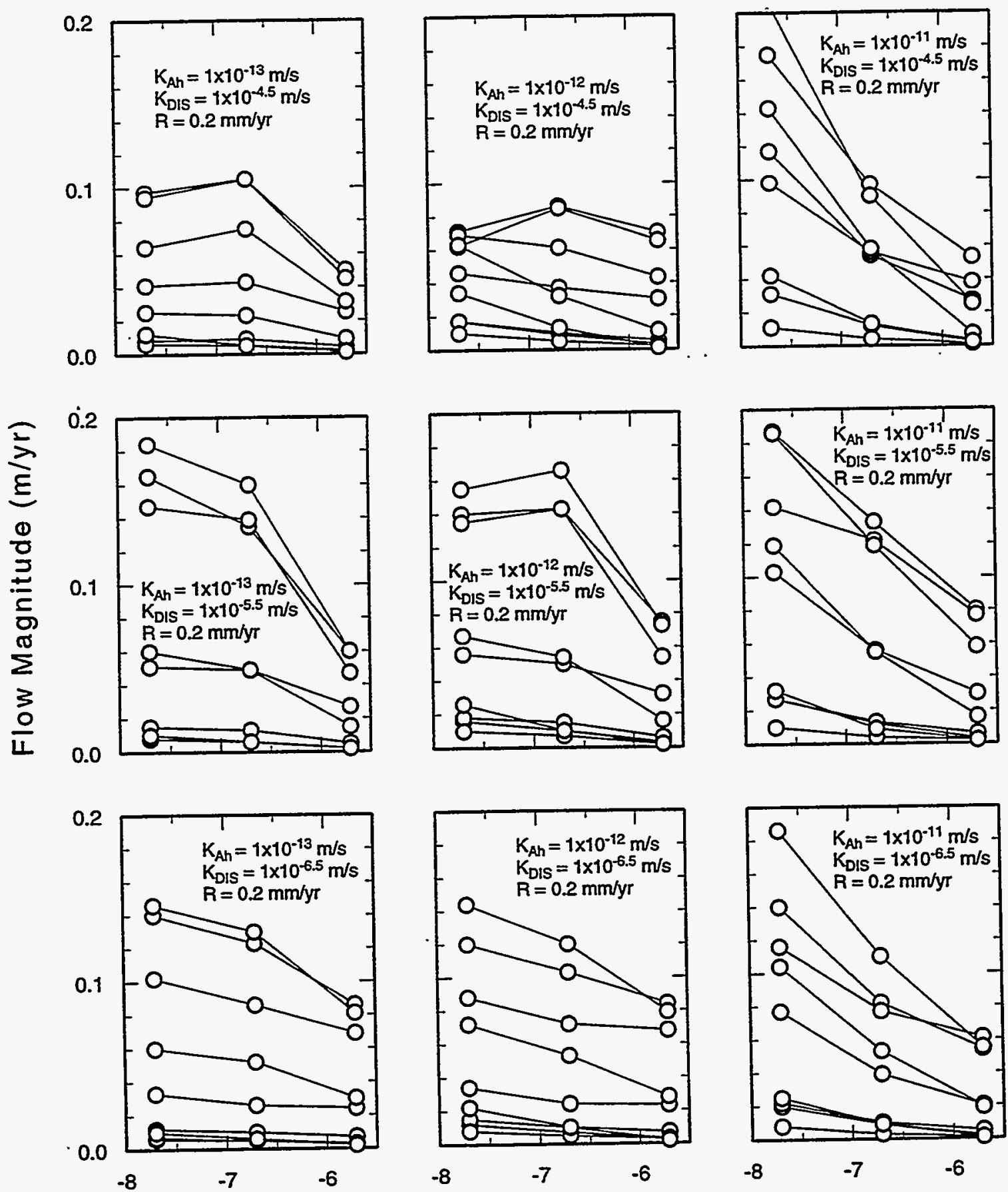

Hydraulic Conductivity of Triassic Rock/Dewey Lake ( $\log \mathrm{m} / \mathrm{s}$ )

TRI-6115-445-0

Figure 3-14. Simulated lateral specific discharge $(\mathrm{m} / \mathrm{yr})$ in the Culebra at nine locations within the WIPP site versus the conductivity of the Dewey Lake/Triassic rocks. Potential recharge is equal to $0.2 \mathrm{~mm} / \mathrm{yr}$. 
0.2

0.1

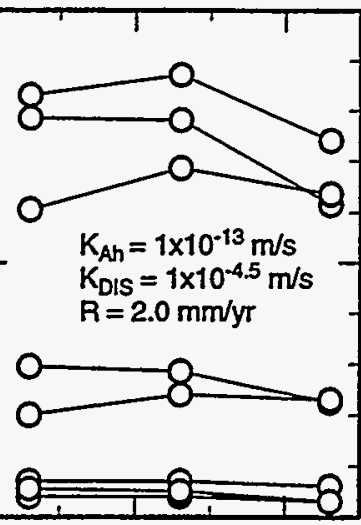

0.0

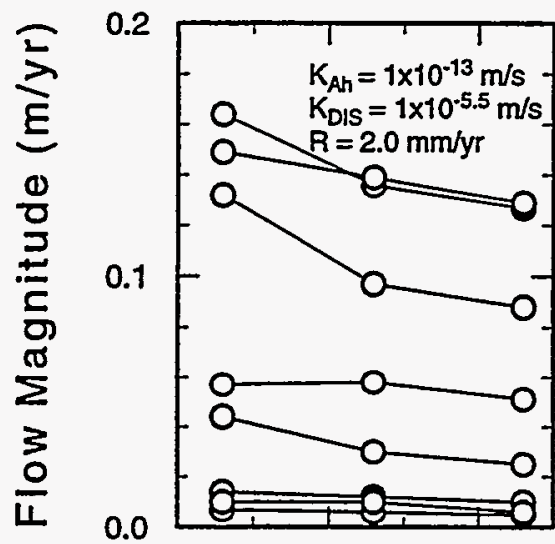

0.2

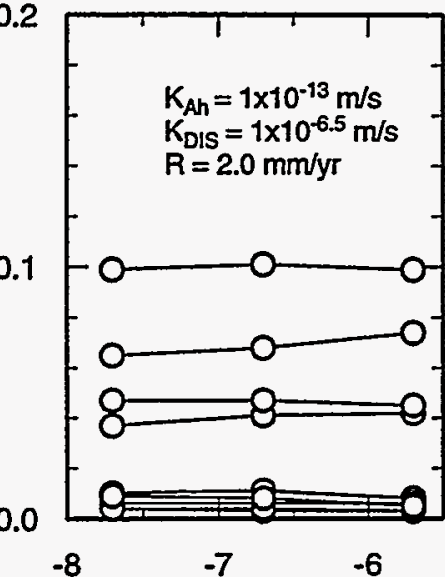

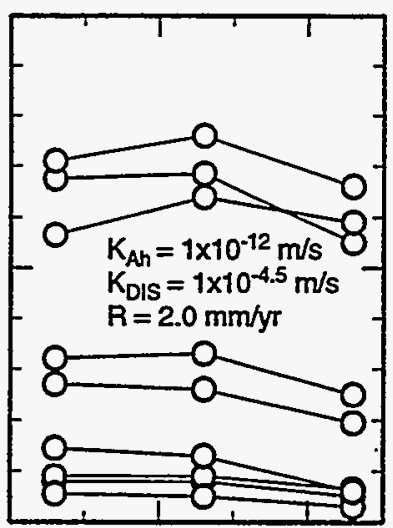
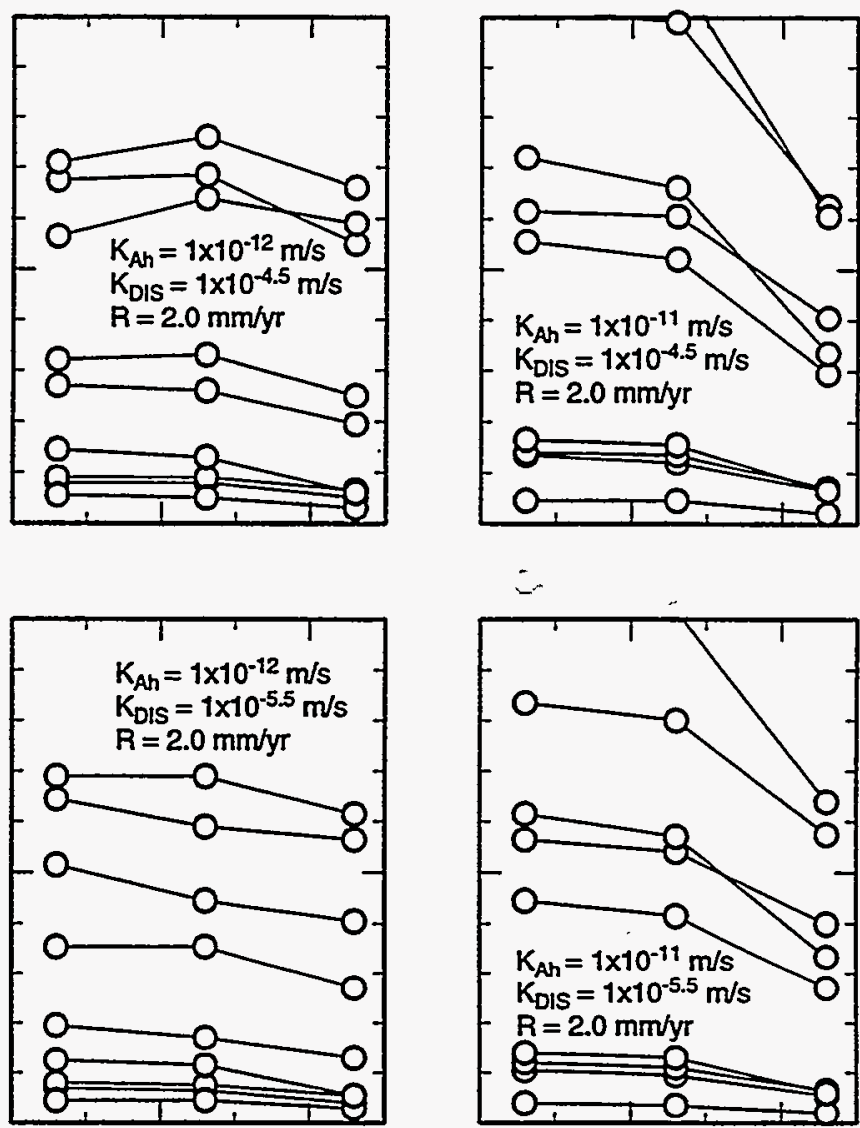

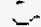
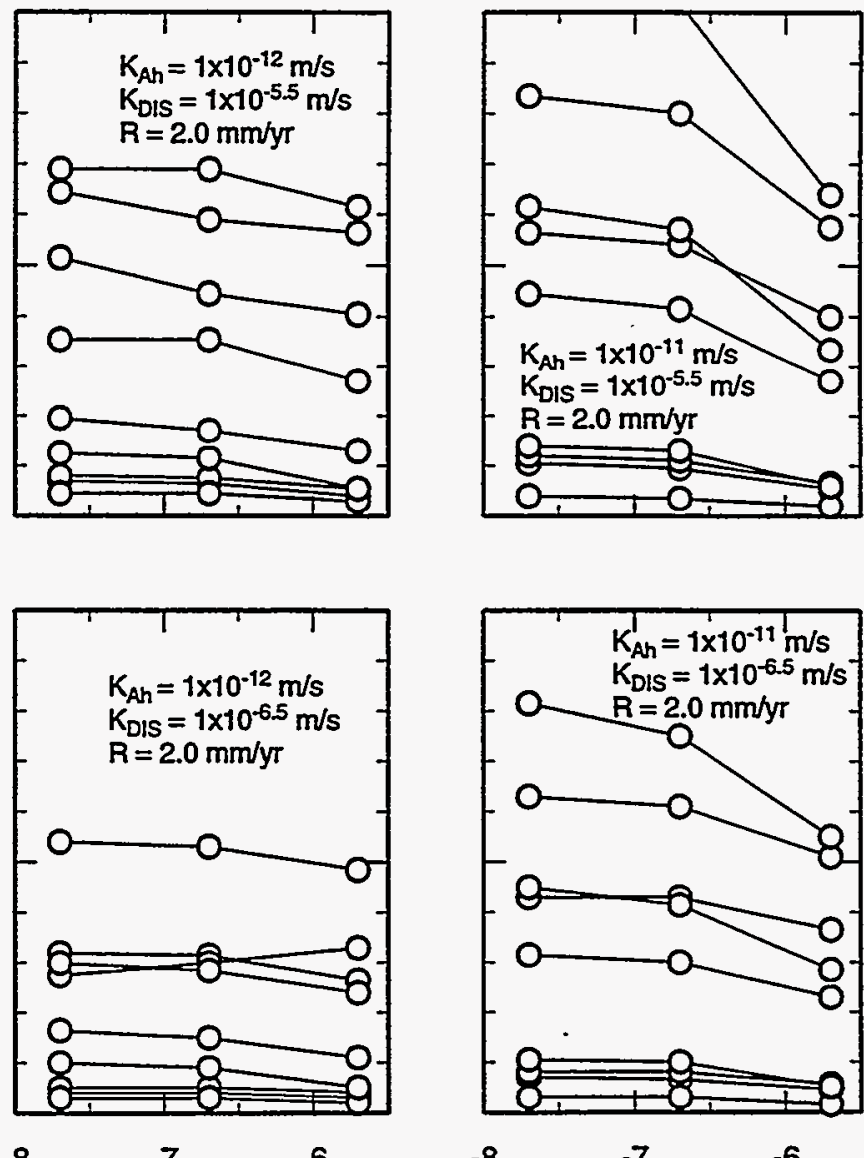

$-6$

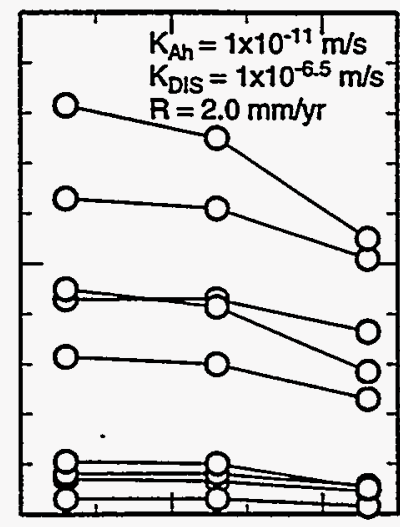

$-7 \quad-6$

Hydraulic Conductivity of Triassic Rock/Dewey Lake ( $\mathrm{log} \mathrm{m} / \mathrm{s}$ )

TRI-6115-446-0

Figure 3-15. Simulated lateral specific discharge $(\mathrm{m} / \mathrm{yr})$ in the Culebra at nine locations within the WIPP site versus the conductivity of the Dewey Lake/Triassic rocks. Potential recharge is equal to $2.0 \mathrm{~mm} / \mathrm{yr}$. 
0.2

0.1
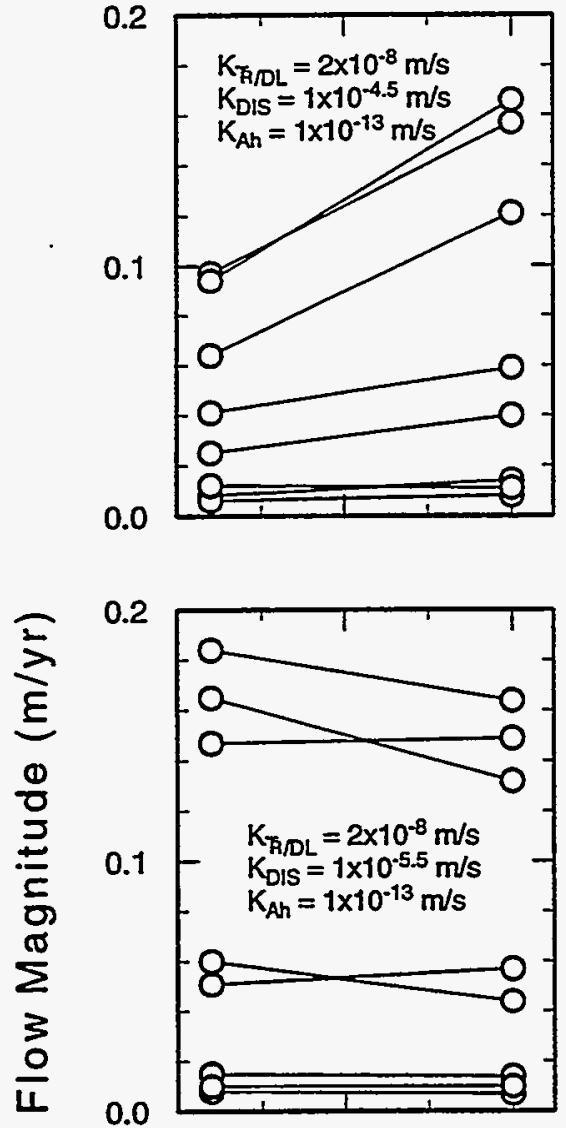

0.2

0.1

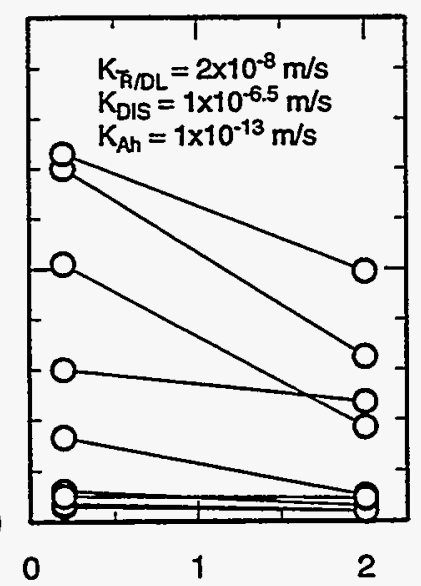

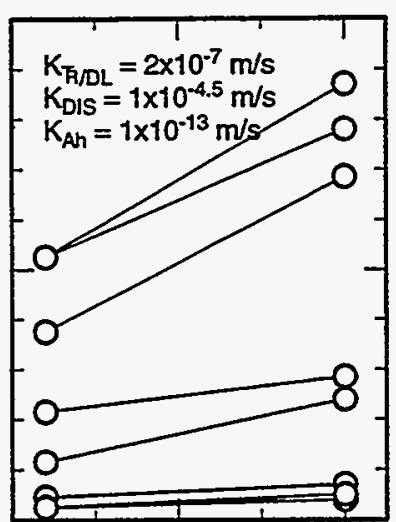
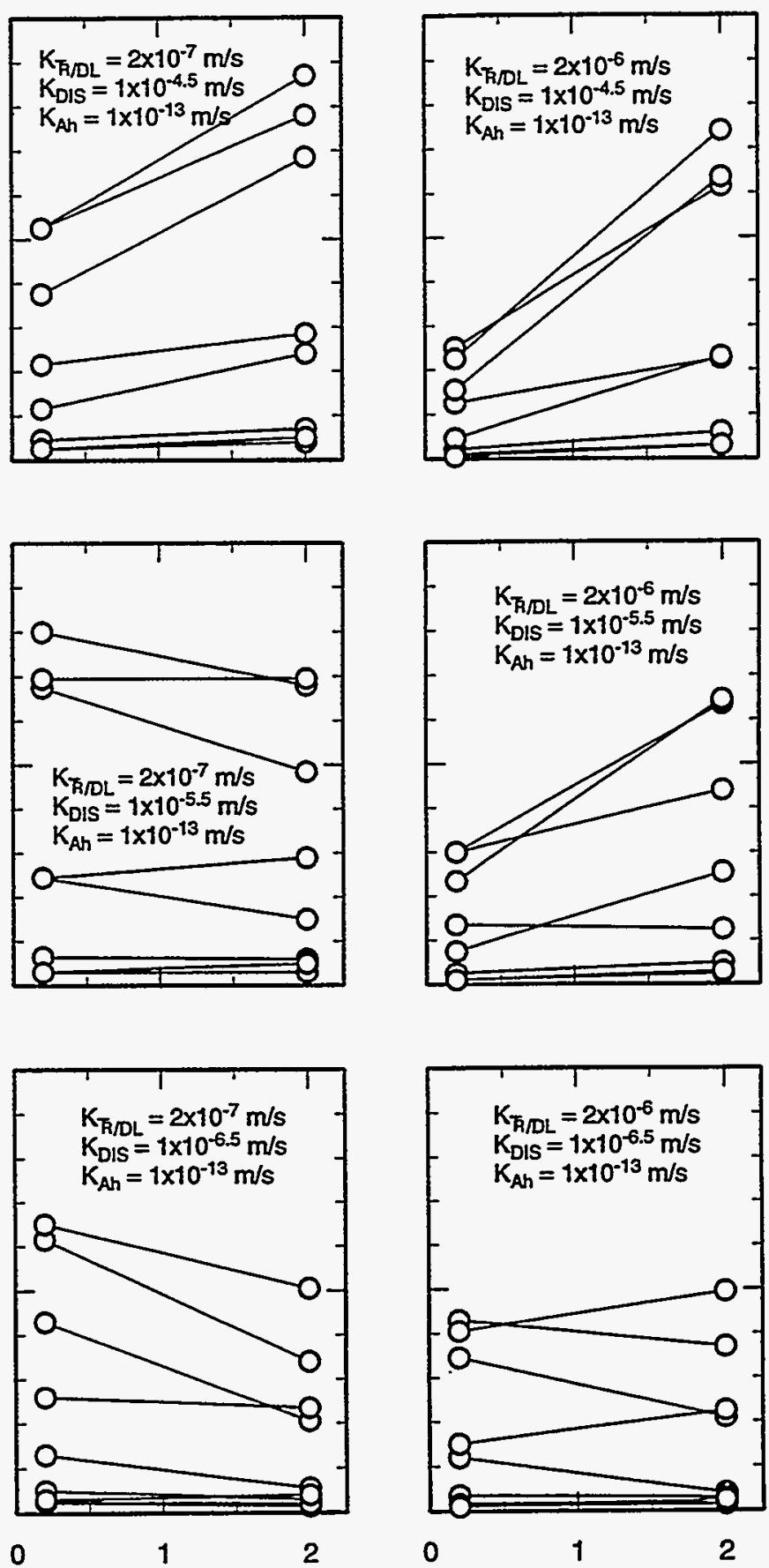

Recharge (log $\mathrm{mm} / \mathrm{yr})$

TRI-6115-447-0

Figure 3-16. Simulated lateral specific discharge ( $\mathrm{m} / \mathrm{yr}$ ) in the Culebra at nine locations within the WIPP site versus the rate of potential recharge. The conductivity of intact anhydrite is $1 \times$ $10^{-13} \mathrm{~m} / \mathrm{s}$. 

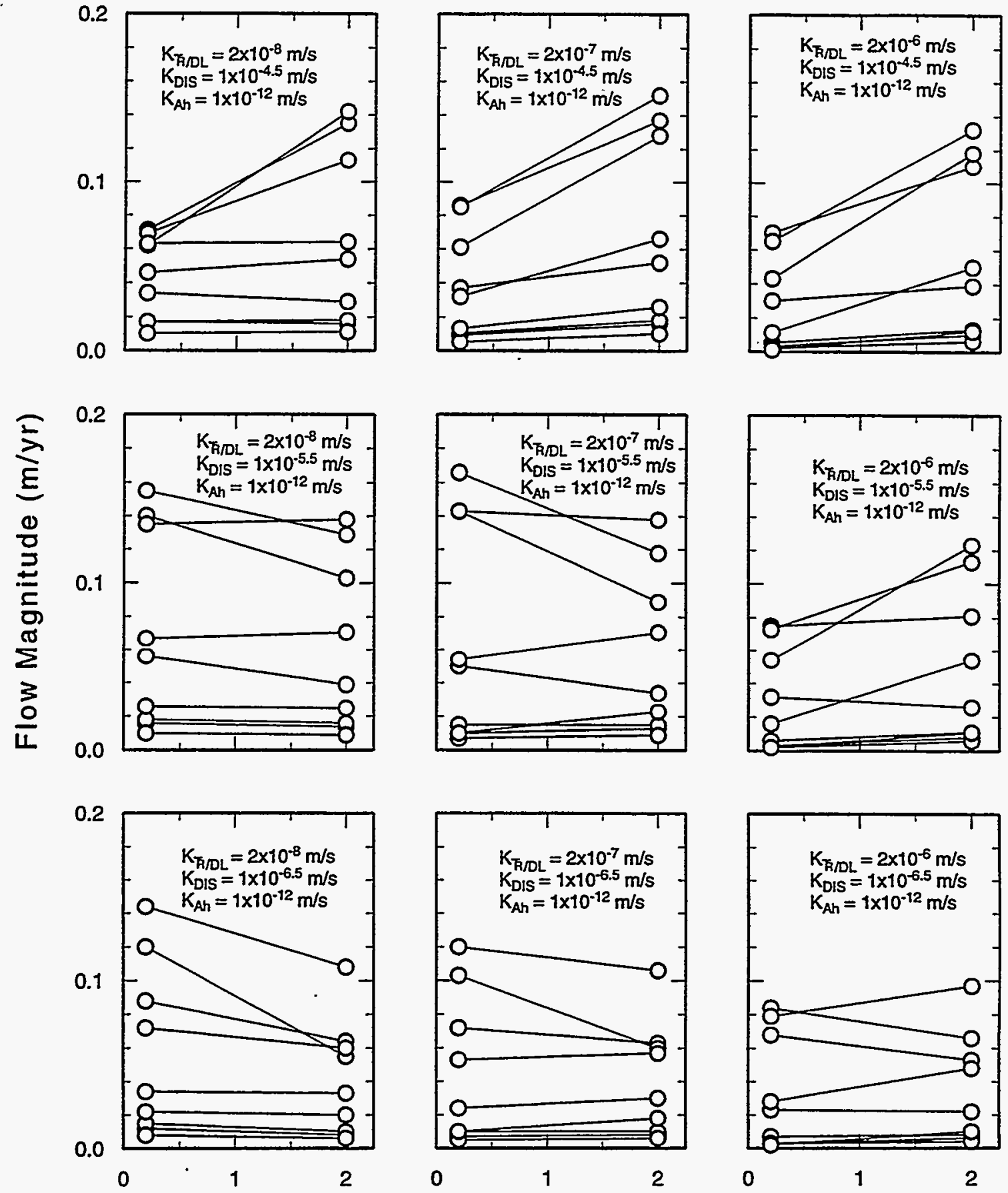

Recharge (log $\mathrm{mm} / \mathrm{yr})$

TRI-6115-448-0

Figure 3-17. Simulated lateral specific discharge $(\mathrm{m} / \mathrm{yr})$ in the Culebra at nine locations within the WIPP site versus the rate of potential recharge. The conductivity of intact anhydrite is $1 \times$ $10^{-12} \mathrm{~m} / \mathrm{s}$. 


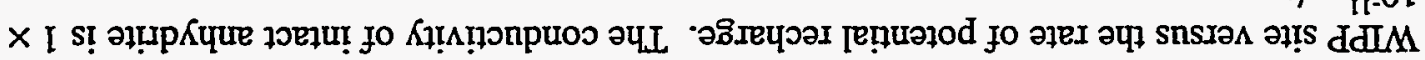

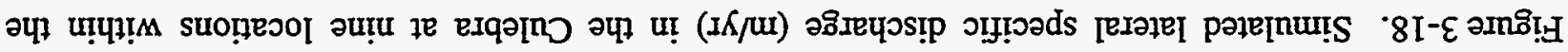

0-6\$-SแL-|4|

(АК/uس бор) әБдечәәу
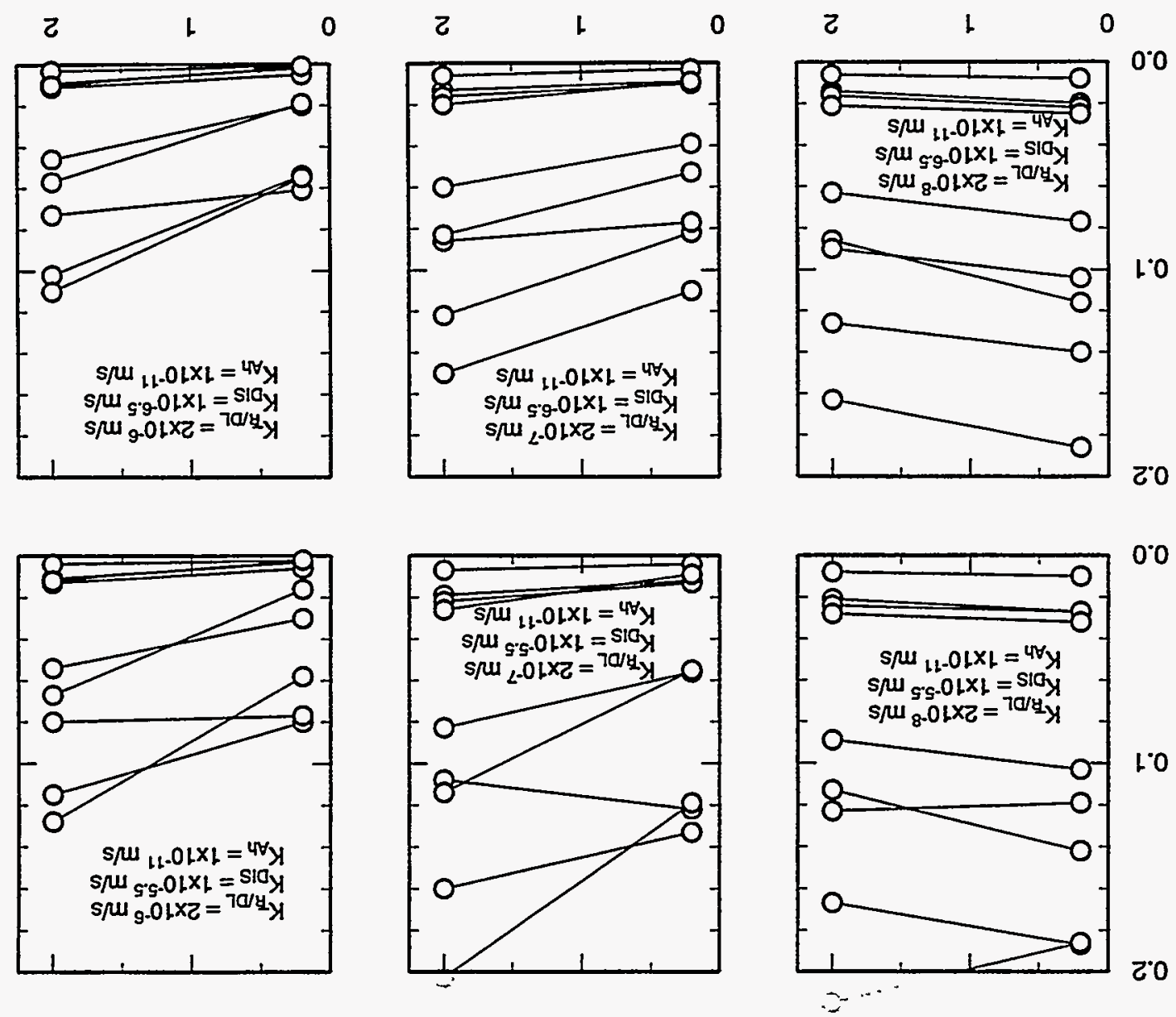

0.0

$\frac{\pi}{0}$
$\Sigma$
3
0
0
$\frac{1}{2}$
$\frac{1}{2}$
$\frac{0}{10}$
3
3
3
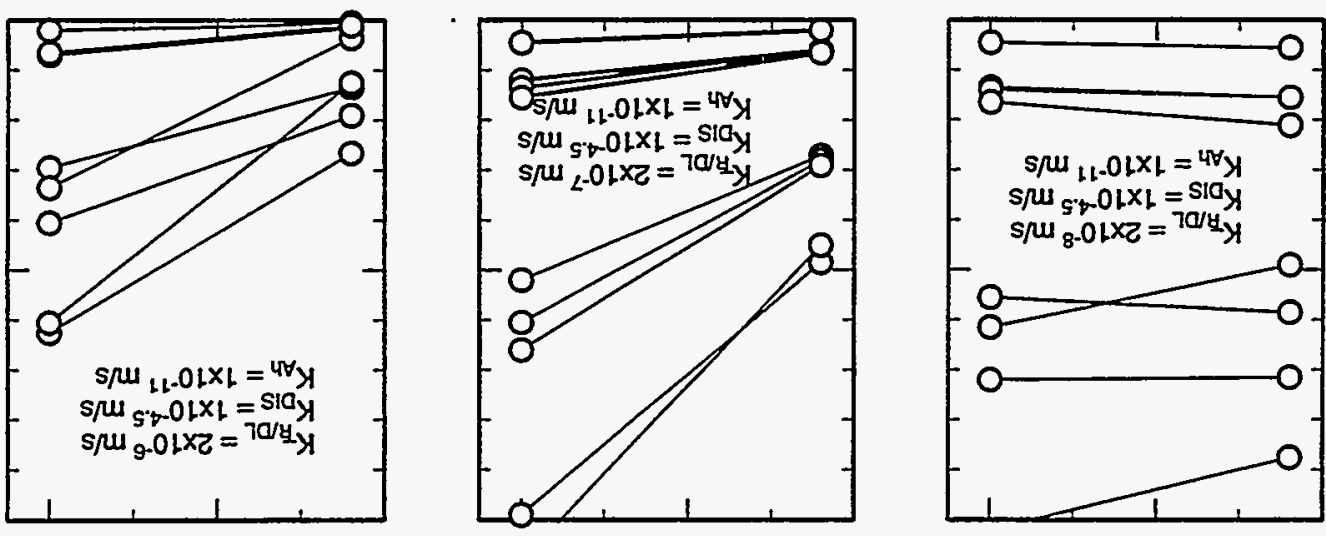

0.0

100 


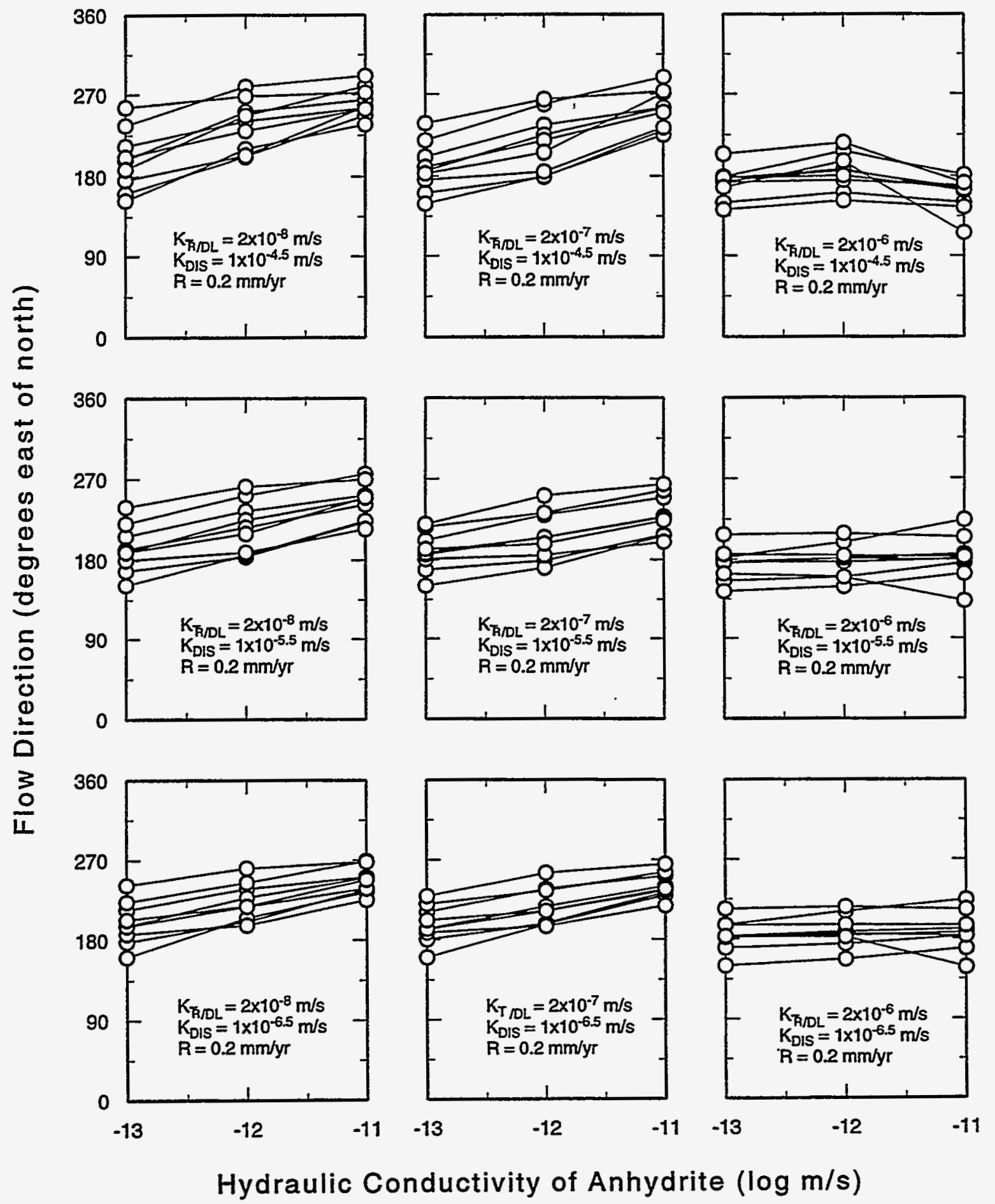

TAl-6115-450-0

Figure 3-19. Simulated lateral flow direction (degrees east of north) in the Culebra at nine locations within the WIPP site versus the conductivity of intact anhydrite. Potential recharge is equal to $0.2 \mathrm{~mm} / \mathrm{yr}$. 


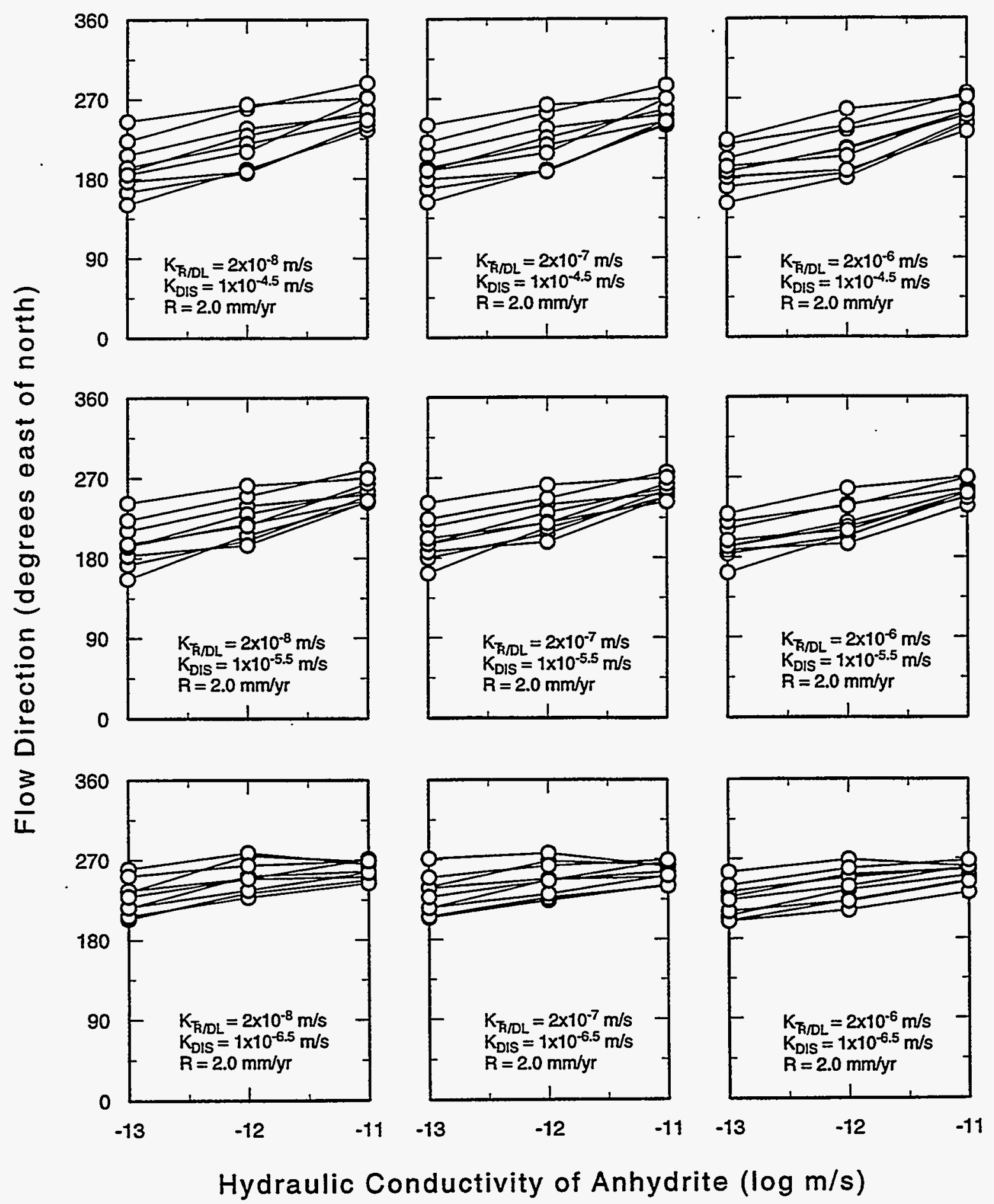

TR1-6115-451-0

Figure 3-20. Simulated lateral flow direction (degrees east of north) in the Culebra at nine locations within the WIPP site versus the conductivity of intact anhydrite. Potential recharge is equal to $2.0 \mathrm{~mm} / \mathrm{yr}$. 


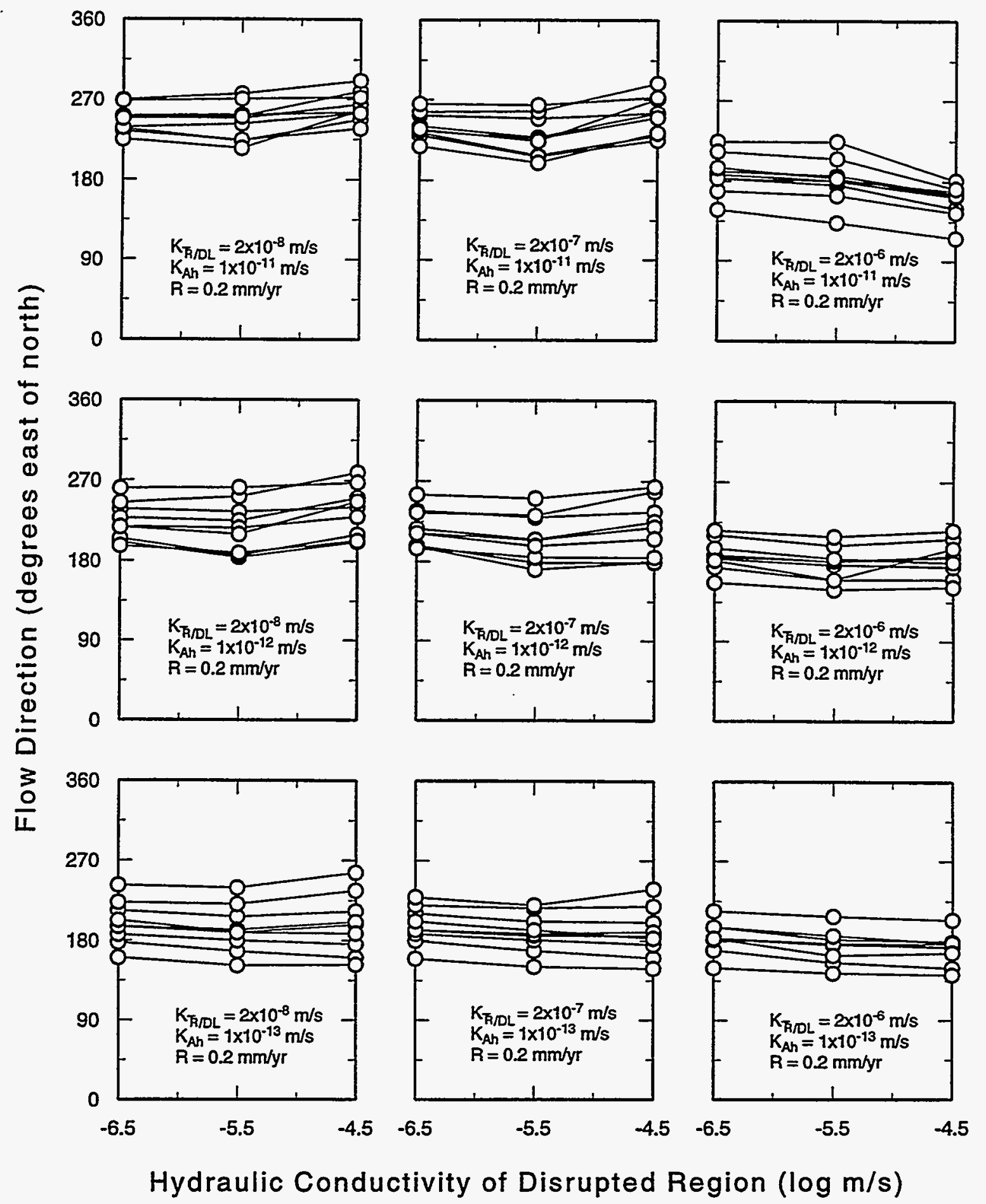

TR1-6115-452-0

Figure 3-21. Simulated lateral flow direction (degrees east of north) in the Culebra at nine locations within the WIPP site versus the conductivity of the disrupted region. Potential recharge is equal to $0.2 \mathrm{~mm} / \mathrm{yr}$. 


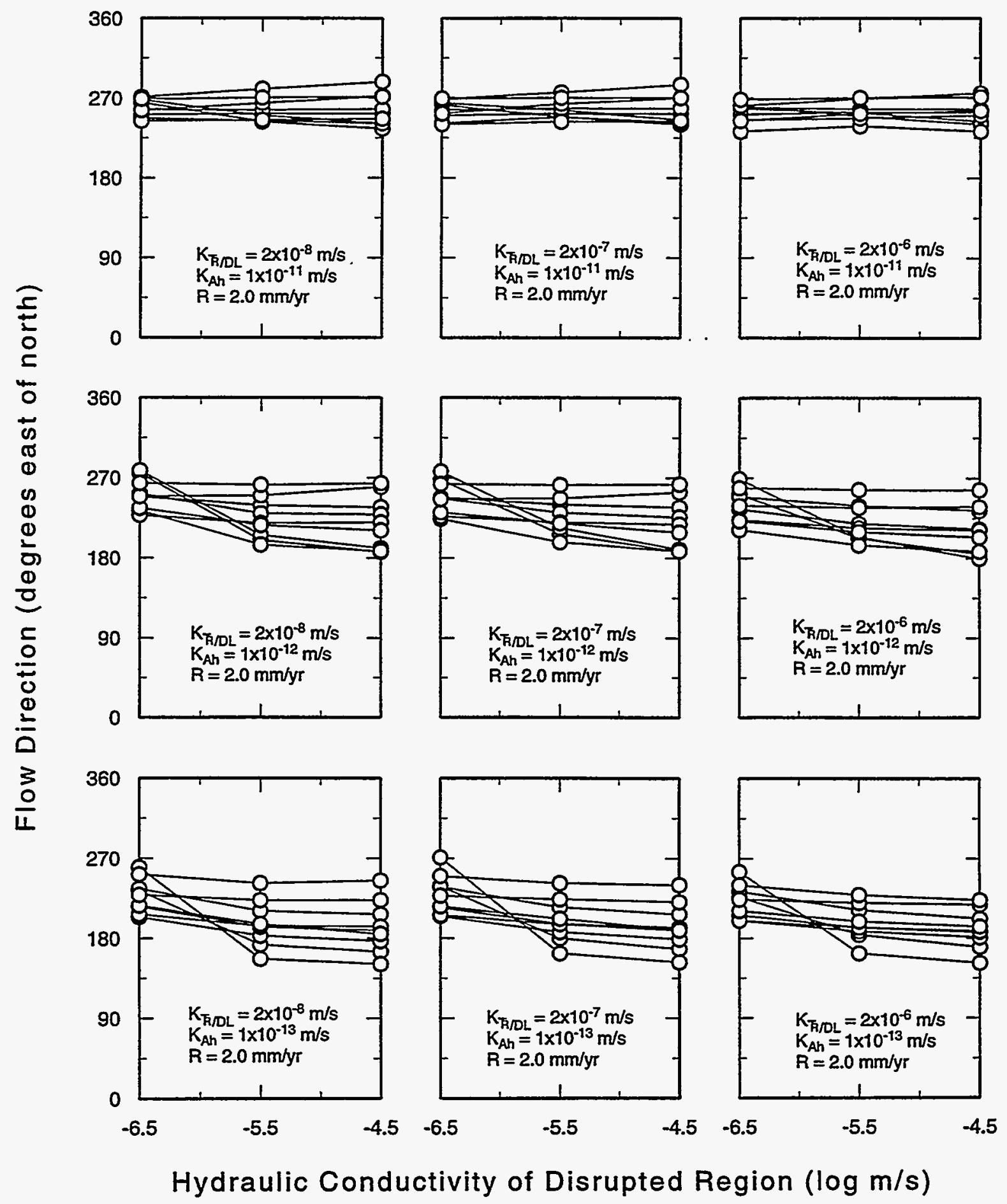

TีI-6115-453-0

Figure 3-22. Simulated lateral flow direction (degrees east of north) in the Culebra at nine locations within the WIPP site versus the conductivity of disnupted region. Potential recharge is equal to $2.0 \mathrm{~mm} / \mathrm{yr}$. 

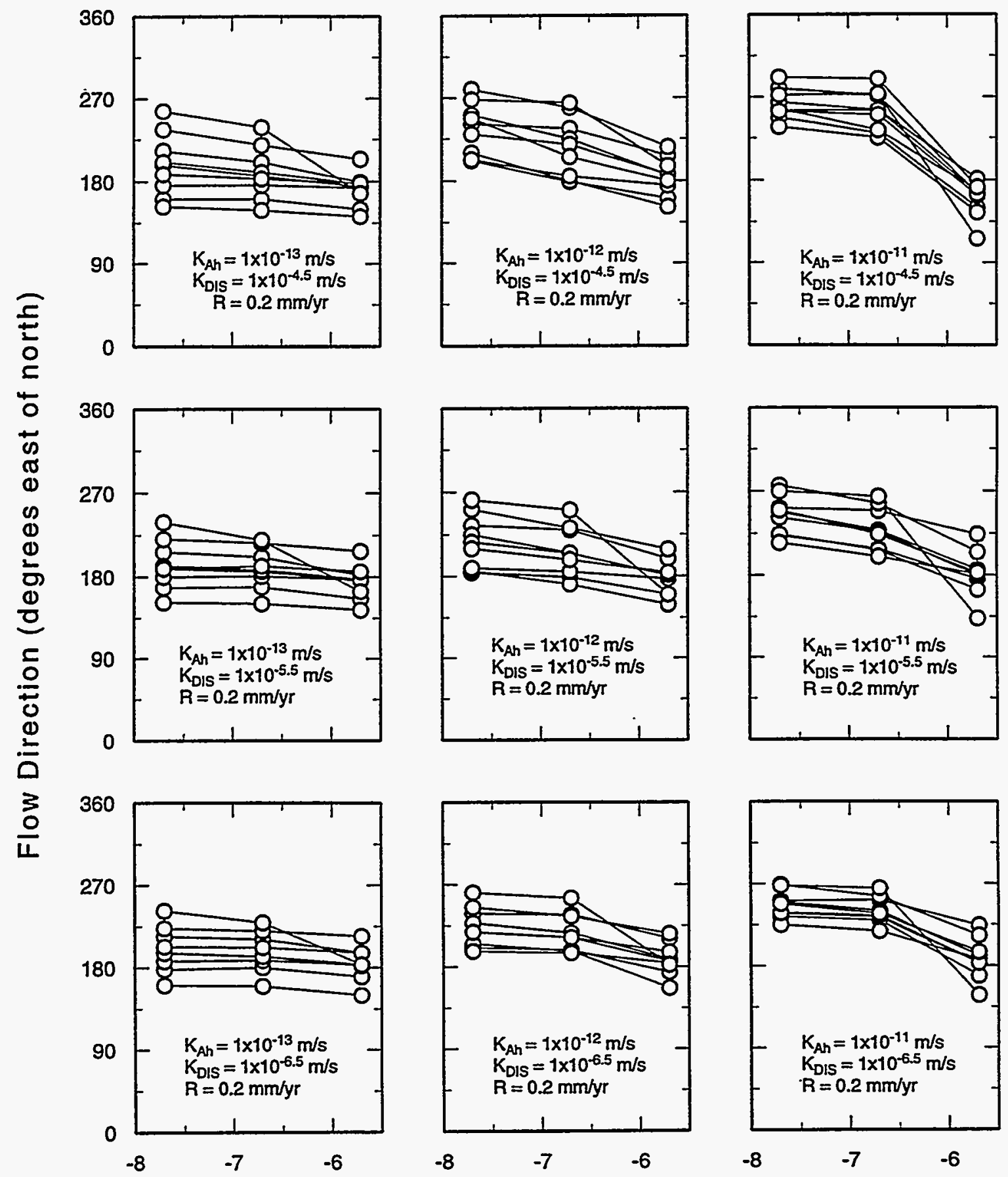

Hydraulic Conductivity of Triassic Rocks/Dewey Lake ( $\log \mathrm{m} / \mathrm{s}$ )

TR1-6115-454-0

Figure 3-23. Simulated lateral flow direction (degrees east of north) in the Culebra at nine locations within the WIPP site versus the conductivity of the Dewey Lake/Triassic rocks. Potential recharge is equal to $0.2 \mathrm{~mm} / \mathrm{yr}$. 

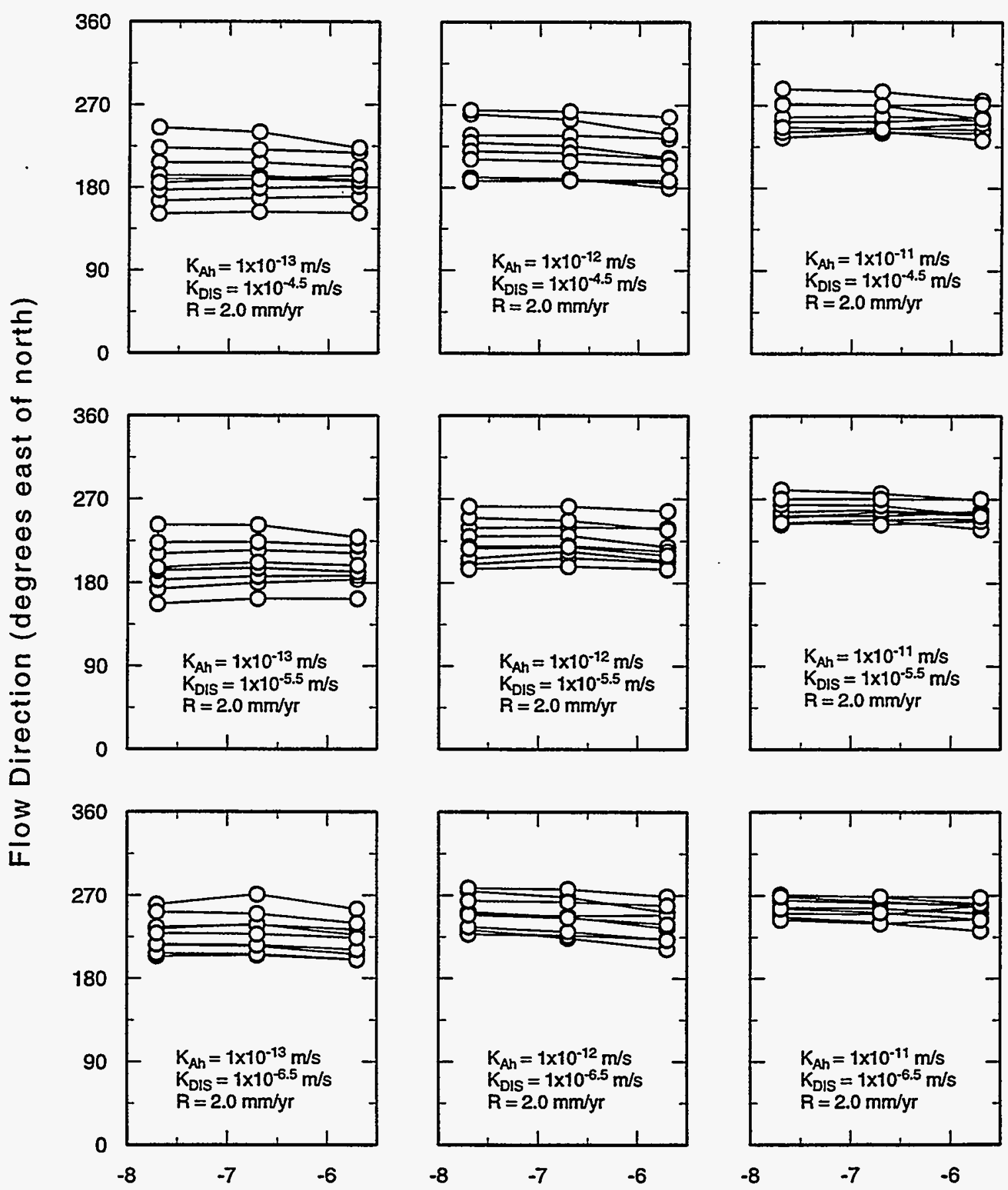

Hydraulic Conductivity of Triassic Rocks/Dewey Lake ( $\log \mathrm{m} / \mathrm{s}$ )

TRI-6115-455-0

Figure 3-24. Simulated lateral flow direction (degrees east of north) in the Culebra at nine locations within the WIPP site versus the conductivity of the Dewey Lake/Triassic rocks. Potential recharge is equal to $2.0 \mathrm{~mm} / \mathrm{yr}$. 


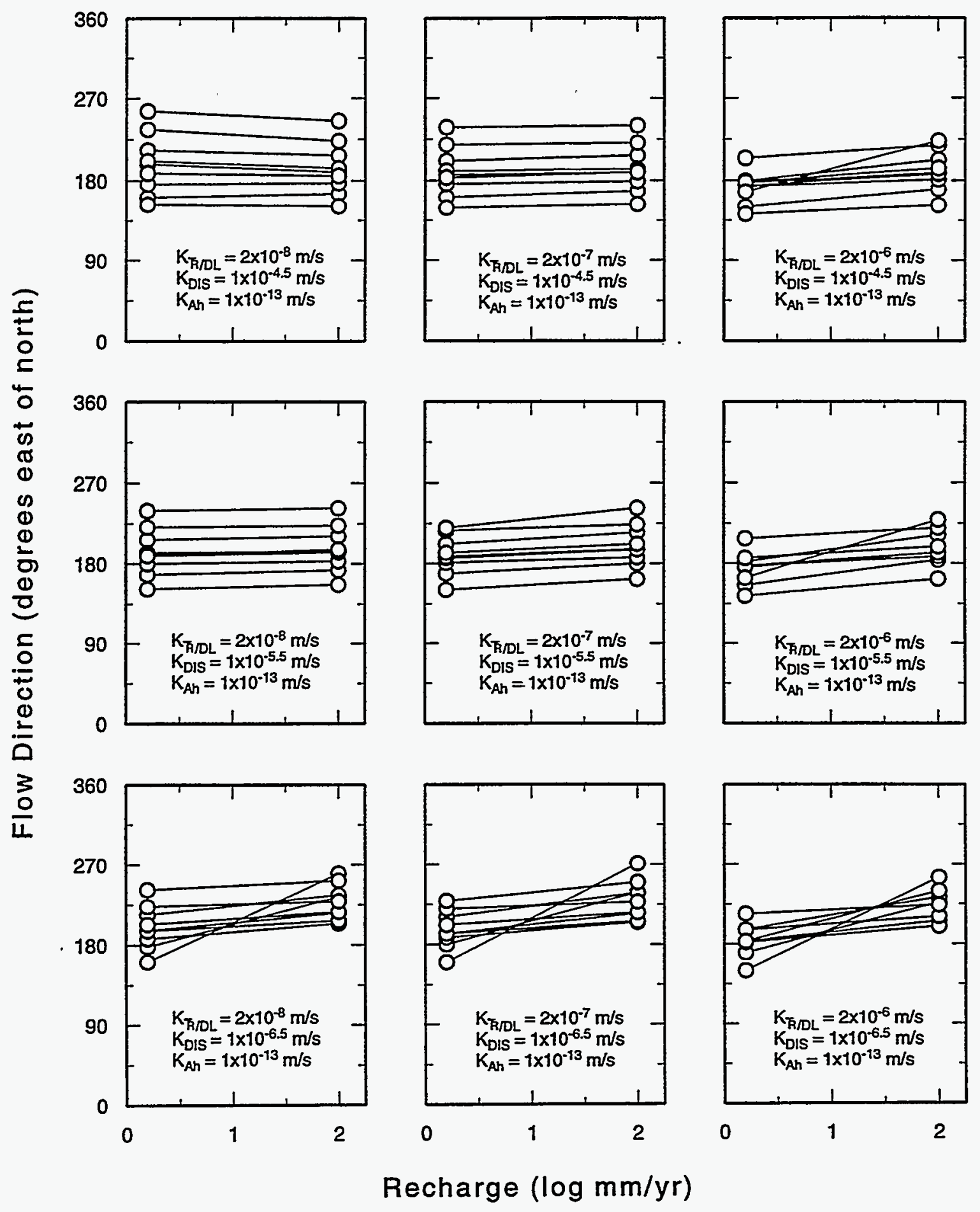

TRI-6115-456-0

Figure 3-25. Simulated lateral flow direction (degrees east of north) in the Culebra at nine locations within the WIPP site versus the rate of potential recharge. The conductivity of intact anhydrite is $1 \times 10^{-13} \mathrm{~m} / \mathrm{s}$. 


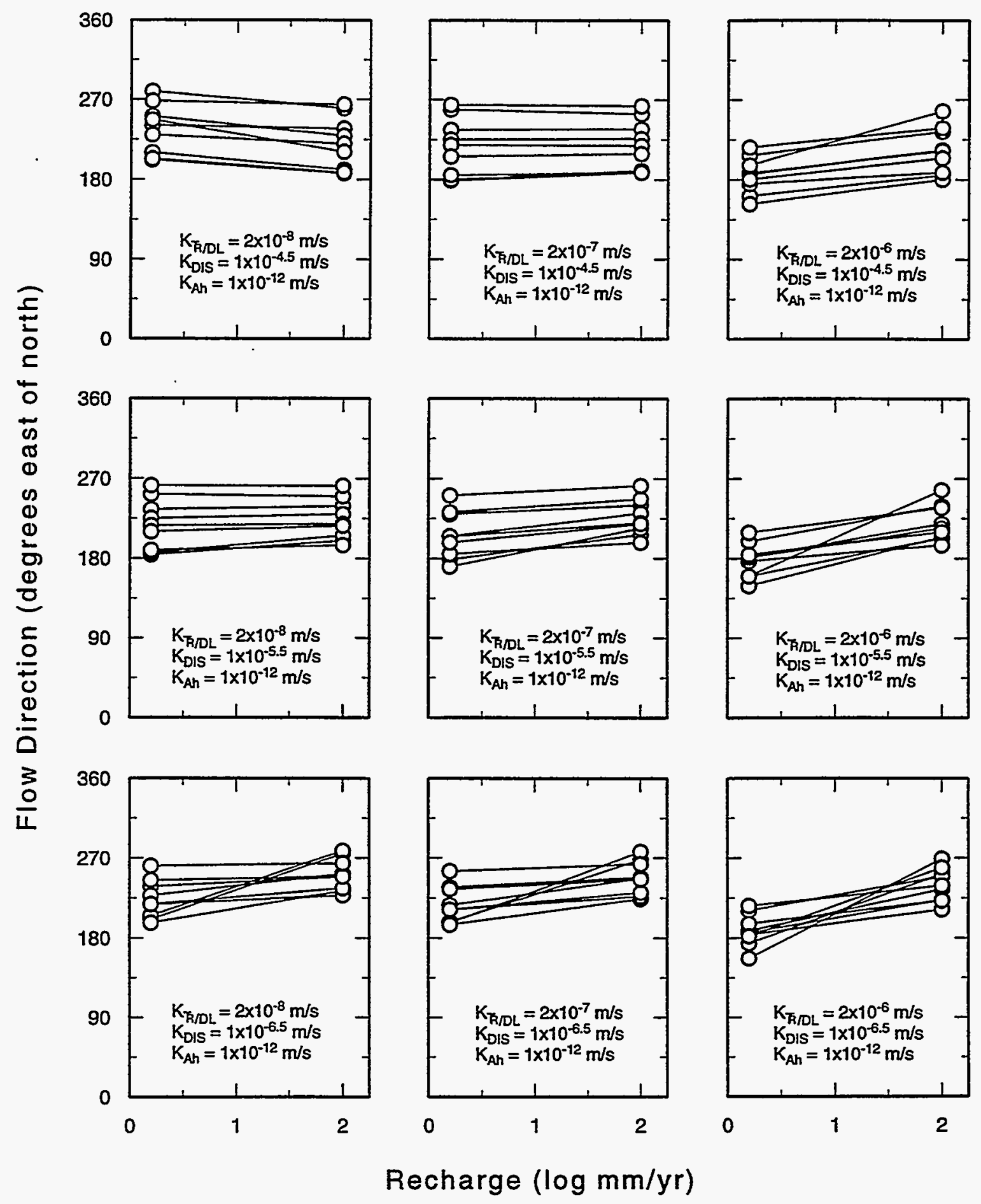

TRI-6115-457-0

Figure 3-26. Simulated lateral flow direction (degrees east of north) in the Culebra at nine locations within the WIPP site versus the rate of potential recharge. The conductivity of intact anhydrite is $1 \times 10^{-12} \mathrm{~m} / \mathrm{s}$. 


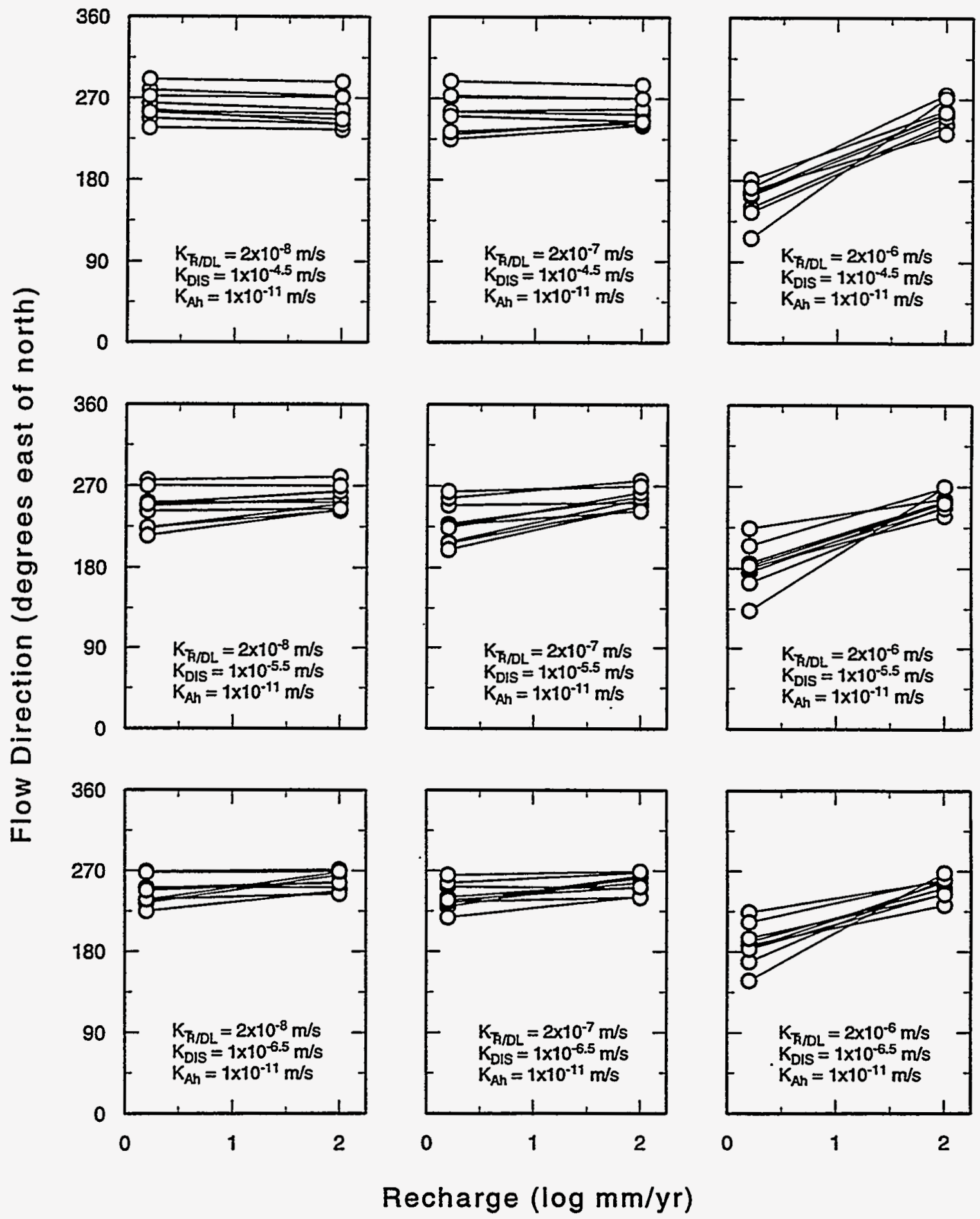

TRI-6115-458-0

Figure 3-27. Simulated lateral flow direction (degrees east of north) in the Culebra at nine locations within the WIPP site versus the rate of potential recharge. The conductivity of intact anhydrite is $1 \times 10^{-11} \mathrm{~m} / \mathrm{s}$. 
The results of these simulations do not show a clear trend of lateral flow rate with anhydrite conductivity (Figures 3-10 and 3-11). Also, the results suggest that lateral flow rate in the Culebra is relatively insensitive to the hydraulic conductivity of anhydrite confining layers.

Figures 3-12 and 3-13 show that the magnitude of flow in the Culebra increases with the conductivity of the disrupted region if the recharge rate is large, i.e., if the recharge rate is $2.0 \mathrm{~mm} / \mathrm{yr}$. Flow magnitude is also not very sensitive to this parameter.

Figures 3-14 and 3-15 indicate an overall trend of an increase in lateral flow rate in the Culebra with decreases in the conductivity of the Dewey Lake/Triassic rocks. The sensitivity of flow magnitudes to this parameter is enhanced if the conductivity of the anhydrite is relatively large $\left(1 \times 10^{-11} \mathrm{~m} / \mathrm{s}\right) .^{2}$

Given that heads in the Culebra show a clear trend of scaling with recharge, it might be expected that flow rates also are faster at larger recharge rates. However the results shown in Figures 3-16, 3-17, and 3-18 show that a larger recharge rate does not uniformly increase head in the vicinity of WIPP. Instead, a more complex pattern of change in the gradient of head occurs as indicated in these figures as changes in specific discharge. Lateral flow rates show a clear increase with recharge in only about half of the 27 pairs of simulations that differ only in recharge rate. The lateral flow rate in the others shows either a decreasing or mixed trend. Lateral flow rates increase at some positions while decreasing at others for several of the parameter combinations.

Overall, the sensitivity of lateral flow rates in the Culebra to recharge rate is low. The largest changes in flow rates occur if the conductivity of the disrupted region is large $\left(1 \times 10^{-4.5} \mathrm{~m} / \mathrm{s}\right)$.

\subsubsection{Sensitivity of Lateral Flow Directions in the Culebra to Model Parameters}

The calculated flow directions differ from the flow magnitudes in that they show a more systematic change with anhydrite conductivity. Flow directions are typically toward the south or southeast if the anhydrite conductivity is smaller and toward the south or southwest if the conductivity is larger (Figures 3-19 and 3-20). Flow directions are given as the number of degrees east of north. We will refer to shifts that increase this number as shifts toward the west and those that decrease this number

2 This value of hydraulic conductivity is provided only as a reference to specific simulation results. We note that in this statement, as well as in other similar statements, the trend indicated by the simulation results is more meaningful than the actual value of the model parameter. 
as shifts toward the east. Maximum shifts over the range of anhydrite considered are about 65 degrees, or approximately equal to the spatial variation of flow direction for any parameter combination.

Flow directions do not show a clear trend or sensitivity to the conductivity of the disturbed region (Figures 3-21 and 3-22).

Flow directions in the Culebra show a clear trend with the conductivity of the Dewey Lake/Triassic rocks if the recharge rate is small (Figures 3-23 and 3-24), that is opposite to the shift due to the anhydrite conductivity; flow shifts toward the east as the conductivity of the Dewey Lake/Triassic rocks increases. The magnitude of the shift, however, is typically less than the spatial variation of the flow directions.

An increase in the recharge rate shifts flow directions in the Culebra slightly toward the west

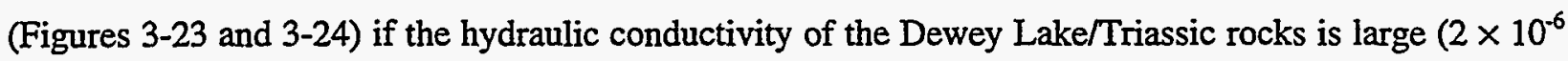
$\mathrm{m} / \mathrm{s}$ ). The amount of the shift scales with the conductivity of the anhydrites. For the largest value of anhydrite conductivity, the typical shift is larger than the spatial variation of the data.

\subsubsection{Sensitivity of Mass Balance over the Culebra Reference Volume to Model Parameters}

Figures 3-28, 3-29, and 3-30 show the percent of the total inflow to the Culebra reference volume that is contributed by vertical leakage across its upper surface, graphed versus hydraulic conductivity of the anhydrite, disrupted zone, and Dewey Lake/Triassic rocks respectively. Each of these figures contains the results for all 54 steady-state simulations. The lines in each graph connect results from simulations using the same value for potential recharge.

Clearly, the degree that vertical leakage contributes to the total inflow to the Culebra reference volume is very sensitive to anhydrite conductivity (Figure 3-28). The percent of contribution by vertical leakage across the upper surface of the Culebra increases with anhydrite conductivity. The contribution ranges from a few to nearly $100 \%$ of total inflow. In all of the steady-state simulations, the vertical leakage across the upper surface and lateral inflow to the Culebra sum to at least $96 \%$ of the total inflow. Therefore, there is an inverse relationship between the vertical and lateral contributions to total flow.

There does not seem to be a clear correlation of percent contribution of vertical leakage into the Culebra with the conductivity of the disrupted region (Figure 3-29). 

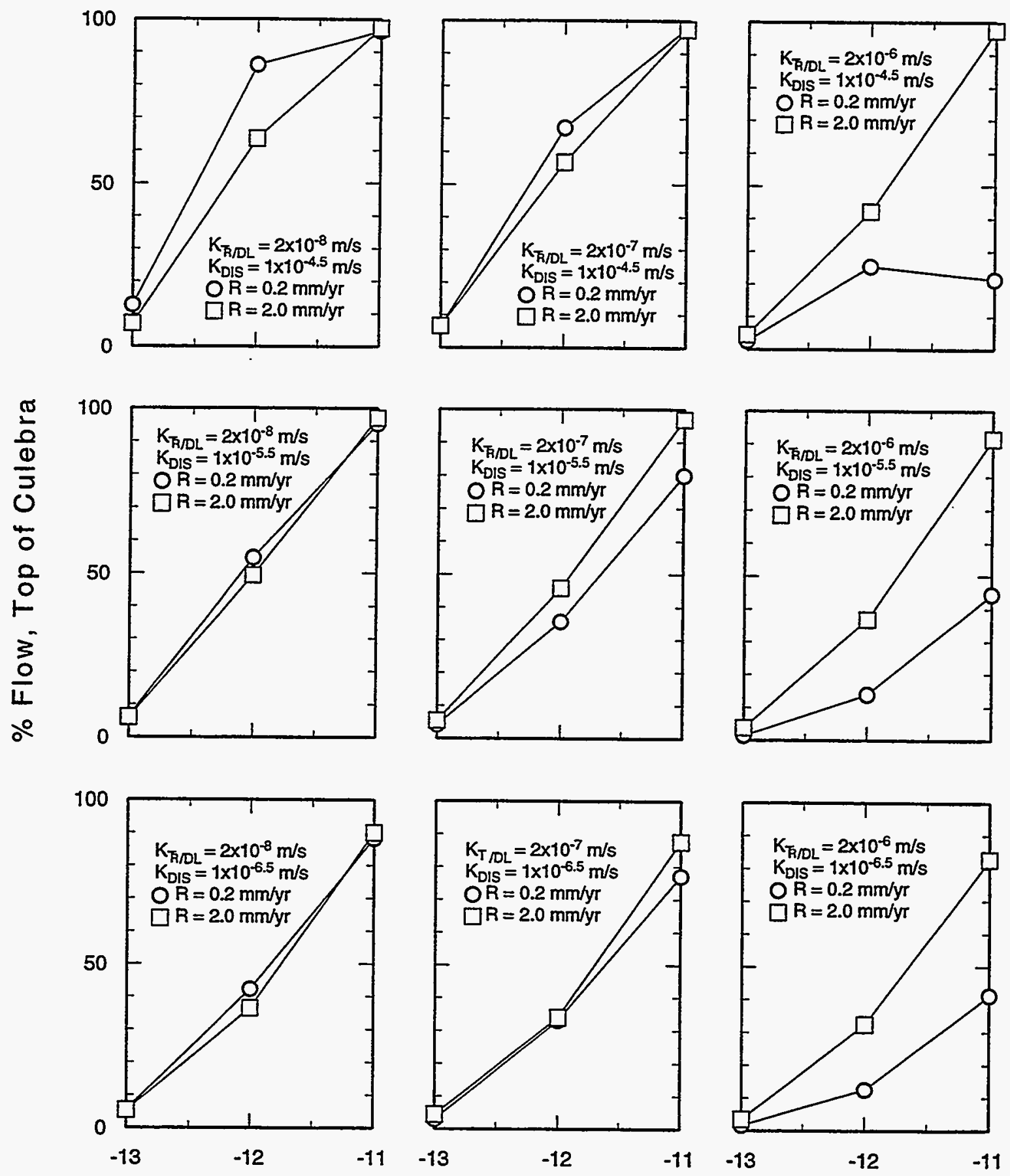

Hydraulic Conductivity of Anhydrite $(\log \mathrm{m} / \mathrm{s})$

TRI-6115-459-0

Figure 3-28. Percent of total inflow to the Culebra reference volume that leaks across the upper surface of the Culebra versus the conductivity of intact anhydrite. 

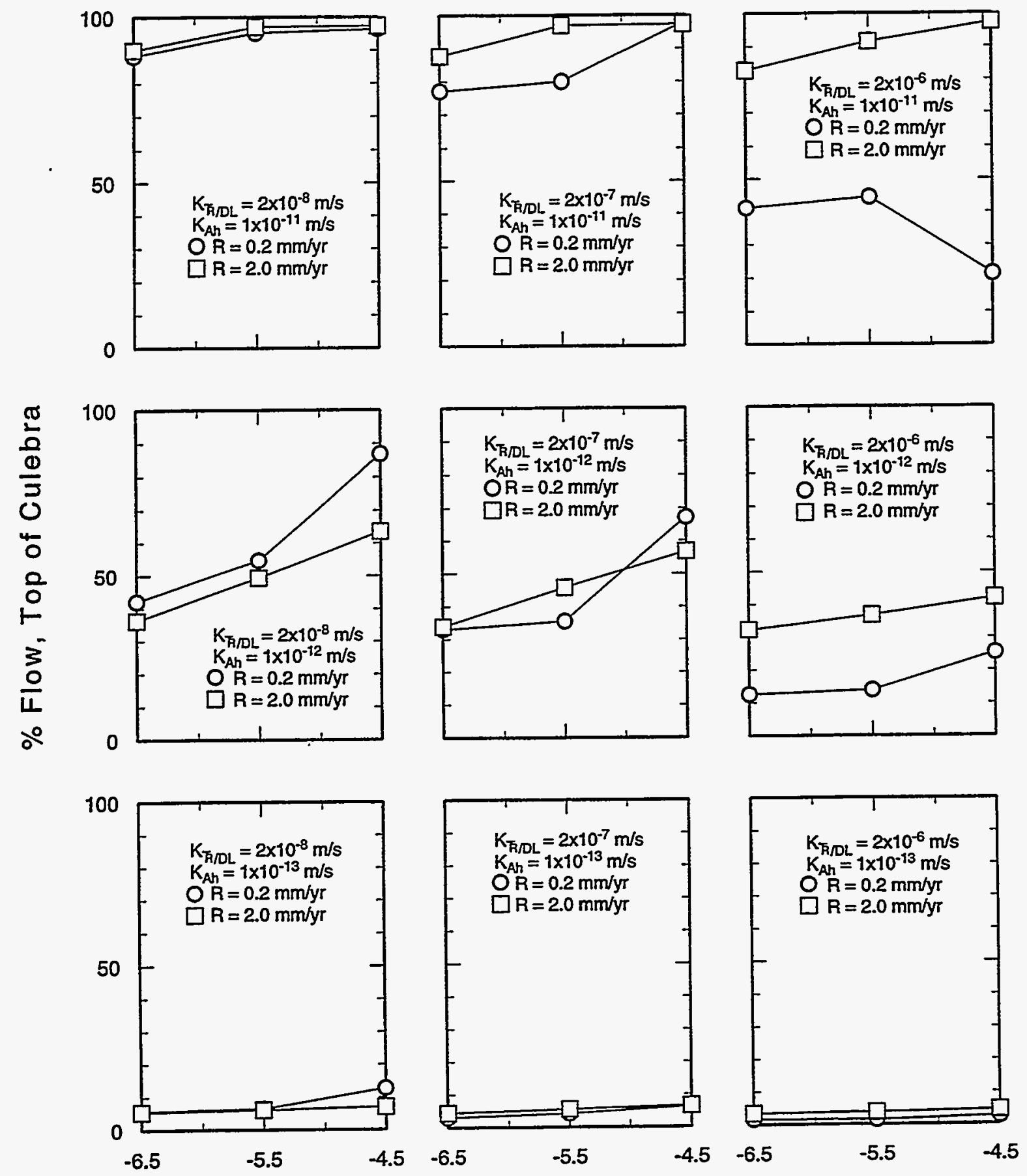

Hydraulic Conductivity of Disrupted Region ( $\log \mathrm{m} / \mathrm{s}$ )

TRI-6115-460-0

Figure 3-29. Percent of total inflow to the Culebra reference volume that leaks across the upper surface of the Culebra versus the conductivity of the disrupted region. 
The conductivity of the Dewey Lake/Triassic rocks has a strong influence on the contribution of vertical leakage to total inflow to the Culebra reference volume (Figure 3-30). Increasing the conductivity of the Dewey Lake/Triassic rocks results in a smaller contribution by vertical leakage.

Figures 3-28 through 3-30 give results for the small $(0.2 \mathrm{~mm} / \mathrm{yr})$ and large $(2.0 \mathrm{~mm} / \mathrm{yr})$ values for the rate of potential recharge. Differences in the contribution of vertical leakage are large only if the conductivity of the Dewey Lake/Triassic rocks is relatively large $\left(2 \times 10^{-6} \mathrm{~m} / \mathrm{s}\right)$ and the conductivity of the anhydrite is relatively large $\left(1 \times 10^{-12}\right.$ or $\left.1 \times 10^{-11} \mathrm{~m} / \mathrm{s}\right)$. The larger recharge rate results in a greater contribution of vertical leakage in these cases in which the differences are large. Otherwise, there is not a clear pattern as to which recharge rate results in the larger contribution.

Figures 3-31, 3-32, and 3-33 show the total lateral outflow from the Culebra reference volume versus hydraulic conductivity of the anhydrite, disrupted zone, and Dewey Lake/Triassic rocks. It is clear that this outflow increases as the conductivity of the anhydrite increases (Figure 3-31). There is some increase in the lateral outflow from the Culebra reference volume with increasing conductivity of the disrupted region if the anhydrite conductivity is relatively large (Figure 3-32). Increasing the conductivity of the Dewey Lake/Triassic rocks acts to decrease the total lateral outflow from the Culebra reference volume (Figure 3-33). The effect is particularly strong if the conductivity of the anhydrite is $1 \times 10^{-11} \mathrm{~m} / \mathrm{s}$.

For most, but not all parameter combinations, the total lateral outflow from the Culebra is larger if the recharge rate is 2.0 rather than $0.2 \mathrm{~mm} / \mathrm{yr}$. Parameter sets for which the flow is significantly larger at the lower recharge rate are those in which the conductivity of the Dewey Lake/Triassic rocks is relatively small $\left(2 \times 10^{-8} \mathrm{~m} / \mathrm{s}\right)$ and the conductivity of the disrupted region is relatively small $\left(1 \times 10^{-6.5}\right.$ $\mathrm{m} / \mathrm{s})$. The lateral-flow ratios for the steady-state simulations are given in Table 3-4.

\subsection{Results of Transient Simulations}

We first describe, in Section 3.2.1, the base-case transient simulation in somewhat more detail than the other simulations. The intent is to use this simulation to demonstrate some of the important concepts conceming groundwater flow at the groundwater basin and WIPP-site scales. We then describe, in Section 3.2.2 (Variation of Rock Properties), six additional simulations that differ from the base simulation only in the assumed value for a single rock property, for example, the hydraulic conductivity 

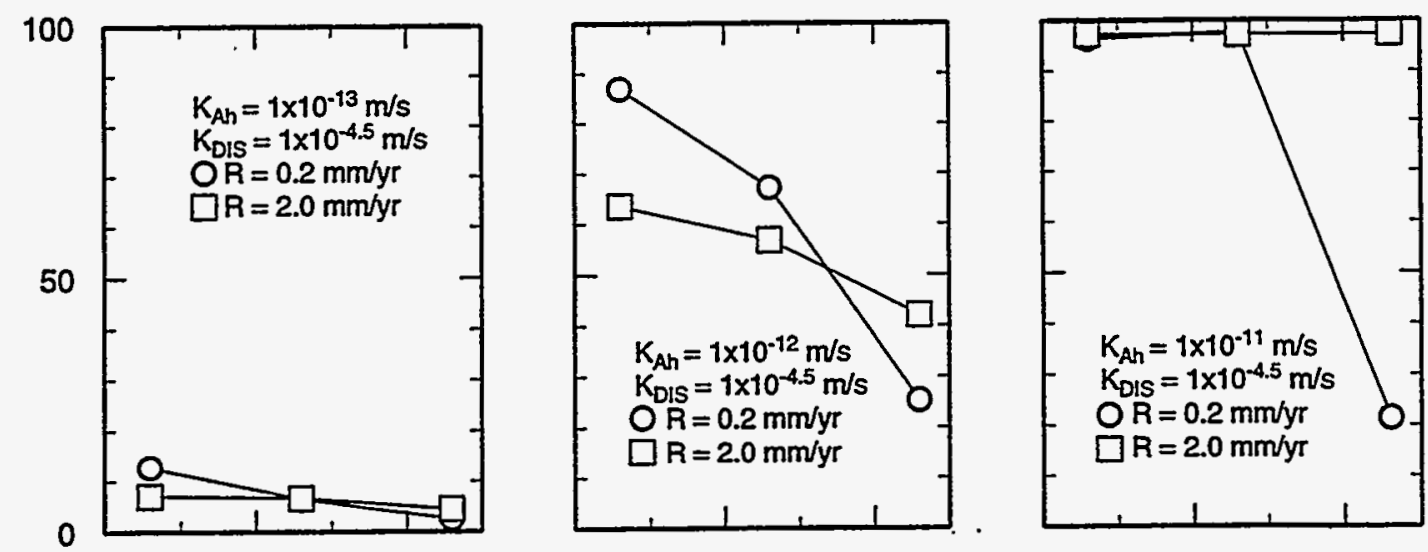

$\frac{\pi}{0}$
$\frac{0}{3}$
0
4
0
0
0
$1-$
3
0
$\frac{0}{11}$
0
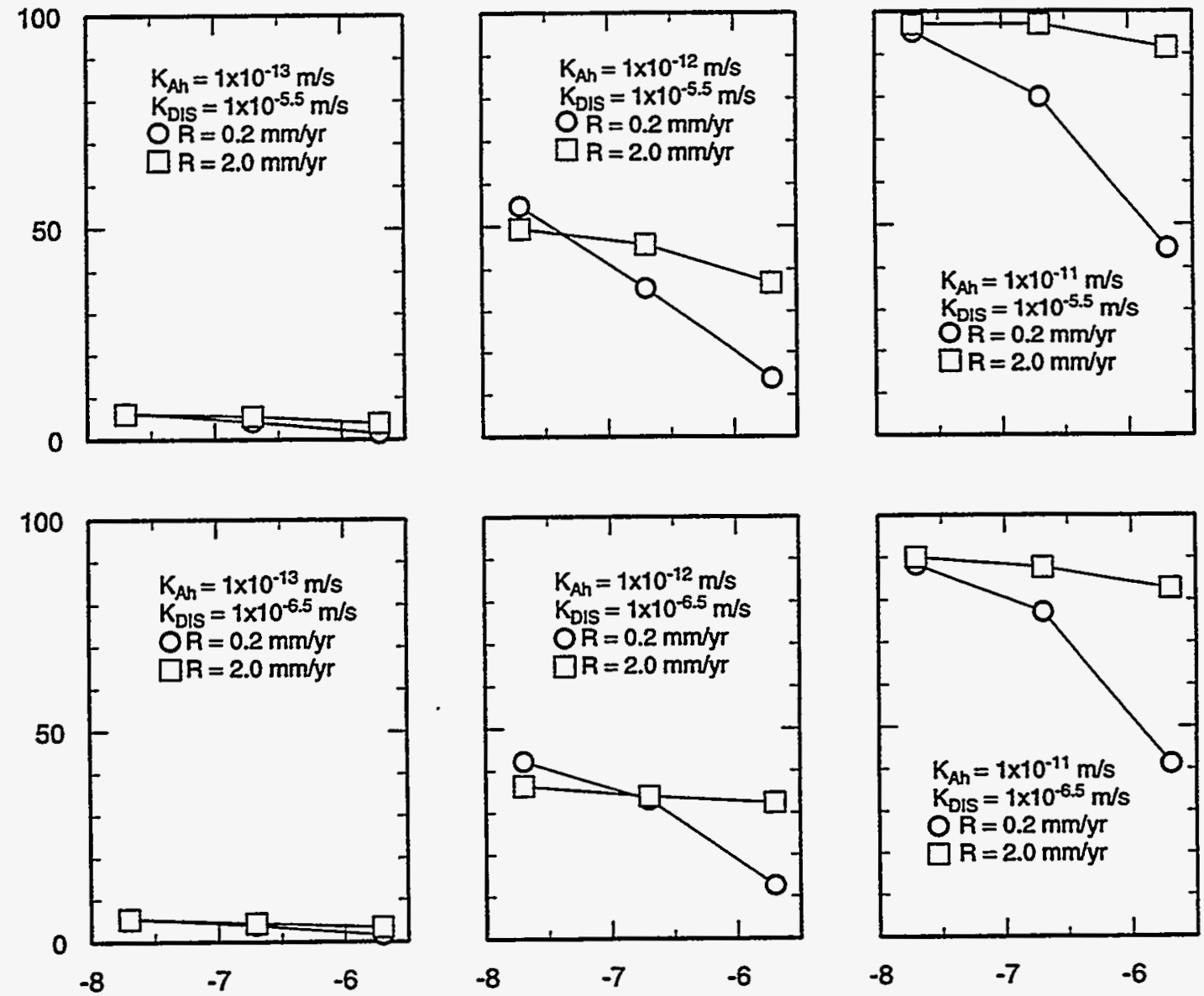

Hydraulic Conductivity of Triassic Rocks/Dewey Lake ( $\log \mathrm{m} / \mathrm{s}$ )

TRI-6115-461-0

Figure 3-30. Percent of total inflow to the Culebra reference volume that leaks across the upper surface of the Culebra versus the conductivity of the Dewey Lake/Triassic rocks. 

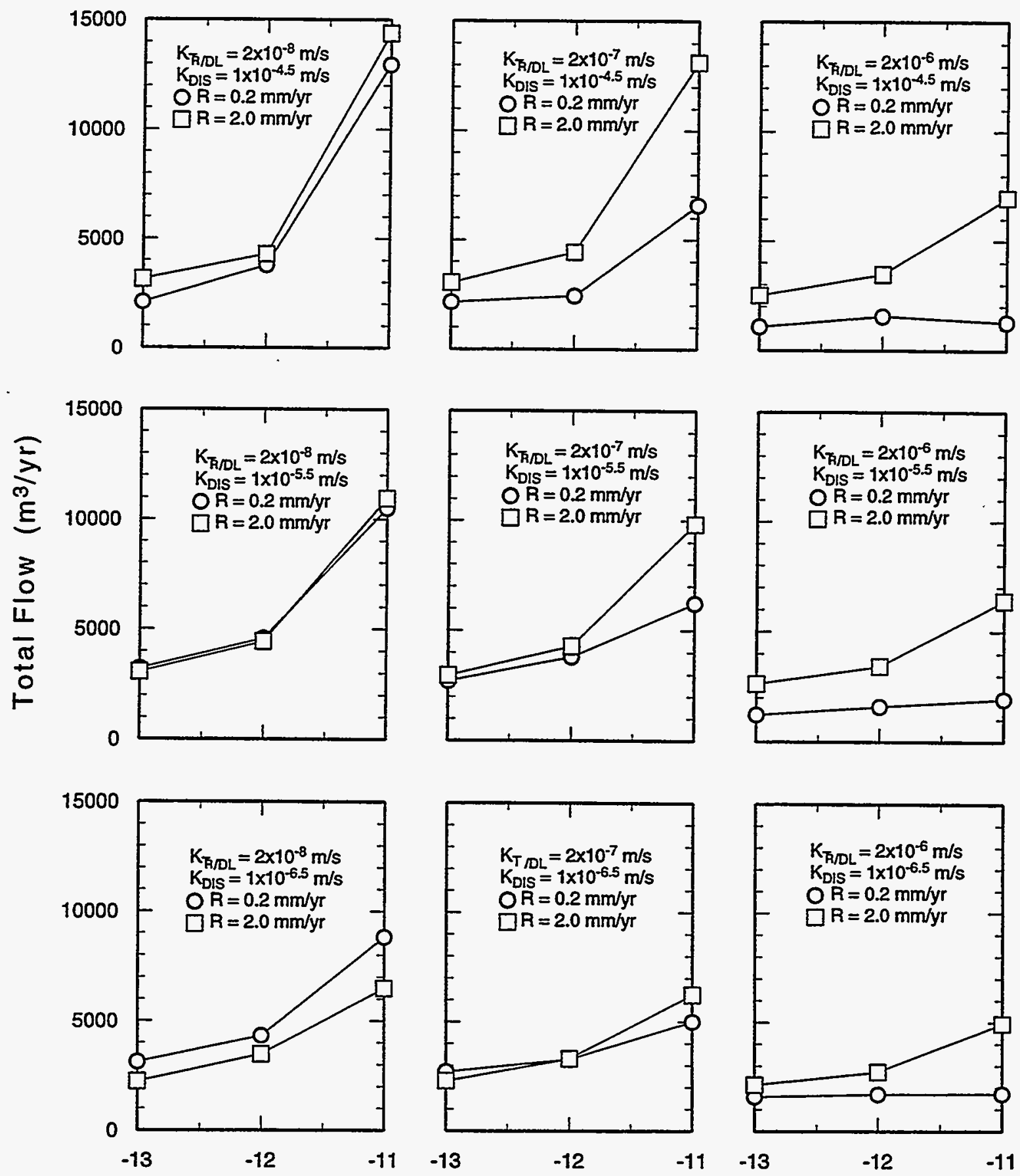

Hydraulic Conductivity of Anhydrite ( $\log \mathrm{m} / \mathrm{s}$ )

TA1-6115-462-0

Figure 3-31. Total lateral outflow from the Culebra reference volume versus the conductivity of intact anhydrite. 

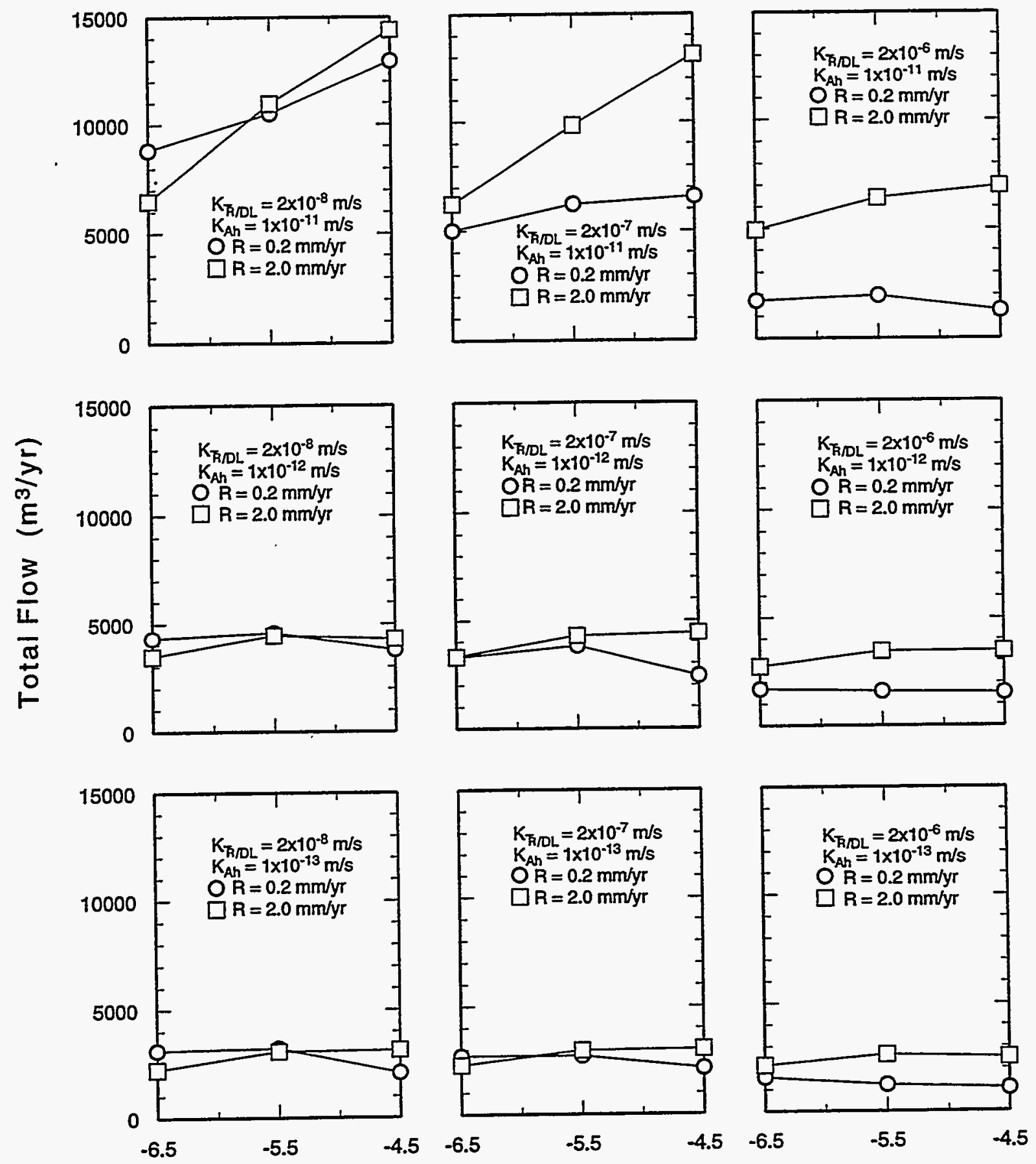

Hydraulic Conductivity of Disrupted Region ( $\log \mathrm{m} / \mathrm{s}$ )

TR1-6115-403-0

Figure 3-32. Total lateral outflow from the Culebra reference volume versus the conductivity of the disrupted region. 

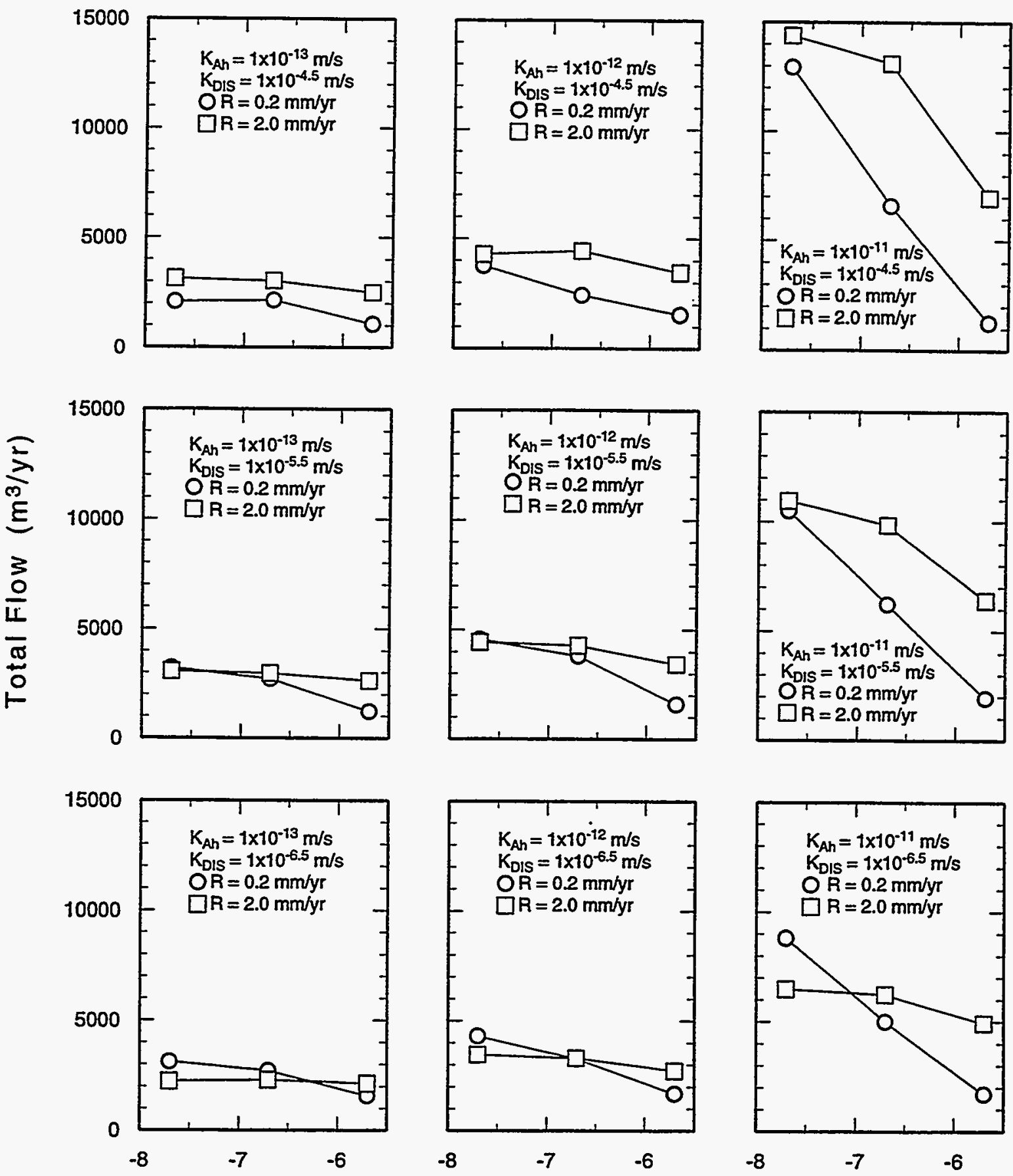

Hydraulic Conductivity of Triassic Rocks/Dewey Lake $(\log \mathrm{m} / \mathrm{s})$

TA1-6115-464-0

Figure 3-33. Total lateral outflow from the Culebra reference volume versus the Dewey Lake/Triassic rocks. 
of intact anhydrite. Section 3.2.3 (Variation of Potential Recharge), contains a discussion of ten additional simulations that were designed to examine the effects of the pattern and rate of recharge during the Holocene.

Appendix D contains tables that summarize the mass balances for the transient simulations at the simulated present time and at 10,000 years in the future. These tables present the mass balance in terms of flow rates, across the top, bottom, or sides of the reference volumes, or in terms of base-case ratios or lateral-flow ratios. The base-case ratio is, for example, the total lateral outflow from the Culebra reference volume, divided by that same number for the base-case simulation. The definition of lateralflow ratio and the locations of the reference volumes are provided in the introduction to Section 3.

\subsubsection{Base-Case Simulation}

Results of the base case are presented both at the scale of the model domain and at the scale of the WIPP-site. Model-scale results are presented either in map view or as profiles of the water table along vertical cross sections. A map view shows a model result for a selected hydrostratigraphic unit at a given time. For example, a map of simulated hydraulic head in the Culebra at 10,000 years into the future could be presented. Results at the WIPP-site scale are presented as graphs of a flow metric versus time. For example, the magnitude of flow in the Culebra at nine locations within the WIPP site could be graphed versus time.

\subsubsection{RESULTS AT THE SCALE OF THE MODEL DOMAIN}

Figure 3-34 shows the simulated water table at 14,000 years in the past. The features of this surface are very similar to the topography of the land surface. Figure 3-35 shows that the water table is at a depth of less than 15 m over much of the model domain. In two regions, about $2 \mathrm{~km}$ south and $2 \mathrm{~km}$ northwest from the WIPP site, the water table is at a depth of more than $45 \mathrm{~m}$. Figure 3-36 shows vertical profiles of the water table and the land surface. Profile (a) is oriented north-south and passes through the center of the WIPP site and the region of deep water table south of the WIPP site. This profile shows the steep drop-off of the water table that occurs at the edge of the disrupted zone. A profile that cuts through the center of the WIPP site along an east-west orientation (profile (b)) illustrates that the recharge rate is not sufficient to maintain the water table at the land surface under the relatively sharper topographic highs. Such topographic highs correspond to the regions east and north east of the WIPP site where the water table is a much as $30 \mathrm{~m}$ below the land surface. 


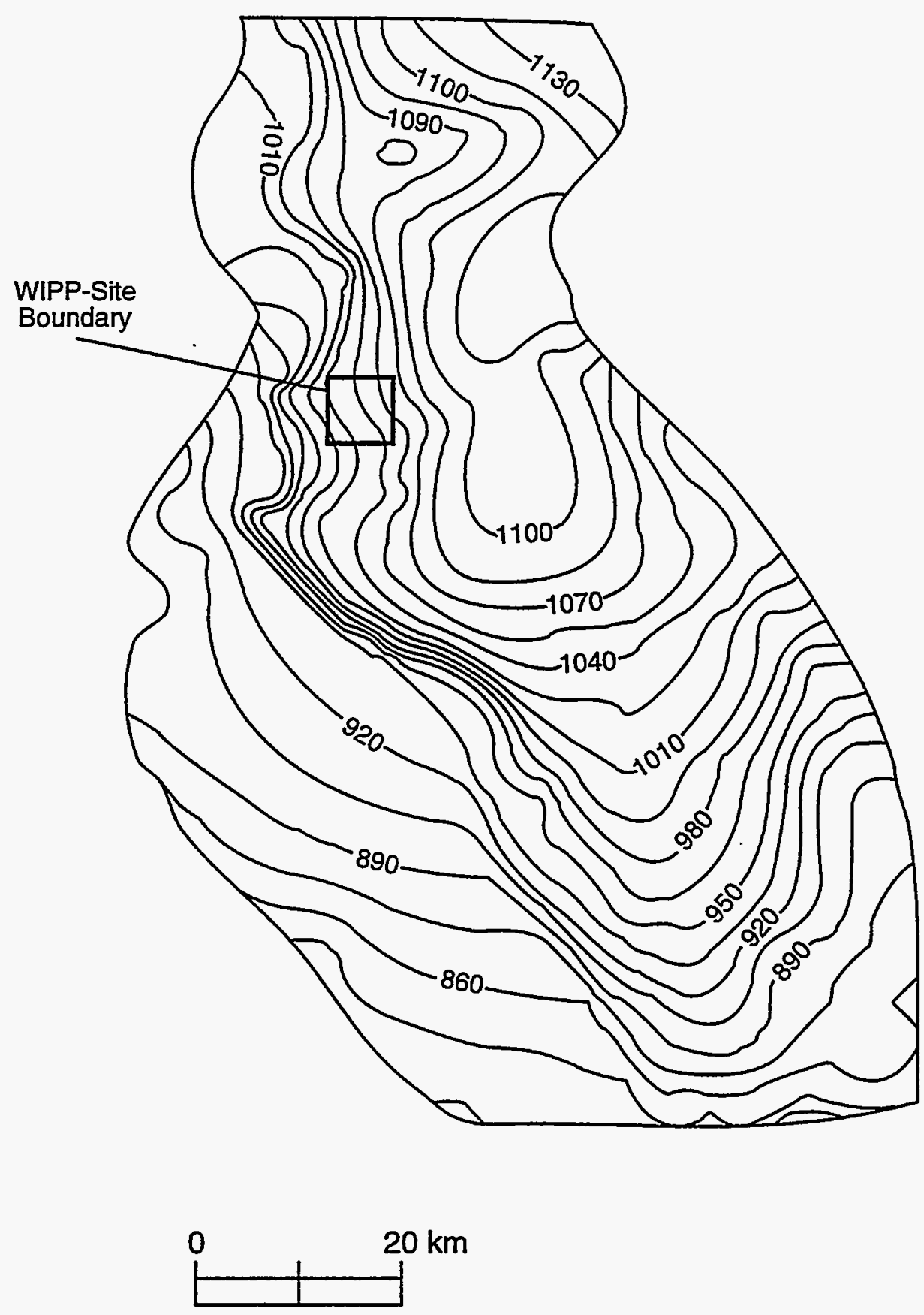

TRI-6115-397-0

Figure 3-34. Elevation of the water table at 14,000 years in the past for the base-case simulation. The contour interval is $15 \mathrm{~m}$. 


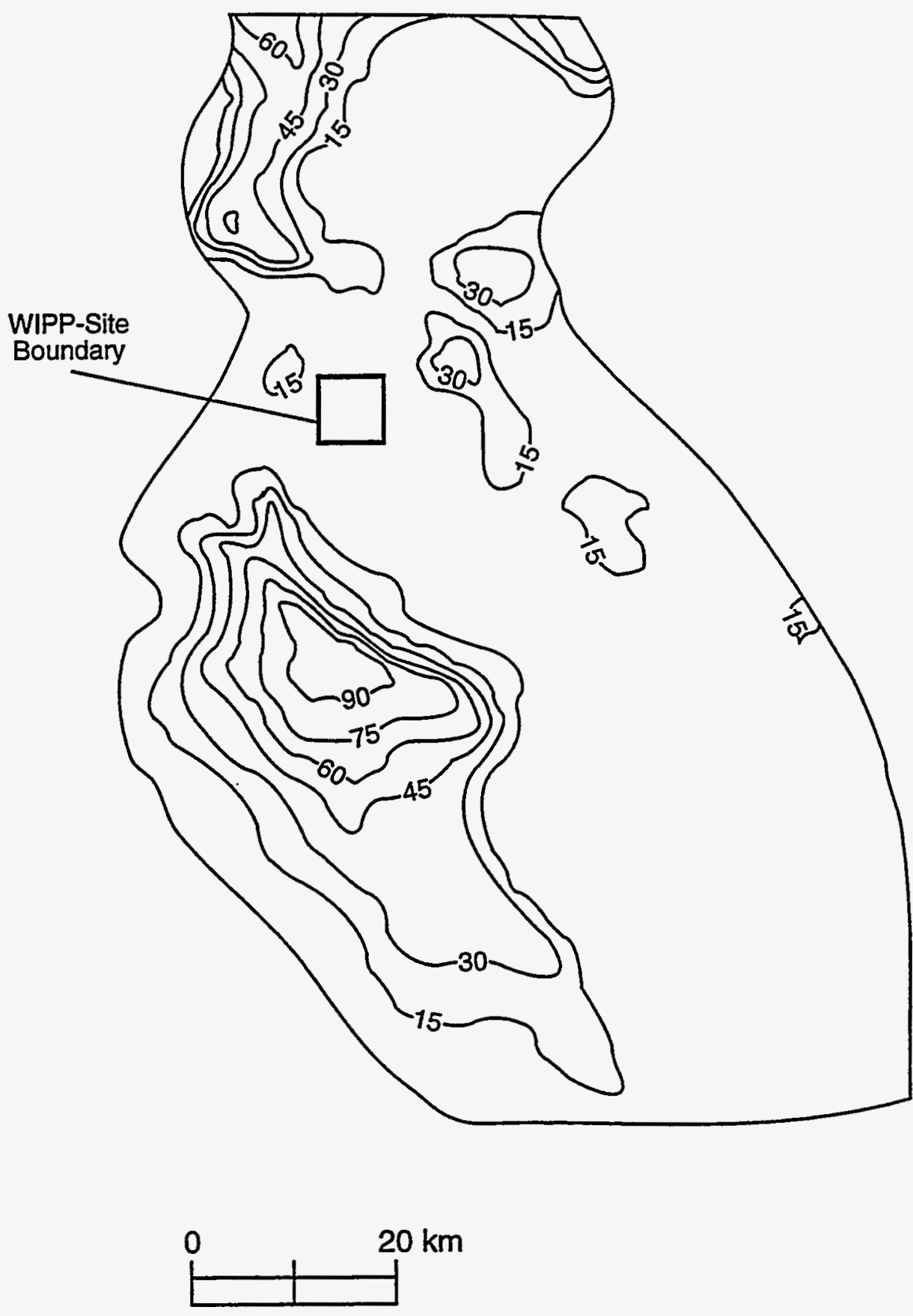

TRI-6115-398-0

Figure 3-35. Depth to the water table at 14,000 years in the past for the base-case simulation. The contour interval is $15 \mathrm{~m}$. 

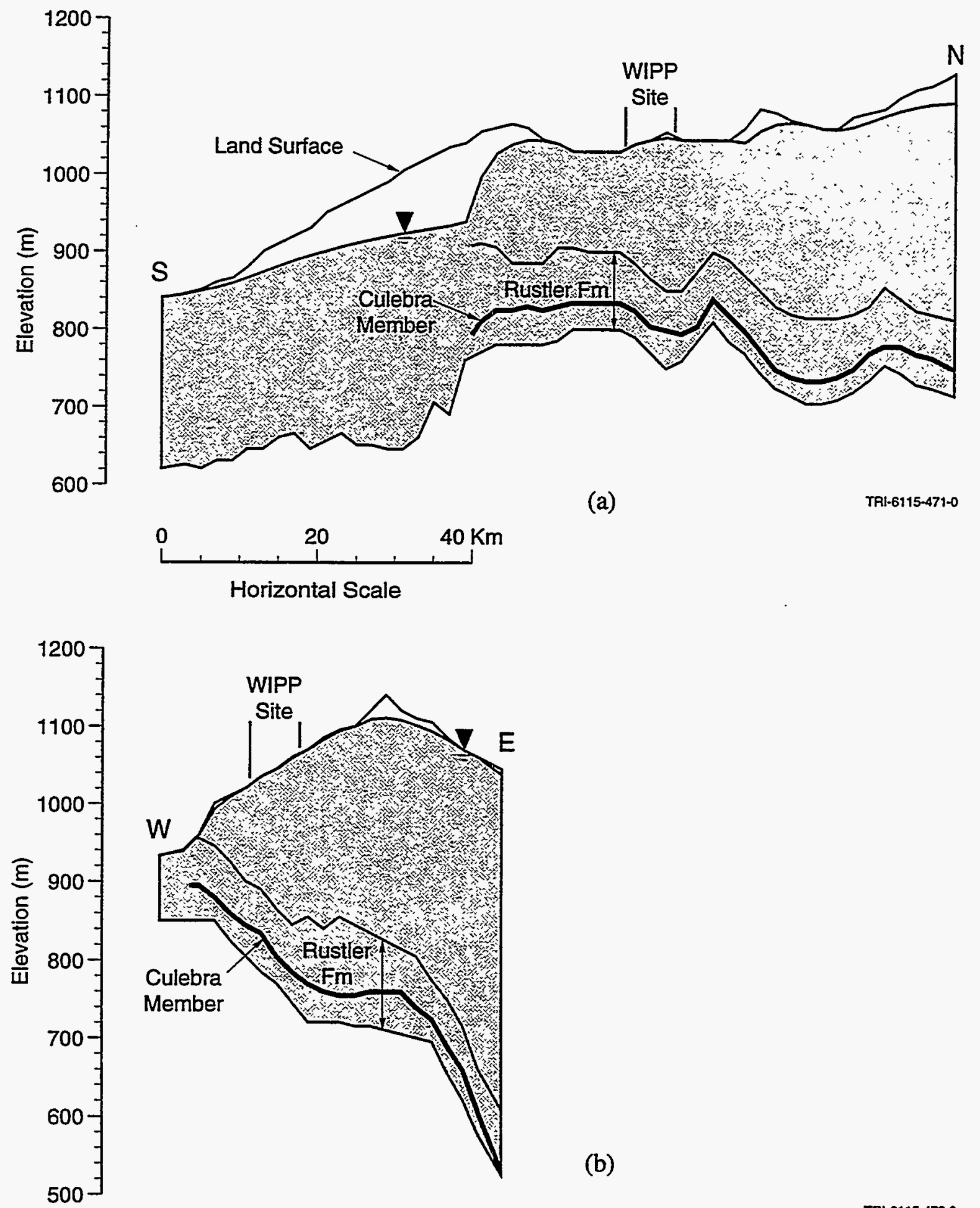

(b)

Figure 3-36. Vertical cross-sections showing the land surface and the water table at 14,000 years in the past for the base-case simulation. The sections pass through the center of the WIPP site and are oriented in a north-south direction (a) or an east-west direction (b). 
Comparison of the distribution of hydraulic head in the Culebra (Figure 37) with the water table (Figure 3-31) shows that the Culebra potentiometric surface is a subdued replica of the water table. The influence of the water table is apparent at depth even though there are strata with extremely low hydraulic conductivity between the Culebra and the water table. Figure 3-38 shows the simulated velocity of lateral flow in the Culebra. Flow directions are controlled by intermediate scale features of the land surface topography. A flow divide follows the ridge line of high topography orientated approximately north-south. Flow is directed toward the topographically low areas that occur along most of the east, south, and west boundaries of the model domain. Flow in the vicinity of the WIPP site is westward toward Nash Draw. The magnitude of flow is controlled primarily by the distribution of hydraulic conductivity. Specific discharges are greater than a tenth of a meter per year only in the disrupted zone.

After 14,000 years of simulated time, the water table has dropped by more than $75 \mathrm{~m}$ over most of the model domain due to the decrease in recharge. Figure 3-39(a) and (b) are profiles along the same lines as Figures 3-36(a) and (b). Comparison of the corresponding figures indicates that the decline of the water table is greatest under areas of high topography. These figures illustrate an important aspect of groundwater basins. As the water tables drops to lower elevations, it becomes smoother because it no longer follows the local scale features of the topography. Consequently, as the water table drops, groundwater flow directions at depth increasingly reflect regional rather than local features of the topography.

Figure 3-40 shows the simulated distribution of hydraulic head in the Culebra at the present time. Comparison with the head at 14,000 years ago (Figure 3-37) confirms that in response to the change in the water table, the Culebra potentiometric surface is also smoother and at a lower elevation. Two closed regions (local maxima) of hydraulic head greater than $1025 \mathrm{~m}$ located northeast and southeast of the WIPP site illustrate an important feature of transient flow in groundwater basins. That is, disequilibrium flow conditions can occur in regions where the rocks have a low hydraulic diffusivity. These regions do not correspond to features on the water table and are not in equilibrium with the water table. These local highs in the potentiometric surface occur because groundwater flow away from these regions is too slow to decrease fluid pressures fast enough to remain in equilibrium with the falling water table. These regions correspond to areas of assumed extremely low hydraulic conductivity due to the presence of halite in the overlying Tamarisk member (Figure 2-7). 


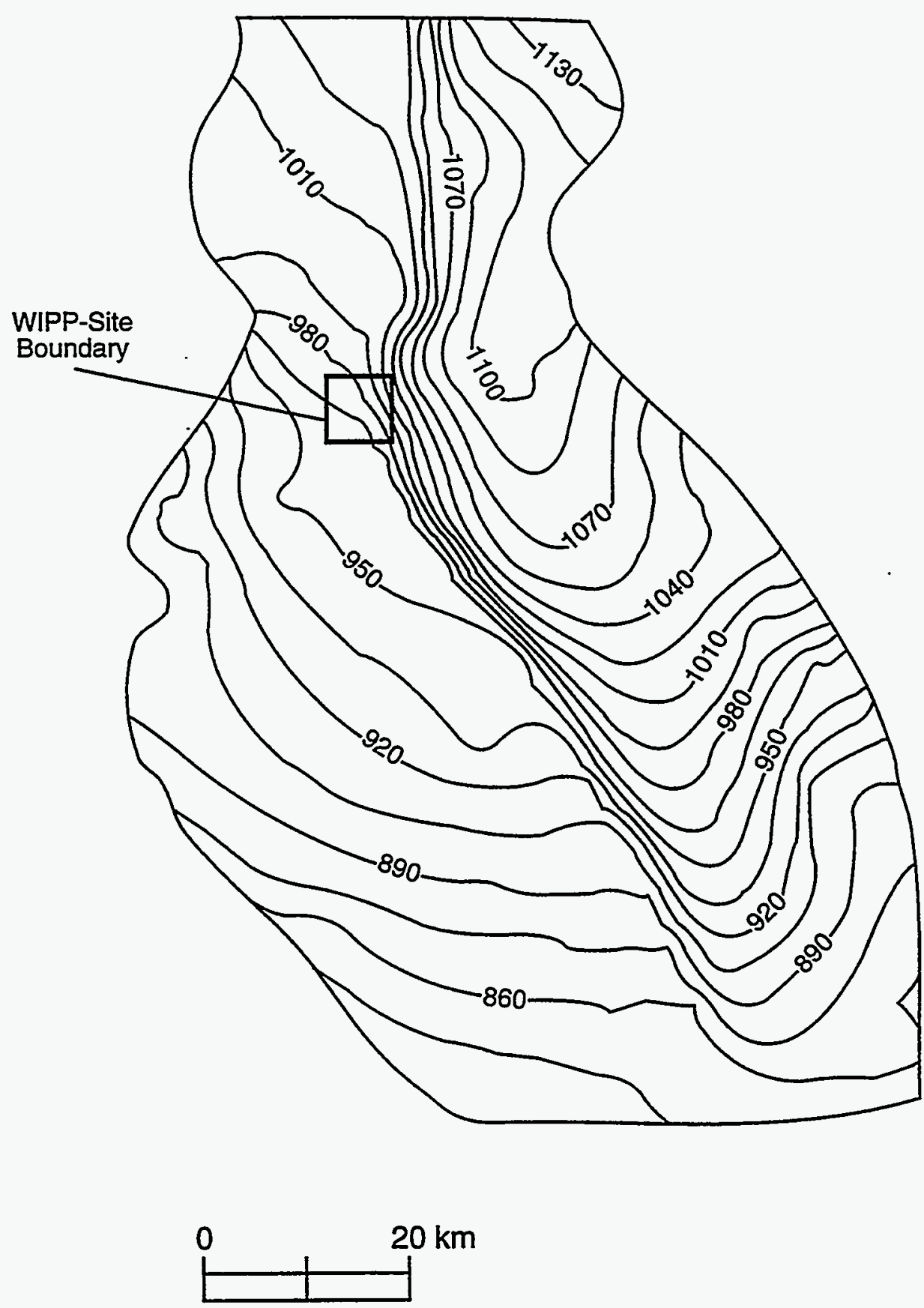

TRI-6115-399-0

Figure 3-37. Head distribution in the Culebra at 14,000 years in the past for the base-case simulation. The contour interval is $15 \mathrm{~m}$. 

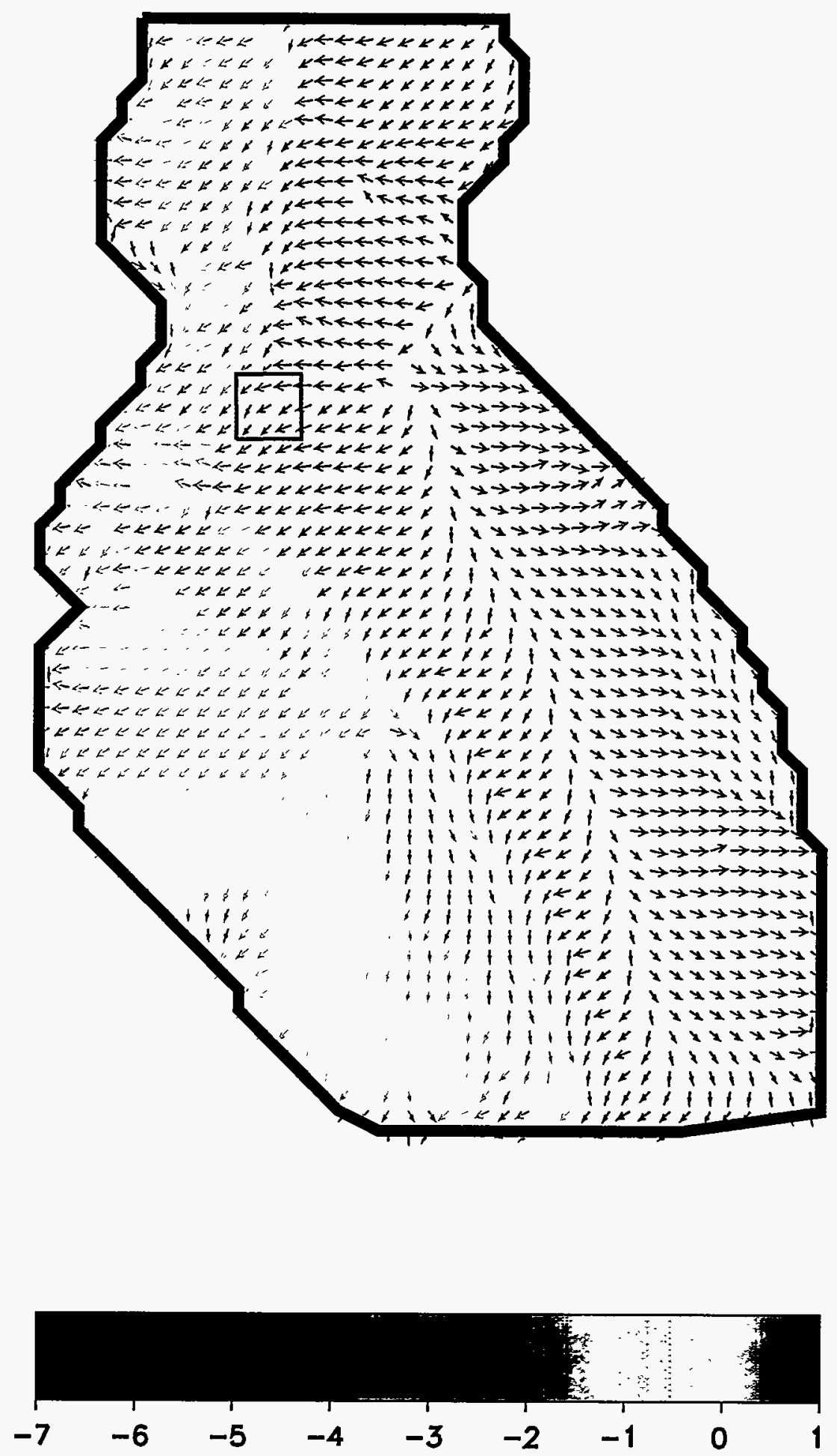

Figure 3-38. Lateral specific discharge in the Culebra at 14,000 years in the past for the base-case simulation. Colors represent the $\log$ of the magnitude of flow in $\mathrm{m} / \mathrm{yr}$. 

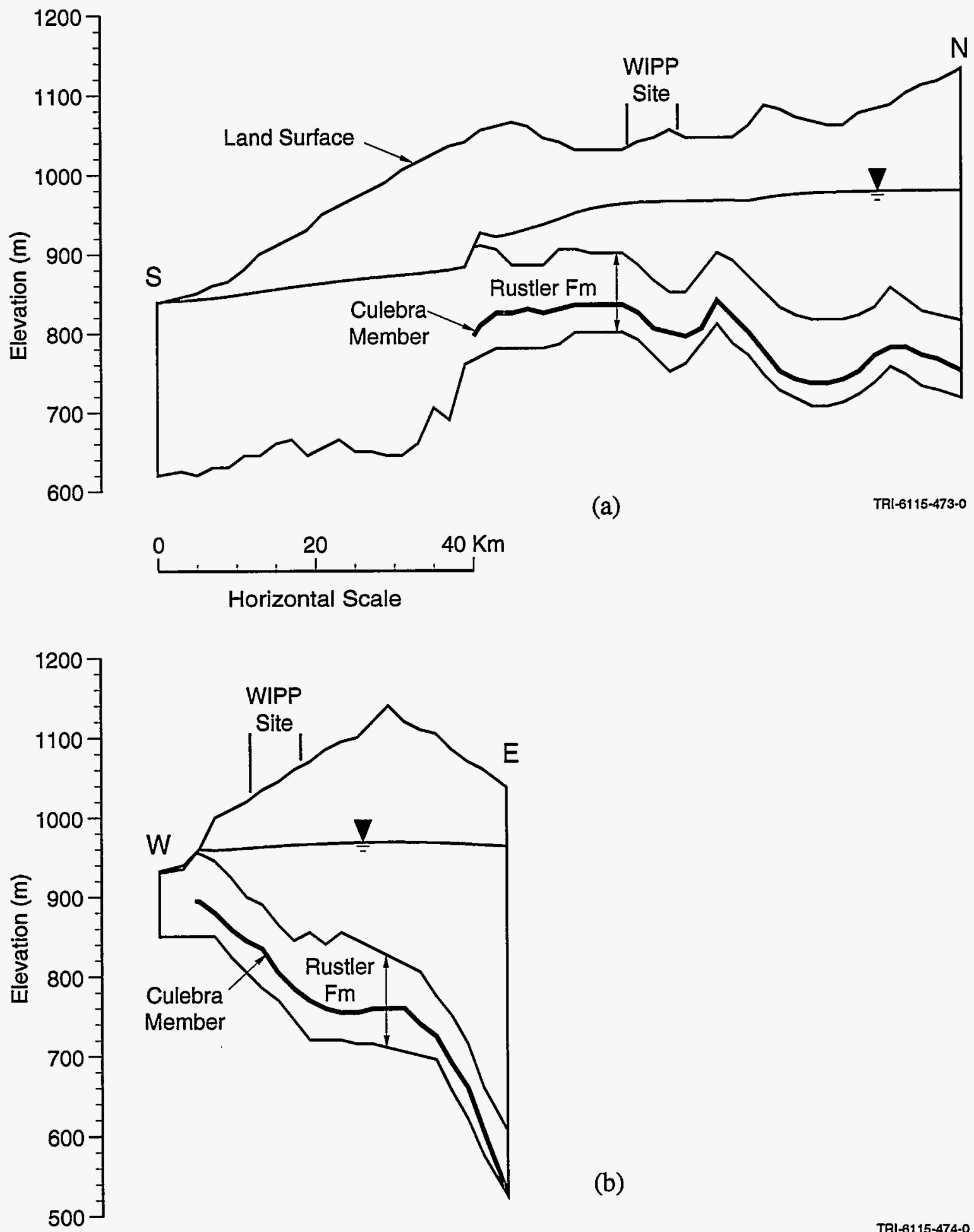

(b)

TRI-81 15-474-0

Figure 3-39. Vertical cross-sections showing the land surface and the water table at the present time for the base-case simulation. The sections pass through the center of the WIPP site and are oriented in a north-south direction (a) or an east-west direction (b). 


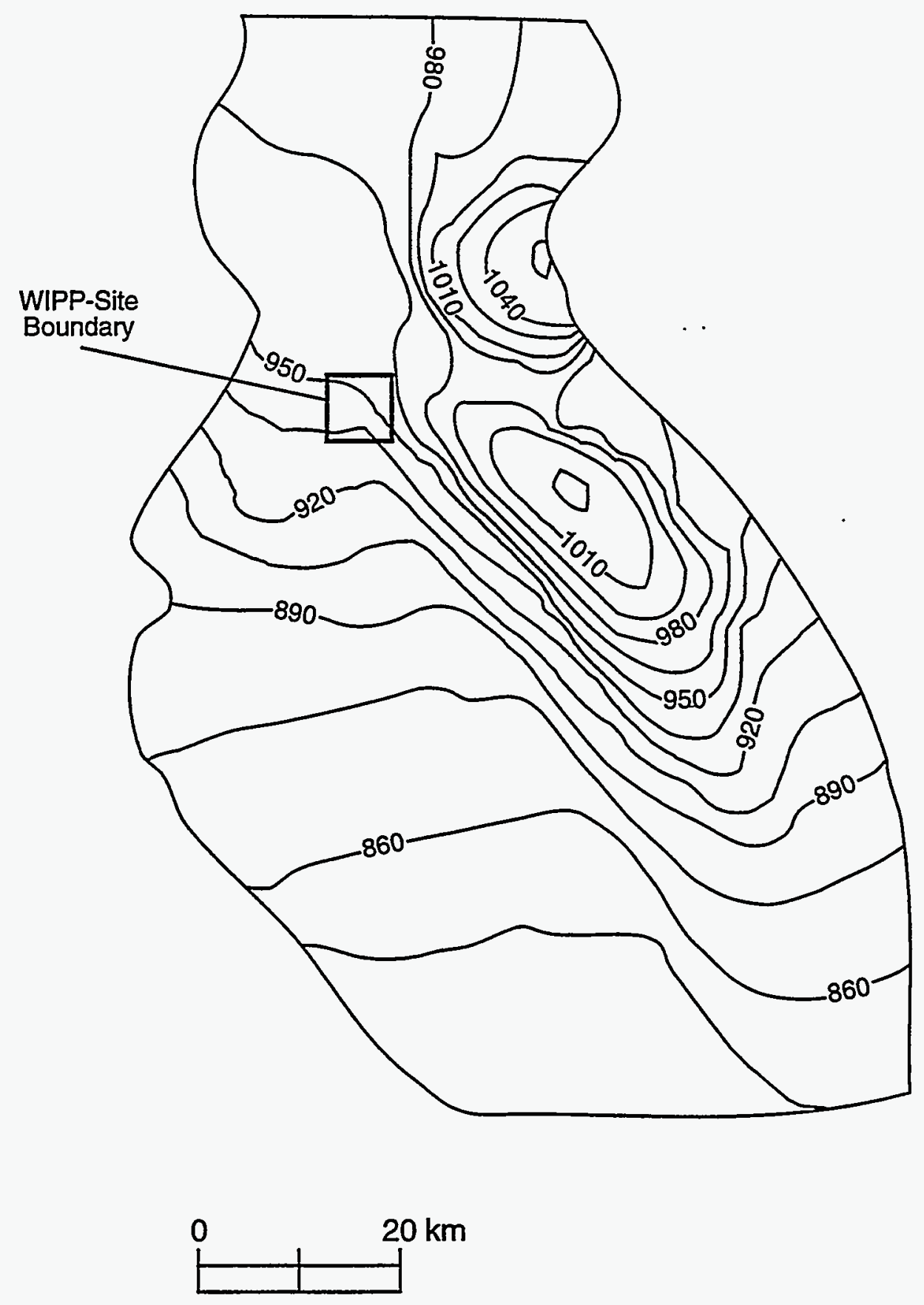

TRI-6115-395-0

Figure 3-40. Head distribution in the Culebra at the present time for the base-case simulation. The contour interval is $15 \mathrm{~m}$. 
Flow velocities in the Culebra at the present time (Figure 3-41) differ from the initial conditions primarily within the regions in which the hydraulic conductivity has been modified by processes related to the formation of Nash Draw. At the higher recharge, flow in the disrupted zone is directed toward Nash Draw and the Pecos River. At lower recharge, flow in the disrupted zone is directed approximately parallel to these features and toward downstream portions of the Pecos River along the southern boundary of the model. Simulated flow away from the WIPP site is toward the south at the present time rather than toward the west as it was at the start of the simulation. This simulation is consistent with the present-day observed direction of flow away from the WIPP site.

Figures 3-42 through 3-44 show the simulated position of the water table and Culebra flow conditions at 10,000 years in the future assuming the step recharge pattern. The water table is higher than at the simulated present time but is still far below the land surface. The Culebra potentiometric surface is also at a somewhat higher elevation and the closed areas of high potential have dissipated. Consequently, the main change in flow velocities in the Culebra over the final 10,000 years of the simulation is in the regions previously occupied by the high potentials. Groundwater flow in these regions is no longer directed away from the previous centers of these features.

\subsubsection{RESULTS AT THE SCALE OF THE WIPP SITE}

Figure 3-45 shows the simulated hydraulic head with time in each of the model hydrostratigraphic units near the center of the WIPP site. This graph illustrates several important aspects of the long-term behavior of the hydrologic system. First, the water table (upper-most line) remains level for about 4,200 years after the start of the simulation. The water table does not drop even though the rate of potential recharge decreased over this time because over most of the range in change of recharge, the recharge is more than sufficient to maintain the water table at the land surface at WIPP. However, head in the Culebra (lower-most line) decreased from the start of the simulation. This shows that flow in the Culebra responds to changes in the regional-scale flow system caused by the water table dropping faster in other parts of the model domain. Once the water table becomes a free surface at WIPP, heads in all layers begin to decrease more rapidly.

The overall trend over the first 14,000 years of the simulation was a decrease in the elevation of the water table and the heads in all strata. The water table dropped about $80 \mathrm{~m}$ and head in the Culebra dropped about $35 \mathrm{~m}$. This overall trend reflects the decline in the rate of potential recharge from 2.0 to 

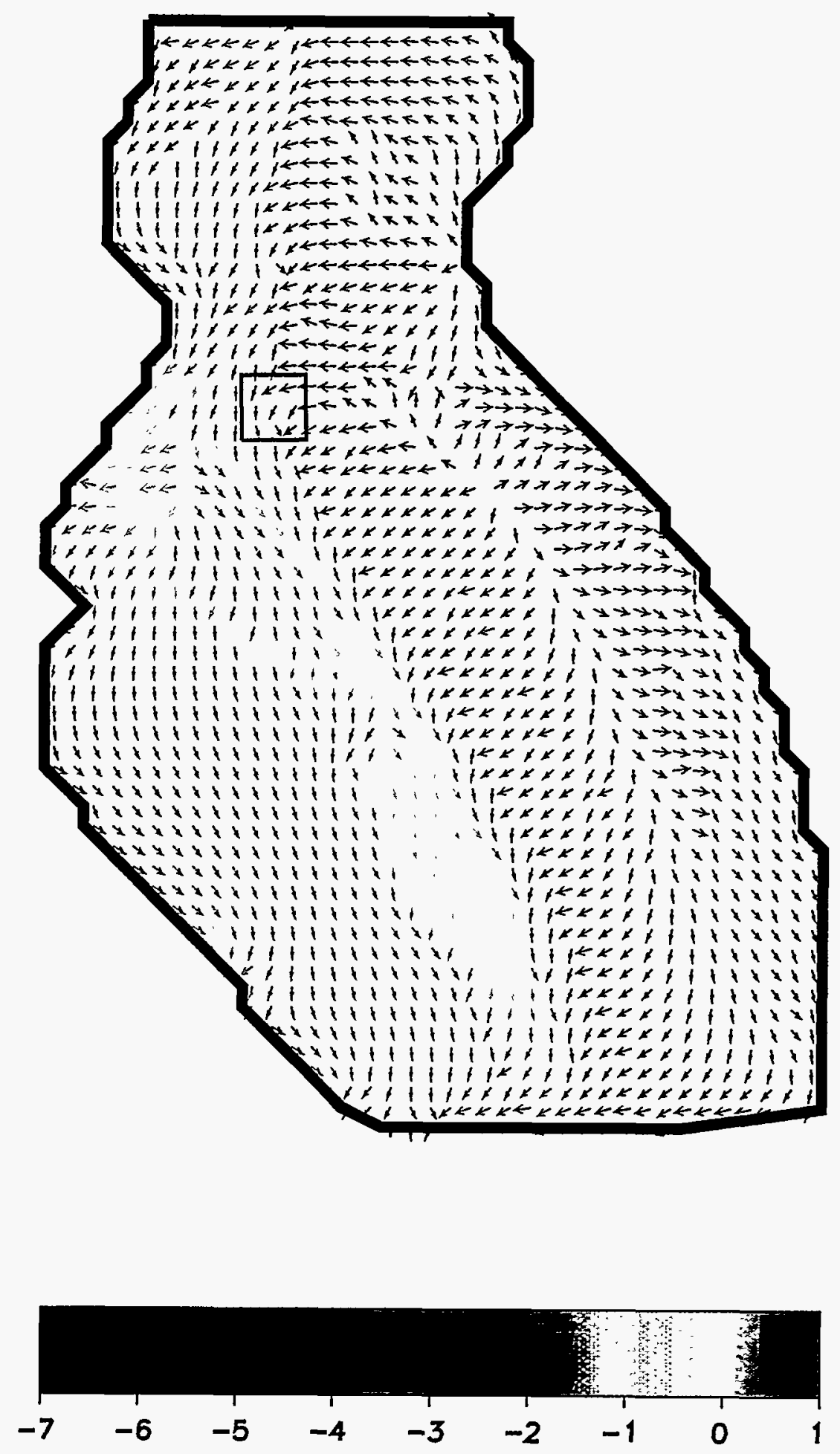

Figure 3-41. Lateral specific discharge in the Culebra at the present time for the base-case simulation. Colors represent the $\log$ of the magnitude of flow in $\mathrm{m} / \mathrm{yr}$. 

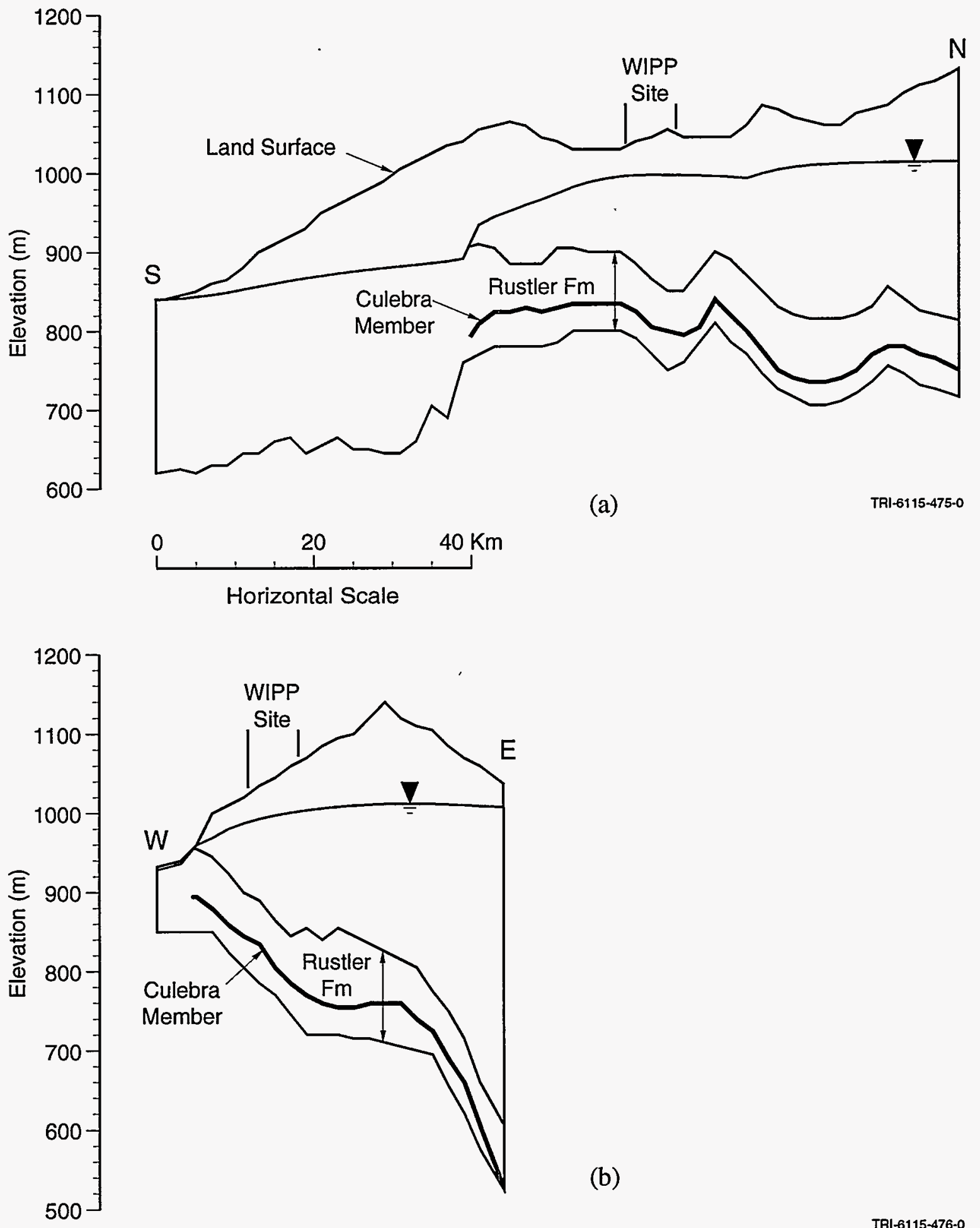

(b)

TRI-6115-476-0

Figure 3-42. Vertical cross-sections showing the land surface and the water table at 10,000 years in the future for the base-case simulation. The sections pass through the center of the WIPP site and are oriented in a north-south direction (a) or an east-west direction (b). 


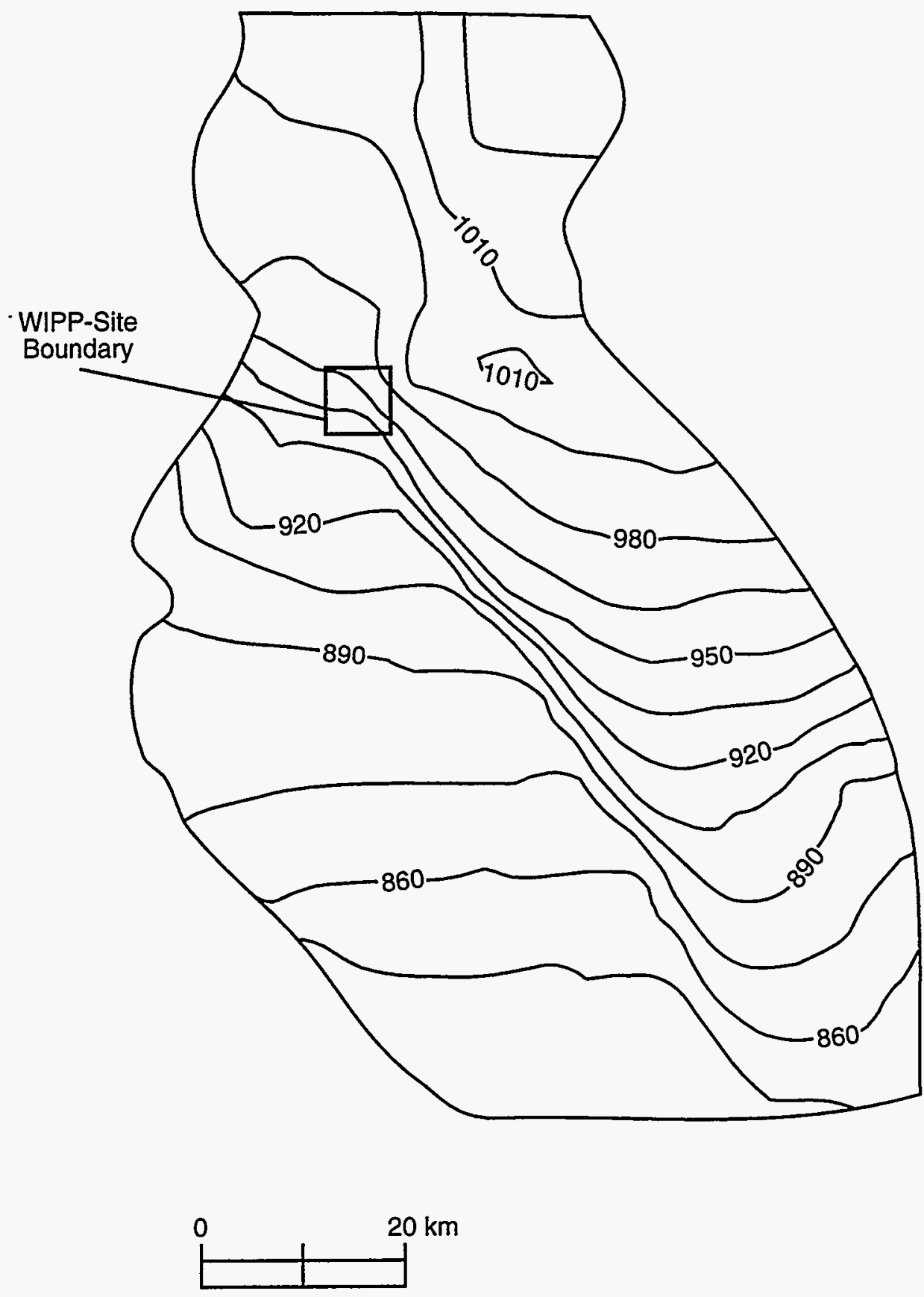

TRI-6115-394-0

Figure 3-43. Head distribution in the Culebra at 10,000 years in the future for the base-case simulation. The contour interval is $15 \mathrm{~m}$. 

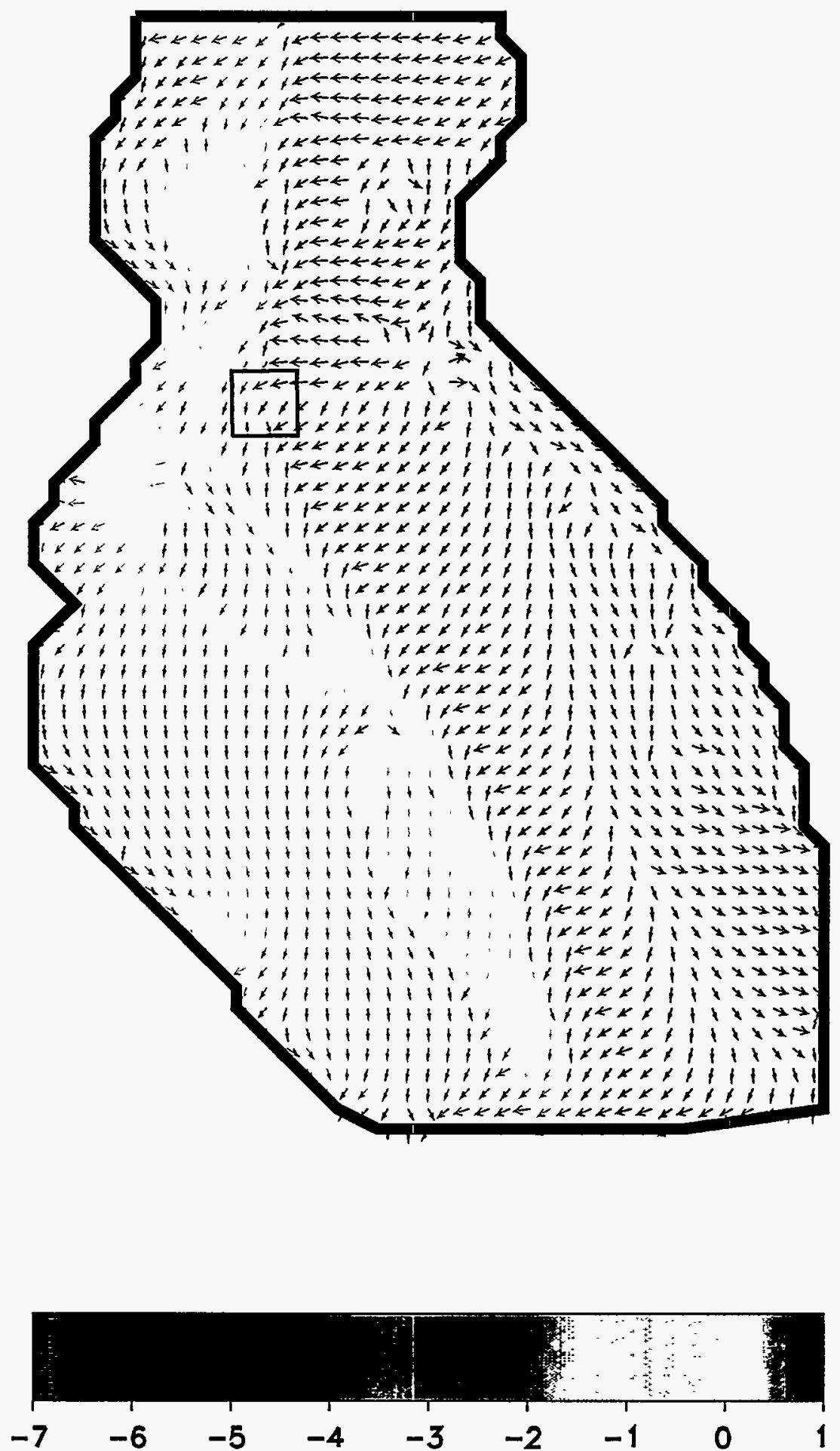

Figure 3-44. Lateral specific discharge in the Culebra at 10,000 years in the future for the base-case simulation. Colors represent the log of the magnitude of flow in $\mathrm{m} / \mathrm{yr}$. 


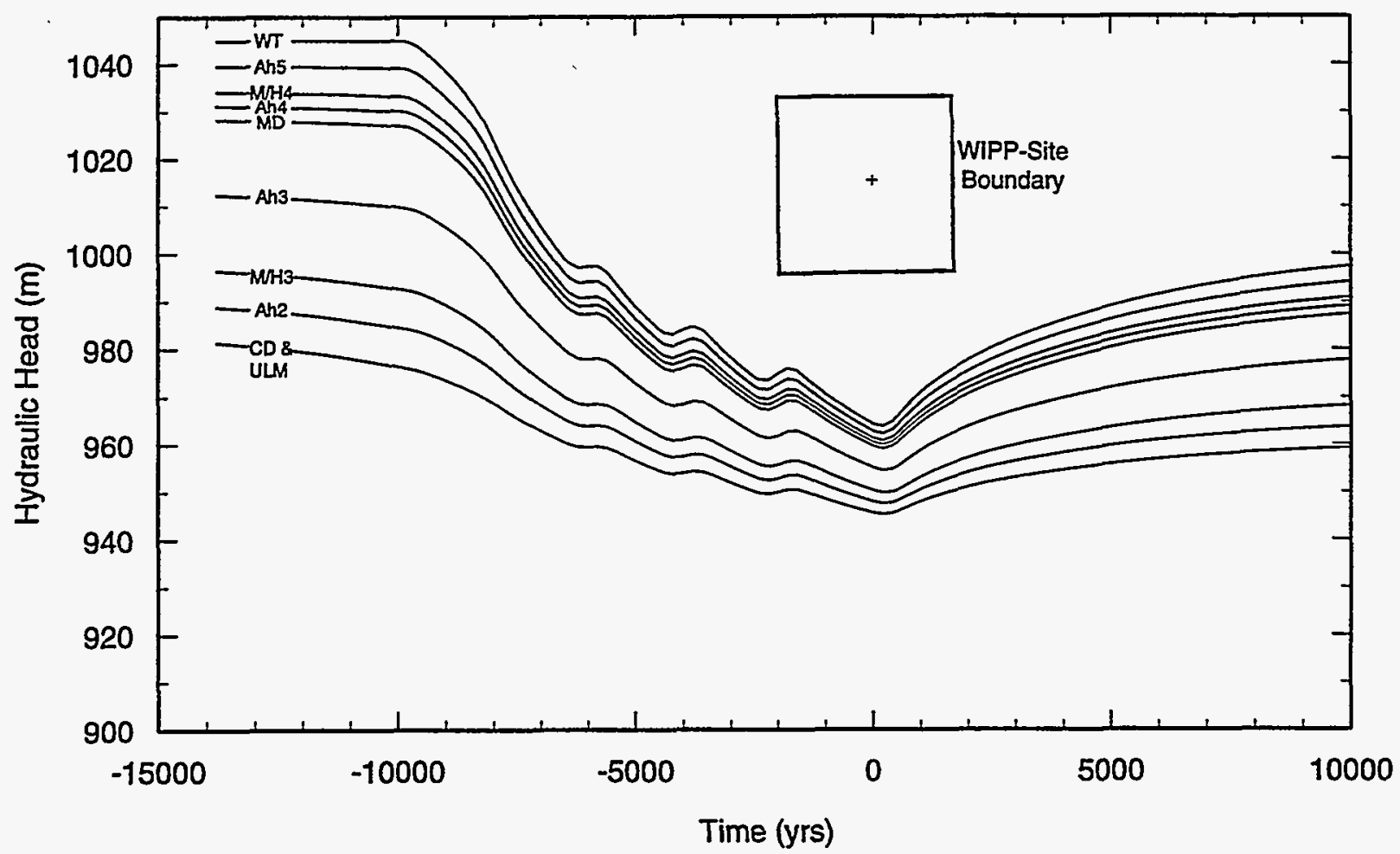

TRI-6115-465-0

Figure 3-45. Elevation of the water table (WT) and head in each hydrostratigraphic unit near the center of the WIPP site versus time for the base-case simulation. The maximum Holocene recharge rate is $0.2 \mathrm{~mm} / \mathrm{yr}$ and the step recharge pattern is used.

$0.0 \mathrm{~mm} / \mathrm{yr}$ over the first 6,000 years of the simulation. Superimposed on the trend are short-term increases in heads that correspond to the periodic increases in potential recharge. The peaks of head increases lag about 300 years behind the corresponding peaks on the recharge function.

Heads increase continuously after the simulated present time. This increase represents the flow system's attempt to equilibrate with a recharge rate of $0.2 \mathrm{~mm} / \mathrm{yr}$ that was assumed to occur for the simulated time period between 500 and 10,000 years in the future. Heads are still increasing at the end of the simulation. Given sufficient time, these heads would reach the equilibrium elevations of steadystate simulation 14 .

We performed mass balances over the reference volumes (defined in the introduction to Section 3) of the more conductive layers. This was accomplished by summing the flow across each face of the reference volumes in order to calculate total flow through each reference volume, as well as the proportions of lateral and vertical inflow and outflow from the reference volumes. 
Figure 3-46 shows how the mass balance for the Dewey Lake/Triassic reference volume varies over the course of the simulation. Positive flow rates represent inflow to the reference volume and negative numbers represent outflow. The uppermost and lowermost lines represent the total inflow and outflow respectively. These lines are nearly symmetrical about the zero flow axis; small differences in the absolute magnitudes of inflow and outflow (not visible at the scale of these graphs) are equal to the rate of change in water stored in the reference volumes. The other lines on the graph are the flow rates in and out across the water table, the contact with the Rustler Formation, and the vertical faces of the reference volume.

There two main points that are illustrated by Figure 3-46. First, the total flow through the Dewey Lake/Triassic reference volume is quite sensitive to the rate of potential recharge. The total flow at the start of the simulation is more than five times what it is at the end of the simulation. The second point is that the vertical leakage downward into the Rustler Formation is much less sensitive to the recharge rate and is a small fraction of the total outflow from the Dewey Lake/Triassic reference volume. This second point is important because vertical leakage from the Dewey Lake/Triassic rocks is, in these simulations, the source of all the water that flows through the intact portion of Rustler. ${ }^{3}$ It is important to note that the outflow across the water table is zero after 10,500 years ago. After this time, the water table is below the land surface in the vicinity of the WIPP site and consequently no groundwater discharge is possible. Also, vertical flow downward across the water table and lateral flow contribute about equally to the total inflow to the Dewey Lake/Triassic reference volume at all times in the simulation.

Figures 3-47 and 3-48 show the mass balance for the Magenta and the Culebra. The lines on these graphs represent the same information as in the graph for the Dewey Lake/Triassic rocks except that inflow and outflow is provided for the upper surface of each formation rather than the water table. Note that the scale for the vertical axis of these figures is different from that used for the Dewey Lake/Triassic rocks. These figures show that the flow through the Magenta and the Culebra is much less sensitive to changes in the recharge rate. This suggests that even though hydraulic heads are quite sensitive to recharge rates (Figure 3-45), gradients of head are not. These figures also show, for example, that nearly all the inflow to the Magenta reference volume is vertical leakage from the overlying Dewey Lake/Triassic rocks and that all of the outflow from the Culebra reference volume is by lateral flow within the Culebra.

\footnotetext{
3 Because the lateral boundaries of the numerical model are impervious to flow, all inflow to the intact portion of the Rustler Formation must be either vertical leakage from the Dewey Lake Formation or lateral flow from the disrupted zone. However, little or no flow from the disrupted zone to the Rustler occurs in these simulations. This is because the disrupted zone is a region of relatively high hydraulic conductivity which acts as a drain for the rest of the model domain.
} 


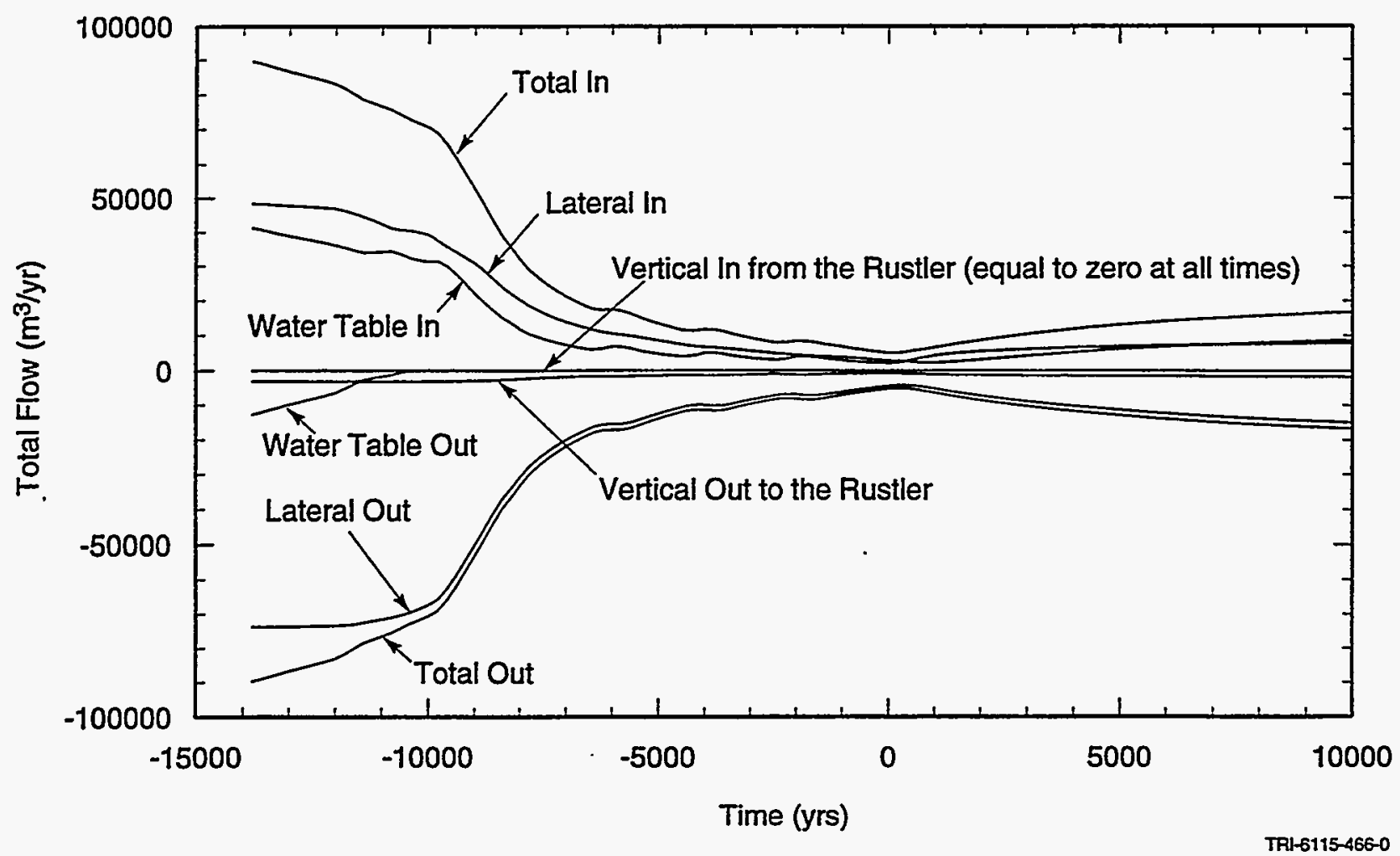

Figure 3-46. Mass balance for the Dewey Lake/Triassic reference volume versus time for the base-case simulation. The uppermost and lowermost lines represent the total inflow and outflow respectively. The other lines are the inflow and outflow across the water table, the contact with the Rustler Formation, and the vertical faces of the reference volume. Positive flow rates represent inflow to the reference volume. The vertical scale of this figure covers a range that is ten times greater than that of the following two figures.

Figures such as $3-46,3-47$, and $3-48$ provide a clear overview of the mass balance but are difficult to interpret quantitatively. To complement these figures, we have included tables in Appendix D that summarize the mass balance data at two simulated times: at the present time (zero years) and at 10,000 years into the future. The total inflow to the Dewey Lake/Triassic rocks, Magenta, and Culebra reference volumes at the simulated present time are 5015, 784, and 2100 cubic meters per year (base case in Table D-1). The inflow rates for these units at 10,000 years are somewhat larger: 16738 , 1736, and 3354 cubic meters per year (base case in Table D-4). These numbers show that, in this simulation, most of the flow occurs in the Dewey Lake/Triassic rocks and that more flow occurs in the Culebra than the Magenta. 


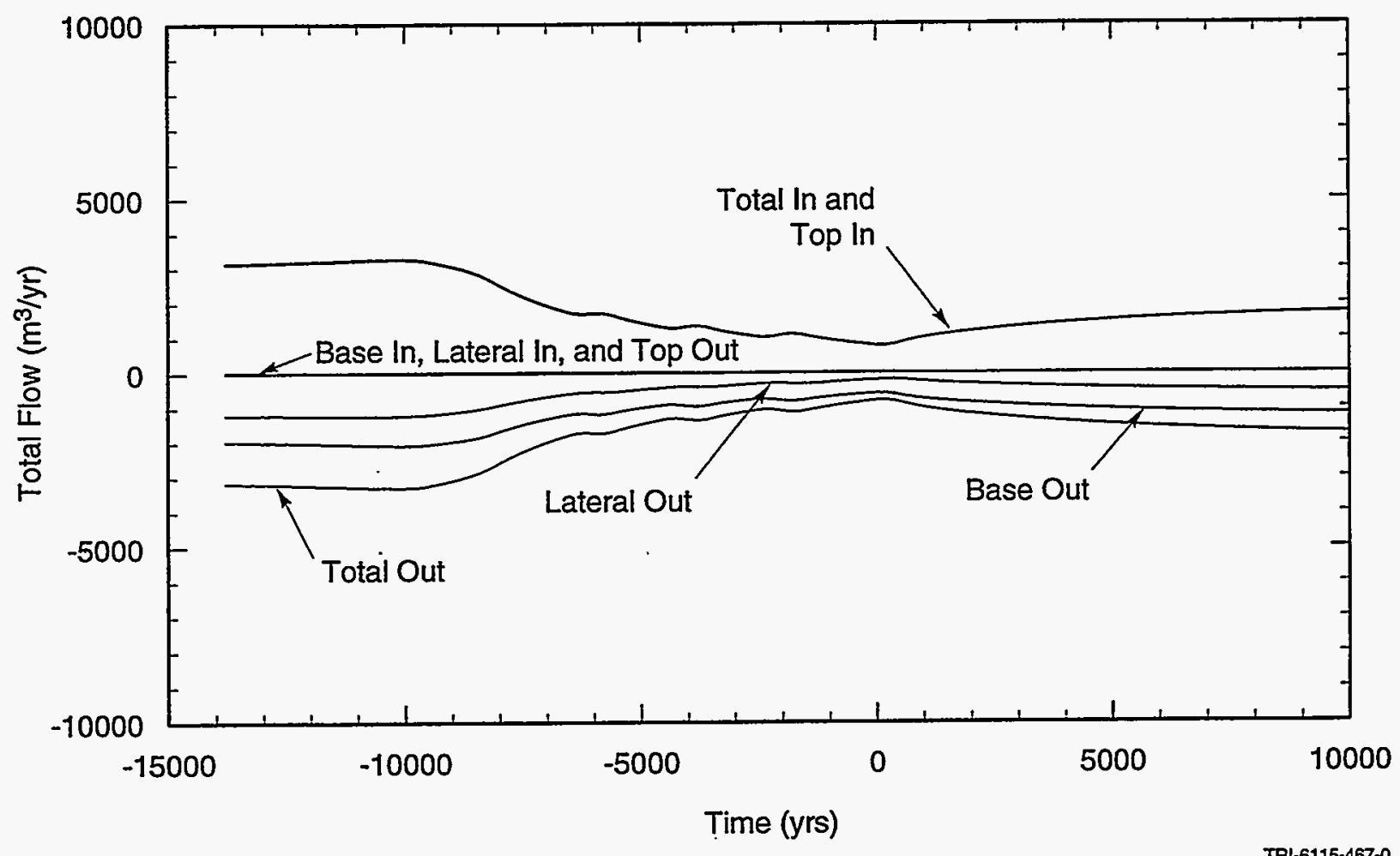

Figure 3-47. Mass balance for the Magenta reference volume versus time for the base-case simulation. The uppermost and lowermost lines represent the total inflow and outflow respectively. The other lines are the inflow and outflow across the top, base, and vertical faces of the reference volume.

Table D-2 gives the total flow across the upper surface, lower surface, and sides as a percentage of the total flow through the reference volume at zero years simulation time. For the base-case simulation, $42 \%$ of the inflow to the Dewey Lake/Triassic reference volume is from groundwater recharge (i.e., $42 \%$ of the inflow to the Dewey Lake/Triassic rocks is across the top). Zero percent of the inflow to the Dewey Lake/Triassic is from upward vertical leakage. In fact, an important aspect of all of the transient simulations performed for this study is that the vertical flow components are directed downward in all layers within the vicinity of the WIPP site. $98 \%$ of the inflow to the Magenta reference volume is vertical leakage from the Dewey Lake/Triassic and $30 \%$ of the inflow to the Culebra is leakage from the Magenta. All of the outflow from the Culebra reference volume is by lateral flow. Table D-5 provides the same information at 10,000 years.

The rates (Figure 3-49) and directions (Figure 3-50) of lateral flow in the Culebra are also examined. We consider the degree of spatial variability (as represented by the 9 locations), and the 


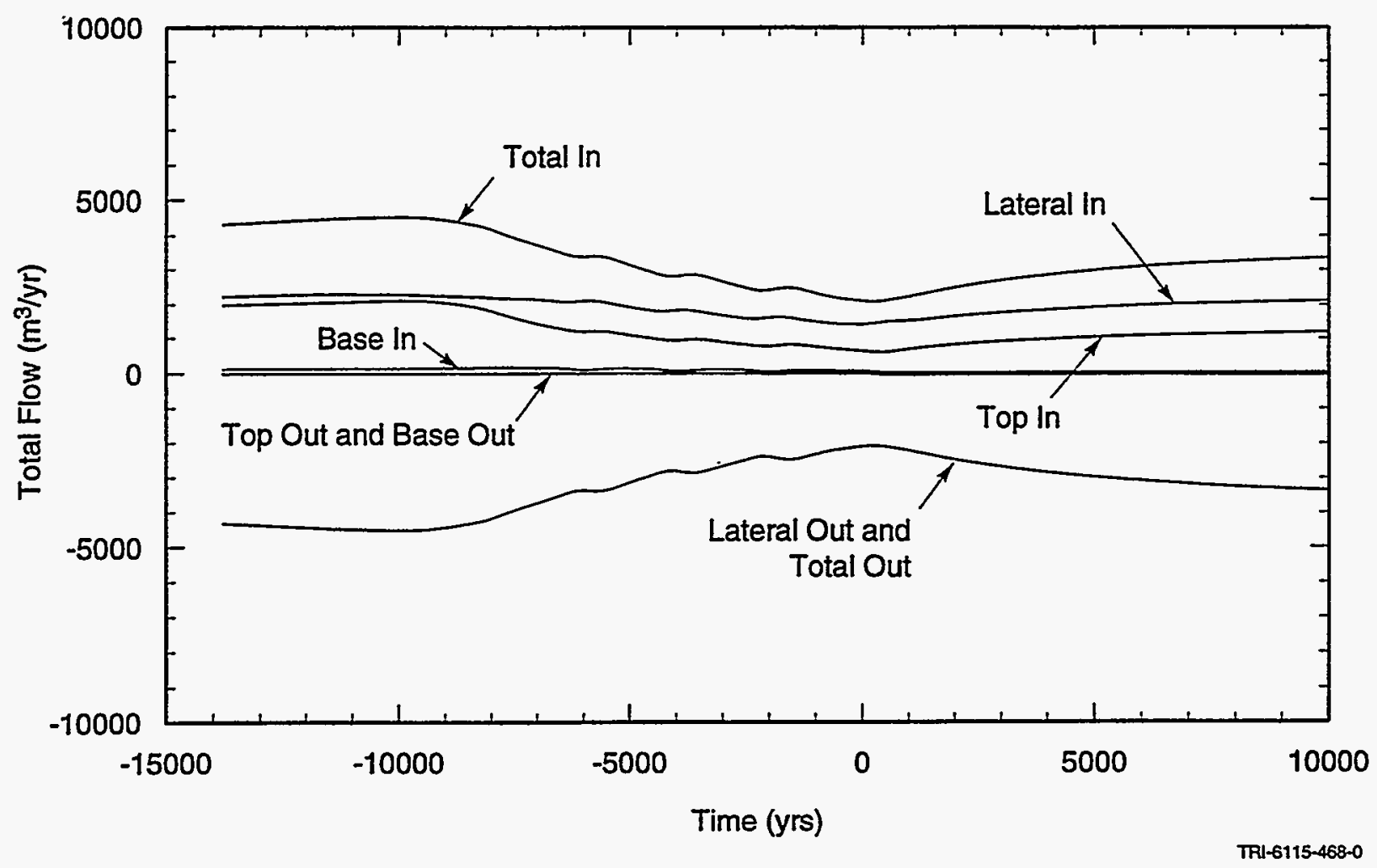

Figure 3-48. Mass balance for the Culebra reference volume versus time for the base-case simulation. The uppermost and lowermost lines represent the total inflow and outflow respectively. The other lines are the inflow and outflow across the top, base, and vertical faces of the reference volume.

temporal variation. After about 8,000 years ago, rates of lateral flow in the Culebra at these locations show a temporal variation that is clearly related to the change in head (Figure 3-45). Previous to that time, the temporal variation is more complex. Flow rates can decrease at one location while increasing at another. The fastest flow reaches rates of $0.145 \mathrm{~m} / \mathrm{yr}$. The maximum temporal variation at a single location is about $.04 \mathrm{~m} / \mathrm{yr}$. This temporal variation is 3.5 times less than the spatial variation.

Flow directions as well as flow rates vary spatially and temporally in these simulations. Figure 3-50 shows the direction of lateral flow in the Culebra. Flow directions range from 150 to 270 degrees east of due north. There is a trend for a slight shift toward the south during times of decreasing recharge and toward the west during times of increasing recharge. Clearly the spatial variation at any time is much larger than the temporal variation at any location. 


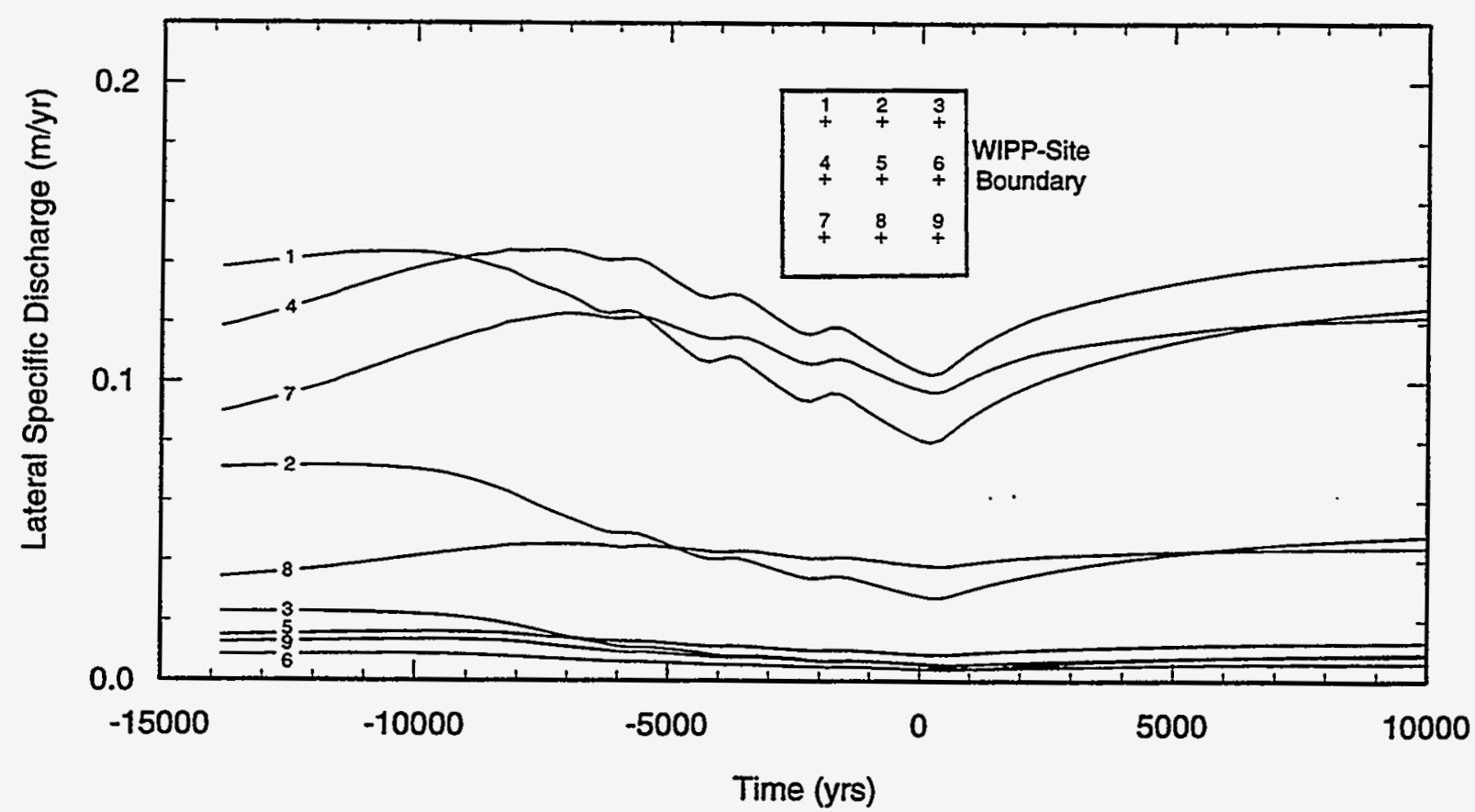

TRI-6115-459-0

Figure 3-49. Lateral specific discharge $(\mathrm{m} / \mathrm{yr})$ in the Culebra versus time for the base-case simulation. Data are for nine locations within the WIPP-site boundary (insert).

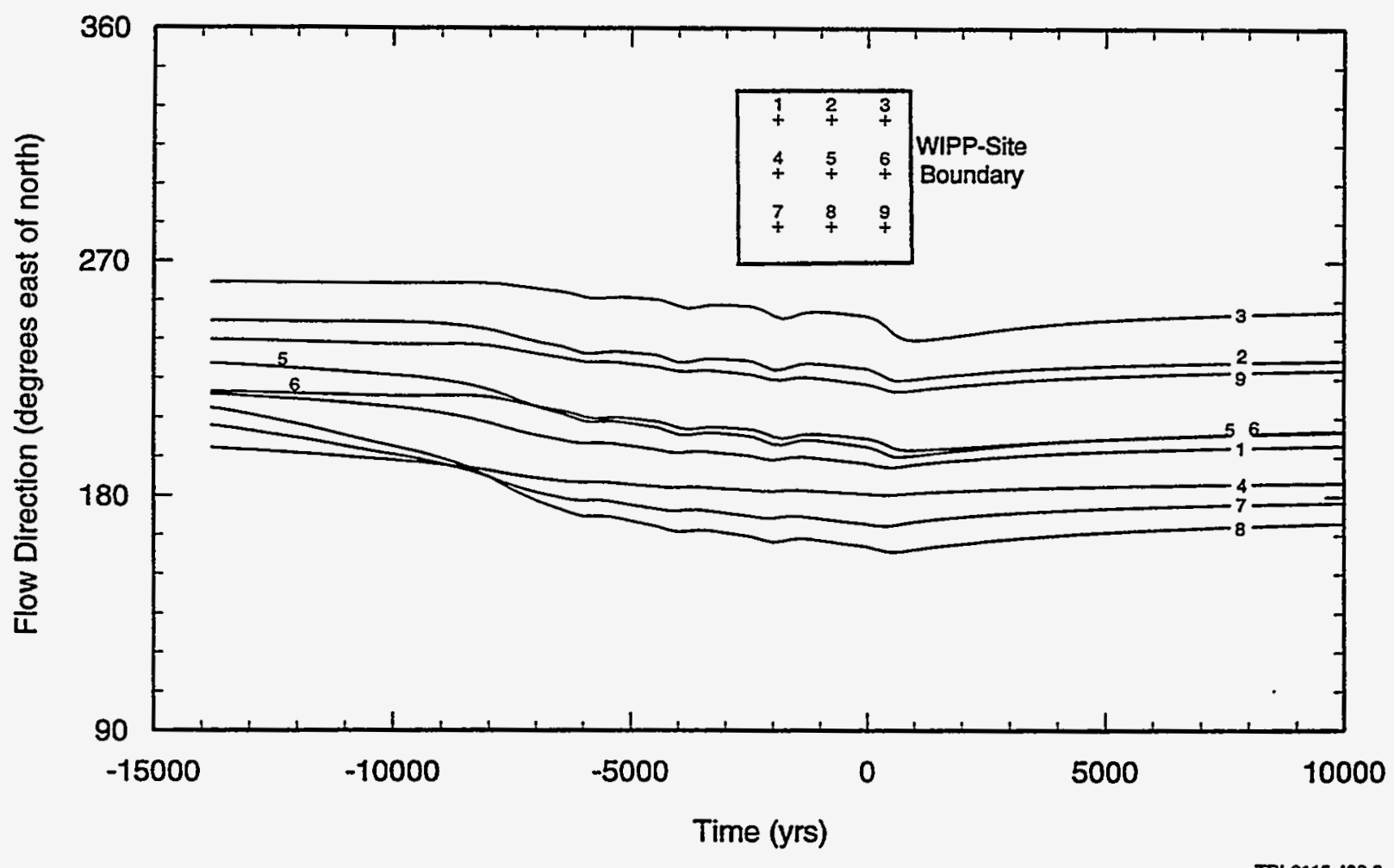

Figure 3-50. Lateral flow direction (degrees east of north) in the Culebra versus time for the base-case simulation. Data are for nine locations within the WIPP-site boundary (insert). 


\subsubsection{Variation of Rock Properties}

We performed six transient simulations (numbers 1 through 6 in Table 3-2) to examine the sensitivity of the simulation results to the assumed values of hydraulic properties. Each of these simulations differs from the base case only in the value of one hydraulic property.

\subsubsection{TRANSIENT SIMULATION 1: REDUCED ANHYDRITE CONDUCTIVITY}

This simulation differs from the base-case simulation in that the hydraulic conductivity of intact anhydrite is reduced by a factor of 10 , to $1 \times 10^{-13} \mathrm{~m} / \mathrm{s}$. This change decreases the amount of vertical leakage into the Culebra but enhances lateral flow in this unit.

The change in head with time in this simulation (Figure 3-51) is similar to that of the base case (Figure 3-45) except that the water table is about $5 \mathrm{~m}$ higher and the head in the Culebra is about $5 \mathrm{~m}$ lower. Therefore an additional 10 meters of head difference are available to drive vertical leakage.

The rate of vertical leakage is less, however, because the steeper vertical gradients are not sufficient to make up for the lower conductivity of the anhydrites. Consequently, the base-case ratios (defined in the intrduction to Section 3.2) for vertical leakage into the tops of the Magenta and Culebra at the simulated present time are 0.28 and 0.13 respectively. The lateral flow into the Culebra is increased by a factor of 1.5 . These relative changes in inflow to the Culebra reference volume approximately cancel each other so that the lateral outflow from the Culebra is very close to that of the base case.

Comparison of Figures 3-52 and 3-49 confirms that lateral flow rates in the Culebra are similar in these two simulations. Culebra flow directions in transient simulation 1 (Figure 3-53) are less sensitive to changes in recharge and are shifted slightly to the south as compared to the base case (Figure 3-50). 


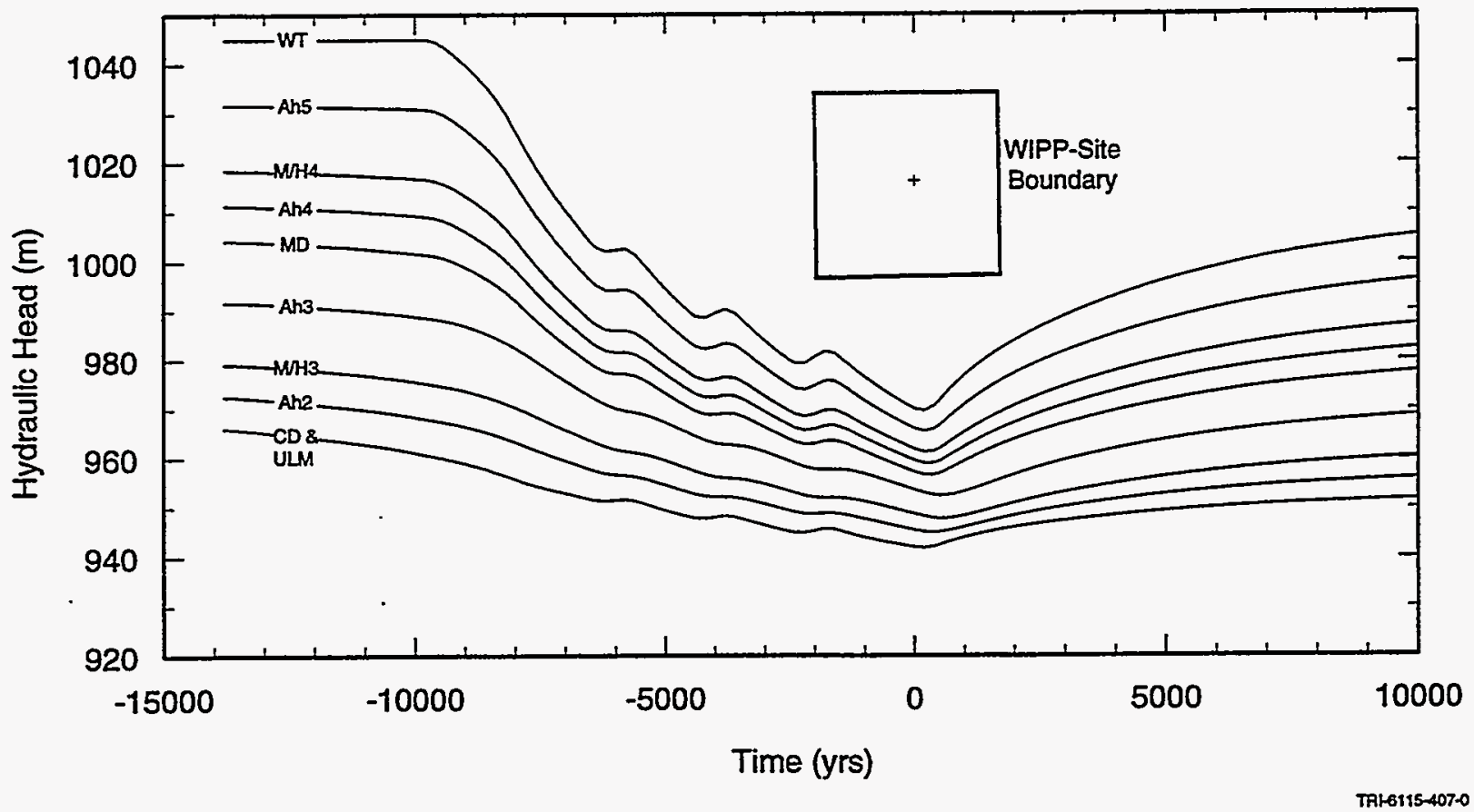

Figure 3-51. Elevation of the water table (WT) and head in each hydrostratigraphic unit near the center of the WIPP site (insert) versus time for transient simulation 1.

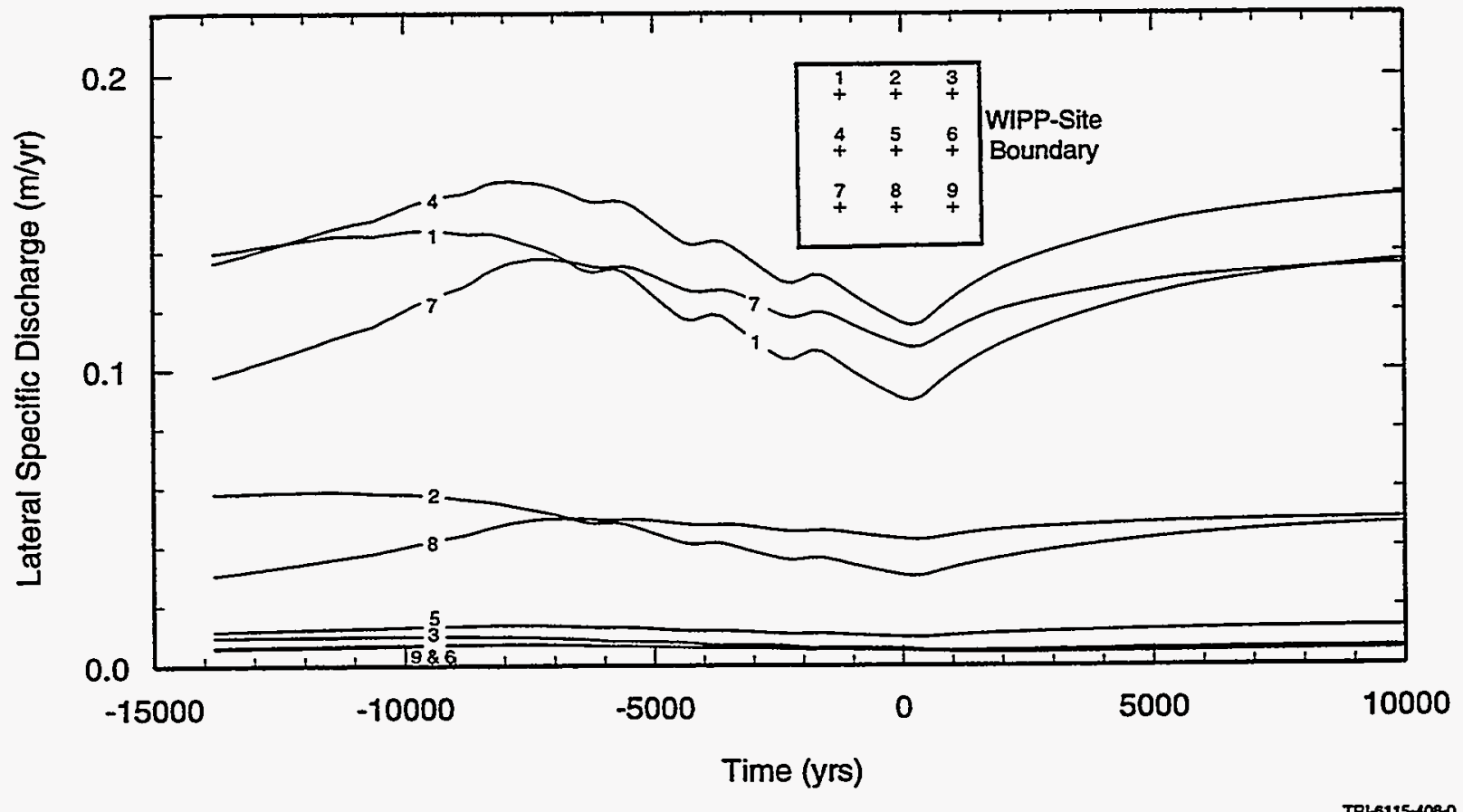

Figure 3-52. Lateral specific discharge $(\mathrm{m} / \mathrm{yr})$ in the Culebra versus time for transient simulation 1. Data are for nine locations within the WIPP-site boundary (insert). 


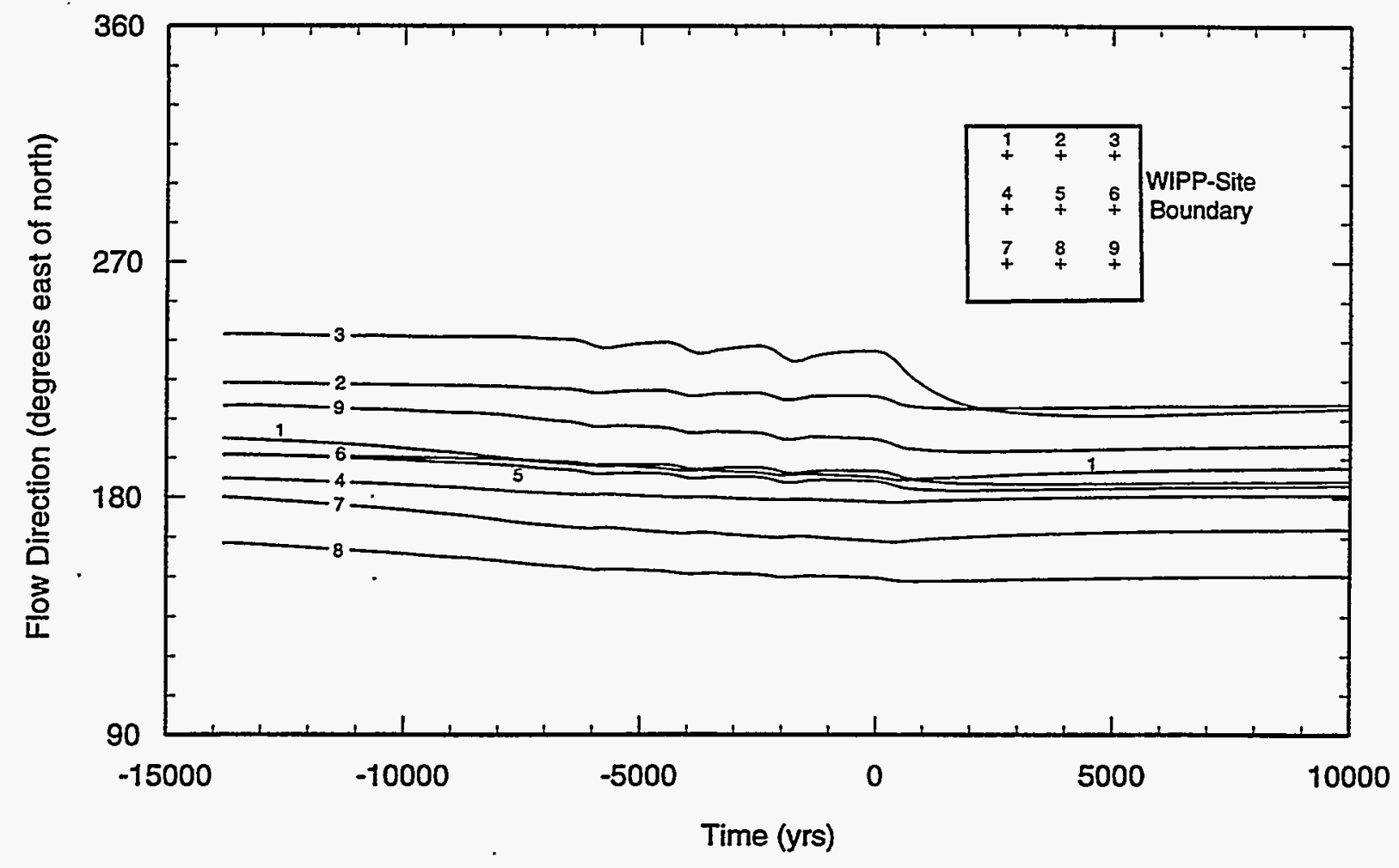

TRI-6115-409-0

Figure 3-53. Lateral flow direction (degrees east of north) in the Culebra versus time for transient simulation 1. Data are for nine locations within the WIPP-site boundary (insert).

\subsubsection{TRANSIENT SIMULATION 2: INCREASED DISRUPTED ZONE CONDUCTIVITY}

This simulation differs from the base case in that the hydraulic conductivity of disrupted region is increased by one order of magnitude, to $1 \times 10^{-4.5} \mathrm{~m} / \mathrm{s}$. The major impact of this change is to lower heads and flatten gradients in the distupted region. Consequently, the water table and heads are lowered in all units relative to the base case. Heads near the base of the Rustler are lowered more than the water table resulting in steeper vertical gradients and faster vertical leakage to the Culebra. However, lateral flow rates in the Culebra are less than in the base case.

Figure 3-54 shows the simulated variation in head with time near the center of the WIPP site. Comparing this with a similar figure for the base case (Figure 3-45) illustrates some of the impact of the hydraulic conductivity of the disrupted region. Increasing the conductivity of the disrupted region moves the water table down by about $15 \mathrm{~m}$ and lowers head at the base of the Rustler by about $25 \mathrm{~m}$. This differential lowering of heads results in somewhat steeper vertical gradients of head. 


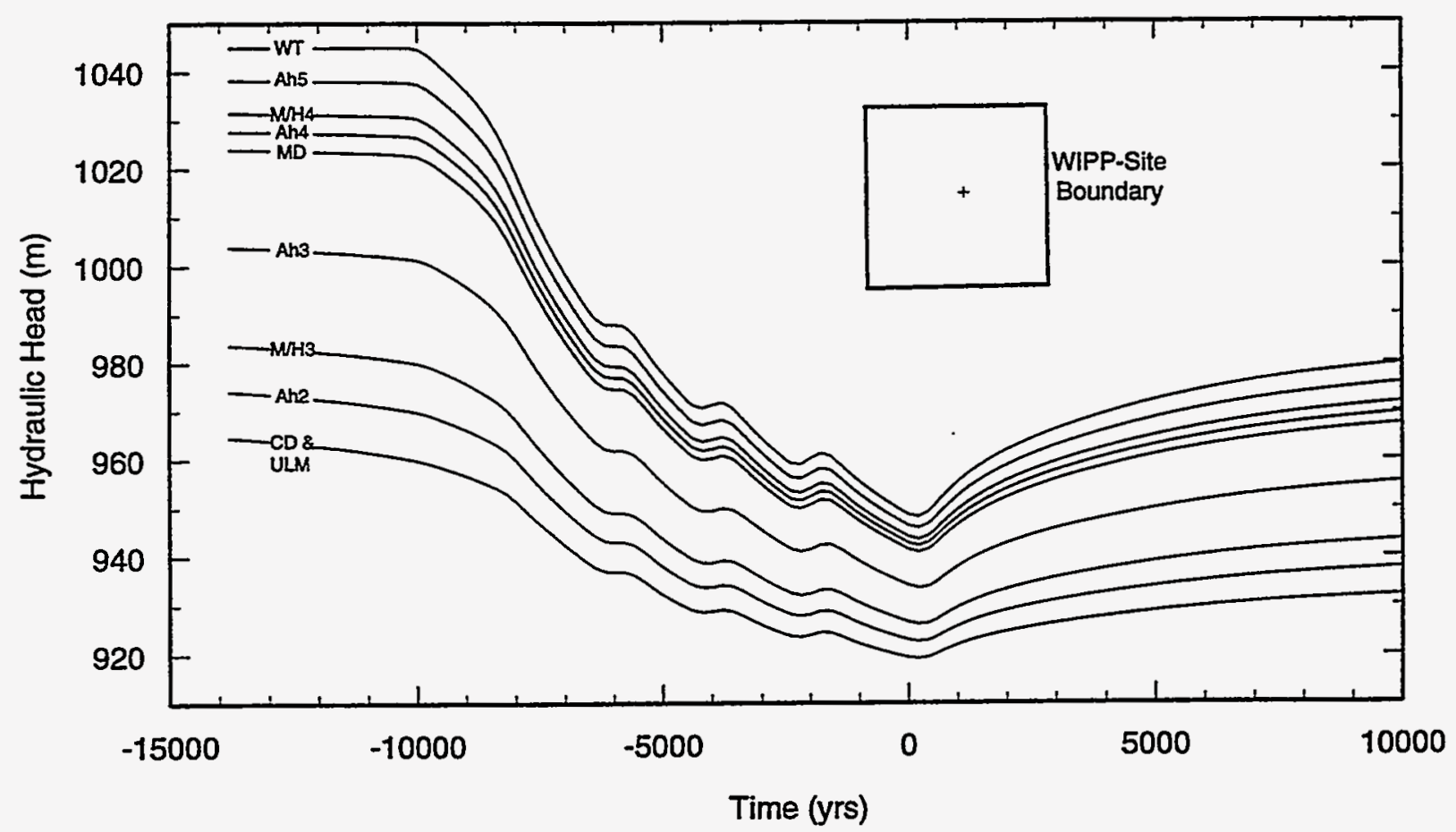

TAI-6115-410-0

Figure 3-54. Elevation of the water table (WT) and head in each hydrostratigraphic unit near the center of the WIPP site (insert) versus time for transient simulation 2 .

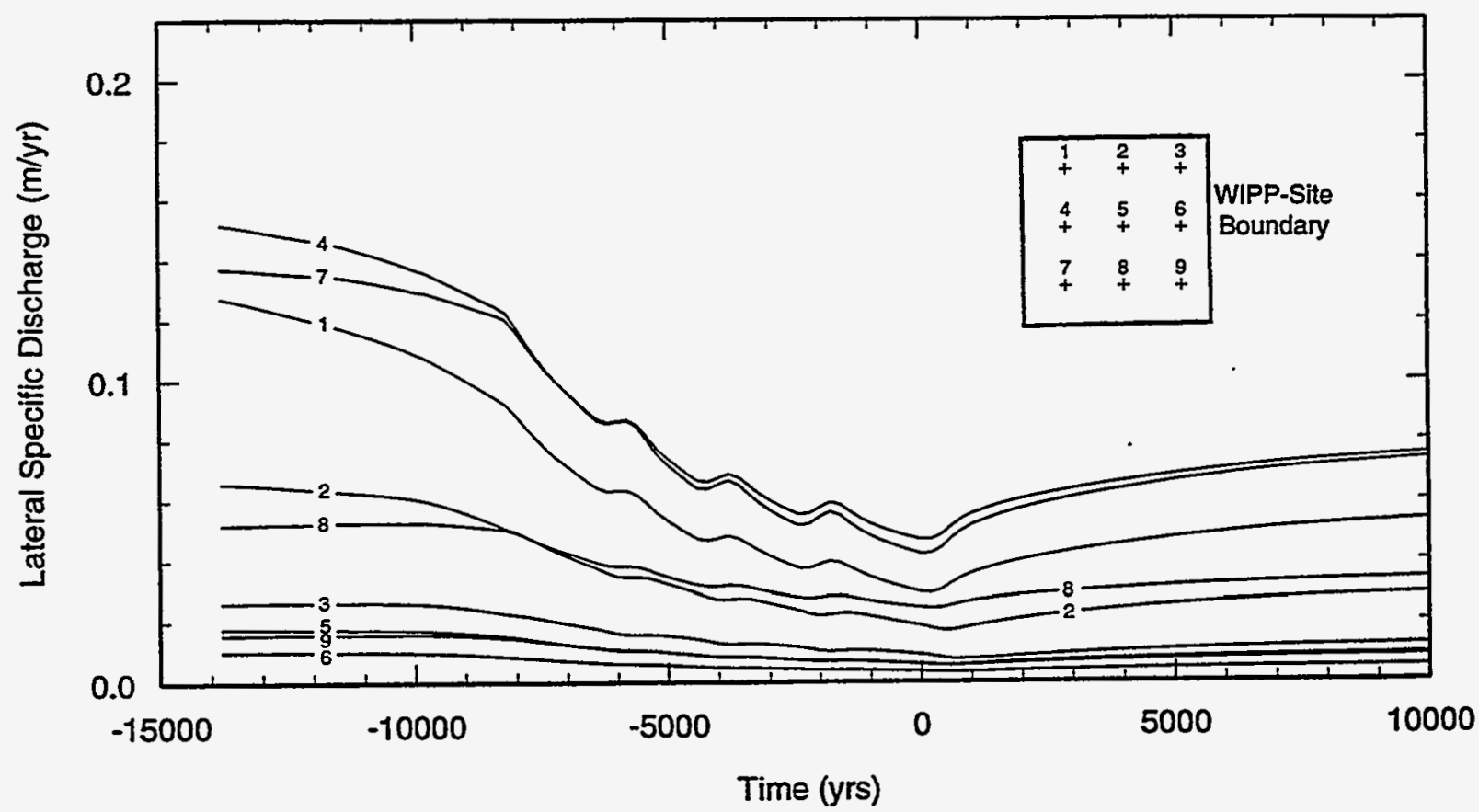

TA1-6115-411-0

Figure 3-55. Lateral specific discharge ( $\mathrm{m} / \mathrm{yr})$ in the Culebra versus time for transient simulation 2. Data are for nine locations within the WIPP-site boundary (insert). 


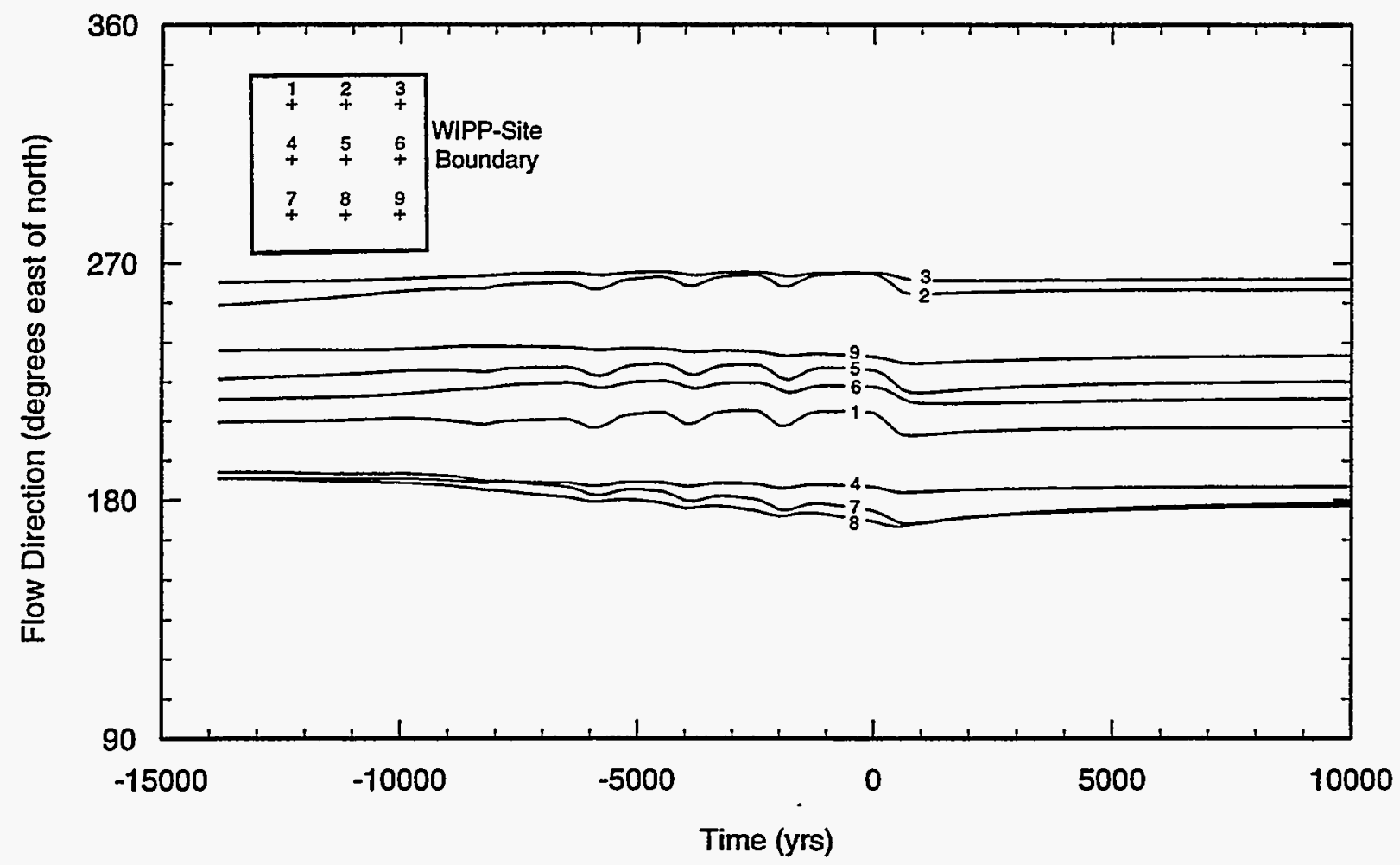

TFI-6115-412-0

Figure 3-56. Lateral flow direction (degrees east of north) in the Culebra versus time for transient simulation 2. Data are for nine locations within the WIPP-site boundary (insert).

The steeper vertical gradients are reflected in faster vertical leakage. The base-case ratios at zero years for vertical leakage from the Dewey Lake/Triassic rocks to the Magenta, and from the Magenta to the Culebra are 1.7 and 1.6 respectively. This additional vertical leakage to the Culebra is not enough to offset the decrease in lateral inflow to the Culebra (base-case ratio $=0.22$ ). The base-case ratio for lateral outflow from the Culebra is 0.66 .

The magnitude of lateral specific discharge (Figure 3-55) decreases more sharply with decreasing recharge than in the base case (Figure 3-49). Flow directions (Figure 3-58) are somewhat less sensitive to recharge than in the base case.

\subsubsection{TRANSIENT SIMULATION 3: INCREASED DEWEY LAKE/TRIASSIC ROCKS CONDUCTIVITY}

This simulation differs from the base in that the intact hydraulic conductivity of the Dewey Lake/Triassic rocks is increased by a factor of 5 , to $1 \times 10^{-6} \mathrm{~m} / \mathrm{s}$. The main effects of this change are to lower the water table and heads in all units, increase lateral flow rates in the Dewey Lake/Triassic rocks, but decrease lateral flow rates in the Magenta and Culebra, and decrease vertical leakage between strata. 
Figure 3-57 shows the simulated variation in head with time near the center of the WIPP site. Comparing this with a similar figure for the base case (Figure 3-45) illustrates some of the impact of the hydraulic conductivity of the Dewey Lake/Triassic rocks on the regional flow field. One point that stands out in this figure is that the vertical gradients of head are much less in Case 3 than in the base case. Also, the water table starts to fall at the start of this simulation and falls more relative to the base case. Head does not decrease as rapidly in the lower units, and consequently the vertical gradient of head decreases as the water table falls.

The water table and consequently the heads in the other units are lower in Case 3 than the base case at all times. This observation reflects the fact that the flatter lateral gradients of head in the Dewey Lake/Triassic rocks are required to transmit the same amount of water if the conductivity of the Dewey Lake/Triassic rocks is increased.

The increase in conductivity of the Dewey Lake/Triassic rocks results in an increase in the total flow through this unit. At the simulated present time the base-case ratio for total flow through the Dewey Lake/Triassic rocks is 5.0. The main cause of the increase in total flow is faster lateral flow. The basecase ratios for lateral inflow and outflow from the Dewey Lake/Triassic reference volume are 7.4 and 5.8. The base-case ratio for leakage from the Dewey Lake/Triassic to the Magenta, however, is 0.1 .

Because less water leaks downward from the Dewey Lake/Triassic rocks, the total flow in both the Magenta and Culebra is reduced. Base-case ratios for lateral outflow from the Magenta and Culebra reference volumes at the present time are 0.1 and 0.4 respectively. The lateral outflow from the reference volume is more similar to that of the base case during times of faster recharge. At 10,000 years, the basecase ratio for total flow through the Dewey Lake/Triassic is 1.1 and the ratios for lateral outflow from the Magenta and Culebra are 0.2 and 0.5 .

Lateral flow rates in the Culebra (Figure 3-58) are similar to those of the base case at the start of the simulation. However the rates decrease more rapidly starting about 8,000 years ago. Trends in the variation of flow direction with time in the Culebra are similar to those of the base case (Figure 3-50), but are more exaggerated. 


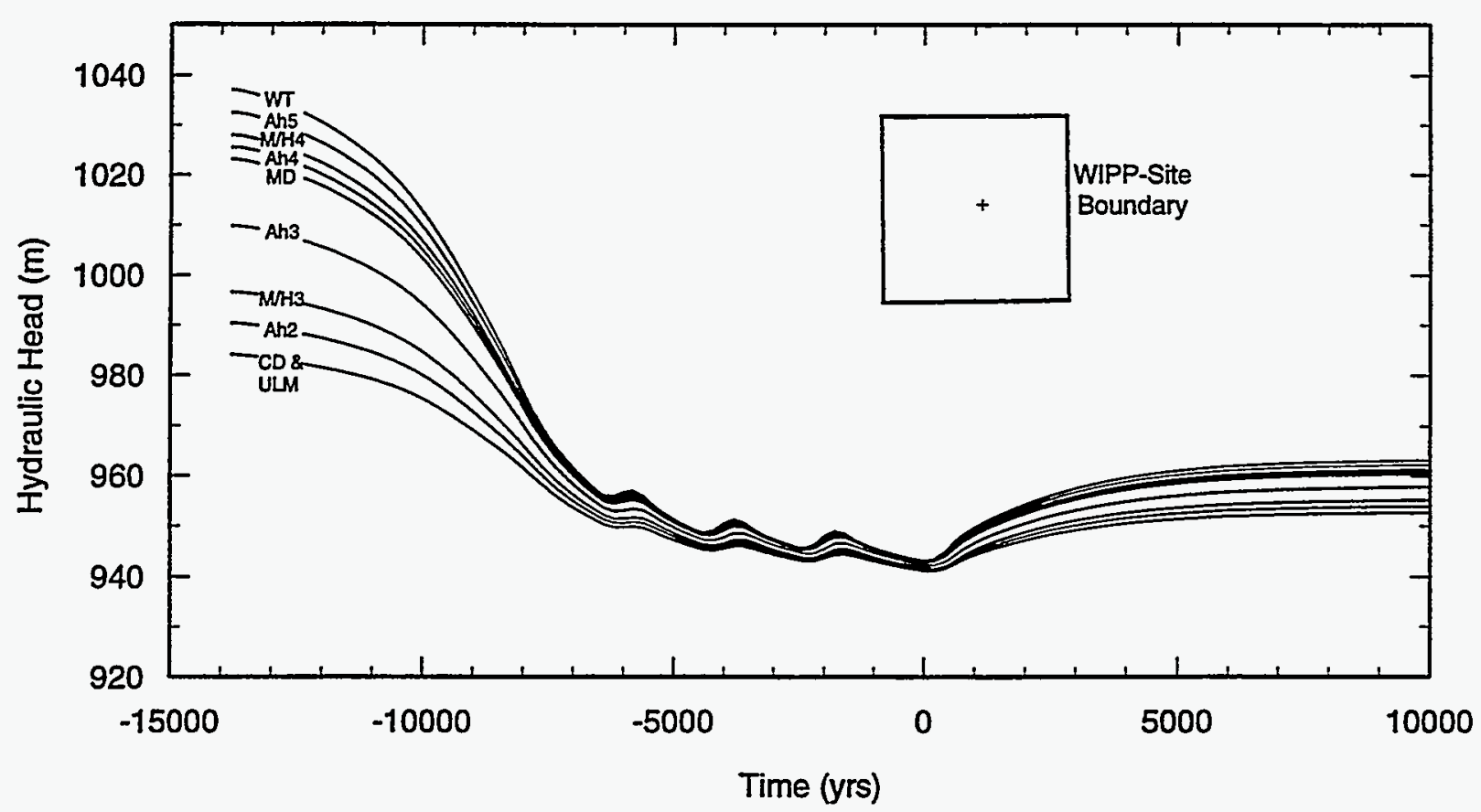

TRI-6115-413-0

Figure 3-57. Elevation of the water table (WT) and head in each hydrostratigraphic unit near the center of the WIPP site (insert) versus time for transient simulation 3.

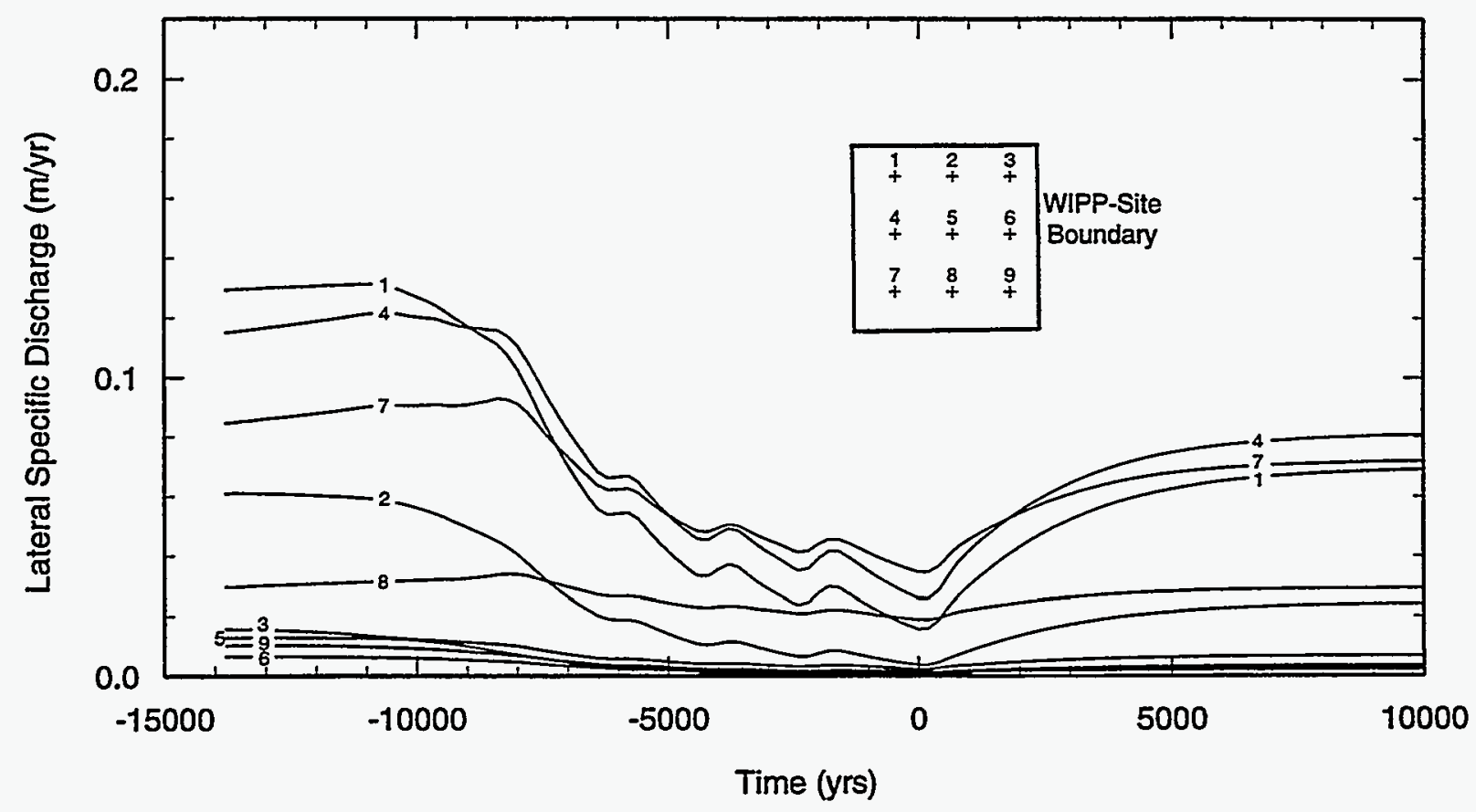

Figure 3-58. Lateral specific discharge $(\mathrm{m} / \mathrm{yr})$ in the Culebra versus time for transient simulation 3. Data are for nine locations within the WIPP-site boundary (insert). 


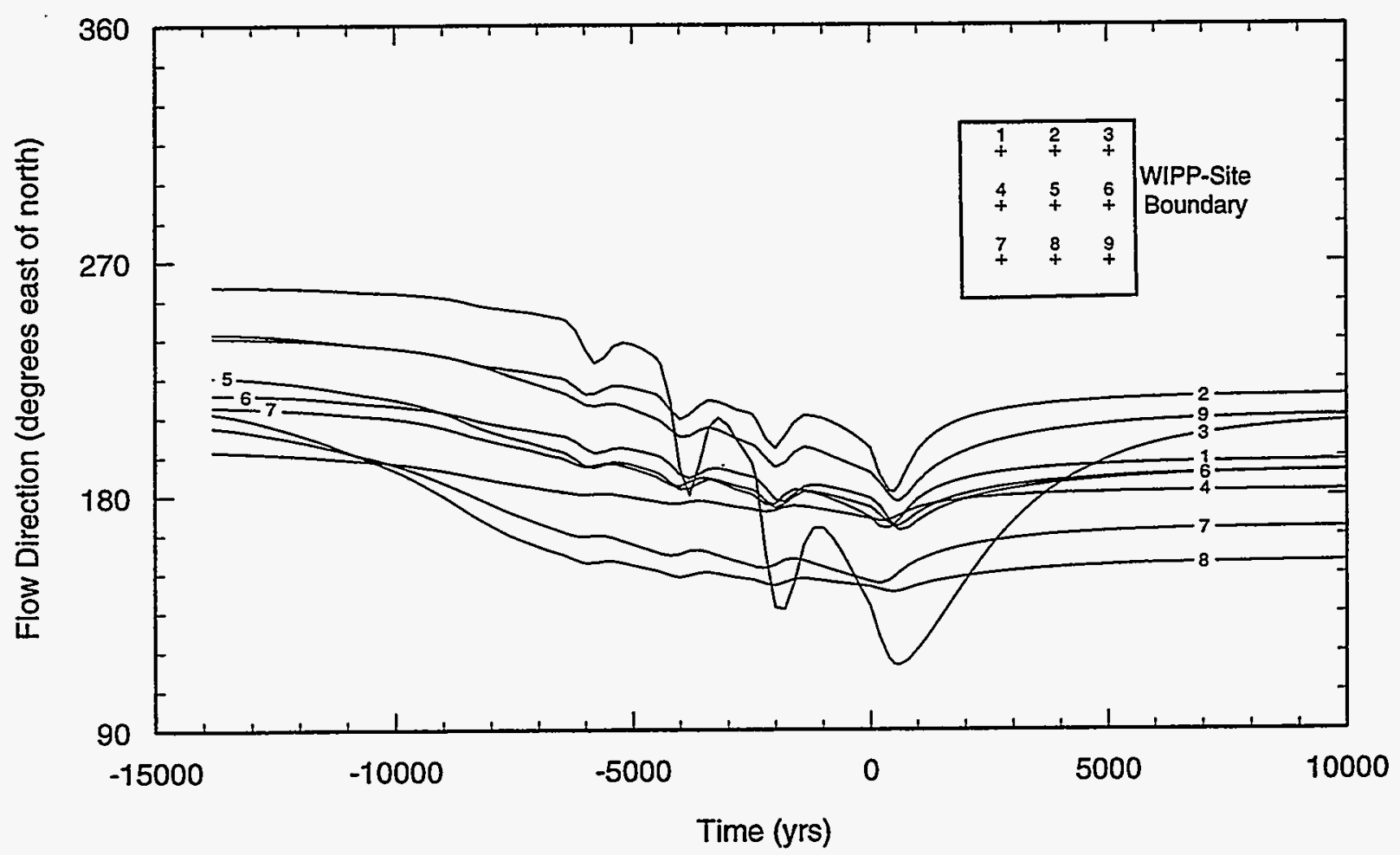

TRI-6115-415-0

Figure 3-59. Lateral flow direction (degrees east of north) in the Culebra versus time for transient simulation 3. Data are for nine locations within the WIPP-site boundary (insert). 


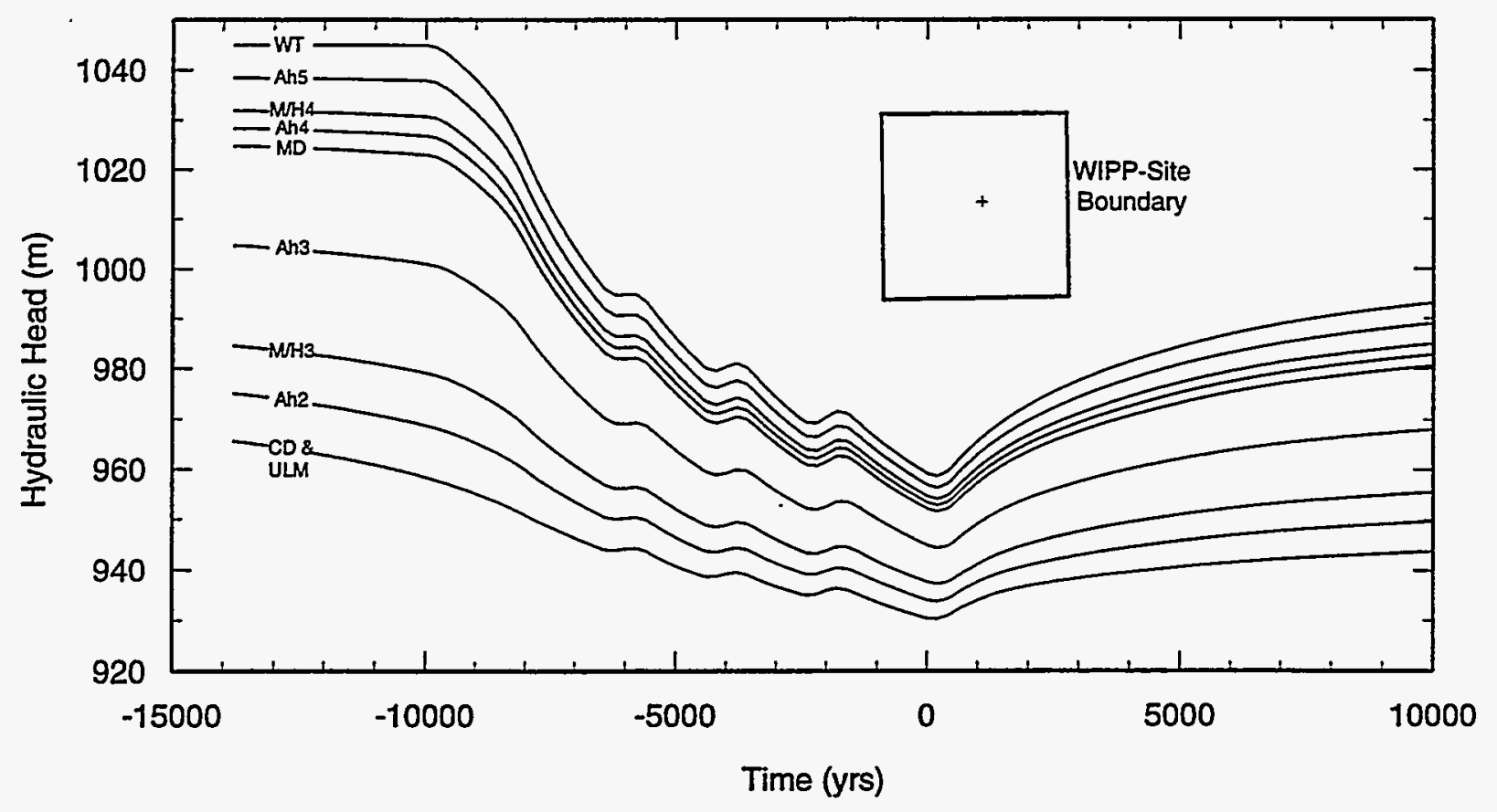

Figure 3-60. Elevation of the water table (WT) and head in each hydrostratigraphic unit near the center of the WIPP site (insert) versus time for transient simulation 4.

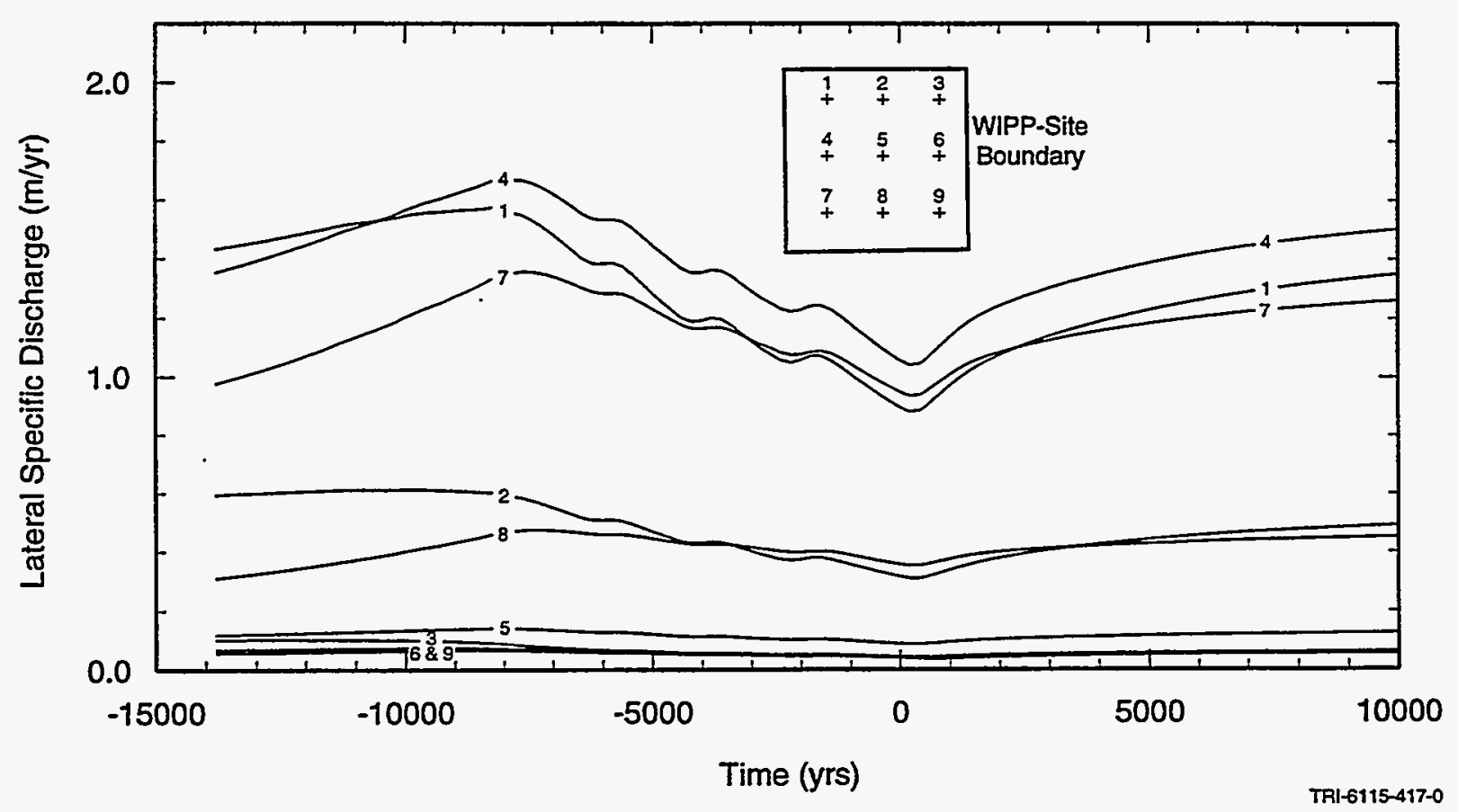

Figure 3-61. Lateral specific discharge $(\mathrm{m} / \mathrm{yr})$ in the Culebra versus time for transient simulation 4. Data are for nine locations within the WIPP-site boundary (insert). 


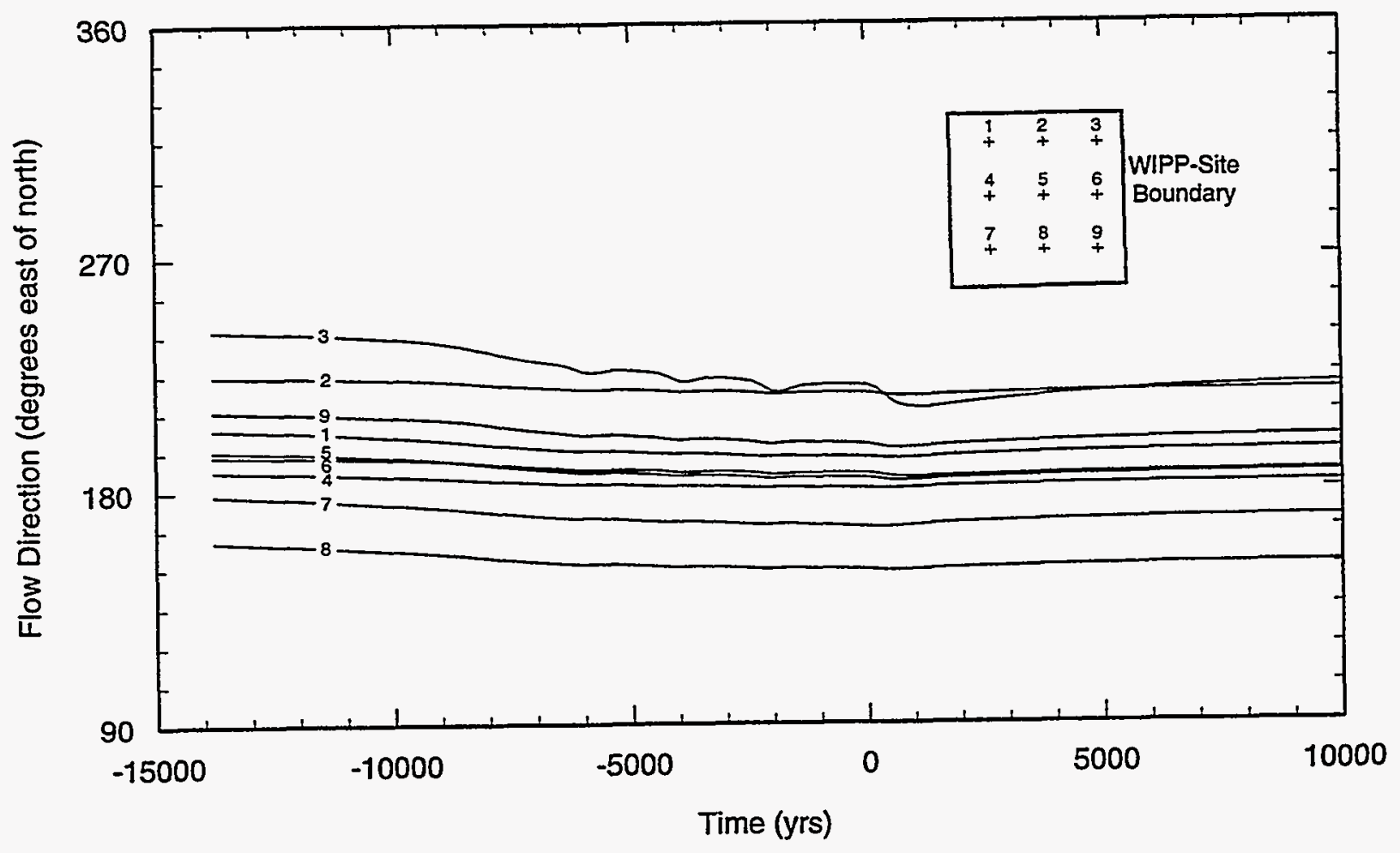

Figure 3-62. Lateral flow direction (degrees east of north) in the Culebra versus time for transient simulation 4. Data are for nine locations within the WIPP-site boundary (insert). 


\subsubsection{TRANSIENT SIMULATION 4: INCREASED CULEBRA CONDUCTIVITY}

This simulation differs from the base in that the intact hydraulic conductivity of Culebra is increased by an order of magnitude, to $1 \times 10^{-6.5} \mathrm{~m} / \mathrm{s}$. The main impact of this change was to increase the rate of lateral flow in the Culebra.

The main difference in heads from the base case is that heads in the lower part of Rustler are lower by about $15 \mathrm{~m}$. The lower heads act to increase vertical gradients because the elevation of the water table is not much different from that of the base case.

Base-case ratios for downward vertical leakage from the Dewey Lake/Triassic and Magenta are 1.2 and 1.3 respectively at 10,000 years. However the main effect is to increase the rate of lateral inflow (base-case ratio $=12.0$ ) and outflow (base-case ratio $=8.1$ ) from the Culebra. In the base case, vertical leakage accounted for $35 \%$ of the inflow to the Culebra reference volume as compared to $5 \%$ in this simulation.

\subsubsection{TRANSIENT SIMULATION 5: INCREASED MAGENTA CONDUCTIVITY}

This simulation differs from the base in that the intact hydraulic conductivity of Magenta is increased by an order of magnitude, to $1 \times 10^{-7.5} \mathrm{~m} / \mathrm{s}$. This change increases lateral flow rates in the Magenta reference volume but has little effect on flow in the Culebra.

Comparing simulated heads in the base case (Figure 3-45) with simulated heads from this simulation (Figure 3-63) shows that increasing the conductivity of the Magenta lowers heads in that unit by about $10 \mathrm{~m}$. The water table and Culebra heads are about $5 \mathrm{~m}$ lower than in the base case.

Increasing the conductivity of the Magenta by a factor of 10 results in a base-case ratio for lateral flow out of the Magenta reference volume of 6.5 at 10,000 years. However the base-case ratio for total inflow to the Magenta reference volume at this time is only 2.4. Much of the increased lateral outflow from the Magenta comes at the expense of vertical leakage to the Culebra. The base-case ratio for inflow across the top surface of the Culebra is 0.6. An increase in the lateral inflow to the Culebra (base-case ratio of 1.1) is not sufficient to balance the loss in vertical inflow. Consequently, the basecase ratio for lateral flow out of the Culebra reference volume at 10,000 years is 0.9 . Lateral flow rates (Figure 3-64) and flow directions (Figure 3-65) in the Culebra are similar to those of the base case. 


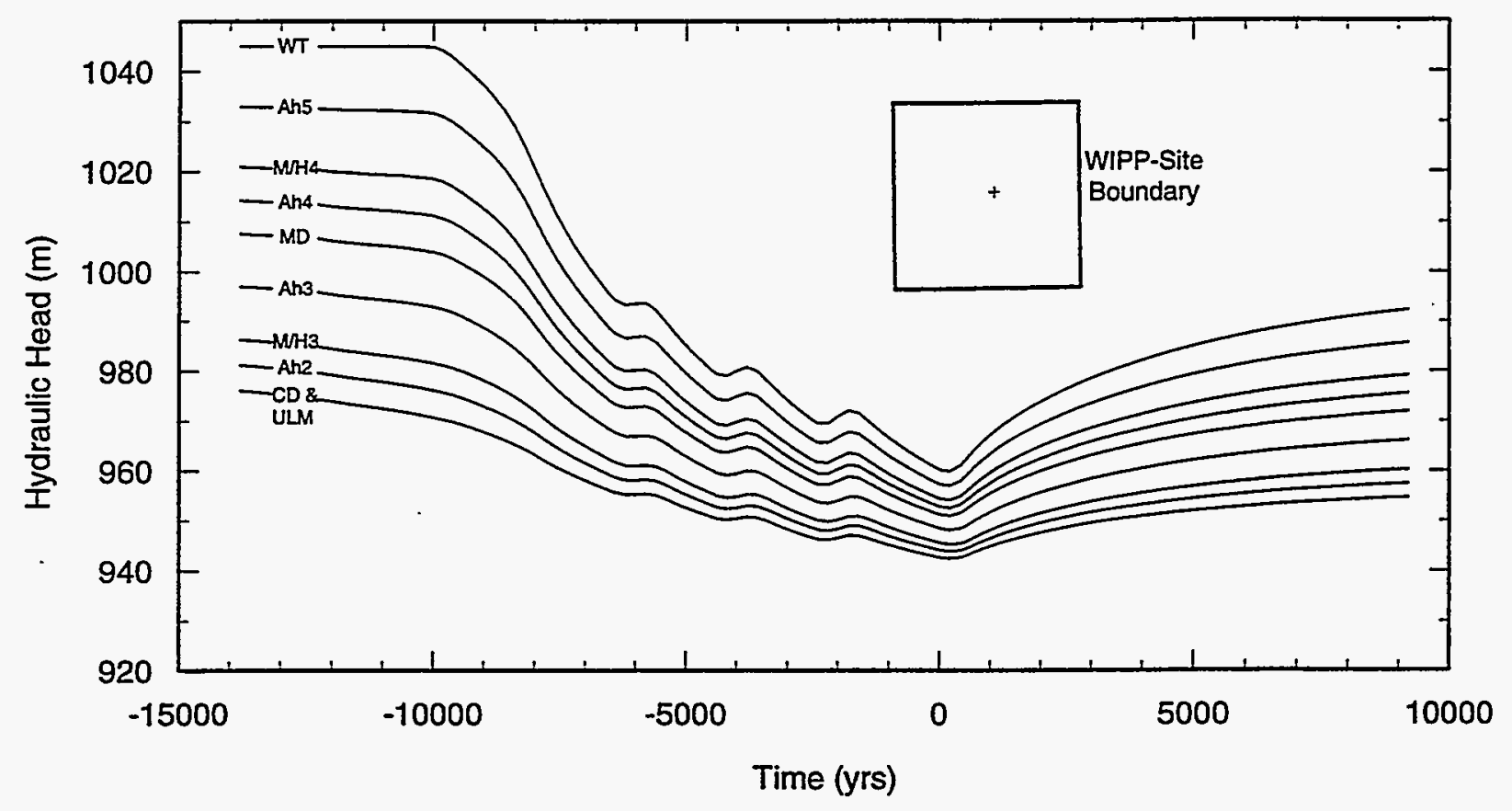

Figure 3-63. Elevation of the water table (WT) and head in each hydrostratigraphic unit near the center of the WIPP site (insert) versus time for transient simulation 5 .

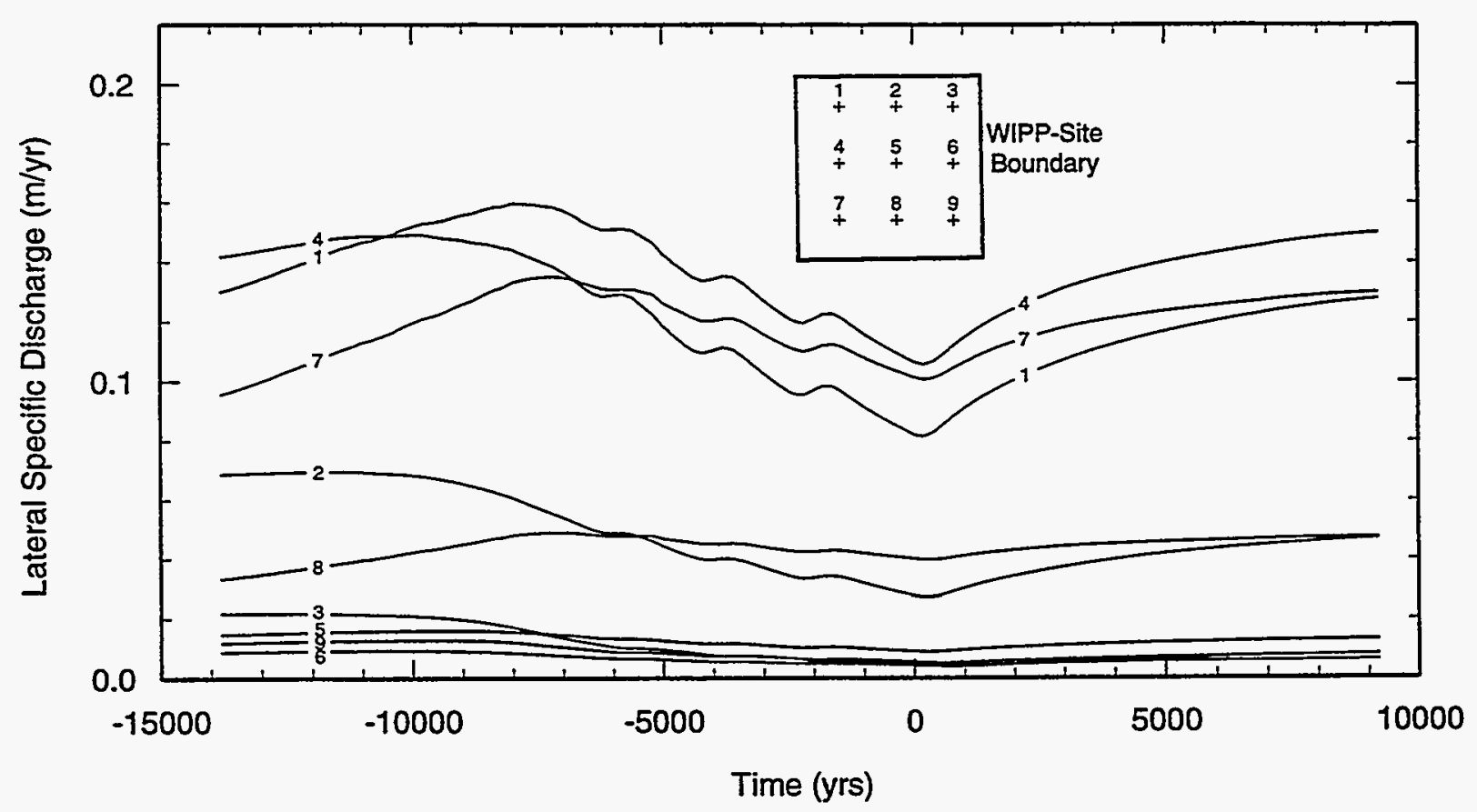

Figure 3-64. Lateral specific discharge ( $\mathrm{m} / \mathrm{yr})$ in the Culebra versus time for transient simulation 5. Data are for nine locations within the WIPP-site boundary (insert). 


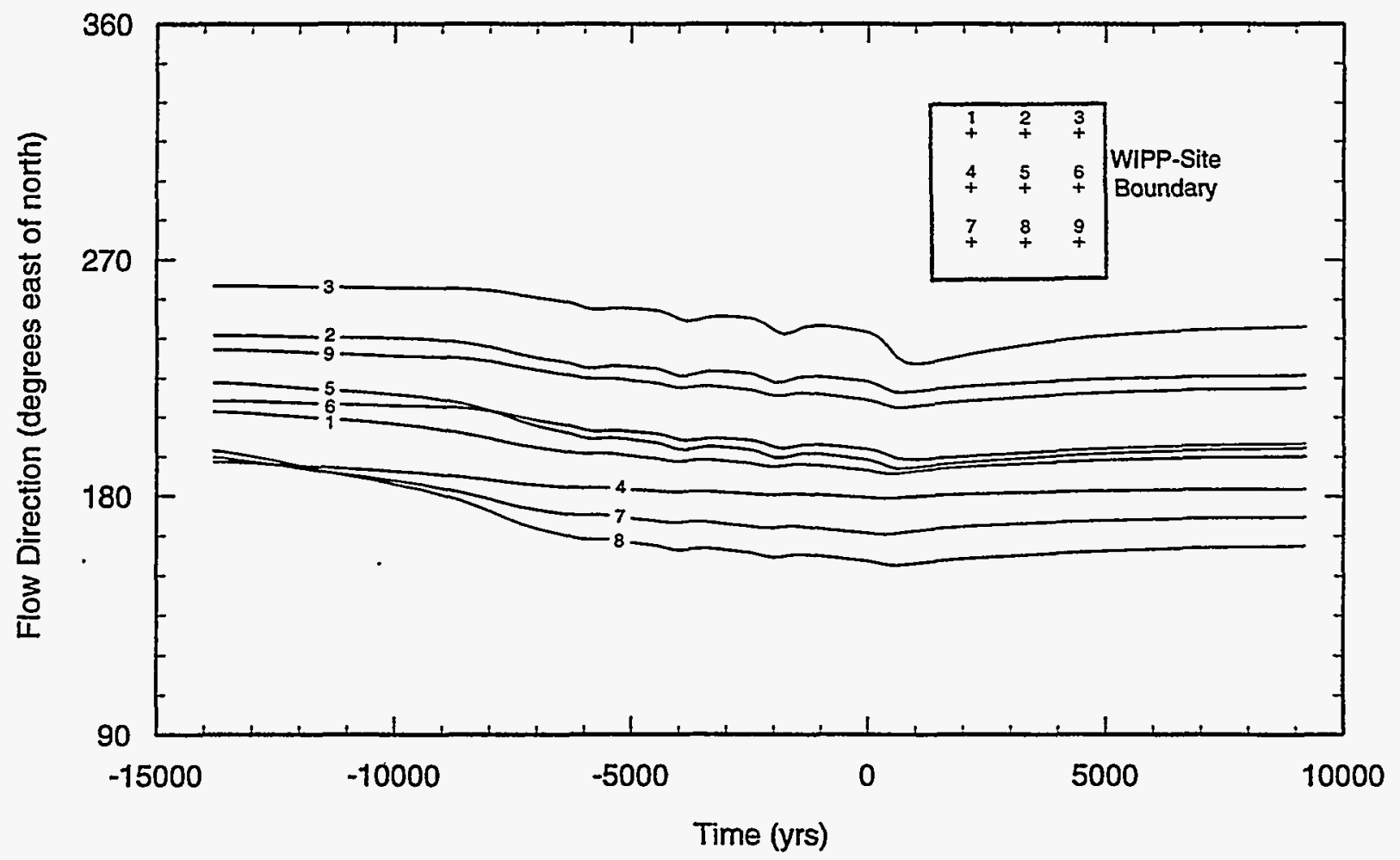

TRI-6115-421-0

Figure 3-65. Lateral flow direction (degrees east of north) in the Culebra versus time for transient simulation 5. Data are for nine locations within the WIPP-site boundary (insert).

\subsubsection{TRANSIENT SIMULATION 6: INCREASED SPECIFIC YIELD}

This simulation differs from the base in that the specific yield is increased by a factor of 5 relative to the base case, to 0.05 . Therefore, 5 times more water is stored in the groundwater basin at the start of the simulation. The main effects of the increased storage are greater lateral flow through the Dewey Lake/Triassic rocks and Culebra, a slower decline of the water table, and less sensitivity of flow rates and directions in the Culebra to changes in recharge.

Because the specific yield appears in the kinematic boundary condition with the time derivative of head, we expect that the specific yield does not affect the solution if the simulation is at or near steady state. Comparing Figure 3-66 with 3-45 confirms that heads are the same at the start of the simulations. The two simulations differ during the transient portions of the simulation. The change in the water table and other heads is less and slower during times of decreasing recharge. For example, the water table at the center of the WIPP site dropped by $82 \mathrm{~m}$ in the base case, but only $40 \mathrm{~m}$ in this simulation. Although 
the decline in the water table is less in this simulation, the amount of water drained from storage in the Dewey Lake/Triassic at this location is nearly 2.4 times as much as in the base case.

The additional capacity to store water clearly impacts the mass balance of the reference area. At 0 years, 4.4 times as much water flows through the Dewey Lake/Triassic reference volume. Increases in the lateral flow and flow across the water table contribute about equally to the increase in total flow. A portion of the additional flow into the Dewey Lake/Triassic leaks downward into the Rustler. The basecase ratio for vertical leakage to the Rustler is 2.7. In tum, more water leaks from the Magenta to the Culebra (base-case ratio of 2.3) and consequently, the lateral flow out of the Culebra is 1.7 times larger than that of the base case.

Lateral outflow from the Culebra (Figure 3-67) is somewhat larger than those of the base case after 8,000 years ago. The lateral flow rates and directions show less variation with time and, in particular, are less sensitive to the short-term changes in recharge.

\subsubsection{Variation of Potential Recharge}

We performed ten additional simulations (numbers 7 through 16 in Tables 3-2 and 3-3) to investigate the sensitivity of model results to the assumed maximum rate of potential recharge during the Holocene wet periods and the temporal pattern of recharge in the future. Maximum values of Holocene recharge of $0.2,0.4$, or $0.6 \mathrm{~mm} / \mathrm{yr}$ were used. We used either the step or the Holocene pattern to represent future recharge. Two of the previous transient simulations, the base-case simulation and simulation 2, were used as the basis for these additional simulations. Combining the ten additional simulations with the previous two simulations results in simulations with maximum recharge equal to $0.2,0.4$, and $0.6 \mathrm{~mm} / \mathrm{yr}$ for each of the two recharge patterns and each of the two sets of rock properties.

Figure 3-69(a) shows the variation of head with time assuming the base-case rock properties, the Holocene recharge pattern, and a maximum Holocene recharge equal to $0.2 \mathrm{~mm} / \mathrm{yr}$ (transient simulation 11). Dashed lines representing the head variation for the step recharge pattern are included for comparison. The overall trend of heads is a gradual decrease from the time that the water table became a free surface about 10,000 years in the past. Short-term head increases due to the wet periods are superimposed on the long-term trend. The long-term effect of the wet periods is to slow the long-term 


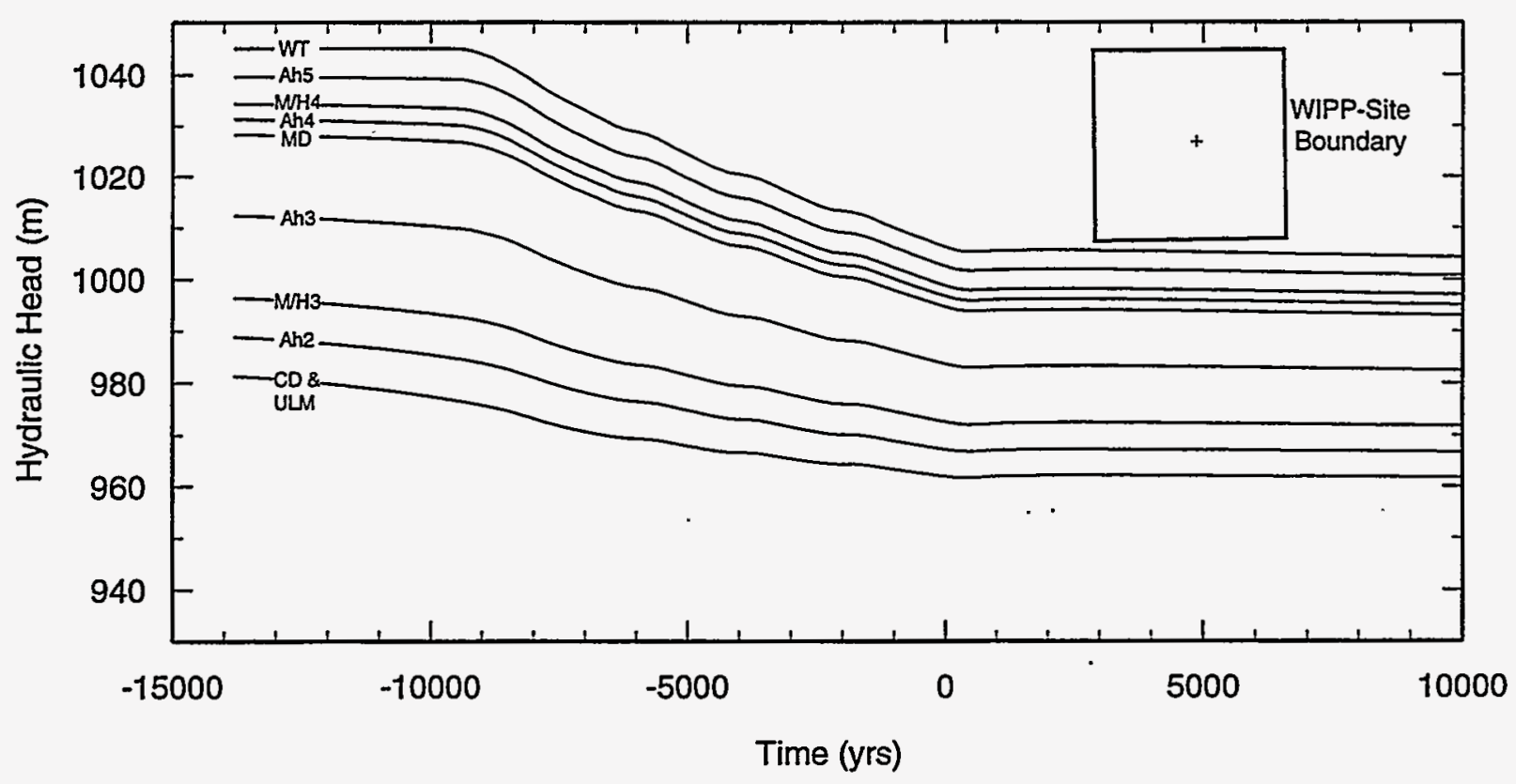

TRI-6115-422-0

Figure 3-66. Elevation of the water table (WT) and head in each hydrostratigraphic unit near the center of the WIPP site (insert) versus time for transient simulation 6 .

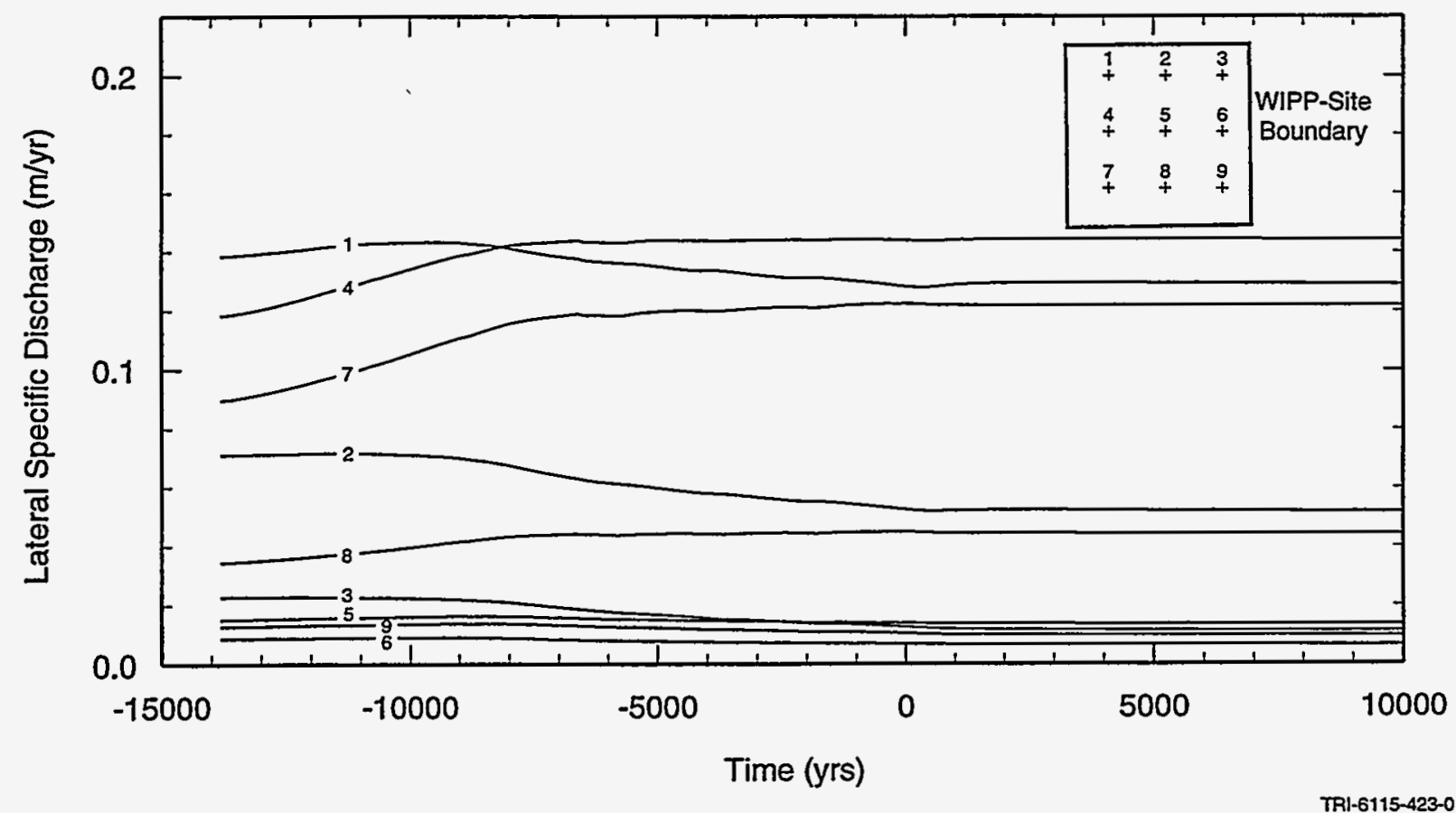

Figure 3-67. Lateral specific discharge $(\mathrm{m} / \mathrm{yr})$ in the Culebra versus time for transient simulation 6 . Data are for nine locations within the WIPP-site boundary (insert). 


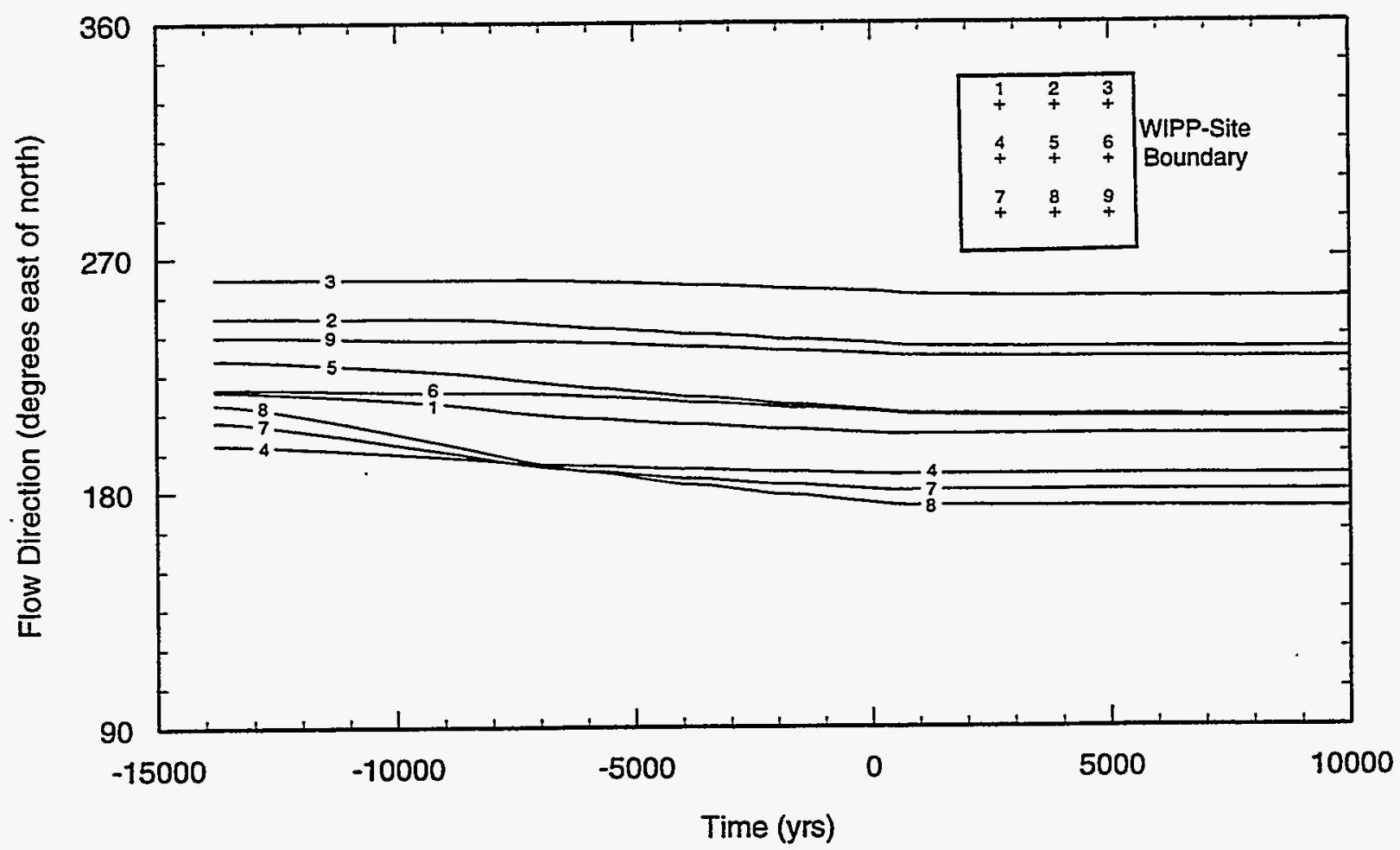

Figure 3-68. Lateral flow direction (degrees east of north) in the Culebra versus time for transient simulation 6. Data are for nine locations within the WIPP-site boundary (insert).

downward trend. The Holocene pattern results in a continuation of this interaction of long- and shortterm trends into the future. The elevation of the water table at 10,000 years is about $7 \mathrm{~m}$ less than the elevation at 0 years. The head in the Culebra is about $4 \mathrm{~m}$ less at 10,000 years than at 0 years.

The heads at 10,000 years that result from assuming the Holocene recharge pattern are considerably different from those obtained by assuming a step pattern. The water table for the step future is $43 \mathrm{~m}$ higher and the Culebra head is $18 \mathrm{~m}$ greater. Clearly, the vertical gradient of head is steeper for the step pattern.

Figure 3-69(b) shows the lateral flow magnitude in the Culebra for both future recharge patterns. The differences in flow rates for the two recharge patterns are analogous to the differences in head. The flow rates show an overall decline with the superimposed effects of the wet periods. Note, however, that the degree to which the wet periods alter flow rates varies spatially and even the largest fluctuations due to the wet periods are small relative to the spatial differences in lateral flow magnitude. 


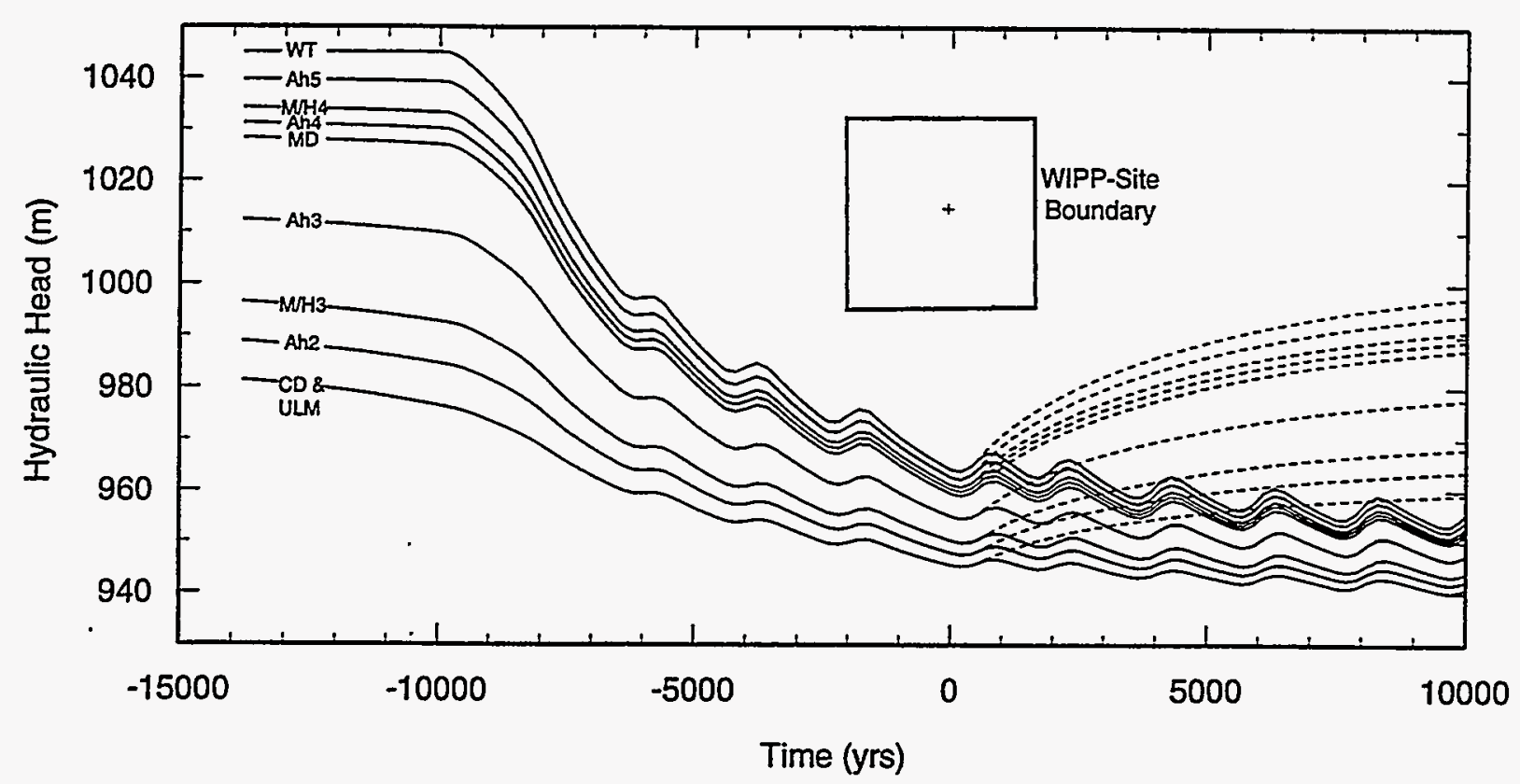

(a)

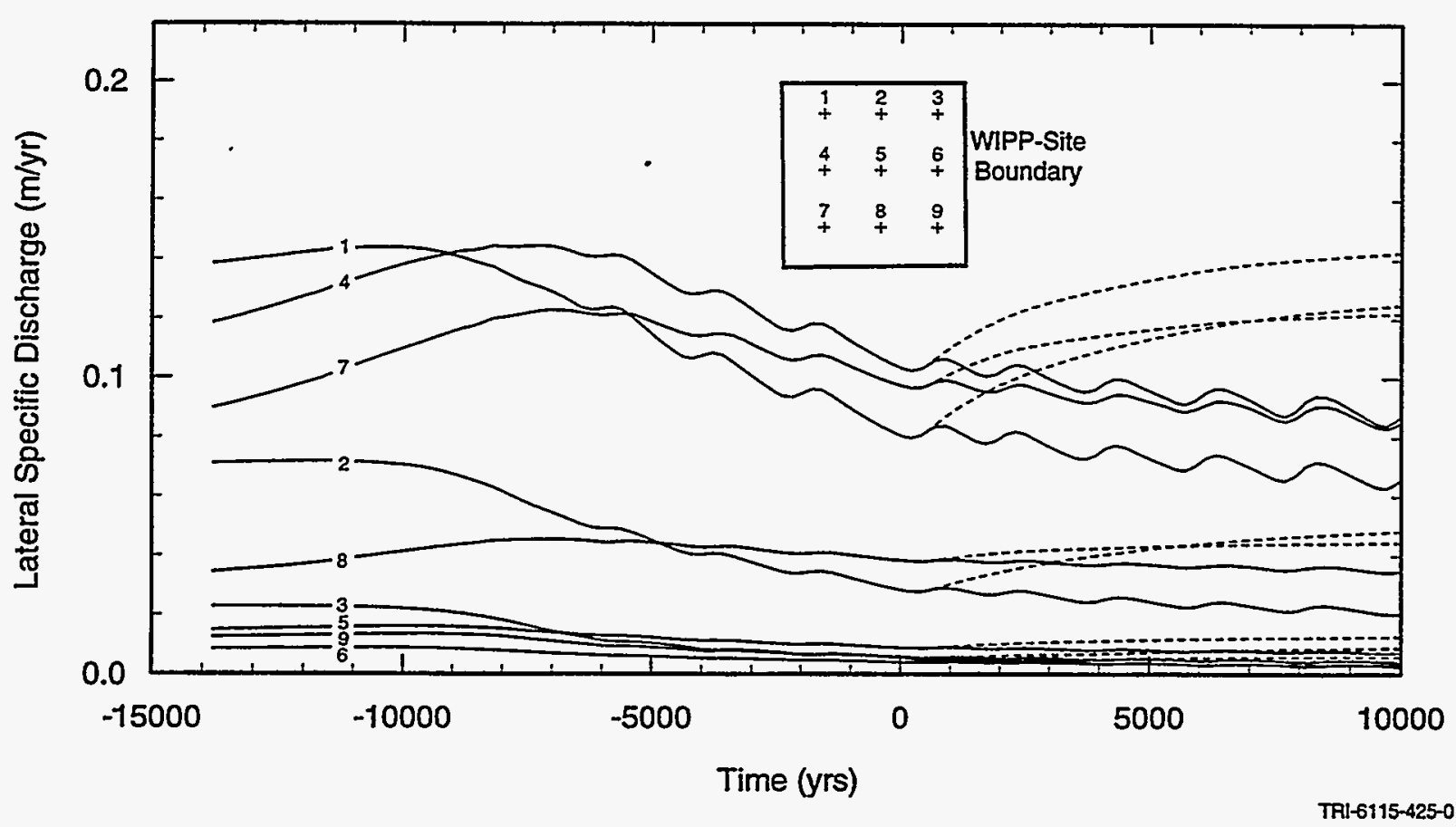

(b)

Figure 3-69. Elevation of the water table (WT) and head in each hydrostratigraphic unit (a) and lateral specific discharge (b) in the Culebra near the center of the WIPP site (insert) versus time for transient simulation 11. The maximum Holocene recharge is $0.2 \mathrm{~mm} / \mathrm{yr}$ and the Holocene recharge pattern is used. Dashed lines show heads and discharge rates for the step pattern of recharge. 
The lateral-flow ratios summarize the effect of the pattem of future recharge on flow rates in these simulations. Assuming the step pattern, the ratio of total lateral outflow from the Culebra reference volume at 10,000 years to that at 0 years is 1.6 . This ratio is 0.9 if the Holocene pattern is assumed.

The lateral-flow ratios for total lateral outflow from the Culebra reference volume for these series of simulations are shown in Table D-7 of Appendix D. There is little change in the lateral outflow from the Culebra if the future pattern of recharge is similar to the past Holocene pattern, regardless of the maximum recharge rate. The maximum that flow rates could change, as indicated by the effects of the step pattern of recharge, is by a factor of about 2 .

Figure 3-70 shows the variation of head with time for the step (transient simulation 7) and Holocene (transit simulation 12) recharge patterns assuming a maximum Holocene recharge rate of 0.4 $\mathrm{mm} / \mathrm{yr}$. Figure 3-71 shows the same information for the step (transient simulation 8) and Holocene (transient simulation 13) recharge patterns assuming a maximum Holocene recharge rate of $0.6 \mathrm{~mm} / \mathrm{yr}$. The rock properties are the same as those used in the base-case simulation. As expected, the effects of the wet periods increases with larger maximum recharge rates. A rate of $0.6 \mathrm{~mm} / \mathrm{yr}$ is almost sufficient to return heads to their initial levels at 14,000 years ago if the step pattern of recharge is used. Also, this recharge rate is nearly large enough to eliminate future long-term decreases in head if the Holocene future is used.

Figures 3-72, 3-73, and 3-74, along with Figure 3-54, show the head variation for the six combinations of maximum Holocene recharge rate and recharge pattern if the rock properties are those used for transient simulation 2. These results are similar to using the base-case rock properties except that the elevation of the water table is lower and the vertical gradient of head is steeper. The lateral magnitude of flow for transient simulation 16 for which the maximum Holocene recharge is rate is 0.6 $\mathrm{mm} / \mathrm{yr}$ and Holocene recharge pattern is used is shown in Figure 3-75. Note that in this simulation there is considerable difference in the degree to which flow rates at different locations are effected by wet periods. 


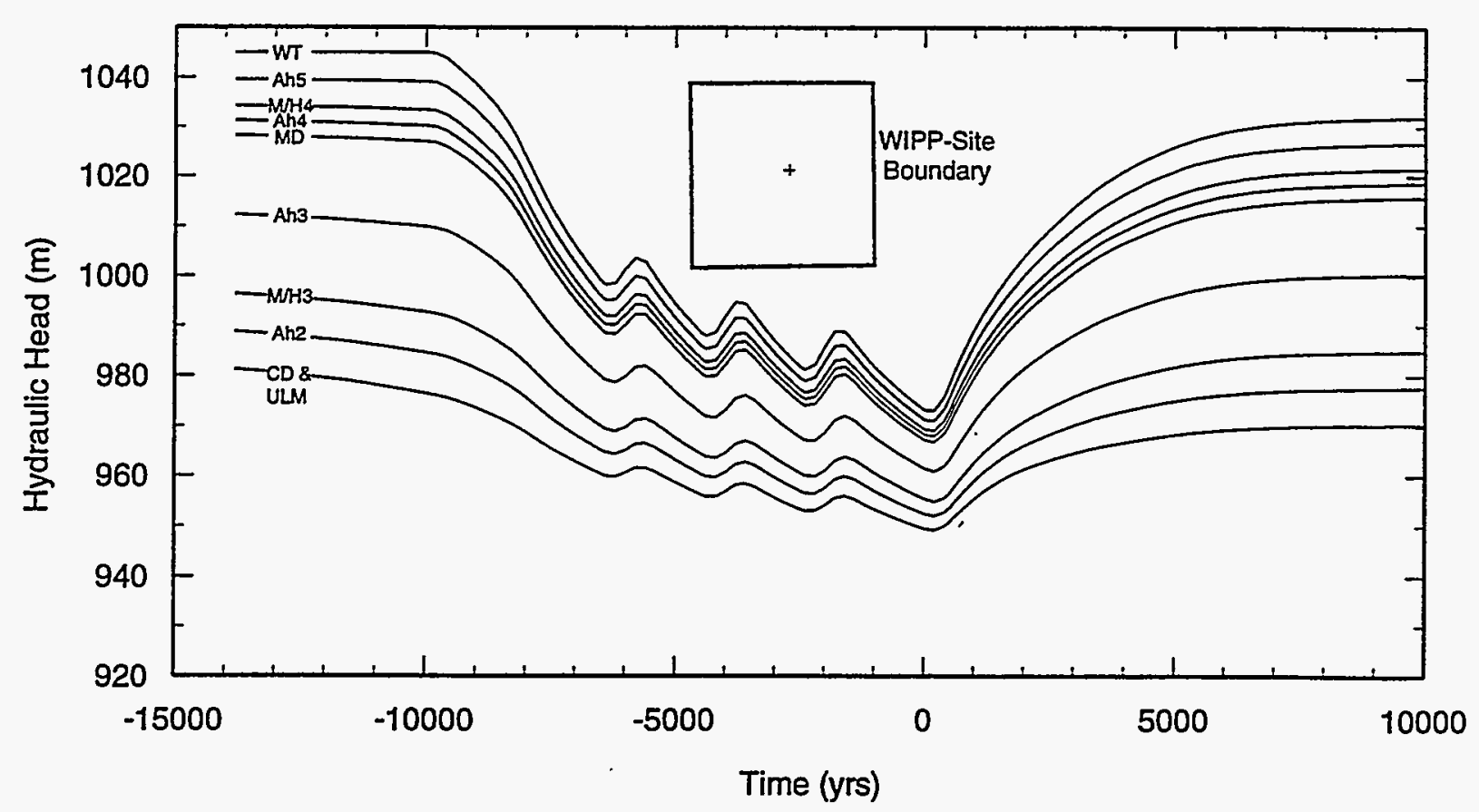

(a)

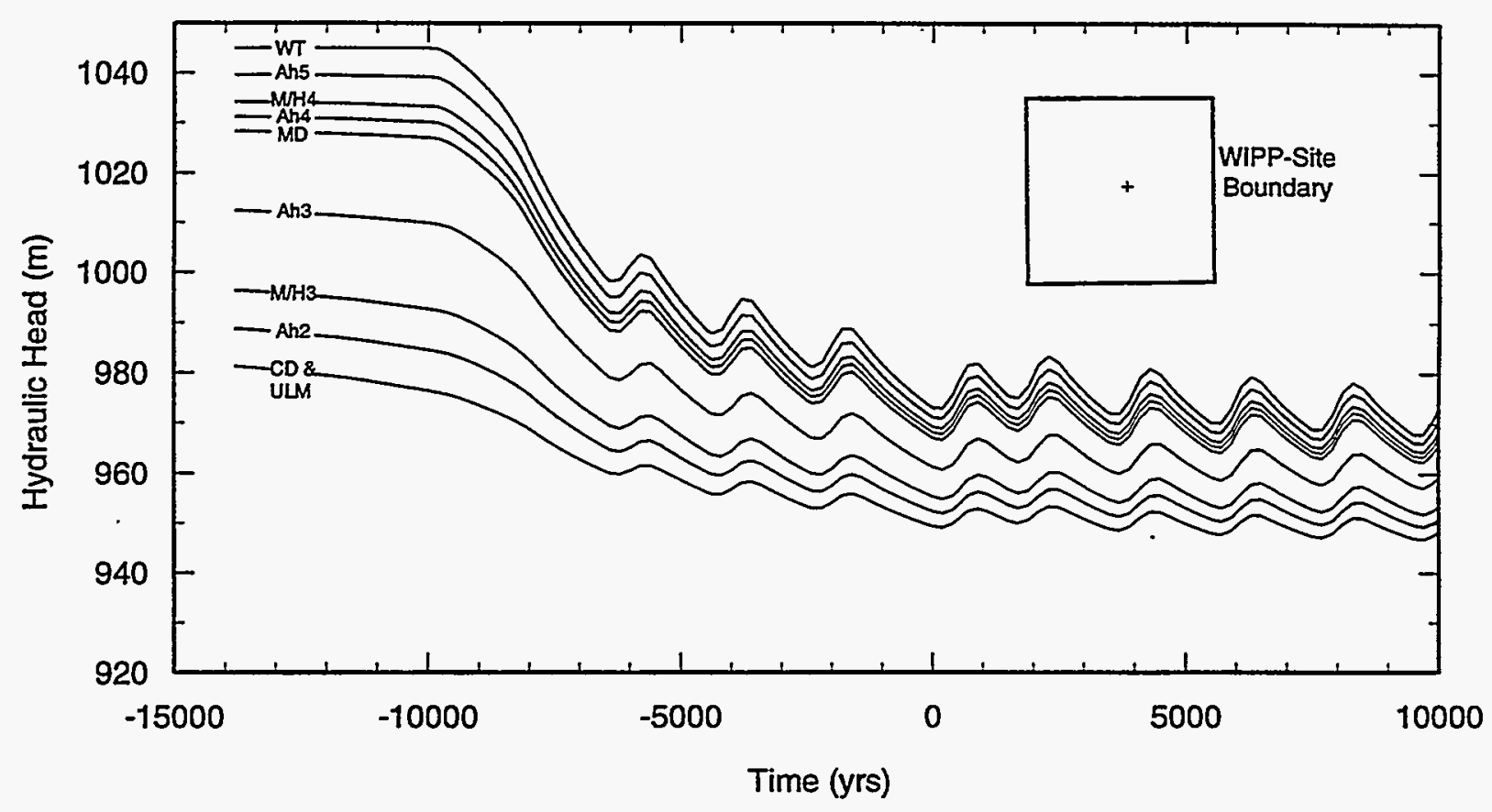

(b)

Figure 3-70. Elevation of the water table (WT) and head in each hydrostratigraphic unit versus near the center of the WIPP site time for the step pattern of recharge (transient simulation 7, (a)) and the Holocene pattern of recharge (transient simulation 12, (b)). The maximum Holocene recharge is $0.4 \mathrm{~mm} / \mathrm{yr}$. 


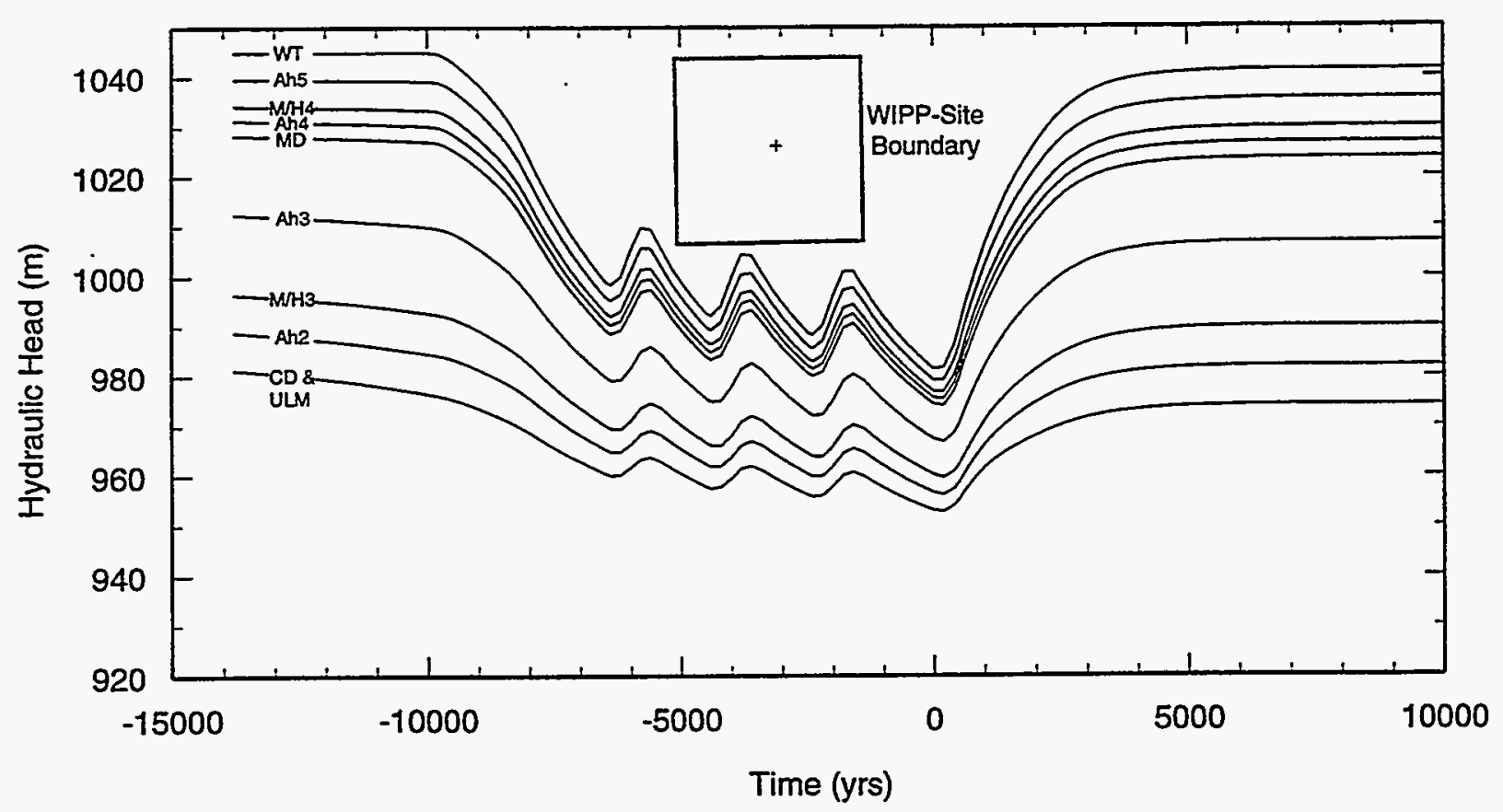

(a)

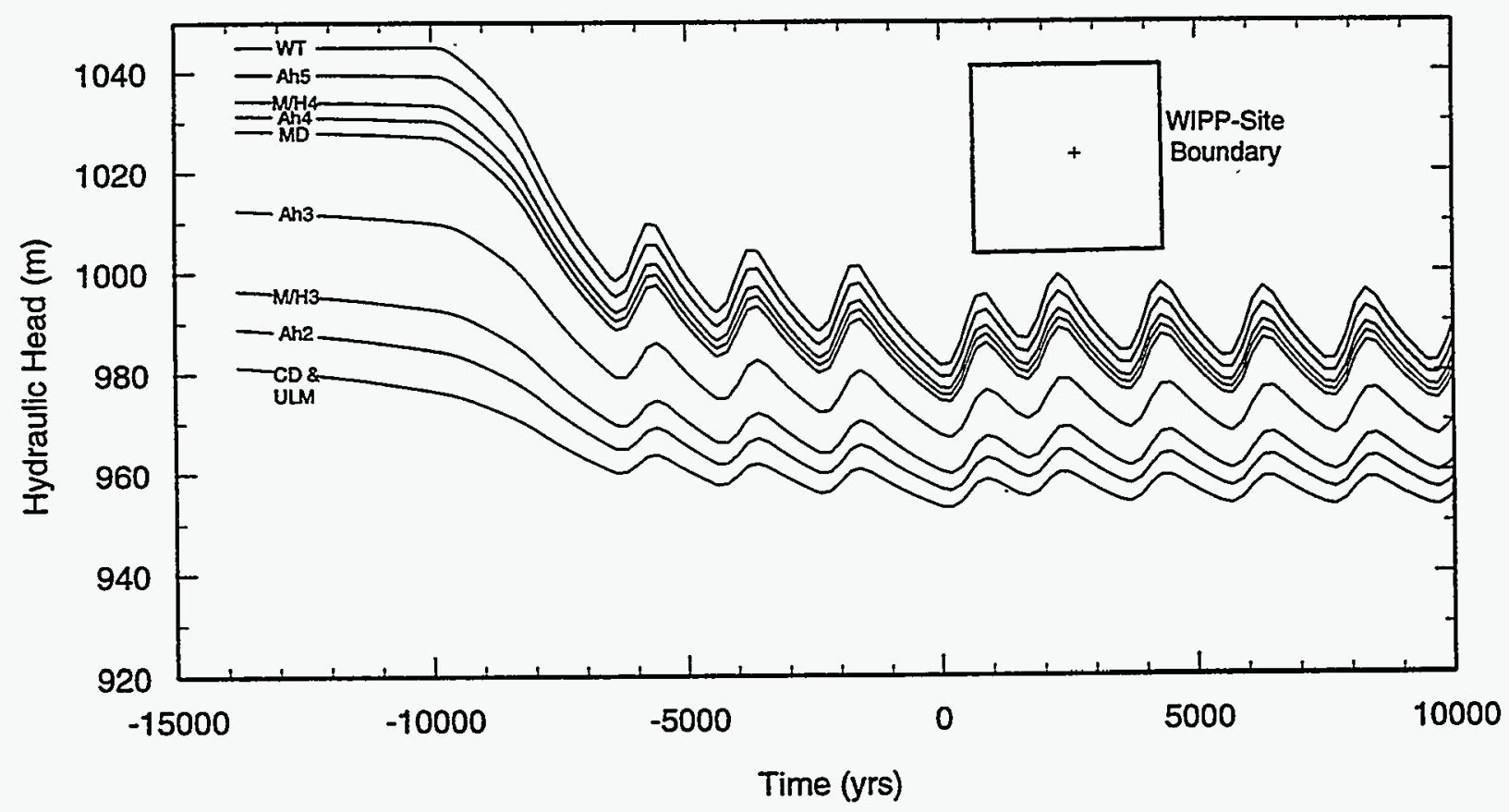

(b)

Figure 3-71. Elevation of the water table (WT) and head in each hydrostratigraphic unit versus time near the center of the WIPP site for the step pattern of recharge (transient simulation 8, (a)) and the Holocene pattern of recharge (transient simulation 13, (b)). The maximum Holocene recharge is $0.6 \mathrm{~mm} / \mathrm{yr}$. 


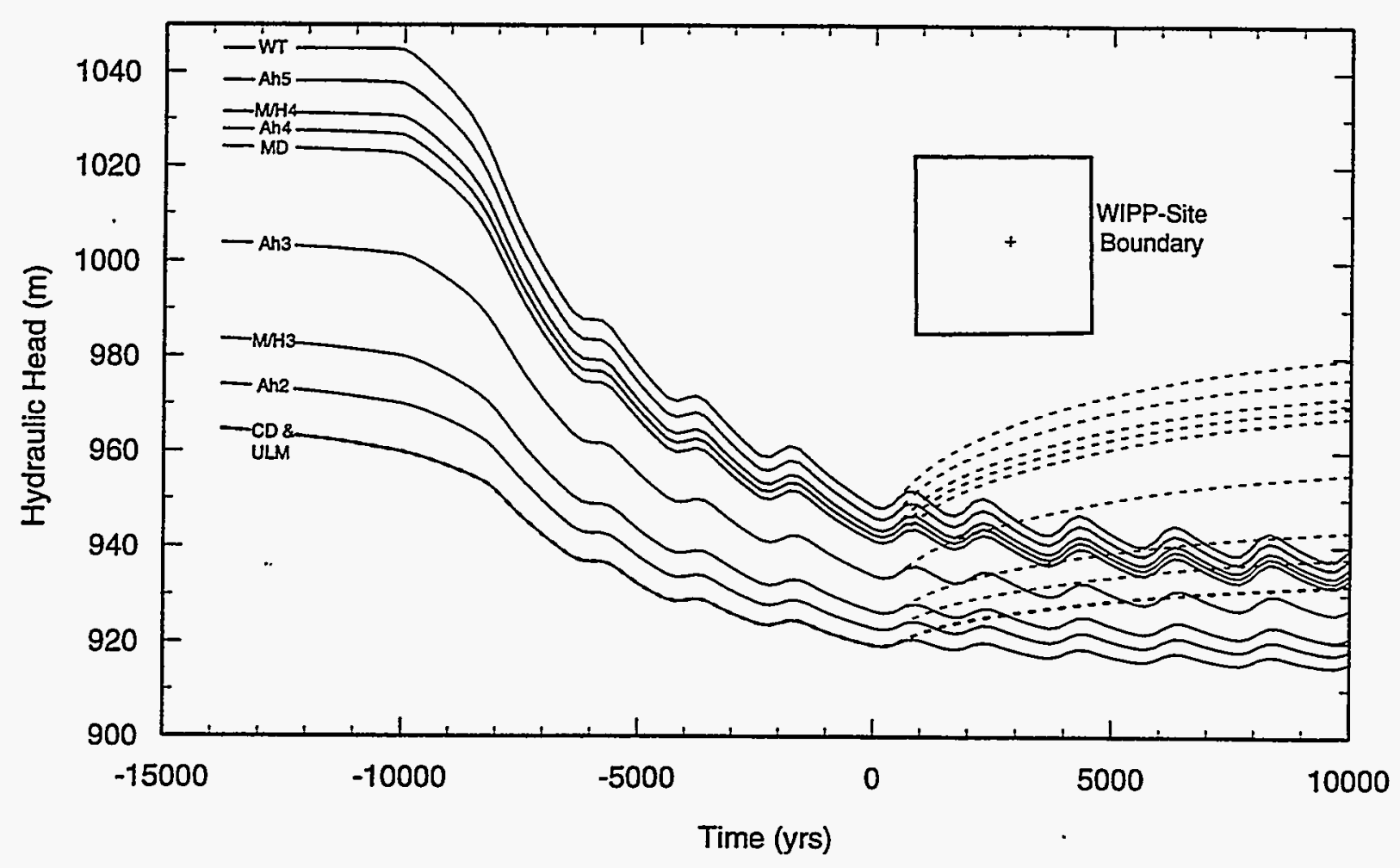

Figure 3-72. Elevation of the water table (WT) and head in each hydrostratigraphic unit versus time near the center of the WIPP site for transient simulation 14. The maximum Holocene recharge is $0.2 \mathrm{~mm} / \mathrm{yr}$ and the Holocene pattern of recharge is used. Dashed lines show heads for the step pattern of recharge. 


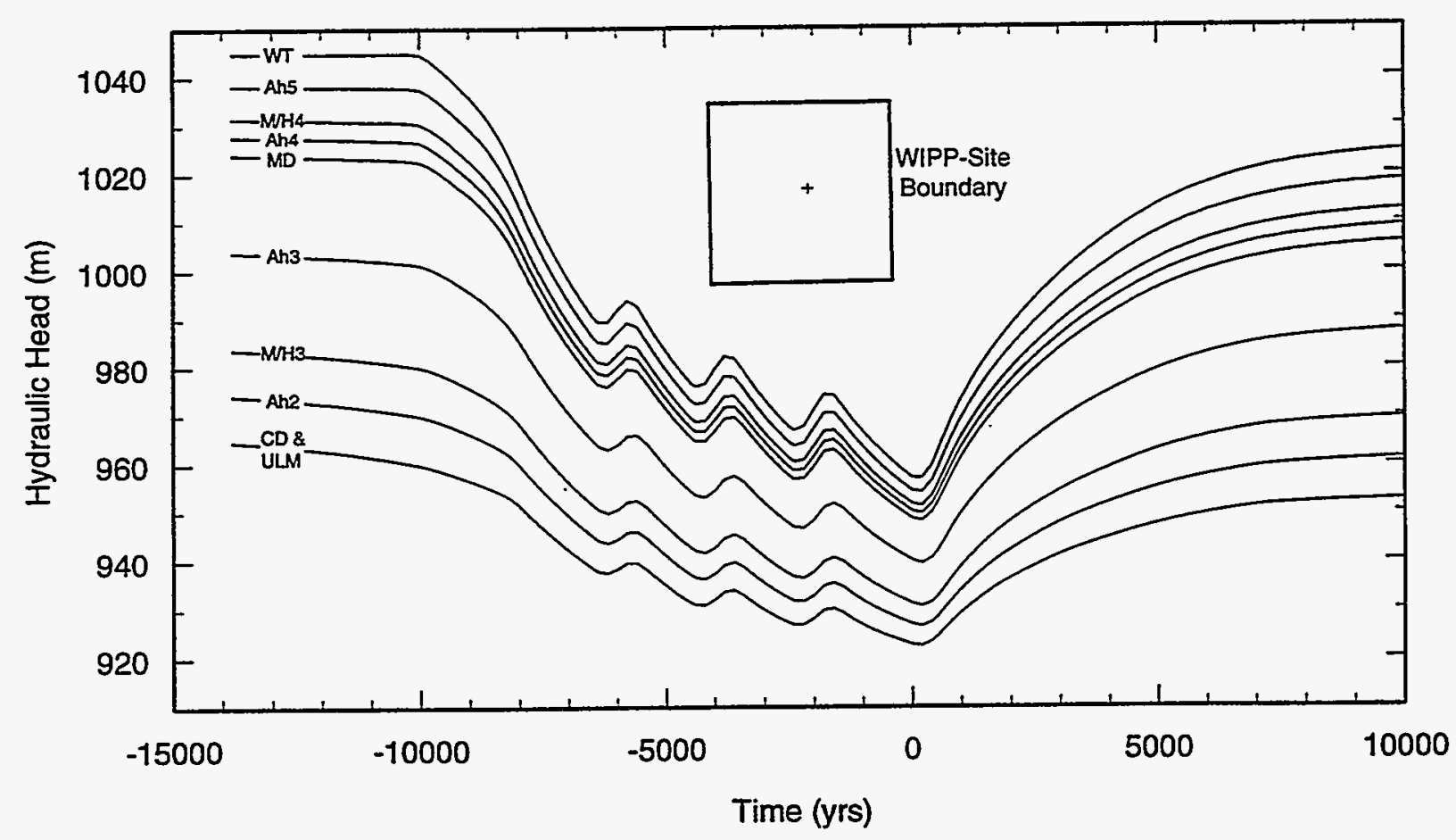

(a)

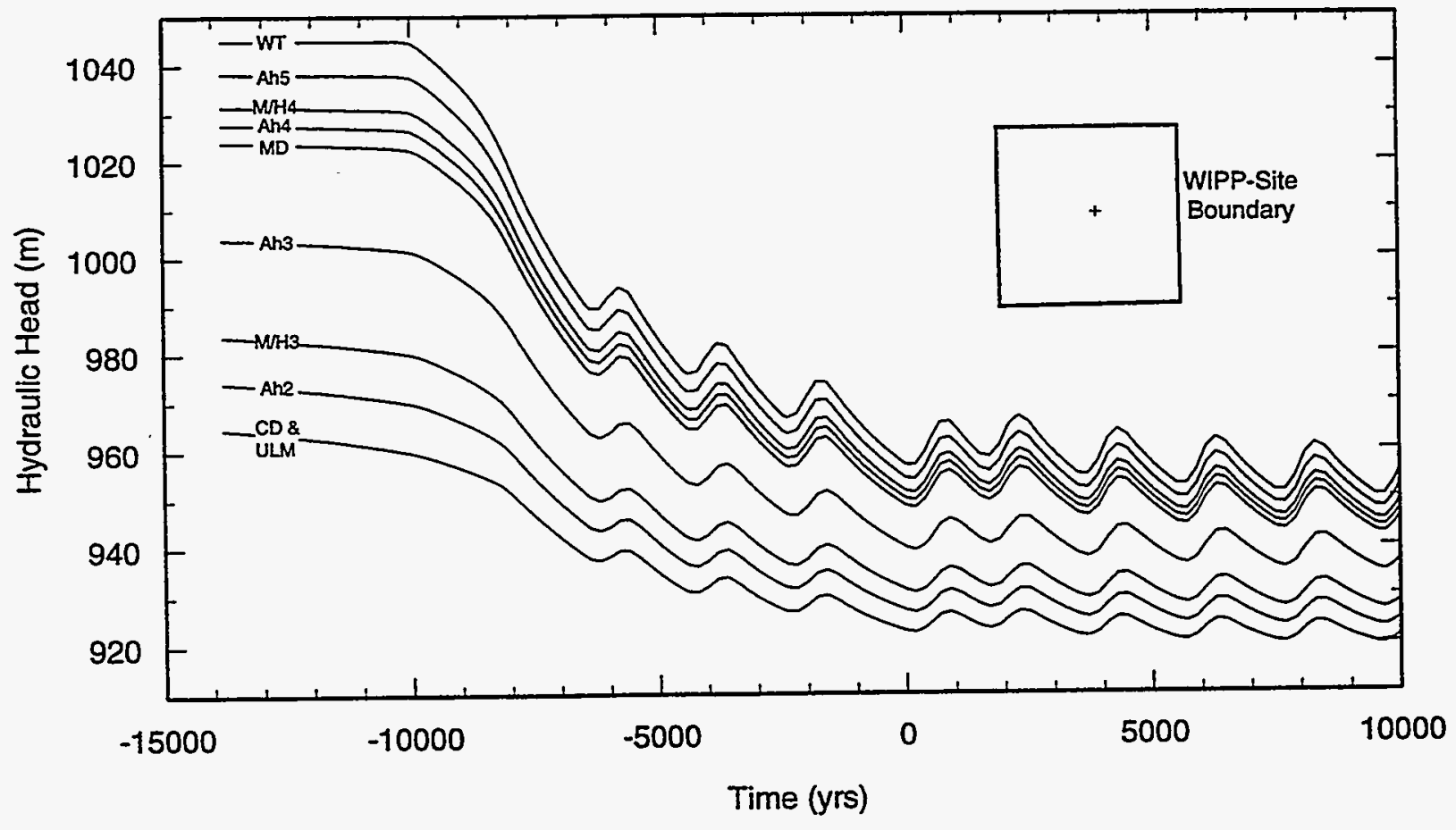

(b)

Figure 3-73. Elevation of the water table (WT) and head in each hydrostratigraphic unit versus time for transient simulations 9 (a) and 15 (b). The maximum Holocene recharge is $0.4 \mathrm{~mm} / \mathrm{yr}$. 


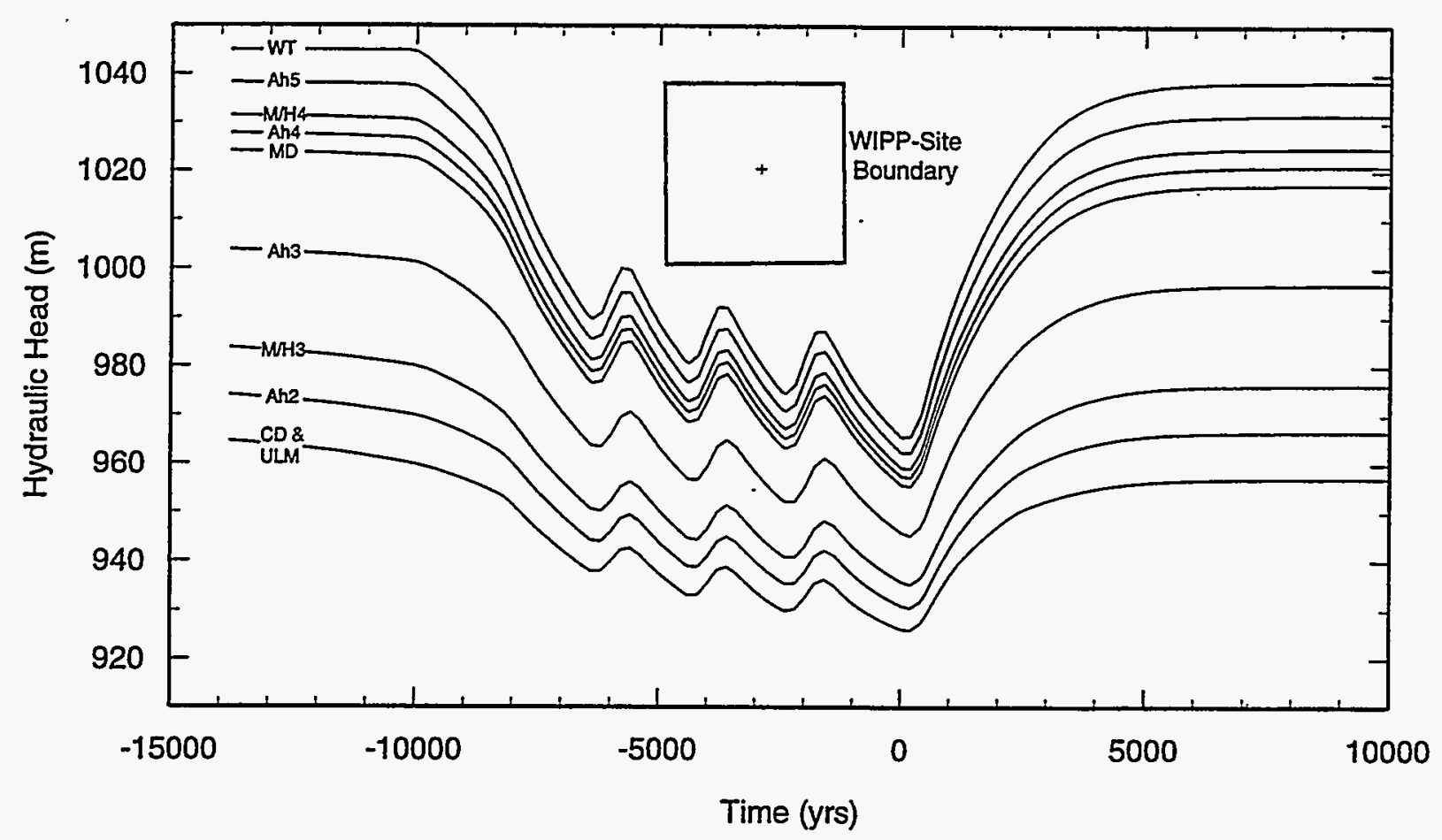

(a)

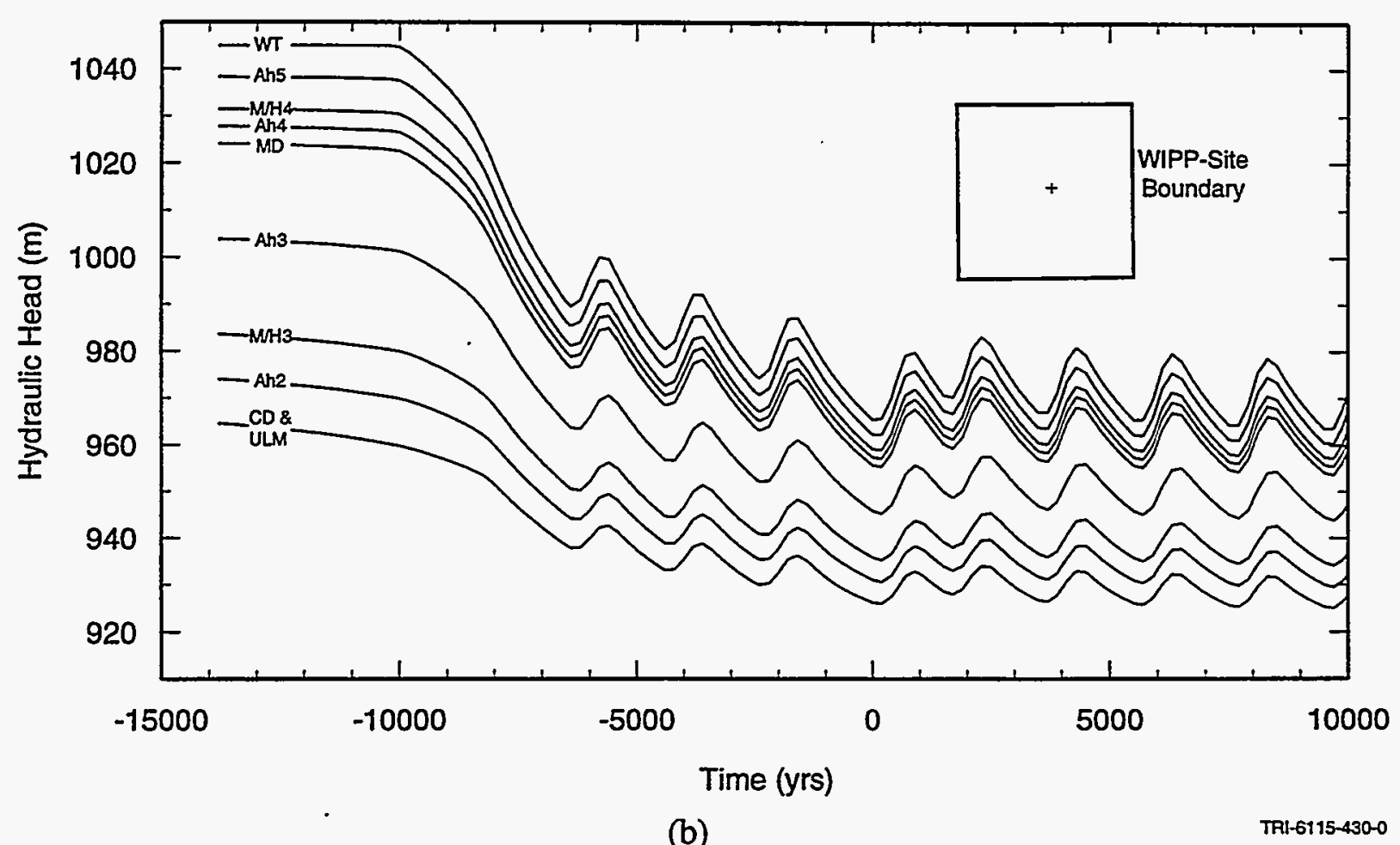

Figure 3-74. Elevation of the water table (WT) and head in each hydrostratigraphic unit versus time for transient simulations 10 (a) and 16 (b). The maximum Holocene recharge is $0.6 \mathrm{~mm} / \mathrm{yr}$. 


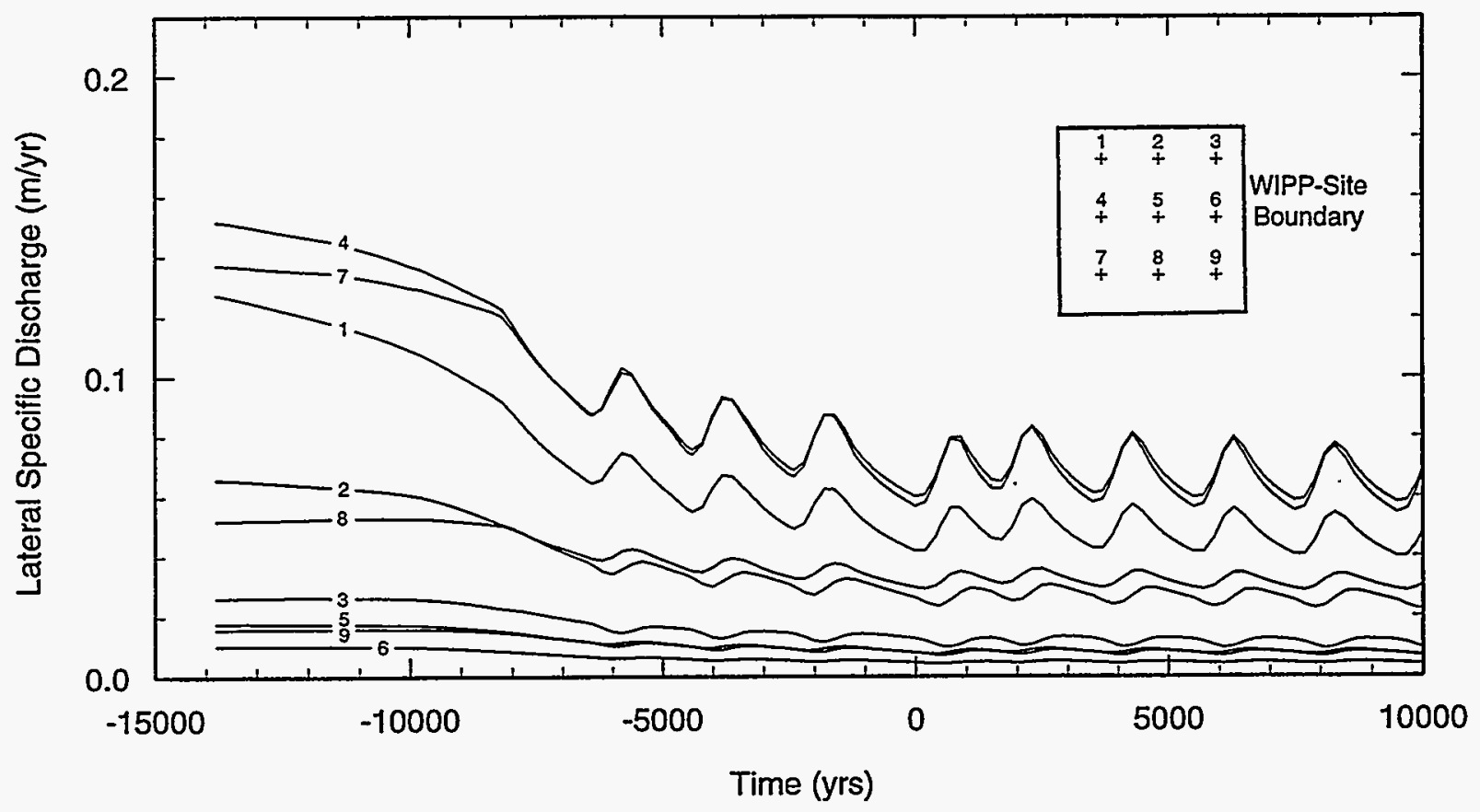

TAI-6115-431-0

Figure 3-75. Lateral specific discharge in the Culebra versus time for transient simulation 16 at nine locations within the WIPP-site boundary (insert). The maximum Holocene recharge is 0.6 $\mathrm{mm} / \mathrm{yr}$ and the Holocene recharge pattern is used. 


\section{DISCUSSION}

The objective of this study is to obtain better insight into groundwater flow in the Culebra dolomite in the context of basin-scale hydrology and past and future climate changes. Although we have pushed simulation capabilities beyond the previous state-of-the-art, the intended use of this numerical model is not to make quantitative predictions. Rather we consider it to be an instrument to advance our conceptual vision and to identify sensitive parameters. Here we reflect on what we are able to see, how accurate the vision is, and what it means for the performance of the WIPP.

\subsection{Evaluating Simulation Results}

We used a numerical model to get a better insight into the Culebra hydrology in the context of a more-regional flow-system and over extended periods of time. As with any effort to simulate complex natural systems, we have necessarily made a number of assumptions and simplifications. In addition, there is large uncertainty in model parameters. It is prudent to ask, "How well do model results represent the real hydrogeologic system?". This section contains a discussion of the factors that we considered in reaching the conclusion that the simulation results are indeed accurate enough to provide input into a conceptual model of how this groundwater basin works. Discussion in this section also pertains to a related issue: why the simulations do not provide quantitative predictions of future groundwater flow. The major reasons why this is true are that detailed rock hydraulic properties are not known over much of the model domain, and it is not possible to obtain quantitative predictions of future climate.

The governing equations solved in these simulations describe saturated flow of a constantdensity fluid subject to free-surface and seepage-face boundary conditions. The most important simplifications are that these equations do not consider variable density effects or flow in the unsaturated

zone. We know that fluid density varies spatially within the small portion of the model domain for which chemical data are available. In particular, Davies (1989) demonstrated lateral differences in density are sufficiently large to impact flow directions in the Culebra in some regions. We suspect, however, that variations in density do not play a large role in determining flow patterns at the scale and resolution of these simulations. We note that presently it is difficult or impossible to include the effects of variable density because there is no reason to assume that the distribution of fluid density will not vary over the long period of time simulated. 
The main effect of not including the unsaturated zone in our simulations is that we cannot account for the time lag between a change in infiltration rate at the land surface and change in recharge at the water table. Given that we know very little about past or future spatial and temporal distributions in infiltration, there does not seem to be any benefit to be obtained from including unsaturated flow.

The highly non-linear nature of the governing equations and the extreme contrasts in hydraulic conductivity make it very numerically challenging to solve these equations. We have demonstrated that our code matches analytical results for simple problems (Knupp, 1996). In these simulations we have driven scaled residuals to small, but arbitrary levels. Achieving tighter residuals is possible but limited by the computer time required. Transient simulation 5 , for example, ran for about $20 \mathrm{cpu}$ days on our fastest workstation (an HP Model 735/125) in order to meet the target residuals at every time step. We have, however, examined the solution sensitivity to these tolerances and found that there would be no benefit to further decreasing scaled residuals. We found, for example, that the maximum movement of the water table within an intra-time-step interation is less than $10^{-3} \mathrm{~m}$. Overall, we feel confident that the solutions are accurate to at least the level required for the objectives of this simulation exercise.

We assume that the lateral boundaries of our model domain follow groundwater divides that do not change position over the period of time simulated. This is perhaps the most difficult assumption to evaluate because it concerns the interactive nature of conceptual modeling and mathematical modeling. In this case, the boundaries represent our conceptual model of the regional flow system before the mathematical modeling started. There are no aspects of the simulation results that would lead us to suspect that these boundaries are unreasonable. The northern portion of the boundary is the least defensible. The model domain would have to be extended along a narrow strip some $25 \mathrm{~km}$ to the north in order for the northern boundary to fall on a well-defined topographic feature. We believe, but have not demonstrated, that including this strip in the model would not have much effect on the solution within the current domain.

There is large uncertainty in values of hydraulic conductivity and recharge rates. Consequently, variational studies examining the sensitivity of model results to assumed values are a main focus of these simulations. We examined sensitivity of simulated hydraulic heads, Culebra flow velocity, amount of vertical leakage into the Culebra, and total lateral outflow from the Culebra to assumed values for conductivity of the Rustler anhydrites, Dewey Lake/Triassic rocks, and the region disrupted by Salado dissolution, as well as to recharge rate. We are more confident in those results that are less sensitive to assumed parameter values. We note in Section 4.3 , for example, that the result that nearly all of the 
outflow from the Culebra reference volume is by lateral flow is quite robust. This result is considered to be robust because it holds for all the combinations we assumed for hydraulic conductivity.

Only estimated rates of annual precipitation are available for the past climates in southeastern New Mexico. In dry climates such as in southeastern New Mexico, the amount of water that infiltrates below the root zone is only a small percentage of annual precipitation. The present-day infiltration rate at the WIPP is perhaps a few millimeters per year (Campbell et al., 1996), while the mean annual precipitation rate is estimated to be between 28 and $34 \mathrm{~cm} / \mathrm{yr}$ (Hunter, 1985). We have no quantitative way to correlate precipitation and recharge. We make the reasonable, but untested, assumption that maximum recharge occurs during cool wet periods. This assumption is consistent with geologic evidence that the water table was at a higher elevation in the late Pleistocene (Davies, 1989; Bachman, 1981; Bachman, 1985).

An important limitation of these simulations is the necessarily coarse discretization of hydraulic properties. Because the horizontal dimension of the model cells is $2 \mathrm{~km}$, these simulations can't represent the details of the Culebra head and conductivity distribution within the region covered by the sitecharacterization. Consequently, a direct and quantitative coupling of these simulations and the flow calculations performed for the WIPP performance assessment is not possible. We are aware of observations at the scale of the WIPP site that are not reproduced in our results. For example, our results show head at the WIPP site decreasing with depth from the water table. Analysis of pressure and fluiddensity data from 16 boreholes within the WIPP site confirm that vertical leakage between the Magenta and the Culebra is directed downward (Lappin et al., 1989). However, data from four boreholes indicate that leakage between the Forty-niner claystone and the Magenta, in contrast to the simulation results, is directed upward. We consider this to be an example of a level of local detail that can't be resolved at the scale of our simulations.

There is no meaningful way to quantitatively calibrate these simulations because the available head data cover only a small portion of the model domain and a single point in time (the present). Even if we could refine the discretization in the region of the data, we believe that it would be misleading to claim that matching this data would constitute a calibration of the model. Instead, we place more emphasis on a qualitative evaluation of the results in which we have more confidence in simulations that reproduce larger-scale features of the modern-day flow pattern. We used this logic, for example, to conclude above that the vertical conductivity of the confining layers is not larger than $1 \times 10^{-12} \mathrm{~m} / \mathrm{s}$. 
Finally, confidence in simulation results is enhanced if the results are similar to those of other calculations. The calculations performed by Davies (1989) are the best available benchmark for these simulations. A direct comparison is difficult because the Davies calculations represent the threedimensional nature of the flow system by conceptually coupling two-dimensional calculations that are oriented either horizontally or vertically. These simulations support the main conclusions of Davies concerning the nature of the regional flow system. In particular, the Davies simulations and these simulations show that it is physically reasonable that slow drainage of water stored in the Rustler Formation and overlying Dewey Lake/Triassic rocks during the Pleistocene could still be occurring at the present time. Both sets of simulations suggest that enhancement of hydraulic conductivity by dissolution of the upper Salado to the west and southwest of WIPP, coupled with large contrasts in conductivity of the hydrostratigraphic units where they are undisturbed, results in downward vertical flow in the vicinity of the WIPP. Both studies reached the conclusion that vertical inflow is likely a significant contribution of water to the Culebra in the vicinity of the WIPP.

There are two notable areas in which the results of our simulations differ from those of Davies. First, is in the estimation of upper limit of the contribution of vertical leakage to flow in the Culebra. Davies concluded that, over the domain of his two-dimensional horizontal model, as much as $25 \%$ of the total inflow to the Culebra could be entering as vertical flux. The simulations presented here suggest that, over a smaller region approximating the WIPP site, the contribution of vertical leakage could be as high as $60 \%$ (Figure 3-29). (This percentage assumes the lower rate of potential recharge, that the conductivity of the anhydrites is less than $1 \times 10^{-11} \mathrm{~m} / \mathrm{s}$, that the conductivity of the Dewey Lake/Triassic rocks is less than $2 \times 10^{-6} \mathrm{~m} / \mathrm{s}$.) The difference in the estimates is not explained by the difference in regions considered. In fact, a smaller contribution of vertical leakage would be expected for the WIPPsite region because it is smaller and because it does not extend to the area in which Salado dissolution has disrupted the confining units. A smaller region results in a smaller relative contribution of vertical leakage because the ratio of the area of the upper surface of the Culebra to the cross-sectional area of the lateral boundaries of the region increases as the size of the region increases.

This difference in the estimated upper limit of vertical leakage into the Culebra might exist because these studies use different domains and boundary conditions. In the simulations reported here, the vertical leakage depends mostly on the assumed conductivities of the confining units and simulated heads in units other than the Culebra. The Davies simulations limit vertical leakage by calculating how much vertical inflow the Culebra can receive without generating unrealistically high heads. Davies' simulations possibly result in a better estimate of maximum vertical leakage because he used a more detailed conductivity distribution for the Culebra and because he constrained the maximum contribution 
of vertical flux by calibrating to observed heads. On the other hand, Davies' simulations might be biased toward smaller contributions of vertical flux because the conductivity distribution in the region for which most of the head data is available was calculated using a model that assumes zero vertical flux (Haug et al., 1987). The three-dimensional simulation may have an advantage in that vertical gradients of head, as well as the heads along the lateral boundaries of the region considered, are a simulation result rather than fixed. This allows both the vertical and horizontal components of inflow to vary freely. In any event, the upper bound for the contribution of vertical leakage to total inflow to the Culebra remains uncertain. The simulations performed for this study do not lower estimates of the upper bound.

The second area in which the results of this study differ from those of Davies (1989) concerns movement of the water table. The two-dimensional transient simulations of Davies suggest that the postPleistocene drop of the water table would initiate in the down-stream portions of his model domain, i.e., close to Nash draw at the west end of his cross section. The results of our simulations suggest instead that the water table would first drop in the regions in which the water table is relatively high. These regions correspond to the east end of Davies' cross section. It is possible that these differences are simply due to the choice in parameter values in each study. However, we believe that our results are more realistic because our model incorporates a rigorous treatment of the free-surface boundary condition and because our initial condition (a steady-state flow field and water table equilibrated to an assumed rate of potential recharge) is a better starting point than the initial condition used by Davies (a vertical hydrostatic head distribution beneath a water table that was assumed to be a subdued replica of the topography).

\subsection{Conceptual Model of Groundwater Flow in the Culebra}

An objective of this study is to use numerical simulations to enhance conceptual understanding of the hydrogeology of the Culebra Dolomite in the context of regional groundwater flow. We consider a conceptual model to be a qualitative description of the hydrologic processes, the geometry of the hydrogeologic system, the hydrostratigraphy, and the pattern of groundwater flow. In short, a conceptual model is an interpretation of reality. In this section we present aspects of the conceptual model of groundwater flow in the Culebra that was formulated by integrating our previous conceptual understanding with the new information provided by these numerical simulations. Simulation results are incorporated without specifically identifying them as such. We have also taken the liberty to write this section as if it were reality so that it would reflect the spirit of what we believe a conceptual model is. 
Groundwater flow in the Culebra in the vicinity of the WIPP is a portion of a larger hydrologic system that includes all of the rock units that overlie the Salado Formation. This system extends laterally well beyond the WIPP site to the boundaries of a groundwater basin. The basin boundary is not fixed in time; the basin is more extensive during dry periods in which the water table is at depth and less extensive during wet periods in which the water table is near to the land surface. The boundaries of the numerical model (Figure 2-2) approximately represent the basin boundaries for dry periods. These boundaries, therefore, outline the minimum region that must be considered to conceptually understand the evolution of modern-day flow conditions from past, wetter climates and their extrapolation into the future.

There is a continuous water table across the groundwater basin. This water table is probably in the Dewey Lake Formation within the WIPP-site boundary. In places the hydraulic conductivity of the Dewey Lake is small enough that groundwater inflow to an open drill hole penetrating the saturated portion of this unit is too slow to be easily observed. It is also possible that some saturated portions of the Dewey Lake might be perched, i.e., that they overlie a partially saturated region. Perched regions, if they exist, are part of the percolation process. They might affect the distribution of percolation at the water table but do not directly affect flow in the saturated zone.

A fundamental aspect of the conceptual model that has evolved from this study and previous studies is that the groundwater system is dynamic and is responding to the drying of the climate that has occurred since the end of the Pleistocene. Recharge rates at the end of the Pleistocene were sufficient to maintain the water table near the land surface over much of the model domain. Groundwater flow, at that time, was controlled by the intermediate features of the land-surface topography. The gentle east-to-west slope of the land surface in the vicinity of WIPP, for example, caused groundwater in the Culebra to flow toward and discharge into Nash Draw. As the amount of moisture available to recharge the groundwater system decreased after the last glacial pluvial period, the elevation of the water table declined. The decline occurred first in areas of high topography. As the water table dropped, groundwater flow began to increasingly reflect the land-surface topography at the scale of the entire groundwater basin. That is, the flow was away from the areas along the north and north-east boundaries of the basin where landsurface elevations are greater than $1100 \mathrm{~m}$ and toward areas below $850 \mathrm{~m}$ in the Pecos River valley along the south boundary of the basin.

Dissolution of the upper Salado and associated processes has generated a zoned distribution of hydraulic conductivity at the basin scale. Hydraulic conductivities in the region in which dissolution is 
assumed to have disrupted stratigraphic layering (Zone 1 of Figure 2-6) is orders of magnitude larger than the region in which the strata are intact (Zone 4). A transition interval separates these regions. Flow magnitudes and directions are quite different in these regions. Lateral flow in the intact strata is slow and, regardless of the elevation of the water table, is directed toward the disrupted region in areas that are within about a kilometer of the transition interval. In contrast, flow in the disrupted region is relatively rapid and its direction depends on the elevation of the water table. Flow is toward topographic depressions along the west and south boundaries of the model domain if the water table is near land surface. Flow is directed toward the portion of the Pecos River valley along the south boundary if the water table is at depth.

Within the region of intact strata, the contrast in hydraulic conductivities plays an important role in determining flow patterns. The Dewey Lake and Triassic rocks are more permeable than the anhydrites at the top of the Rustler Formation. Consequently most of the water that recharges the groundwater basin flows only in these rocks above the Rustler. The rest leaks vertically through the upper anhydrites and is available for flow through the rest of the Rustler. Differences in hydraulic head along the base of the Dewey Lake provide the driving force for flow in the Rustler.

Groundwater flow in the Rustler Formation is characterized by very slow vertical leakage through confining units and faster lateral flow in conductive units. Specific discharges (flow rates per unit area) in the Culebra are 2 to 3 orders of magnitude greater than the vertical specific discharges across the top of the Culebra. However, vertical leakage can contribute a significant portion of the total inflow to portions of the Culebra that are extensive enough that the upper surface is very much larger than the area available for lateral flow. It is difficult to quantify the relative contribution of vertical leakage because the hydraulic conductivity of the anhydrite confining layers at a regional scale is not well known.

Studies of the isotopic composition of groundwater above the Salado have generated debate about where and when the groundwater that is currently in the Culebra within the WIPP site was recharged. Conceptually, we can find this information by tracing various flowpaths from the WIPP site upstream to the water table. We did not identify flow paths as part of the simulation study, but can reach some understanding by examining a large number of velocity distributions for the Culebra, Magenta, and Dewey Lake/Triassic units. These results suggest that flowpaths would have reached the water table in areas that are north and northeast of the WIPP site. The various flowpaths to the WIPP site would include relatively rapid lateral flow in the conductive units and slow vertical flow through the Rustler 
confining units. Flow paths that enter the WIPP-site portion of the Culebra by vertical leakage across its upper surface originated outside of the WIPP site but closer to the WIPP site than the flow paths that enter the WIPP site by lateral flow within the Culebra. None of the water in the Culebra is conceptualized as having been recharged in areas where the Culebra is at or near to the land surface. We also note that the travel time along the various flowpaths to the Culebra probably vary greatly. Therefore, the water currently in the Culebra is a mix of water with much different residence times.

The modern-day pattern of groundwater flow has not equilibrated to the present climate. There are two aspects to this disequilibrium. First, the position of the water table has not yet adjusted to past changes in recharge rates. A decrease in recharge that started at the end of the Pleistocene was complete by 8,000 years ago. The water table, however, is still in the process of adjusting to this change in recharge. Second, hydraulic heads in rocks with small conductivities are not adjusted to the current position of the water table. The base-case transient simulation shows, for example, that closed regions of maximum head occur in the Culebra at the present time. These maxima are in regions where the Culebra's conductivity is believed to have been reduced by precipitation of halite in pore space. Groundwater flows out of these regions too slowly for heads to remain in equilibrium with a falling water table. The persistence of these regions of high head delay the transition of the flow field to one that fully reflects the basin-scale topography.

We have said that the slow response of the water table to long-term changes in recharge is the dominant aspect of the transient nature of the groundwater system. However, superimposed on long-term changes in the flow system are short-term changes caused by alternating wet and dry periods during the Holocene. Each wet-and-dry cycle results in a rise and fall of the water table. The amount of change in the water table depends on the peak recharge rate and the rock properties. The simulated change is typically 5 to $15 \mathrm{~m}$. Changes in hydraulic head in the Culebra lag behind changes in the water table and have a smaller amplitude. The overall effect of the Holocene wet periods is to slow the long-term decline of the water table and to superimpose short-term, and relatively small, variations to long-term flow velocities.

\subsection{Implications for Flow in the Culebra in the Vicinity of WIPP}

In addition to contributing to a conceptual model of basin-scale groundwater flow, these numerical simulations provide information about the values of hydraulic parameters that cannot be measured in the lab and are extremely expensive or impossible to measure in the field. One of these 
parameters is the vertical conductivity of confining units averaged over areas that are large enough to be used to study regional flow. (This area is perhaps of the order of $10^{3}$ to $10^{6}$ square meters.) The conductivity of the confining units at this scale is difficult to infer from lab measurements because these measurements do not include the important affect of widely-spaced fractures. Pumping tests could theoretically measure the vertical conductivity of the confining layers over areas that are large enough to include the affects of fractures. However, the pumping periods for such tests would have to be significantly longer than the pumping periods of several months that have been used to date for tests at the WIPP site and are therefore not feasible. We compared the simulated steady-state vertical differences in head with field observations in order to estimate an upper bound for the Rustler confining layers in the vicinity of the WIPP. In this area, the confining units consist almost entirely of anhydrite. Representative values of fresh-water head for the Magenta and Culebra at the center of the WIPP site are 960 and $920 \mathrm{~m}$ respectively. The elevation of the water table has not been measured directly, but it is estimated to be at $980 \mathrm{~m}$ (Axness et al., 1995). The simulations suggest that the vertical conductivity of intact anhydrite is not larger than $1 \times 10^{-12} \mathrm{~m} / \mathrm{s}$ because all the simulations that use a larger value result in maximum head differences between the Culebra and Magenta of only $20 \mathrm{~m}$ (Figure 3-5).

A similar argument can be made that an upper bound for the conductivity of the Dewey Lake/Triassic rocks is about $1 \times 10^{-7} \mathrm{~m} / \mathrm{s}$. Simulations that use a higher value $\left(2 \times 10^{-6} \mathrm{~m} / \mathrm{s}\right)$ result in vertical head differences between the Magenta and Culebra of less than $5 \mathrm{~m}$ (Figure 3-1).

These simulations can also be used to estimate an upper bound on the long-term average rate at which recharge can occur. This number is not the same as the maximum average rate at which infiltration can occur. The latter depends on soil characteristics, climate factors, and plant communities. The former, in contrast, depends entirely on the geometry of the groundwater basin and the distribution of hydraulic conductivity. The average rate of recharge can't exceed the rate that is sufficient to maintain the water table near the land surface for more than a few thousand years. The simulated steady-state elevations of the water table (Figure 3-2) show that a recharge rate of $2.0 \mathrm{~mm} / \mathrm{yr}$ is more than sufficient to maintain the water table near the surface unless the conductivity of the Dewey Lake and Triassic rocks is $2 \times 10^{-6} \mathrm{~m} / \mathrm{s}$. As discussed in the previous paragraph, this value is too high for these rocks. Therefore, $2.0 \mathrm{~mm} / \mathrm{yr}$ appears to be the upper bound for the average rate of recharge over long periods of time.

These simulations suggest that, in the vicinity of the WIPP site, vertical flow across the top of the Culebra is directed downward. The amount of vertical leakage into Culebra at this site cannot be estimated with confidence. It contributes a small portion of the total inflow to the Culebra reference 
volume, perhaps $5 \%$ to $10 \%$, if the vertical conductivity of the confining units is $1 \times 10^{-13} \mathrm{~m} / \mathrm{s}$ or less. However vertical leakage may contribute more than $50 \%$ of the total inflow if the conductivity is an order of magnitude larger.

A robust implication of these simulations is that nearly all (greater than $90 \%$ in all simulations) outflow from the Culebra reference volume is by lateral flow. Therefore, contaminants introduced into the Culebra will travel toward the accessable environment within the Culebra rather than by leaking upward or downward into other units. This result provides confidence that a flow and transport model that assumes that flow occurs only in the Culebra would include the appropriate release pathways.

The simulation results suggest that natural changes in the flow system over the next 10,000 years will be small and will mainly reflect future short-term wet periods such as have occurred over the past 8,000 years. We assume that the simulated total lateral outflow from the portion of the Culebra that underlies the WIPP site is the model result that is most representative of possible impacts of climate change on future flow and transport in the Culebra. The results suggest that this flow rate will not be more than about two times the present rate. The actual increases, however, will most likely be less than a factor of two.

Of the model parameters varied in the simulations, the total lateral outflow from Culebra is most sensitive to the hydraulic conductivity of anhydrite layers in the Rustler Formation (Figures 3-31, 3-32, and 3-33). Total lateral flow increases as the conductivity of the anhydrites increases. This result suggests that the total lateral flow in the Culebra could increase in the future if boreholes or fracturing increase the vertical conductivity of the anhydrite confining units. The results also suggest that total lateral flow in the Culebra would be sensitive to the recharge rate and the conductivity of other units if the anhydrite conductivity is larger that $1 \times 10^{-12} \mathrm{~m} / \mathrm{s}$. As noted above, the simulation results suggest that the present-day conductivity of the anhydrites is less than this value.

\subsection{Summary}

Our objective was to use numerical simulations to enhance conceptual understanding of the hydrogeology of the Culebra Dolomite in the context of regional groundwater flow. We used, as a starting point, a general conceptual model of flow in groundwater basins that emphasizes the important role of the water table and topography of the land surface in driving regional groundwater flow. This conceptual model provided guidance to identify the lateral extent of the natural system and consequently, the location of boundaries of the numerical model . Recognizing that long-term changes in flow are due 
to movement of the water table in response to changes in climate, we used a free surface/seepage-face upper boundary condition. The results of the numerical simulations provided information that was used to formulate a site-specific conceptual model of regional groundwater flow in the vicinity of the WIPP.

The conceptual model that emerged from taking a groundwater-basin approach represents a significant advance in understanding. It differs from previous conceptual models in that it includes a description of the geometry of the groundwater basin, the distribution of rock hydraulic properties, and the physical mechanisms that drive groundwater flow. Previous conceptual models were limited to describing current flow conditions. They provided little basis to extrapolate backward or forward in time or to predict the impact of human induced disturbances to the hydrologic system. The new contributions to the conceptual understanding of the regional hydrogeology of the Culebra include the following:

- The shape and elevation of the water table largely determine rates and directions of groundwater flow in the Culebra.

- Groundwater inflow to the portion of the Culebra within the WIPP-site boundary is by a combination of lateral flow within the Culebra and extremely slow vertical leakage from the overlying Tamarisk.

- The term "recharge" refers to a process that occurs at the water table. Inflow to the Culebra originated as recharge distributed over large areas of the groundwater basin. Recharge that eventually reaches the Culebra within the WIPP site does not occur where the Culebra outcrops or where overlying confining units have been removed or fractured. The paths that water follows as it flows from the water table to the Culebra at the WIPP site necessarily include vertical leakage across confining layers. The travel time to reach the Culebra varies greatly along the various paths. The travel times are probably thousands or tens of thousands of years.

- Climate change alters recharge rates. Consequently the position of the water table changes and groundwater velocities at depth adjust accordingly. During wet climates, the water table is near the land surface and flow directions in the Culebra are controlled by local-scale features of the landsurface topography. As the water table drops to lower elevations during dry periods, it becomes smoother because it no longer follows the local features of the topography. Consequently, groundwater flow directions in the Culebra increasingly reflect regional rather than local features of the topography. 
- Modern-day flow velocities in the Culebra at the WIPP site can be understood and simulated using the groundwater basin conceptual model. The generally north-to-south flow is a result of the modern-day depth of the water table and the basin-scale distribution of hydraulic conductivity. Flow in wetter climates would rotate toward Nash Draw to the west. Flow in the Culebra directed away from Nash Draw is not supported by this model.

- The size and shape of the hydrogeologic system that determines groundwater flow velocities in the Culebra at the WIPP site have been identified.

Because this conceptual model includes the physical processes, actual system boundaries, and a qualitative description of rock properties, it is the best available starting point to evaluate the possible impacts of a some of the events or processes that are considered by the WIPP performance assessment.

Two new tools, the regional free-surface approach and a numerical model were developed as part of this study. To our knowledge, a free-surface approach has not previously been applied at the spatial scale of regional flow problems or to hydrologic systems that are transient over thousands of years. This approach was extremely helpful in this study and might be applied to better understand the groundwater hydrology in other arid or semi-arid regions. Finally, the numerical model is the only code that we are aware of that is designed to apply a free surface/seepage face boundary condition to a regional scale groundwater flow problem. We believe that it will prove to be a valuable tool in other studies of long-term regional groundwater flow. 


\section{REFERENCES}

Alt, H.W. 1980. "Numerical Solution of Steady-State Porous Flow Free Boundary Problems," Numerische Mathematik. Vol. 36, no. 1,73-98.

Axness, C., R. Beauheim, Y. Behl, K. Brinster, T. Corbet, K. Economy, G. Freeze, L. Meigs, H. Papenguth, D. Powers, P. Swift, M. Wallace, and S. Webb. 1995. "Systems Prioritization Method - Iteration 2, Baseline Position Paper: Non-Salado Flow and Transport." Albuquerque, NM: Sandia National Laboratories. (Copy on file in the Sandia WIPP Central Files, Sandia National Laboratories, Albuquerque, NM.)

Bachman, G.O. 1981. Geology of Nash Draw, Eddy County, New Mexico. Open-File Report 81-31. Denver, CO: U.S. Geological Survey.

Bachman, G.O. 1985. Assessment of Near-Surface Dissolution At and Near the Waste Isolation Pilot Plant (WIPP), Southeastern New Mexico. SAND84-7178. Albuquerque, NM: Sandia National Laboratories.

Bear, J., and A. Verruijt. 1987. Modeling Groundwater Flow and Pollution. Dordrecht; Boston, MA: D. Reidel Publishing; Norwell, MA: Sold and distributed in the U.S. and Canada by Kluwer Academic Publishers.

Beauheim, R.L., and R.M. Holt. 1990. "Hydrogeology of the WIPP Site," Geological and Hydrological Studies of Evaporites in the Northern Delaware Basin for the Waste Isolation Pilot Plant (WIPP), New Mexico, Field Trip \#14 Guidebook, Geological Society of America 1990 Annual Meeting, Dallas, TX, October 29-November 4, 1990. Leaders: D.W. Powers, R.M. Holt, R.L. Beauheim, and N. Rempe. SAND90-2035J. Dallas, TX: Dallas Geological Society. 131-179.

Borja, R.I., and S.S. Kishnani. 1991. "On the Solution of Elliptic Free-Boundary Problems via Newton's Method," Computer Methods in Applied Mechanics and Engineering. Vol. 88, no. 3, 341-361.

Bruch, J.C., Jr. 1980. "A Survey of Free Boundary Value Problems in the Theory of Fluid Flow through Porous Media: Variational Inequality Approach; Part I," Advances in Water Resources. Vol. 3, no. 2, 65-80.

Campbell, A.R., F.M. Phillips, and R.J. Vanlandingham. 1996. "Stable Isotope Study of Soil Water, WIPP Site New Mexico: Estimation of Recharge to Rustler Aquifers," Radioactive Waste Management and Environmental Restoration. Vol. 20, no. 2-3, 153-165.

COHMAP (Cooperative Holocene Mapping Project) Members. 1988. "Climatic Changes of the Last 18,000 Years: Observations and Model Simulations," Science. Vol. 241, no. 4869, 1043-1052.

Corbet, T.F., and M.G. Wallace. 1993. "Post-Pleistocene Patterns of Shallow Groundwater Flow in the Delaware Basin, Southeastern New Mexico and West Texas," Carlsbad Region, New Mexico and West Texas, New Mexico Geological Society Forty-fourth Annual Field Conference, Carlsbad, NM, October 6-9, 1993. Eds. D.W. Love, J.W. Hawley, B.S. Kues, J.W. Adams, G.W. Austin, and J.M. Barker. [Socorro, NM: New Mexico Geological Society]. 321-325.

Crank, J. 1984. Free and Moving Boundary Problems. Oxford; New York: Clarendon Press. 
Dagan, G. 1967. "Linearized Solutions of Free-Surface Groundwater Flow with Uniform Recharge," Journal of Geophysical Research. Vol. 72, no. 4, 1183-1193.

Dagan, G. 1989. Flow and Transport in Porous Formations. New York, NY: Springer-Verlag.

Dassargues, A., J.-P. Radu, and R. Charlier. 1988. "Finite Element Modeling of a Large Water Table Aquifer in Transient Conditions," Advances in Water Resources. Vol. 11, no. 2, 58-66.

Davies, P.B. 1989. Variable-Density Ground-Water Flow and Paleohydrology in the Waste Isolation Pilot Plant (WIPP) Region, Southeastern New Mexico. Open-File Report 88-490. Albuquerque, NM: U.S. Geological Survey.

de Marsily, G. 1986. Quantitative Hydrogeology: Groundwater Hydrology for Engineers. Orlando, FL: Academic Press.

Durbin, T.J., and C. Berenbrock. 1985. "Three-Dimensional Simulation of Free-Surface Aquifers by Finite-Element Method," Selected Papers in the Hydrologic Sciences 1985. Water-Supply Paper 2270. [Washington, DC: U.S. Geological Survey]. 51-67.

France, P.W., C.J. Parekh, J.C. Peters, and C. Taylor. 1971. "Numerical Analysis of Free Surface Seepage Problems," Journal of the Irrigation and Drainage Division, American Society of Civil Engineers. Vol. 97, no. IR1, 165-179.

Freeze, R.A., and J.A. Cherry. 1979. Groundwater. Englewood Cliffs, NJ: Prentice-Hall.

Freeze, R.A., and P.A. Witherspoon. 1967. "Theoretical Analyses of Regional Groundwater Flow: 2. Effect of Water-Table Configuration and Subsurface Permeability Variation," Water Resources Research. Vol. 3, no. 2, 623-634.

Haug, A., V.A. Kelley, A.M. LaVenue, and J.F. Pickens. 1987. Modeling of Ground-Water Flow in the Culebra Dolomite at the Waste Isolation Pilot Plant (WIPP) Site: Interim Report. SAND86-7167. Albuquerque, NM: Sandia National Laboratories.

Hawken, D.F., J.J. Gottlieb, and J.S. Hansen. 1991. "Review of Some Adaptive Node-Movement Techniques in Finite-Element and Finite-Difference Solutions of Partial Differential Equations," Journal of Computational Physics. Vol. 95, 254-302.

Holt, R.M., and D.W. Powers. 1988. Facies Variability and Post-Depositional Alteration Within the Rustler Formation in the Vicinity of the Waste Isolation Pilot Plant, Southeastern New Mexico. DOE/WIPP-88-004. Carlsbad, NM: Westinghouse Electric Corporation for U.S. Department of Energy.

Hubbert, M.K. 1940. "The Theory of Ground-Water Motion," The Journal of Geology. Vol. 48, no. 8, pt. $1,785-944$.

Hunter, R.L. 1985. A Regional Water Balance for the Waste Isolation Pilot Plant (WIPP) Site and Surrounding Area. SAND84-2233. Albuquerque, NM: Sandia National Laboratories.

Kipp, K.L., Jr. 1987. HST3D: A Computer Code for Simulation of Heat and Solute Transport in ThreeDimensional Ground-Water Flow Systems. Water-Resources Investigations 86-4095. Denver, CO: U.S. Geological Survey. 
Knupp, P. 1996. "A Moving Mesh Algorithm for 3-D Regional Groundwater Flow with Water Table and Seepage Face," Advances in Water Resources. Vol. 19, no. 2, 83-95. WPO \# 41661

Knupp, P., and S. Steinberg. 1993. The Fundamentals of Grid Generation. Boca Raton, FL: CRC Press.

Lacy, S.J., and J.H. Prevost. 1987. "Flow Through Porous Media: A Procedure for Locating the Free Surface," International Journal for Numerical and Analytical Methods in Mechanics. Vol. 11, no. 6, 585-601.

Lambert, S.J. 1987. Feasibility Study: Applicability of Geochronologic Methods Involving Radiocarbon and Other Nuclides to the Groundwater Hydrology of the Rustler Formation, Southeastern New Mexico. SAND86-1054. Albuquerque, NM: Sandia National Laboratories. WPO \# 24475

Lambert, S.J., and J.A. Carter. 1987. Uranium-Isotope Systematics in Groundwaters of the Rustler Formation, Northern Delaware Basin, Southeastern New Mexico. I: Principles and Preliminary Results. SAND87-0388. Albuquerque, NM: Sandia National Laboratories. WPO \# 24453

Lambert, S.J., and D.M. Harvey. 1987. Stable-Isotope Geochemistry of Groundwaters in the Delaware Basin of Southeastern New Mexico. SAND87-0138. Albuquerque, NM: Sandia National Laboratories. WPO \# 24150

Lappin, A.R., R.L. Hunter, D.P. Garber, P.B. Davies, R.L. Beauheim, D.J. Borns, L.H. Brush, B.M. Butcher, T. Cauffman, M.S.Y. Chu, L.S. Gomez, R.V. Guzowski, H.J. Iuzzolino, V. Kelley, S.J. Lambert, M.G. Marietta, J.W. Mercer, E.J. Nowak, J. Pickens, R.P. Rechard, M. Reeves, K.L. Robinson, and M.D. Siegel. 1989. Systems Analysis, Long-Term Radionuclide Transport, and Dose Assessments, Waste Isolation Pilot Plant (WIPP), Southeastern New Mexico; March 1989. SAND89-0462. Albuquerque, NM: Sandia National Laboratories. WPO \# 24125

LaVenue, A.M., and B.S. RamaRao. 1992. A Modeling Approach to Address Spatial Variability within the Culebra Dolomite Transmissivity Field. SAND92-7306. Albuquerque, NM: Sandia National Laboratories. WPO \# 23889

LaVenue, A.M., A. Haug, and V.A. Kelley. 1988. Numerical Simulation of Ground-Water Flow in the Culebra Dolomite at the Waste Isolation Pilot Plant (WIPP) Site: Second Interim Report. SAND88-7002. Albuquerque, NM: Sandia National Laboratories. WPO \# 28558

Liggett, J.A. 1977. "Location of Free Surface in Porous Media," Journal of the Hydraulics Division, American Society of Civil Engineers. Vol. 103, no. HY 4, 353-365.

Liggett, J.A., and P.L.F. Liu. 1983. The Boundary Integral Method for Porous Media Flow. London; Boston: Allen and Unwin.

McDonald, M.G., and A.W. Harbaugh. 1988. A Modular Three-Dimensional Finite-Difference GroundWater Flow Model. Open-File Report 83-875. Denver, CO: U.S. Geological Survey.

McDonald, M.G., A.W. Harbaugh, B.R. Orr, and D.J. Ackerman. 1991. A Method of Converting NoFlow Cells to Variable-Head Cells for the U.S. Geological Survey Modular Finite-Difference Ground-Water Flow Model. Open-File Report 91-536. Denver, CO: U.S. Geological Survey. 
Neuman, S.P., and P.A. Witherspoon. 1970. "Finite Element Method of Analyzing Steady Seepage with a Free Surface," Water Resources Research. Vol. 6, no. 3, 889-897.

Neuman, S.P., and P.A. Witherspoon. 1971. "Analysis of Nonsteady Flow with a Free Surface Using the Finite Element Method," Water Resources Research. Vol. 7, no. 3, 611-623.

Polubarinova-Kochina, P.Y. 1962. Theory of Groundwater Movement. Translated from Russian by J.M.R. DeWiest. Princeton, NJ: Princeton University Press.

Potter, S.T., and W.J. Gburek. 1987. "Seepage-Face Stimulation Using PLASM," Ground Water. Vol. 25 , no. $6,722-732$.

Powers, D.W., and R.M. Holt. 1990. "Sedimentology of the Rustler Formation near the Waste Isolation Pilot Plant (WIPP) Site," Geological and Hydrological Studies of Evaporites in the Northern Delaware Basin for the Waste Isolation Pilot Plant (WIPP), New Mexico, GSA Field Trip \#14, November 1-4, 1990. Leaders: D. Powers, R. Holt, R.L. Beauheim, and N. Rempe. Dallas, TX: Dallas Geological Society. 79-106.

Reeves, M., D.S. Ward, N.D. Johns, and R.M. Cranwell. 1986. Theory and Implementation for SWIFT II: The Sandia Waste-Isolation Flow and Transport Model for Fractured Media, Release 4.84. SAND83-1159. Albuquerque, NM: Sandia National Laboratories.

Richey, S.F. 1987. Water-Level Data from Wells in the Vicinity of the Waste Isolation Pilot Plant, Southeastern New Mexico. Open-File Report 87-120. Albuquerque, NM: U.S. Geological Survey.

Swift, P.N. 1993. "Long-Term Climate Variability at the Waste Isolation Pilot Plant, Southeastern New Mexico, USA," Environmental Management. Vol. 17, no. 1, 83-97.

Tóth, J. 1963. "A Theoretical Analysis of Groundwater Flow in Small Drainage Basins," Journal of Geophysical Research. Vol. 68, no. 16, 4795-4812.

Wang, K.P., and J.C. Bruch, Jr. 1989. "Solutions of a Steady State Free Surface Seepage Problem on a Hypercube Concurrent Computer," Engineering Computations. Vol. 6, no. 3, 225-236. 
APPENDIX A

A-1 
This page intentionally left blank

A-2 


\section{APPENDIX A \\ A Simplified Derivation of the Steady-State Kinematic Boundary Condition}

Assume a $2 \mathrm{D}$ vertical slab geometry so that all derivatives in the $y$-direction are zero (i.e., we are in the $x$-z plane). To simplify the discussion, consider the steady-state case, which, as we shall see, also has the quadratic term in its corresponding kinematic boundary condition (KBC). The steady-state mass conservation statement at the water-table is: the fluid mass injected across the water-table (due to recharge) must equal the fluid mass drained away from the water-table by Darcy flow. Let $\rho$ be the density of the fluid, $\Delta x \Delta y$ be the local area of the water-table surface, $\Delta t$ the time interval (only needed to get the units right), and $\omega$ be the specific yield. Let the conductivity tensor $\kappa$ be diagonal and the specific discharge due to Darcy Flow be $\omega \mathbf{u}=-\kappa \nabla h, v$ be the unit outward normal to the water-table surface, and $\mathrm{N}$ be the infiltration vector. Then, the mass conservation statement can be given as

$$
\rho \frac{\mathbf{N}}{\omega} \cdot v \Delta x \Delta y \Delta t=\rho \mathbf{u} \cdot v \Delta x \Delta y \Delta t
$$

It is usual to assume that $\mathbf{N}$ is parallel to the $z$-axis, i.e., purely vertical infiltration, so let $\mathbf{N}=-R \hat{k}$ with $R>0$ representing recharge. Then the previous equation may be re-arranged to give

$$
\kappa \nabla h \cdot v=R \hat{k} \cdot v
$$

The Cartesian components of these vectors are:

$$
\begin{gathered}
\hat{k}=(0,1), \\
v=(-\sin \theta, \cos \theta), \\
\kappa \nabla h=\left(K_{11} \frac{\partial h}{\partial x}, K_{33} \frac{\partial h}{\partial z}\right),
\end{gathered}
$$

where $\theta$ is the angle between the surface normal and the vertical. One therefore has

$$
-K_{11} \sin \theta \frac{\partial h}{\partial x}+K_{33} \cos \theta \frac{\partial h}{\partial z}=R \cos \theta
$$

Now if the water-table is level, $\theta=0$ and this relationship reduces to the intuitive result, vertical flow equals recharge. However, if the water-table is inclined to the vertical, this simple relation no longer 
holds. To see this, consider Figure 2-13, where it is clear that $\tan \theta=\partial z / \partial x$. From the boundary condition $h(x, z(x, t), t)=z(x, t)$ we have that

$$
\frac{\partial h}{\partial x}+\frac{\partial h}{\partial z} \frac{\partial z}{\partial x}=\frac{\partial z}{\partial x}
$$

from which one has

$$
\tan \theta=\frac{\partial h / \partial x}{1-\partial h / \partial z}
$$

Substituting this result into (49) gives the following kinematic condition:

$$
\left(K_{33}+R\right) \frac{\partial h}{\partial z}-R=K_{11}\left(\frac{\partial h}{\partial x}\right)^{2}+K_{33}\left(\frac{\partial h}{\partial z}\right)^{2}
$$

which contains the quadratic terms. Thus, the non-linear relationship is a direct result of simple mass conservation for the case of a non-level water-table. 
APPENDIX B

B-1 
This page intentionally left blank

B-2 


\section{APPENDIX B \\ Existence and Uniqueness of Solutions: A 1D Model Problem}

The goal in this section is to illustrate the likelihood that there can be multiple (or no) solutions to the steady-state free-surface problem. It is not likely that exact solutions to the full $3 \mathrm{D}$ free-surface problem can be found, so suppose we look for solutions to the following model problem which represents a simplified steady-state 'free-surface' example. Let the dependent variable be the head, $h$, and the independent variable be the elevation, $z$. The problem domain is $z_{B} \leq z \leq z_{T}$ with $z_{B}$ given and $z_{T}$ the elevation of the free surface (to be determined). Let $K(z)>0$ e the hydraulic conductivity and let the head satisfy the usual flow equation,

$$
\frac{\partial}{\partial z} K \frac{\partial h}{\partial z}=0
$$

on the interior. Because $z_{T}$ is unknown, we need three boundary conditions to close the problem. The boundary conditions are

- $h=h_{B}$ at $z=z_{B}$,

- $\partial h / \partial z=R / K$ at $z=z_{T}$, and

- $h=z_{T}$ at $z=z_{T}$.

The first boundary condition (Dirichlet) is imposed in lieu of the seepage boundary condition in the regional flow simulation. It's main purpose is to provide an outlet for the fluid that is injected into the domain via the recharge term $R$ so that a steady-state solution may exist. The second boundary condition is a simplified form of the steady-state kinematic boundary condition (the quadratic term has been dropped, but this remains a non-linear boundary condition because the conductivity at $z_{T}$ depends upon the location of the water-table). The third boundary condition is the usual head equals elevation Dirichlet condition that holds at the free surface.

The solution to these equations is readily found by integrating the interior equation and applying the first two boundary conditions:

$$
h(z)=h_{B}+R \int_{z_{B}}^{z} d s / K(s)
$$

To find the water-table elevation, we must find $z_{T}$ that satisfies the third boundary condition:

$$
z_{T}=h_{B}+R \int_{z_{B}}^{z_{T}} d s / K(s)
$$


The non-linearity of the problem now becomes readily apparent.

Even in the simplest case where $K$ is a constant, one can have multiple solutions. If $K$ is constant, the previous equation for $z_{T}$ becomes

$$
z_{T}=h_{B}+\rho\left(z_{T}-z_{B}\right)
$$

The head varies linearly with $z_{T}$ and, if $\rho \neq 1$, the water-table elevation can be found by solving a linear equation:

$$
z_{T}=\frac{h_{B}-\rho z_{B}}{1-\rho}
$$

In this case $z_{T}$ exists, uniquely. But if $\rho=1$. then (56) has no solution unless $h_{B}=z_{B}$. If the latter holds, then $z_{T}$ is indeterminate, i.e., there are an infinite number of solutions.

Physically, note that because the vertical gradient is always positive, one must have downward flow at all elevations. if $\rho<1$, then in order to have $z_{T}>z_{B}$ one must have $h_{B}>z_{B}$, i.e., positive pressure at the bottom. Conversely, if $\rho>1$, then one must have negative pressure at the bottom in order for $z_{T}>$ $z_{B}$. If $\rho=1$, there can be no steady-state because the flow in through the top cannot be balanced by the flow through the bottom unless the pressure at the bottom is exactly zero.

Now consider the case $K=K_{B} z_{B} / z$ with $K_{B}>0$. Then $K^{-1}$ is linear in $z$ so that the solution will be quadratic in $z$. Let $r=h_{B} / z_{B}, \rho_{B}=R / K_{B}$. Then one can show that the water-table elevation is

$$
\rho_{B}\left(z_{T} / z_{B}\right)_{ \pm}=1 \pm \sqrt{1-2 r \rho_{B}+\rho_{B}^{2}}
$$

i.e., there are two real solutions or there are none, depending on the sign of the radicand. If $\mathrm{r} \leq\left(1+\rho_{B}^{2}\right) /$ $2 \rho_{B}$, then there are two real solutions. To ensure that $z_{T}>z_{B}$ in this case, one needs $1<\mathrm{r}<\left(1+\rho_{B}^{2}\right) / 2 \rho_{B}$ with $\rho_{B} \leq 1$. Physically, this corresponds to having $K_{B} \geq R$ initially, but eventually one has $K<R$ (because $K$ decreases monotonically with $z$ ). The pressure is positive at the bottom.

To have exactly one solution with $z_{T}>z_{B}$ requires $\rho_{B}<1$ and $r=\left(1+\rho_{B}^{2}\right) / 2 \rho_{B}$.

To have no solutions, one needs $r>\left(1+\rho_{B}^{2}\right) / 2 \rho_{B}$. 
Note that it is not necessary that the conductivity be a discontinuous function in order that multiple solutions may exist.

The elevations in (55) are roots of the non-linear equation $F(z)=0$ where $F(z)=z-G(z)$ and

$$
G(z)=h_{B}+R \int_{z_{B}}^{z} d s / K(s)
$$

Assume that

- $R>0$ ( infiltration case), and

- $K(z)$ is a positive, piecewise continuous function on $\left[z_{B}, \infty\right)$.

The following properties of $G(z)$ are easily established:

- $G$ is continuous on $\left[z_{B}, \infty\right)$,

- $G^{\prime}$ exists except where $K$ is discontinuous. Where $K$ is continuous, $G^{\prime}=R / K>0$.

- If $z \geq z_{B}$, then $G(z)>h_{B}$.

$G$ therefore is continuous function, monotonically increasing from the value $h_{B}$. The properties of $F(z)$ are then

- $F$ is continuous on $\left[z_{B}, \infty\right)$,

- When $F^{\prime}$ exists, $F^{\prime}=1-G^{\prime}$. Extremae of $F$ occur when $K(z)=R$.

\section{Theorem One}

Let $z_{1}, z_{2}$ be consecutive zeros of $F$ with $F^{\prime}$ continuous. Then there exists $\tilde{z}, z_{1}<\tilde{z}<z_{2}$, such that $\mathrm{K}(\tilde{z})=R$.

\section{Proof}

A well-known theorem from calculus states that if $F$ is continuous, then there exists $\widetilde{z}$ with $\mathrm{z}_{1}<$ $\tilde{z}<z_{2}$ such that $F^{\prime}(\tilde{z})=0$. The result then follows from the fact that $F^{\prime}=1-G^{\prime}$. \& Corollary. If $R<K$ for $z \in\left[z_{B}, \infty\right)$ and $h_{B}>z_{B}$, then there exists exactly one solution to $F(z)=0$. If $R<K$ on $\left[z_{B}, \infty\right)$ and $h_{B}>$ $z_{B}$ there are no roots. $\S$

Note that this is a sufficient condition for a unique solution, but it is not necessary. For example, one also has a unique solution if $R>K$ on $\left[z_{B}, \infty\right)$ and $h_{B}>z_{B}$. 


\section{Theorem Two}

A sufficient condition for multiple solutions to exist: let the following three items hold,

- $F\left(z_{2}\right)=0$ with $z_{2}>z_{B}$,

- $R / K\left(z_{2}\right)>1$,

- $h_{B}>z_{B}$.

Then there exists $z_{B}<z_{1}<z_{2}$ such that $F\left(z_{1}\right)=0$. $\S$ Alternatively, one could have

- $F\left(z_{2}\right)=0$ with $z_{2}>z_{B}$,

- $R / K\left(z_{2}\right)<1$,

- $h_{B}<z_{B}$. 
SELECTED RESULTS FROM STEADY-STATE SIMULATIONS

C-1 
This page intentionally left blank

C-2 


\section{Appendix C}

\section{Selected Results from Steady-State Simulations}

This appendix contains simulated elevations of the water table, values of hydraulic head in the Magenta and Culebra dolomites, flow magnitudes and directions in the Dewey Lake/Triassic rocks, Magenta Dolomite and Culebra Dolomite, and the vertical specific recharge across the upper surface of the Culebra Dolomite at nine locations within the WIPP site (tables C-1 through C-10). The UTM coordinates of the nine locations are: Node 1, E612000, N3580000; Node 2, E614000, N3580000; Node 3, E616000, N3580000; Node 4, E612000, N3582000; Node 5, E614000, N3582000; Node 6, E616000, N3582000; Node 7, E612000, N3584000; Node 8, E614000, 3584000; Node 9, E616000, N3584000. Node 1 is located in position 7 in the insert of Figure 3-49. Node 2 is in position 8, Node 3 is in position 9, Node 4 is in position 4 , Node 5 is in position 5 , Node 6 is in position 6 , Node 7 is in position 1 , Node 8 is in position 2, and Node 9 is in position 3.

This appendix also contains a summary of the mass balance over the reference volumes of the Magenta and Culebra hydrostratigraphic units (tables C-11 and C-12). Reference volumes are defined in the introduction of Section 3 of this report. These are the portions of the hydrostratigraphic units that underlie a $6 \mathrm{~km}$ by $6 \mathrm{~km}$ area that approximately corresponds to the WIPP site. The UTM coordinates of the corners of the surface trace of the reference volumes are N3585000, E611000; N3585000, E617000; $\mathrm{N} 3570000, \mathrm{E} 617000$; and N357000, E611000. The total flow values in the mass-balance summaries have been truncated to the nearest integer value.

The complete results from these simulations are retained in the WIPP-project central files in electronic form. In that file, the corresponding simulation numbers are preceded by the numbers "0401". For example, simulation number 01 in this report is stored as simulation number 040101 in the central files. 
This page intentionally left blank

C-4 
Table C-1. Simulated Water Table Elevation (m) Near the WIPP Site

\begin{tabular}{|c|c|c|c|c|c|c|c|c|c|c|c|c|c|}
\hline $\begin{array}{l}\text { Rum } \\
\text { ID. }\end{array}$ & $\begin{array}{c}R \\
(m m / y x) \\
\end{array}$ & 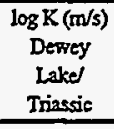 & $\begin{array}{c}\log \mathrm{K}(\mathrm{m} / \mathrm{s}) \\
\text { Arhydate } \\
\end{array}$ & $\begin{array}{c}\log \mathrm{K}(\mathrm{m} / \mathrm{s}) \\
\text { Dissupted } \\
\text { Rezion } \\
\end{array}$ & nodel & de2 2 & node3 & de4 & nodes & node6 & de? & les & nodes \\
\hline 01 & 0.2 & -4.5 & -13.0 & -5.7 & 951.4 & 947.2 & 944.1 & 948.3 & 945.8 & 943.8 & 945.7 & 944.6 & 943.4 \\
\hline 02 & 0.2 & -4.5 & -13.0 & -6.7 & 995.0 & 998.7 & 1001.7 & 991.8 & 996.8 & 1000.7 & 987.7 & 994.2 & 999.2 \\
\hline 03 & 0.2 & -4.5 & -13.0 & -7.7 & 1030.0 & 1040.0 & 1052.2 & 1035.0 & 1045.0 & 1058.9 & 1035.0 & 1047.5 & 1060.0 \\
\hline 04 & 0.2 & -4.5 & -12.0 & -5.7 & 947.7 & 941.8 & 937.8 & 944.7 & 941.1 & 938.5 & 942.1 & 940.3 & 938.6 \\
\hline 05 & 0.2 & -4.5 & -12.0 & -6.7 & 981.9 & 984.9 & 987.7 & 979.6 & 983.8 & 987.4 & 976.2 & 981.8 & 986.5 \\
\hline 06 & 0.2 & -4.5 & -12.0 & -7.7 & 1029.7 & 040.0 & 1051.4 & 1032.4 & 1045.0 & 1058.2 & 1028.8 & 1043.6 & 1080.0 \\
\hline 07 & 0.2 & -4.5 & -11.0 & -5.7 & 923.3 & 920.7 & 918.7 & 923.8 & 922.1 & 920.7 & 924.3 & 923.2 & 922.0 \\
\hline 08 & 0.2 & -4.5 & -11.0 & -6.7 & 958.2 & 961.8 & 965.7 & 957.6 & 962.2 & 966.5 & 955.8 & 961.0 & 966.2 \\
\hline 09 & 0.2 & -4.5 & -11.0 & -7.7 & 985.5 & 1008.4 & 1035.8 & 987.5 & 1013.0 & 1040.1 & 83.7 & 1006.9 & 1039.1 \\
\hline 10 & 0.2 & -5.5 & -13.0 & -5.7 & 957.1 & 954.3 & 951.9 & $95 \dot{6.3}$ & 954.6 & 953.0 & 955.8 & 954.9 & 953.8 \\
\hline 11 & 0.2 & -5.5 & -13.0 & -6.7 & 1006.1 & 1010.4 & 1013.7 & 1004.3 & 1009.7 & 1013.8 & 1001.8 & 1008.5 & 1013.5 \\
\hline 12 & 0.2 & -5.5 & -13.0 & -7.7 & 1030.0 & 1040.0 & 1052.3 & 1035.0 & 1045.0 & 1058.9 & 035.0 & 1047.9 & 060.0 \\
\hline 13 & 0.2 & -5.5 & -12.0 & -5.7 & 955.0 & 951.7 & 949.2 & 954.5 & 952.4 & 950.5 & 954.1 & 952.9 & 951.6 \\
\hline 14 & 0.2 & -5.5 & -12.0 & -6.7 & 996.4 & 1000.5 & 1003.8 & 996.0 & 1001.0 & 1005.0 & 994.7 & 1000.7 & 1005.5 \\
\hline 15 & 0.2 & -5.5 & -12.0 & -7.7 & 1030.0 & 1040.0 & 1051.6 & 1034.2 & 1045.0 & 1058.4 & 1033.0 & 1046.2 & 1060.0 \\
\hline 16 & 0.2 & -5.5 & -11.0 & -5 & 935.9 & 934.2 & 932.7 & 937.5 & 936.2 & 935.0 & 938.6 & 937.7 & 936.7 \\
\hline 17 & 0.2 & -5.5 & -11.0 & -6 & 980.7 & 984.9 & 989.0 & 982.6 & 987.5 & 991.7 & 3.3 & 988.7 & 993.5 \\
\hline 18 & 0.2 & -5.5 & -11.0 & -7. & 1001.7 & 1020.3 & 1042.7 & 1007.0 & 1027.5 & 1049.5 & 1006.8 & 1026.2 & 1051.4 \\
\hline 19 & 0.2 & -6.5 & -13.0 & -5 & 964.5 & 963.2 & 962.0 & 965.4 & 964.6 & 963.7 & 966.3 & 965.8 & 965.1 \\
\hline 20 & 0.2 & -6.5 & -13.0 & -6 & 1017.4 & 1022.8 & 1026.9 & 1017.2 & 1023.1 & 1027.7 & 1016.3 & 1023.0 & 1028.2 \\
\hline 21 & 0.2 & -6.5 & -13.0 & -7 & 1030.0 & 1040.0 & 1052.3 & 1035.0 & 1045.0 & 1058.9 & 035.0 & 1048.0 & 9060.0 \\
\hline 22 & 0.2 & -6.5 & -12.0 & -5 & 959.8 & 958.8 & 957.7 & 961.2 & 960.5 & 959.7 & $9 \varsigma 2.4$ & 961.9 & 961.3 \\
\hline 23 & 0.2 & -6.5 & -12.0 & -6 & 1013.7 & 1018.5 & 1022.3 & 1013.5 & 1019.1 & 1023.4 & 10128 & 1019.1 & 1024.1 \\
\hline 24 & 0.2 & -6.5 & -12.0 & -7 & 1030.0 & 1040.0 & 1051.8 & 1034.9 & 1045.0 & 1058.5 & 034.6 & 1047.0 & 1060.0 \\
\hline 25 & 0.2 & -6.5 & -11. & -5 & 957.9 & 956.9 & 955.9 & 959.4 & 958.7 & 957.9 & 160.7 & 960.3 & 959.7 \\
\hline 26 & 0.2 & -6.5 & -11.0 & -6 & 1004.5 & 1009.4 & 1013.6 & 1005.4 & 1010.9 & 1015.5 & 1005.6 & 1011.7 & 1016.8 \\
\hline 27 & 0.2 & -6.5 & -11.0 & -7 & 1020.4 & 1034.2 & 1049.4 & 1024.1 & 1040.3 & 1056.7 & 4.2 & 1040.3 & 1059.9 \\
\hline 28 & 2.0 & -4.5 & -13.0 & -5 & 1008.6 & 1013.0 & 1016.4 & 1006.5 & 1012.1 & 1016.3 & 3.8 & 1010.7 & 1015.8 \\
\hline 29 & 2.0 & -4.5 & -13.0 & -6 & 1030.0 & 1040.0 & 1052.4 & 1035.0 & 1045.0 & 1059.0 & 35.0 & 1048.5 & 1060.0 \\
\hline 30 & 2.0 & -4.5 & -13.0 & -7 & 1030.0 & 1040.0 & 1055.0 & 1035.0 & 1045.0 & 1060.0 & 35.0 & 1055.0 & 1080.0 \\
\hline 31 & 2.0 & -4.5 & -120 & -5 & 1007.4 & 1011.8 & 1015.2 & 1005.5 & 1011.0 & 1015.2 & 2.9 & 1009.7 & 1014.8 \\
\hline 32 & 2.0 & -4.5 & -12.0 & -6 & 1030.0 & 1040.0 & 1052.4 & 1035.0 & 1045.0 & 1059.0 & 5.0 & 1048.4 & 1060.0 \\
\hline 33 & 2.0 & -4.5 & & -7 & 1030.0 & 1040.0 & 1055.0 & & 1045.0 & 1060.0 & & 1055.0 & 1050.0 \\
\hline 34 & 2.0 & -4.5 & -1 & -5 & 03.7 & 1007.9 & 1011.3 & 1002.2 & 1007.6 & 1011.7 & 0.0 & 1006.6 & 1011.6 \\
\hline 35 & 2.0 & -4.5 & -11 & -6 & 1030.0 & 1040.0 & 1052.3 & 1035.0 & 1045.0 & 1058.9 & 5.0 & 1048.0 & 1060.0 \\
\hline 36 & 2.0 & -4.5 & & -7 & 1030.0 & 1040.0 & & & 1045.0 & 1060.0 & & 1055.0 & 1060.0 \\
\hline 37 & 2.0 & -5.5 & & & 1018.5 & 1024.2 & 1028.4 & 1018.3 & 1024.5 & 1029.1 & 7.5 & 1024.3 & 1029.6 \\
\hline 38 & 2.0 & -5.5 & -13 & -6 & 1030.0 & 1040.0 & 1052.4 & 1035.0 & 1045.0 & 1059.0 & 5.0 & 1048.6 & 1050.0 \\
\hline 39 & 2.0 & -5.5 & & -7 & 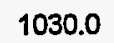 & 104 & & & .0 & & & & 1060.0 \\
\hline 40 & 2.0 & 5 & & & 18 & 1023.8 & 1028.0 & 1018.0 & 1024.1 & 1028.7 & .1 & 1024.0 & 1029.2 \\
\hline 41 & 2.0 & -5.5 & -12 & -6 & 1030.0 & 1040.0 & 1052.4 & 1035.0 & 1045.0 & 1059.0 & 5.0 & 1048.4 & 1060.0 \\
\hline 42 & 2.0 & -5.5 & -12 & -7 & 30.0 & 1040.0 & & & 1045.0 & 1060.0 & & & 1080.0 \\
\hline 43 & 2.0 & & & & 促 & 1022.3 & 10 & 1016.7 & 1022.7 & 1027.3 & 5.9 & 1022.7 & 1027.9 \\
\hline 44 & 2.0 & -5.5 & & -6 & 1030.0 & 1040.0 & 1052.3 & 1035.0 & 1045.0 & 1059.0 & 5.0 & 1048.1 & 1060.0 \\
\hline 45 & 2.0 & -5.5 & -11 & -7 & 1030.0 & 1040.0 & & 1035.0 & 1045.0 & & & & 1060.0 \\
\hline 46 & 2.0 & & & & a & 1032.0 & 1037.5 & 1026.6 & 1033.3 & 1038.5 & 7.0 & 3.9 & 1039.4 \\
\hline 47 & 2.0 & -6 & -13.0 & -6 & 1030.0 & 1040.0 & 1052.5 & 1035.0 & 1045.0 & 1059.0 & 1035.0 & 1048.6 & 1060.0 \\
\hline 48 & 2.0 & -6.5 & -13.0 & -7. & 1030.0 & 1040.0 & 1055.0 & 1035.0 & 1045.0 & 1060.0 & 1035.0 & 1055.0 & 1060.0 \\
\hline 49 & 2.0 & -6.5 & -12.0 & -5 & 1024.5 & 1031.9 & 1037.4 & 1026.5 & 1033.2 & 1038.4 & 1027.0 & 3.8 & 1039.3 \\
\hline 50 & 2.0 & -6.5 & -12.0 & -6.7 & 1030.0 & 1040.0 & 1052.4 & 1035.0 & 1045.0 & 1059.0 & 1035.0 & 1048.5 & 1060.0 \\
\hline 51 & 2.0 & -6.5 & -12.0 & -7.7 & 1030.0 & 1040.0 & 1055.0 & 1035.0 & & 1060.0 & 1035.0 & 1055.0 & 1060.0 \\
\hline 52 & 2.0 & -6.5 & & -5 & 1024.4 & 1031.7 & 1037.1 & 1026.3 & 1033.0 & 1038.2 & 9026.8 & 10 & 1039.0 \\
\hline 53 & 2.0 & -6.5 & -11.0 & -6.7 & 1030.0 & 1040.0 & 1052.4 & 1035.0 & 1045.0 & 1059.0 & 1035.0 & 1048.3 & 1060.0 \\
\hline 54 & 2.0 & -6.5 & -11.0 & -7.7 & 1030.0 & 1040.0 & 1055.0 & 1035.0 & 1045.0 & 1060.0 & 1035.0 & 1055.0 & 1060.0 \\
\hline
\end{tabular}


Table C-2. Simulated Hydraulic Head (m) In the Magenta Dolomite Near the WIPP Site

\begin{tabular}{|c|c|c|c|c|c|c|c|c|c|c|c|c|c|}
\hline $\begin{array}{l}\text { Rmin } \\
\text { ID. }\end{array}$ & $\begin{array}{c}R \\
(m m b y r) \\
\end{array}$ & $\begin{array}{l}\log \mathrm{K}(\mathrm{m} / \mathrm{s}) \\
\text { Dewrey } \\
\text { Lake/ } \\
\text { Triassic }\end{array}$ & $\begin{array}{l}\log K(\mathrm{~m} / \mathrm{s}) \\
\text { Anhydrite }\end{array}$ & $\begin{array}{c}\log K(\mathrm{~m} / \mathrm{s}) \\
\text { Disrupted } \\
\text { Region }\end{array}$ & nodel & node2 & nodes & node4 & nodes & gode6 & node7 & node8 & nodeg \\
\hline 01 & 0.2 & -4.5 & -13.0 & -5.7 & 936.6 & 936.1 & 936.9 & 937.9 & 940.0 & 939.4 & 939.1 & 940.3 & 941.0 \\
\hline 02 & 0.2 & -4.5 & -13.0 & -6.7 & 936.7 & 938.8 & 958.5 & 940.9 & 960.5 & 971.2 & 946.1 & 956.8 & 977.0 \\
\hline 03 & 0.2 & -4.5 & -13.0 & -7.7 & 933.1 & 938.4 & 976.0 & 937.3 & 976.5 & 1001.3 & 944.1 & 966.6 & 1013.2 \\
\hline 04 & 0.2 & -4.5 & -12.0 & -5.7 & 937.3 & 935.2 & 933.3 & 938.6 & 938.4 & 936.0 & 938.7 & 939.4 & 937.7 \\
\hline 05 & 0.2 & -4.5 & -12.0 & -6.7 & 951.2 & 954.7 & 966.2 & 953.5 & 970.5 & 973.1 & 957.3 & 972.6 & 978.1 \\
\hline 06 & 0.2 & -4.5 & -12.0 & -7.7 & 975.3 & 983.3 & 1010.9 & 979.0 & 1017.6 & 1028.1 & 986.4 & 1022.6 & 1040.4 \\
\hline 07 & 0.2 & -4.5 & -11.0 & -5.7 & 922.3 & 919.9 & 918.6 & 923.6 & 922.1 & 920.7 & 924.5 & 923.4 & 922.2 \\
\hline 08 & 0.2 & -4.5 & -11.0 & -6.7 & 944.1 & 949.3 & 961.6 & 946.8 & 958.9 & 964.8 & 949.6 & 958.8 & 964.7 \\
\hline 09 & 0.2 & -4.5 & -11.0 & -7.7 & 964.4 & 982.7 & 1025.4 & 968.2 & 1005.9 & 1035.2 & 973.1 & 1001.8 & 1035.0 \\
\hline 10 & 0.2 & -5.5 & -13.0 & -5.7 & 949.1 & 948.0 & 947.8 & 951.4 & 951.9 & 950.8 & 953.5 & 954.3 & 953.3 \\
\hline 11 & 0.2 & -5.5 & -13.0 & -6.7 & 957.1 & 958.3 & 976.2 & 963.8 & 980.3 & 989.6 & 972.1 & 981.8 & 996.9 \\
\hline 12 & .0 .2 & -5.5 & -13.0 & -7.7 & 955.4 & 958.2 & 989.9 & $9 ธ 3.9$ & 993.6 & 1013.9 & 974.6 & 992.1 & 1026.2 \\
\hline 13 & 0.2 & -5.5 & -12.0 & -5.7 & 949.5 & 947.6 & 946.1 & 951.5 & 950.9 & 949.2 & 953.0 & 952.9 & 951.4 \\
\hline 14 & 0.2 & -5.5 & -120 & -6.7 & 970.5 & 972.9 & 984.2 & 975.3 & 989.9 & 9929 & 981.9 & 994.3 & 999.3 \\
\hline 15 & 0.2 & -5.5 & -12.0 & -7.7 & 986.3 & 992.3 & 1017.5 & 993.5 & 1024.1 & 1034.5 & 1003.5 & 1031.2 & 1045.9 \\
\hline 16 & 0.2 & -5.5 & -11.0 & -5.7 & 932.4 & 931.2 & 931.9 & 935.8 & 935.8 & 934.8 & 938.4 & 937.8 & 936.8 \\
\hline 17 & 0.2 & -5.5 & -11.0 & -6.7 & 968.4 & 972.9 & 985.0 & 974.0 & 984.9 & 990.3 & 979.5 & 987.4 & 992.5 \\
\hline 18 & 0.2 & -5.5 & -11.0 & -7.7 & 983.2 & 997.7 & 1033.8 & 991.0 & 1021.7 & 1045.4 & 999.0 & 1022.4 & 1048.3 \\
\hline 19 & 0.2 & -6.5 & -13.0 & -5.7 & 955.8 & 954.8 & 956.4 & 959.6 & 961.0 & 960.8 & 953.8 & 965.4 & 964.4 \\
\hline 20 & 0.2 & -6.5 & -13.0 & -6.7 & 977.2 & 979.2 & 995.1 & 982.1 & 997.5 & 1006.5 & 989.8 & 999.2 & 1013.3 \\
\hline 21 & 0.2 & -6.5 & -13.0 & -7.7 & 975.1 & 978.4 & 1003.8 & 980.3 & 1005.0 & 10229 & 989.3 & 1004.5 & 1033.1 \\
\hline 22 & 0.2 & -6.5 & -12.0 & -5.7 & 954.5 & 953.5 & 954.5 & 957.7 & 958.8 & 958.1 & 961.1 & 962.0 & 961.1 \\
\hline 23 & 0.2 & -6.5 & -12.0 & -6.7 & 991.6 & 995.4 & 1006.8 & 995.0 & 1009.8 & 1013.4 & 01.2 & 3.3 & 1018.6 \\
\hline 24 & 0.2 & -6.5 & -12.0 & -7.7 & 996.6 & 1003.0 & 1025.9 & 1002.7 & 1029.2 & 1040.1 & 2.5 & 5.3 & 1049.4 \\
\hline 25 & 0.2 & -6.5 & -11.0 & -5.7 & 955.0 & 954.5 & 955.3 & 957.9 & 958.4 & 957.8 & 960.3 & 960.4 & 959.7 \\
\hline 26 & 0.2 & -6.5 & -11.0 & -6.7 & 995.7 & 1000.6 & 1010.6 & 998.5 & 1008.8 & 1014.3 & 1002.4 & 0.5 & 1016.0 \\
\hline 27 & 0.2 & -6.5 & -11.0 & -7.7 & 1005.9 & 1017.3 & 1043.0 & 1011.2 & 1035.8 & 1053.7 & 1017.8 & 1037.3 & 1057.6 \\
\hline 28 & 2.0 & -4.5 & -13.0 & -5.7 & 957.8 & 959.3 & 978.1 & 964.4 & 981.7 & 991.6 & 972.7 & 982.7 & 998.7 \\
\hline 29 & 2.0 & -4.5 & -13.0 & -6.7 & 956.3 & 959.6 & 991.2 & 964.5 & 994.2 & 1014.7 & 975.1 & 992.5 & 1026.6 \\
\hline 30 & 2.0 & -4.5 & -13.0 & -7.7 & 951.7 & 955.4 & 988.4 & 959.6 & 991.0 & 1012.5 & 969.6 & 988.6 & 1024.6 \\
\hline 31 & 2.0 & -4.5 & -12.0 & -5.7 & 977.6 & 981.9 & 994.5 & 981.3 & 998.8 & 1002.1 & 987.4 & & 1007.7 \\
\hline 32 & 2.0 & -4.5 & -12.0 & -6.7 & 984.9 & 992.3 & 1018.2 & 992.8 & 1024.1 & 1035.0 & 1004.1 & & 1046.0 \\
\hline 33 & 2.0 & -4.5 & & -7.7 & & & & & & & & & 1045.6 \\
\hline 34 & 2.0 & -4.5 & -11.0 & -5.7 & 988.0 & 994.4 & 1007.0 & 990.3 & 1004.1 & 1010.0 & 993.7 & & 1010.2 \\
\hline 35 & 2.0 & -4.5 & -11.0 & -6.7 & 004.7 & 1016.8 & 1044.3 & 012.5 & 1038.6 & 1055.2 & 021.2 & 1043.2 & 1057.1 \\
\hline 36 & 2.0 & -4.5 & -11.0 & -7.7 & 1002.5 & 1014.9 & 1045.9 & 1011.0 & 1038.2 & 1056.0 & 1020.5 & 1048.7 & 1057.0 \\
\hline 37 & 2.0 & -5.5 & -13.0 & -5.7 & 975.7 & $978.0^{-}$ & $995.6^{-}$ & $981: 0^{\circ}$ & $997.7^{-}$ & $1007: 5$ & 989.1 & 999.0 & 1014.2 \\
\hline 38 & 2.0 & -5.5 & -13.0 & -6.7 & 973.1 & 976.9 & 1003.6 & 978.4 & 1004.3 & 1022.9 & 987.3 & 1003.0 & 10329 \\
\hline 39 & 2.0 & -5.5 & & -7.7 & & & & & & 0.0 & & & 1031.0 \\
\hline 40 & 2.0 & -5.5 & -12.0 & -5.7 & 992.5 & 997.3 & 1010.2 & 996.2 & 1013.3 & 1017.2 & 002.9 & 1017.0 & 1022.8 \\
\hline 41 & 2.0 & -5.5 & -12.0 & -6.7 & 995.0 & 1002.0 & 1025.2 & 1000.8 & 1028.3 & 1039.5 & 010.6 & 1035.4 & 1048.8 \\
\hline 42 & 2.0 & -5.5 & -12.0 & -7.7 & & & & & & & & & 1048.4 \\
\hline 43 & 2.0 & -5.5 & -11.0 & -5.7 & 003.9 & 1010.7 & 1022.7 & 1006.2 & 1019.7 & 1025.8 & 1010.3 & 1020.7 & 1026.6 \\
\hline 44 & 2.0 & -5.5 & -11.0 & -6.7 & 011.7 & 1022.5 & 1046.0 & 1017.6 & 1040.1 & 1055.9 & 1024.8 & 1044.4 & 1057.7 \\
\hline 45 & 2.0 & -5.5 & -11.0 & -7.7 & 1009.8 & & 1047.7 & & & & & & 1057.8 \\
\hline 46 & 2.0 & -6.5 & -13.0 & -5.7 & 992.1 & 995.8 & 1012.0 & 995.5 & 1011.1 & 1021.1 & 1002.4 & 1011.4 & 1026.1 \\
\hline 47 & 2.0 & -6.5 & -13.0 & -6.7 & 993.2 & 997.9 & 1019.5 & 995.9 & 1016.7 & 1033.4 & 1003.0 & 1015.3 & 1040.2 \\
\hline 48 & 2.0 & -6.5 & & -7.7 & 989.5 & 994.5 & & & & & & & 1038.7 \\
\hline 49 & 2.0 & -6.5 & -12.0 & -5.7 & 1006.6 & 1012.0 & 1024.7 & 1009.7 & 1025.1 & 1029.8 & 1016.0 & 1028.1 & 1034.2 \\
\hline 50 & 2.0 & -6.5 & -12.0 & -6.7 & 1009.6 & 1016.2 & 1035.9 & 1013.2 & 1034.7 & 1046.3 & 1020.6 & 1039.3 & 1052.5 \\
\hline 51 & 2.0 & -6.5 & -12.0 & -7.7 & 1008.3 & & & 1011.8 & 1034.2 & 1046.4 & 1019.7 & 1042.6 & 1052.5 \\
\hline 52 & 2.0 & -6.5 & -11.0 & -5.7 & 1015.9 & 1023.0 & 1034.2 & 1018.8 & 1030.7 & 1037.0 & 1023.0 & 1032.2 & 1038.1 \\
\hline 53 & 2.0 & -6.5 & -11.0 & -6.7 & 1020.1 & 1029.2 & 1048.1 & 1024.5 & 1042.0 & 1056.7 & 1029.7 & 1045.8 & 1058.5 \\
\hline 54 & 20 & -6.5 & -11.0 & -7.7 & 1020.1 & 1029.3 & 1050.3 & 1024.3 & 1042.1 & 1057.6 & 1029.7 & 1051.4 & 1058.7 \\
\hline
\end{tabular}


Table C-3. Simulated Hydraulic Head (m) In the Culebra Dolomite Near the WIPP Site

\begin{tabular}{|c|c|c|c|c|c|c|c|c|c|c|c|c|c|}
\hline $\begin{array}{l}\text { Run } \\
\text { ID. }\end{array}$ & $\begin{array}{c}R \\
(\mathrm{~mm} / \mathrm{y}) \\
\end{array}$ & $\begin{array}{c}\log \mathrm{K}(\mathrm{m} / \mathrm{s}) \\
\text { Dewrey } \\
\text { Laked } \\
\text { Triassic }\end{array}$ & $\begin{array}{c}\log K(\mathrm{~m} / \mathrm{s}) \\
\text { Anhydrite }\end{array}$ & $\begin{array}{c}\log R(\mathrm{~m} / \mathrm{s}) \\
\text { Disnupted } \\
\text { Region } \\
\end{array}$ & nodel & rode? & node3 & node4 & nodes & node6 & node7 & node8 & nodeg \\
\hline 01 & 0.2 & -4.5 & -13.0 & -5.7 & 930.9 & 928.9 & 928.8 & 934.1 & 933.4 & 933.0 & 936.6 & 937.1 & 936.3 \\
\hline 02 & 0.2 & -4.5 & -13.0 & -6.7 & 919.3 & 916.3 & 919.8 & 926.5 & 926.7 & 929.8 & 932.6 & 934.2 & 938.0 \\
\hline 03 & 0.2 & -4.5 & -13.0 & -7.7 & 904.6 & 901.9 & 908.4 & 911.0 & 912.6 & 920.1 & 916.4 & 918.3 & 929.7 \\
\hline 04 & 0.2 & -4.5 & -12.0 & -5.7 & 925.1 & 923.1 & 925.9 & 929.7 & 930.2 & 931.3 & 933.3 & 934.1 & 934.5 \\
\hline 05 & 0.2 & -4.5 & -12.0 & -6.7 & 919.2 & 918.2 & 933.7 & 924.9 & 932.4 & 945.7 & 929.9 & 932.7 & 950.5 \\
\hline 06 & 0.2 & -4.5 & -12.0 & -7.7 & 919.1 & 920.2 & 950.4 & 922.9 & 939.9 & 970.4 & 926.4 & 931.4 & 976.7 \\
\hline 07 & 0.2 & -4.5 & -11.0 & -5.7 & 920.2 & 918.3 & 918.3 & 923.0 & 922.0 & 920.8 & 924.9 & 925.0 & 922.5 \\
\hline 08 & 0.2 & -4.5 & -11.0 & -6.7 & 927.9 & 931.2 & 955.2 & 930.3 & 948.3 & 961.6 & 932.1 & 937.7 & 960.0 \\
\hline 09 & 0.2 & -4.5 & -11.0 & -7.7 & 939.5 & 948.3 & 1009.6 & 940.8 & 983.2 & 1025.9 & 942.2 & 955.0 & 1022.0 \\
\hline 10 & 0.2 & -5.5 & -13.0 & -5.7 & 944.5 & 942.5 & 942.7 & 948.5 & 948.0 & 947.6 & 9521 & 953.1 & 952.0 \\
\hline 11 & 0.2 & -5.5 & -13.0 & -6.7 & 941.4 & 938.1 & 942.7 & 951.4 & 952.6 & 955.8 & 961.7 & 965.2 & 967.9 \\
\hline 12 & .0 .2 & -5.5 & -13.0 & -7.7 & 931.1 & 927.1 & 934.3 & 943.0 & 944.6 & 950.9 & 954.4 & 958.1 & 965.7 \\
\hline 13 & 0.2 & -5.5 & -12.0 & -5.7 & 941.4 & 939.2 & 941.1 & 946.3 & 946.4 & 946.6 & 950.6 & 951.7 & 950.7 \\
\hline 14 & 0.2 & -5.5 & -12.0 & -6.7 & 941.1 & 939.2 & 954.6 & 951.5 & 958.5 & 969.9 & 952.1 & 966.8 & 979,3 \\
\hline 15 & 0.2 & -5.5 & -12.0 & -7.7 & 941.6 & 940.7 & 967.2 & 951.3 & 964.8 & 989.1 & 961.1 & 967.2 & 1000.2 \\
\hline 16 & 0.2 & -5.5 & -11.0 & -5.7 & 928.0 & 926.7 & 930.7 & 933.2 & 934.5 & 934.6 & 937.7 & 938.7 & 937.0 \\
\hline 17 & 0.2 & -5.5 & -11.0 & -6.7 & & 956.1 & 979.0 & & 976.4 & 987.6 & 968.7 & 974.6 & 989.5 \\
\hline 18 & 0.2 & -5.5 & -11.0 & -7.7 & 961.7 & 967.6 & 1020.3 & 968.8 & 1003.4 & 1037.9 & 976.5 & 988.3 & 1038.6 \\
\hline 19 & 0.2 & -6.5 & -13.0 & -5.7 & 949.9 & 948.3 & 949.9 & 955.1 & 955.6 & 956.1 & 960.8 & 962.9 & 962.3 \\
\hline 20 & 0.2 & -6.5 & -13.0 & -6.7 & 962.9 & 961.5 & 966.2 & 9.8 & 972.3 & 976.3 & 978.4 & 982.4 & 986.3 \\
\hline 21 & 0.2 & -6.5 & -13.0 & -7.7 & 953.5 & 951.7 & 958.6 & 961.4 & 964.8 & 971.4 & 971.0 & 975.8 & 984.0 \\
\hline 22 & 0.2 & -6.5 & -12.0 & -5.7 & 947.7 & 946.3 & 949.4 & 952.7 & 954.0 & 955.2 & 958.3 & 960.4 & 960.1 \\
\hline 23 & 0.2 & -6.5 & -12.0 & -6.7 & 971.0 & 971.1 & 983.7 & 976.3 & 983.7 & 994.3 & 983.6 & 988.3 & 1000.9 \\
\hline 24 & 0.2 & -6.5 & -12.0 & -7.7 & 966.9 & 967.5 & 988.5 & 973.0 & 985.2 & 1005.4 & 981.4 & 987.9 & 1015.0 \\
\hline 25 & 0.2 & -6.5 & -11.0 & -5.7 & 951.8 & 951.2 & 954.4 & 955.5 & 957.3 & 957.6 & 959.4 & 960.8 & 959.8 \\
\hline 26 & 0.2 & -6.5 & -11.0 & -6.7 & 985.8 & 988.5 & 1006.1 & 988.7 & 1002.1 & 1012.1 & 993.4 & 999.1 & 1013.2 \\
\hline 27 & 0.2 & -6.5 & -11.0 & -7.7 & 989.6 & 995.1 & 1033.5 & 993.5 & 1021.7 & 1048.0 & 999.9 & 1010.7 & 1050.1 \\
\hline 28 & 2.0 & -4.5 & -13.0 & -5.7 & 943.9 & 940.9 & 945.3 & 953.1 & 954.4 & 957.6 & 962.6 & 966.0 & 969.0 \\
\hline 29 & 2.0 & -4.5 & -13.0 & -6.7 & 933.8 & 930.1 & 937.0 & 945.2 & 946.7 & 952.9 & 955.9 & 959.4 & 957.1 \\
\hline 30 & 2.0 & -4.5 & -13.0 & -7.7 & & & & & 1.0 & .5 & $\$ 47.7$ & 0.6 & 359.3 \\
\hline 31 & 2.0 & -4.5 & -12.0 & -5.7 & 948.4 & 947.4 & 963.4 & 956.4 & 964.3 & 977.0 & 964.9 & 969.4 & 984.5 \\
\hline 32 & 2.0 & -4.5 & -12.0 & -6.7 & 941.4 & 941.0 & 967.8 & 951.0 & 964.7 & 989.2 & 960.5 & 966.5 & 999.9 \\
\hline 33 & 2.0 & -4.5 & -12.0 & -7.7 & 936.3 & 935.8 & 96 & 945.5 & 959.7 & 986.1 & 954.2 & 959.9 & 996.8 \\
\hline 34 & 2.0 & -4.5 & -11.0 & -5.7 & 969.9 & 974.8 & 1000.4 & 972.5 & 992.9 & 1006.7 & 976.2 & 983.2 & 1005.5 \\
\hline 35 & 2.0 & -4.5 & -11.0 & -6.7 & 976.2 & 984.6 & 1032.2 & 979.5 & 1017.7 & 1048.2 & 983.4 & 996.4 & 1047.1 \\
\hline 36 & 2.0 & -4.5 & -11.0 & -7.7 & 971.8 & 980.2 & 1032.2 & 975.6 & 1015.9 & 1048.6 & 979.4 & 993.4 & 1046.9 \\
\hline 37 & 2.0 & -5.5 & -13.0 & -5.7 & 963.9 & 962.7 & 967.6 & 971.0 & 973.6 & 977.6 & 979.9 & 983.8 & 987.7 \\
\hline 38 & 2.0 & -5.5 & -13.0 & -6.7 & 955.1 & 953.5 & 960.2 & 962.8 & 966.1 & 972.7 & 972.2 & 976.7 & 984.9 \\
\hline 39 & 2.0 & -5.5 & -13.0 & -7.7 & 943.8 & 941.2 & 948.4 & 953.8 & 956.5 & 963.3 & 964.6 & 968.9 & 977.4 \\
\hline 40 & 2.0 & -5.5 & -12.0 & -5.7 & 968.6 & 959.0 & 983.6 & 974.5 & 982.9 & 995.1 & 982.4 & 987.3 & 1001.9 \\
\hline 41 & 2.0 & -5.5 & -12.0 & -6.7 & 962.3 & 963.4 & 985.6 & 968.3 & 981.3 & 1002.6 & 976.6 & 983.1 & 1012.0 \\
\hline 42 & 2.0 & -5.5 & -12.0 & -7.7 & 955.2 & 955.9 & 980.2 & 952.2 & 975.8 & 998.9 & 971.0 & 977.5 & 1009.2 \\
\hline 43 & 2.0 & -5.5 & -11.0 & -5.7 & 989.2 & 994.2 & 1016.9 & 990.7 & 1009.8 & 1022.9 & 994.6 & 1001.8 & 1022.4 \\
\hline 44 & 2.0 & -5.5 & -11.0 & -6.7 & 991.6 & 999.0 & 1036.6 & 992.9 & 1024.2 & 1050.1 & 996.8 & 1008.6 & 1050.0 \\
\hline 45 & 2.0 & -5.5 & -11.0 & -7.7 & 987.5 & 995.0 & 1036.8 & 989.5 & 1022.7 & 1050.5 & 993.8 & 1006.5 & 1050.0 \\
\hline 46 & 2.0 & -6.5 & -13.0 & -5.7 & 986.7 & 987.5 & 991.8 & 989.7 & 993.2 & 997.4 & 995.5 & 999.1 & 1003.9 \\
\hline 47 & 2.0 & -6.5 & -13.0 & -6.7 & 986.2 & 987.3 & 992.8 & 988.6 & 992.8 & 999.0 & 994.0 & 998.0 & 1006.1 \\
\hline 48 & 2.0 & -6.5 & -13.0 & -7.7 & 979.2 & 980.1 & 985.9 & 981.5 & 985.7 & 992.5 & 986.7 & 990.7 & 1000.0 \\
\hline 49 & 2.0 & -6.5 & -12.0 & -5.7 & 993.1 & 995.2 & 1006.3 & 995.1 & 1002.9 & 1013.2 & 1000.1 & 1004.5 & 1017.5 \\
\hline 50 & 2.0 & -6.5 & -12.0 & -6.7 & 995.3 & 998.2 & 1012.9 & 996.2 & 1006.5 & 1022.4 & 1000.7 & 1006.0 & 1028.3 \\
\hline 51 & 2.0 & -6.5 & -12.0 & -7.7 & 992.1 & 995.3 & 1011.1 & 992.4 & 1003.5 & 1020.8 & 996.4 & 1001.9 & 1026.9 \\
\hline 52 & 2.0 & -6.5 & -11.0 & -5.7 & 1006.8 & 1011.4 & 1029.8 & 1008.2 & 1023.5 & 1034.6 & 1012.4 & 1018.5 & 1034.9 \\
\hline 53 & 2.0 & -6.5 & -11.0 & -6.7 & 1010.0 & 1015.9 & 1041.9 & 1010.9 & 1032.3 & 1052.4 & 1015.2 & 1024.0 & 1053.6 \\
\hline 54 & 2.0 & -6.5 & -11.0 & -7.7 & 1010.1 & 1016.3 & 1043.4 & 1010.3 & 1032.4 & 1053.3 & 1014.3 & 1023.9 & 1054.0 \\
\hline
\end{tabular}


Table C-4. Simulated Magnitude of Lateral Specific Discharge $(\mathrm{m} / \mathrm{yr})$

in the Dewey Lake/Triassic Rocks Near the WIPP Site

\begin{tabular}{|c|c|c|c|c|c|c|c|c|c|c|c|c|c|}
\hline $\begin{array}{l}\mathrm{Rm} \\
\mathrm{D} \text {. }\end{array}$ & $\begin{array}{c}R \\
\left(\operatorname{mom} / y_{x}\right) \\
\end{array}$ & $\begin{array}{l}\log \mathrm{K}(\mathrm{m} / \mathrm{s}) \\
\text { Dewey } \\
\text { Lakef } \\
\text { Triassic } \\
\end{array}$ & $\begin{array}{c}\log \mathrm{K}(\mathrm{m} / \mathrm{s}) \\
\text { Anhydrite }\end{array}$ & $\begin{array}{c}\log \mathrm{K}(\mathrm{m} / \mathrm{s}) \\
\text { Disupted } \\
\text { Region } \\
\end{array}$ & nodel & node2 & node 3 & node4 & nodes & node6 & rode 7 & node8 & nodes \\
\hline 01 & 0.2 & -4.5 & -13.0 & -5.7 & 0.180 & 0.119 & 0.091 & 0.122 & 0.080 & 0.062 & 0.077 & 0.049 & 0.041 \\
\hline 02 & 0.2 & -4.5 & -13.0 & -6.7 & 0.015 & 0.011 & 0.009 & 0.021 & 0.016 & 0.012 & 0.028 & 0.020 & 0.015 \\
\hline 03 & 0.2 & -4.5 & -13.0 & -7.7 & 0.005 & 0.004 & 0.004 & 0.004 & 0.004 & 0.004 & 0.005 & 0.004 & 0.005 \\
\hline 04 & 0.2 & -4.5 & -12.0 & -5.7 & 0.231 & 0.152 & 0.116 & 0.151 & 0.099 & 0.080 & 0.089 & 0.060 & 0.054 \\
\hline 05 & 0.2 & -4.5 & -12.0 & -6.7 & 0.011 & 0.009 & 0.008 & 0.017 & 0.013 & 0.011 & 0.024 & 0.018 & 0.014 \\
\hline 06 & 0.2 & -4.5 & -120 & -7.7 & 0.004 & 0.004 & 0.004 & 0.004 & 0.004 & 0.004 & 0.005 & 0.005 & 0.005 \\
\hline 07 & 0.2 & -4.5 & -11.0 & -5.7 & 0.046 & 0.082 & 0.093 & 0.050 & 0.060 & 0.069 & 0.037 & 0.048 & 0.056 \\
\hline 08 & 0.2 & -4.5 & -11.0 & -6.7 & 0.010 & 0.012 & 0.012 & 0.014 & 0.014 & 0.013 & 0.018 & 0.017 & 0.015 \\
\hline 09 & 0.2 & -4.5 & -11.0 & -7.7 & 0.006 & 0.008 & 0.008 & 0.007 & 0.008 & 0.008 & 0.007 & 0.009 & 0.009 \\
\hline 10 & 0.2 & -5.5 & -13.0 & -5.7 & 0.103 & 0.080 & 0.079 & 0.059 & 0.053 & 0.058 & 0.026 & 0.035 & 0.045 \\
\hline 11 & 0.2 & -5.5 & -13.0 & -6.7 & 0.016 & 0.012 & 0.010 & 0.021 & 0.015 & 0.012 & 0.026 & 0.019 & 0.015 \\
\hline 12 & 0.2 & -5.5 & -13.0 & -7.7 & 0.005 & 0.004 & 0.004 & 0.004 & 0.004 & 0.004 & 0.005 & 0.004 & 0.005 \\
\hline 13 & 0.2 & -5.5 & -12.0 & -5.7 & 0.121 & 0.095 & 0.092 & 0.071 & 0.064 & 0.069 & 0.035 & 0.044 & 0.054 \\
\hline 14 & 0.2 & -5.5 & -12.0 & -6.7 & 0.015 & 0.012 & 0.011 & 0.018 & 0.014 & 0.012 & 0.023 & 0.017 & 0.014 \\
\hline 15 & 0.2 & -5.5 & -12.0 & -7.7 & 0.004 & 0.004 & 0.004 & 0.004 & 0.004 & 0.004 & 0.005 & 0.004 & 0.005 \\
\hline 16 & 0.2 & -5.5 & -11.0 & -5.7 & 0.060 & 0.087 & 0.093 & 0.054 & 0.066 & 0.073 & 0.044 & 0.055 & 0.063 \\
\hline 17 & 0.2 & -5.5 & -11.0 & -6.7 & 0.016 & 0.016 & 0.016 & 0.017 & 0.015 & 0.014 & 0.019 & 0.016 & 0.015 \\
\hline 18 & 0.2 & -5.5 & -11.0 & -7.7 & 0.005 & 0.007 & 0.007 & 0.006 & 0.007 & 0.006 & 0.006 & 0.007 & 0.007 \\
\hline 19 & 0.2 & -6.5 & -13.0 & -5.7 & 0.055 & 0.063 & 0.070 & 0.037 & 0.049 & 0.058 & 0.032 & 0.044 & 0.052 \\
\hline 20 & 0.2 & -6.5 & -13.0 & -6.7 & 0.020 & 0.015 & 0.012 & 0.021 & 0.016 & 0.013 & 0.025 & 0.019 & 0.015 \\
\hline 21 & 0.2 & -6.5 & -13.0 & -7.7 & 0.005 & 0.004 & 0.004 & 0.004 & 0.004 & 0.004 & 0.004 & 0.004 & 0.005 \\
\hline 22 & 0.2 & -6.5 & -12.0 & -5.7 & 0.062 & 0.068 & 0.074 & 0.044 & 0.055 & 0.062 & 0.039 & 0.049 & 0.056 \\
\hline 23 & 0.2 & -6.5 & -12.0 & -6.7 & 0.017 & 0.014 & 0.012 & 0.020 & 0.015 & 0.013 & 0.024 & 0.018 & 0.015 \\
\hline 24 & 0.2 & -6.5 & -12.0 & -7.7 & 0.004 & 0.004 & 0.004 & 0.004 & 0.004 & 0.004 & 0.005 & 0.004 & 0.005 \\
\hline 25 & 0.2 & -6.5 & -11.0 & -5.7 & 0.068 & 0.073 & 0.077 & 0.047 & 0.058 & 0.065 & 0.043 & 0.052 & 0.059 \\
\hline 26 & 0.2 & -6.5 & -11.0 & -6.7 & 0.017 & 0.015 & 0.014 & 0.019 & 0.016 & 0.014 & 0.022 & 0.018 & 0.015 \\
\hline 27 & 0.2 & -6.5 & -11.0 & -7.7 & 0.004 & 0.005 & 0.005 & 0.005 & 0.005 & 0.005 & 0.005 & 0.006 & 0.006 \\
\hline 28 & 2.0 & -4.5 & -13.0 & -5.7 & 0.168 & 0.123 & 0.098 & 0.214 & 0.157 & 0.121 & 0.273 & 0.194 & 0.148 \\
\hline 29 & 2.0 & -4.5 & -13.0 & -6.7 & 0.045 & 0.042 & 0.043 & 0.040 & $0.040^{\circ}$ & 0.041 & 0.047 & 0.039 & 0.045 \\
\hline 30 & 2.0 & -4.5 & -13.0 & -7.7 & 0.005 & 0.005 & 0.004 & 0.004 & 0.005 & 0.004 & 0.005 & 0.004 & 0.004 \\
\hline 31 & 2.0 & -4.5 & -12.0 & -5.7 & 0.166 & 0.122 & 0.098 & 0.211 & 0.155 & 0.120 & 0.269 & 0.192 & 0.147 \\
\hline 32 & 2.0 & -4.5 & -12.0 & -6.7 & 0.045 & 0.042 & 0.043 & 0.040 & 0.040 & 0.041 & 0.047 & 0.039 & 0.045 \\
\hline 33 & 2.0 & -4.5 & -12.0 & -7.7 & 0.005 & 0.005 & 0.004 & 0.004 & 0.005 & 0.004 & 0.005 & 0.004 & 0.004 \\
\hline 34 & 2.0 & -4.5 & -11.0 & -5.7 & 0.156 & 0.118 & 0.100 & 0.200 & 0.149 & 0.118 & 0.256 & 0.1 & 0.144 \\
\hline 35 & 2.0 & -4.5 & -11.0 & -6.7 & 0.045 & 0.042 & 0.043 & 0.040 & 0.039 & 0.041 & 0.049 & 0.039 & 0.046 \\
\hline 36 & 2.0 & -4.5 & -11.0 & -7.7 & $0: 004$ & 0.005 & 0.004 & 0.004 & 0.005 & 0.004 & 0.005 & 0.004 & 0.004 \\
\hline 37 & 2.0 & -5.5 & -13.0 & -5.7 & 0.213 & 0.157 & 0.123 & 0.221 & 0.169 & 0.134 & 0.256 & 0.191 & 0.151 \\
\hline 38 & 2.0 & -5.5 & -13.0 & -6.7 & 0.045 & 0.042 & 0.043 & 0.040 & 0.040 & 0.041 . & 0.045 & 0.039 & 0.045 \\
\hline 39 & 2.0 & -5.5 & -13.0 & -7.7 & 0.005 & 0.005 & 0.004 & 0.004 & 0.005 & 0.004 & 0.005 & 0.004 & 0.004 \\
\hline 40 & 2.0 & -5.5 & -12.0 & -5.7 & 0.210 & 0.155 & 0.123 & 0.220 & 0.168 & 0.133 & 0.255 & 0.190 & 0.151 \\
\hline 41 & 2.0 & -5.5 & -12.0 & -6.7 & 0.045 & 0.042 & 0.043 & 0.040 & 0.040 & 0.041 & 0.045 & 0.039 & 0.045 \\
\hline 42 & 2.0 & -5.5 & -12.0 & -7.7 & 0.005 & 0.005 & 0.004 & 0.004 & 0.005 & 0.004 & 0.005 & 0.004 & 0.004 \\
\hline 43 & 2.0 & -5.5 & -11.0 & -5.7 & 0.200 & 0.152 & 0.123 & 0.216 & 0.166 & 0.133 & 0.252 & 0.189 & 0.151 \\
\hline 44 & 2.0 & -5.5 & -11.0 & -6.7 & 0.045 & 0.042 & 0.043 & 0.040 & 0.040 & 0.041 & 0.046 & 0.039 & 0.046 \\
\hline 45 & 2.0 & -5.5 & -11.0 & -7.7 & 0.004 & 0.005 & 0.004 & 0.004 & 0.005 & 0.004 & 0.005 & 0.004 & 0.004 \\
\hline 46 & 2.0 & -6.5 & -13.0 & -5.7 & 0.283 & 0.209 & 0.157 & 0.235 & 0.190 & 0.152 & 0.237 & 0.195 & 0.160 \\
\hline 47 & 2.0 & -6.5 & -13.0 & -6.7 & 0.045 & 0.042 & 0.043 & 0.040 & 0.040 & 0.041 & 0.045 & 0.039 & 0.045 \\
\hline 48 & 2.0 & -6.5 & -13.0 & -7.7 & 0.005 & 0.005 & 0.004 & 0.004 & 0.005 & 0.004 & 0.005 & 0.004 & 0.004 \\
\hline 49 & 2.0 & -6.5 & -12.0 & -5.7 & 0.282 & 0.208 & 0.156 & 0.234 & 0.189 & 0.152 & 0.236 & 0.194 & 0.159 \\
\hline 50 & 2.0 & -6.5 & -12.0 & -6.7 & 0.045 & 0.042 & 0.043 & 0.040 & 0.040 & 0.041 & 0.045 & 0.039 & 0.045 \\
\hline 51 & 20 & -6.5 & -12.0 & -7.7 & 0.005 & 0.005 & 0.004 & 0.004 & 0.005 & 0.004 & 0.005 & 0.004 & 0.004 \\
\hline 52 & 2.0 & -6.5 & -11.0 & -5.7 & 0.277 & 0.205 & 0.155 & 0.232 & 0.188 & 0.151 & 0.234 & 0.193 & 0.159 \\
\hline 53 & 2.0 & -6.5 & -11.0 & -6.7 & 0.045 & 0.042 & 0.043 & 0.040 & 0.040 & 0.041 & 0.045 & 0.039 & 0.045 \\
\hline 54 & 2.0 & -6.5 & -11.0 & -7.7 & 0.004 & 0.005 & 0.004 & 0.004 & 0.005 & 0.004 & 0.005 & 0.004 & 0.004 \\
\hline
\end{tabular}


Table C-5. Simulated Magnitude of Lateral Specific Discharge ( $\mathrm{m} / \mathrm{yr})$

in the Magenta Dolomite Near the WIPP Site

\begin{tabular}{|c|c|c|c|c|c|c|c|c|c|c|c|c|c|}
\hline $\begin{array}{l}\text { Rern } \\
\text { ID. }\end{array}$ & 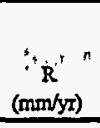 & $\begin{array}{c}1 \log \mathrm{K}(\mathrm{m} / \mathrm{s}) \\
\text { Dewey } \\
\text { Latel } \\
\text { Triassic }\end{array}$ & $\begin{array}{c}\log \mathrm{K} \text { (mi/s) } \\
\text { Anhydite } \\
\end{array}$ & $\begin{array}{c}\log \mathrm{K}(\mathrm{m} / \mathrm{s}) \\
\text { Dissupted } \\
\text { Region } \\
\end{array}$ & node1 & node2 & des & node4 & nodes & node6 & node7 & node8 & node9 \\
\hline 01 & 0.2 & -4.5 & -13.0 & -5.7 & 0.002 & 0.001 & 0.000 & 0.002 & 0.000 & 0.000 & 0.002 & 0.001 & 0.000 \\
\hline 02 & 0.2 & -4.5 & -13.0 & -6.7 & 0.008 & 0.004 & 0.001 & 0.009 & 0.001 & 0.001 & 0.014 & 0.010 & 0.001 \\
\hline 03 & 0.2 & -4.5 & -13.0 & -7.7 & 0.013 & 0.007 & 0.003 & 0.012 & 0.003 & .001 & 031 & 0.021 & 0.003 \\
\hline 04 & 0.2 & -4.5 & -12.0 & -5.7 & 0.004 & 0.002 & 0.000 & 0.001 & 0.000 & 0.000 & 0.002 & 0.001 & 0.000 \\
\hline 05 & 0.2 & -4.5 & -12.0 & -6.7 & 0.007 & 0.004 & 0.001 & 0.008 & 0.001 & 0.000 & 0.024 & 0.013 & 0.000 \\
\hline 06 & 0.2 & -4.5 & -12.0 & -7.7 & 0.015 & 0.009 & 0.002 & 0.016 & 0.003 & 0.001 & 0.057 & 0.030 & 0.001 \\
\hline 07 & 0.2 & -4.5 & -11.0 & -5.7 & 0.006 & 0.003 & 0.000 & 0.002 & 0.000 & 0.000 & 0.002 & 0.001 & 0.000 \\
\hline 08 & 0.2 & -4.5 & -11.0 & -6.7 & 0.007 & 0.005 & 0.001 & 0.006 & 0.001 & .000 & 0.016 & 0.008 & 1.000 \\
\hline 09 & 0.2 & -4.5 & -11.0 & -7.7 & 0.025 & 0.017 & 0.003 & 0.015 & 0.003 & 0.001 & 0.044 & 0.025 & 0.002 \\
\hline 10 & 0.2 & -5.5 & -13.0 & -5.7 & 0.003 & 0.002 & 0.000 & 0.003 & 0.000 & .000 & 003 & 0.001 & .000 \\
\hline 11 & 0.2 & -5.5 & -13.0 & -6.7 & 0.010 & 0.004 & 0.001 & 0.013 & 0.002 & .001 & 0.015 & 0.008 & .001 \\
\hline 12 & 0.2 & -5.5 & -13.0 & -7.7 & 0.014 & 0.006 & 0.002 & 0.017 & 0.003 & 0.001 & 0.024 & 0.016 & 0.002 \\
\hline 13 & 0.2 & -5.5 & -12.0 & -5.7 & 0.004 & 0.002 & 0.000 & 0.003 & 0.000 & 0.000 & .002 & 001 & .000 \\
\hline 14 & 0.2 & -5.5 & -12.0 & -6.7 & 0.008 & 0.004 & 0.001 & 0.010 & 0.001 & 0.000 & 0.019 & 0.010 & .000 \\
\hline 15 & 0.2 & -5.5 & -12.0 & -7.7 & 0.016 & 0.008 & 0.002 & 0.017 & 0.003 & 0.001 & 0.042 & 0.023 & .001 \\
\hline 16 & 0.2 & -5.5 & -11.0 & -5.7 & 0.005 & 0.003 & 0.000 & 0.005 & 0.000 & .000 & 0.003 & 0.001 & .000 \\
\hline 17 & 0.2 & -5.5 & -11.0 & -6.7 & 0.010 & 0.006 & 0.001 & 0.010 & 0.001 & .000 & 0.014 & .007 & .000 \\
\hline 18 & 0.2 & -5.5 & -11.0 & -7.7 & 0.022 & 0.015 & 0.002 & 0.017 & 0.002 & .001 & 0.035 & 0.020 & .002 \\
\hline 19 & 0.2 & -6.5 & -13.0 & -5.7 & 0.005 & 0.002 & 0.000 & 0.006 & 0.001 & 000 & 006 & 102 & .000 \\
\hline 20 & 0.2 & -6.5 & -13.0 & -6.7 & 0.008 & 0.003 & 0.001 & 0.011 & 0.001 & .001 & 015 & 208 & .001 \\
\hline 21 & 0.2 & -6.5 & -13.0 & -7.7 & 0.010 & 0.005 & 0.002 & 0.013 & 0.002 & .001 & 023 & 0.013 & .002 \\
\hline 22 & 0.2 & -6.5 & -12.0 & -5.7 & 0.004 & 0.002 & 0.000 & 0.005 & 0.000 & 000 & 005 & 12 & .000 \\
\hline 23 & 0.2 & -6.5 & -12.0 & -6.7 & 0.009 & 0.004 & 0.001 & 0.010 & 0.001 & .000 & 019 & 0.010 & .000 \\
\hline 24 & 0.2 & -6.5 & -12.0 & -7.7 & 0.016 & 0.008 & 0.002 & $0.016^{\circ}$ & 0.002 & 0.001 & 0.035 & 0.019 & .001 \\
\hline 25 & 0.2 & -6.5 & -11 . & -5.7 & 0.004 & 0.002 & 0.000 & 0.004 & 0.000 & 000 & 003 & 19 & .000 \\
\hline 26 & 0.2 & -6.5 & -11. & -6.7 & 0.009 & 0.005 & 0.001 & 007 & 0.001 & 000 & 014 & 007 & .000 \\
\hline 27 & 0.2 & -6.5 & -11.0 & -7.7 & 0.018 & 0.011 & 0.002 & 0.014 & 0.002 & .001 & 0.031 & 0.016 & .001 \\
\hline 28 & 2.0 & -4.5 & -13.0 & -5.7 & 0.010 & 0.004 & 0.001 & 0.013 & o. & 001 & 015 & D9 & 001 \\
\hline 29 & 2.0 & -4.5 & -13.0 & -6.7 & 0.014 & 0.006 & 0.002 & 0.016 & 0.003 & 001 & 0.024 & 016 & .002 \\
\hline 30 & 2.0 & -4.5 & -13.0 & -7.7 & 0.014 & 0.007 & 0.002 & 0.016 & 0.003 & .001 & 0.025 & 0.017 & .002 \\
\hline 31 & 2.0 & -4.5 & -12.0 & -5.7 & 0.010 & 0.005 & 0.001 & 0.010 & 0.001 & 000 & 022 & 2 & .000 \\
\hline 32 & 2.0 & -4.5 & -12.0 & -6.7 & 0.019 & 0.008 & 0.002 & 0.019 & 0.003 & .001 & 043 & 0.023 & .001 \\
\hline 33 & 2.0 & -4.5 & -12.0 & -7.7 & 0.019 & 0.009 & 0.002 & 0.020 & 0.003 & 001 & 0.047 & 0.027 & .001 \\
\hline 34 & 2.0 & -4.5 & -11.0 & -5.7 & 0.010 & & 0001 & 0.007 & 00 & 000 & 19 & 0.009 & .000 \\
\hline 35 & 2.0 & -4.5 & -11.0 & -6.7 & 0.021 & 0.012 & 0.002 & 017 & 0.002 & 001 & 038 & 0.018 & .001 \\
\hline 36 & 2.0 & -4.5 & -11.0 & -7.7 & 0.022 & 0.013 & 0.002 & 0.018 & 0.002 & .001 & 44 & 0.024 & .001 \\
\hline 37 & 2.0 & -5 & -13.0 & -5.7 & 0.009 & 0.004 & 0.001 & 2 & & 001 & & 0.009 & .001 \\
\hline 38 & 2.0 & -5 & -13 & -67 & 0 & 0005 & 0.002 & 3 & 0.002 & 001 & 3 & 0.014 & .002 \\
\hline 39 & 2.0 & -5.5 & -13. & -7.7 & 0.013 & 0.006 & 0.002 & 0.015 & 0.002 & .001 & 025 & 0.015 & .002 \\
\hline 40 & 2.0 & -5. & -12 & -5.7 & 0.0 & & 0.0 & 1 & & 20 & & & .000 \\
\hline 41 & 2.0 & -5. & -12 & -6.7 & 0 & 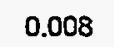 & 00 & 16 & 2 & 01 & 38 & 20 & .001 \\
\hline 42 & 2.0 & -5.5 & -12.0 & -7.7 & 0.017 & 0.008 & 0.002 & 0.018 & 0.003 & 0.001 & 0.042 & 0.024 & 0.001 \\
\hline 43 & 2.0 & -5.5 & -19 & -5.7 & 0.011 & 0.006 & 0.001 & 18 & & 0 & & & .000 \\
\hline 44 & 2.0 & -5 & & & 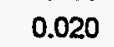 & & 0.002 & 5 & 2 & 001 & 33 & 116 & 0.001 \\
\hline 45 & 2.0 & -5.5 & -11.0 & -7.7 & 0.020 & 0.012 & 0.002 & 0.016 & 0.002 & 0.001 & 0.039 & 0.022 & 0.001 \\
\hline 46 & 2.0 & -6.5 & -13.0 & -5.7 & 0.009 & 0.004 & 0.001 & 0.010 & & .001 & 14 & 0.008 & 0.001 \\
\hline 47 & 2.0 & -6. & & & & & 0.002 & 010 & 0.002 & .001 & 018 & 0.011 & 0.002 \\
\hline 48 & 2.0 & -6.5 & -13.0 & -7.7 & 0.011 & 0.005 & 0.002 & 0.010 & 0.002 & 0.001 & 0.021 & 0.013 & 0.002 \\
\hline 49 & 2.0 & -6.5 & -12.0 & -5.7 & 0.012 & 0.005 & 0.001 & 0.010 & 0.001 & .000 & 19 & 0.010 & 0.000 \\
\hline 50 & 2.0 & -6.5 & & & 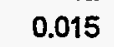 & & na & 013 & 0.002 & 0.001 & 0.028 & 0.016 & 0.001 \\
\hline 51 & 2.0 & -6.5 & -12 & -7.7 & 0.015 & 0.007 & 0.001 & 0.013 & 0.002 & 0.001 & 0.033 & 0.019 & 0.001 \\
\hline 52 & 2.0 & -6.5 & -11.0 & -5.7 & 0.013 & 0.006 & 0.001 & 0.008 & 0.001 & 0.000 & 0.015 & 0.008 & 0.000 \\
\hline 53 & 2.0 & -6.5 & -11 & -6 & 0.0 & 0.009 & 0.001 & 0.012 & 0.001 & 0.001 & 0.025 & 0.014 & 0.001 \\
\hline 54 & 2.0 & -6.5 & -11.0 & -7.7 & 0.018 & 0.009 & 0.001 & 0.012 & 0.002 & 0.001 & 0.031 & 0.019 & 0.001 \\
\hline
\end{tabular}


Table C-6. Simulated Magnitude of Lateral Specific Discharge (m/yr) in the Culebra Dolomite Near the WIPP Site

\begin{tabular}{|c|c|c|c|c|c|c|c|c|c|c|c|c|c|}
\hline $\begin{array}{l}\text { Rin } \\
\mathrm{D} \text {. }\end{array}$ & $\begin{array}{c}R \\
(\operatorname{mm} / y x) \\
\end{array}$ & $\begin{array}{c}\log \mathrm{R}(\mathrm{m} / \mathrm{s}) \\
\text { Dewrey } \\
\text { Lakef } \\
\text { Triassic }\end{array}$ & $\begin{array}{l}\log \mathrm{K}(\mathrm{m} / \mathrm{s}) \\
\text { Ashydrite }\end{array}$ & $\begin{array}{c}\log R(\mathrm{~m} / \mathrm{s}) \\
\text { Disnpted } \\
\text { Region }\end{array}$ & nodel & node2 & node3 & node4 & nodes & node6 & node7 & node8 & nodeg \\
\hline 01 & 0.2 & -4.5 & -13.0 & -5.7 & 0.050 & 0.025 & 0.002 & 0.045 & 0.004 & 0.002 & 0.031 & 0.009 & 0.001 \\
\hline 02 & 0.2 & -4.5 & -13.0 & -6.7 & 0.105 & 0.043 & 0.005 & 0.105 & 0.009 & 0.005 & 0.075 & 0.023 & 0.005 \\
\hline 03 & 0.2 & -4.5 & -13.0 & -7.7 & 0.097 & 0.041 & 0.006 & 0.094 & 0.008 & 0.006 & 0.064 & 0.025 & 0.012 \\
\hline 04 & 0.2 & -4.5 & -12.0 & -5.7 & 0.070 & 0.030 & 0.003 & 0.065 & 0.005 & 0.002 & 0.043 & 0.011 & 0.001 \\
\hline 05 & 0.2 & -4.5 & -12.0 & -6.7 & 0.086 & 0.037 & 0.009 & 0.085 & 0.010 & 0.005 & 0.061 & 0.032 & 0.013 \\
\hline 06 & 0.2 & -4.5 & -12.0 & -7.7 & 0.071 & 0.046 & 0.017 & 0.062 & 0.017 & 0.010 & 0.069 & 0.063 & 0.034 \\
\hline 07 & 0.2 & -4.5 & -11.0 & -5.7 & 0.053 & 0.027 & 0.002 & 0.038 & 0.003 & 0.001 & 0.025 & 0.007 & 0.002 \\
\hline 08 & 0.2 & -4.5 & -11.0 & -6.7 & 0.097 & 0.054 & 0.012 & 0.056 & 0.012 & 0.004 & 0.090 & 0.058 & 0.013 \\
\hline 09 & 0.2 & -4.5 & -11.0 & -7.7 & 0.175 & 0.117 & 0.031 & 0.098 & 0.031 & 0.011 & 0.207 & 0.143 & 0.042 \\
\hline 10 & 0.2 & -5.5 & -13.0 & -5.7 & 0.060 & 0.027 & 0.002 & 0.060 & 0.005 & 0.002 & 0.047 & 0.015 & 0.002 \\
\hline 11 & 0.2 & -5.5 & -13.0 & -6.7 & 0.135 & 0.049 & 0.006 & 0.160 & 0.013 & 0.006 & 0.139 & 0.049 & 0.006 \\
\hline 12 & 0.2 & -5.5 & -13.0 & -7.7 & 0.165 & 0.060 & 0.008 & 0.184 & 0.015 & 0.008 & 0.147 & 0.051 & 0.010 \\
\hline 13 & 0.2 & -5.5 & -12.0 & -5.7 & 0.075 & 0.032 & 0.003 & 0.073 & 0.006 & 0.002 & 0.054 & 0.016 & 0.002 \\
\hline 14 & 0.2 & -5.5 & -12.0 & -6.7 & 0.143 & 0.050 & 0.010 & 0.166 & 0.015 & 0.007 & 0.143 & 0.054 & 0.010 \\
\hline 15 & 0.2 & -5.5 & -12.0 & -7.7 & 0.140 & 0.056 & 0.016 & 0.155 & 8 & 0.010 & 0.135 & 0.067 & 0.026 \\
\hline 16 & 0.2 & -5.5 & -11.0 & -5.7 & 0.080 & 0.030 & 0.003 & 0.077 & 0.006 & 0.002 & 0.058 & 0.016 & 0.002 \\
\hline 17 & 0.2 & -5.5 & -11.0 & -6.7 & 0.133 & 0.056 & 0.012 & 0.122 & 0.013 & 0.004 & 0.119 & 0.055 & 0.009 \\
\hline 18 & 0.2 & -5.5 & -11.0 & -7.7 & 0.187 & 0.103 & 0.027 & 0.142 & 27 & 0.010 & 0.186 & 0.119 & 0.032 \\
\hline 19 & 0.2 & -6.5 & -13.0 & -5.7 & 0.069 & 0.024 & 0.003 & 0.086 & 0.007 & 0.003 & 0.081 & 0.030 & 0.002 \\
\hline 20 & 0.2 & -6.5 & -13.0 & -6.7 & 0.086 & 0.026 & 0.005 & 0.123 & 0.010 & 0.005 & 0.130 & 0.052 & 0.006 \\
\hline 21 & 0.2 & -6.5 & -13.0 & -7.7 & 0.102 & 0.033 & 0.006 & & & 0.007 & 0.146 & 0.060 & 0.010 \\
\hline 22 & 0.2 & -6.5 & -12.0 & -5.7 & 0.068 & 0.023 & 0.003 & 0.084 & 0.007 & 0.003 & 0.079 & 0.028 & 0.002 \\
\hline 23 & 0.2 & -6.5 & -12.0 & -6.7 & 0.072 & 0.024 & 0.007 & 0.103 & 0.010 & 0.005 & 0.120 & 0.053 & 0.010 \\
\hline 24 & 0.2 & -6.5 & -12.0 & -7.7 & 0.088 & 0.034 & 0.012 & 0.120 & 0.015 & 0.008 & 0.144 & 0.072 & 0.022 \\
\hline 25 & 0.2 & -6.5 & -11.0 & -5.7 & 0.054 & 0.020 & 0.002 & 0.061 & 0.005 & 0.001 & 0.055 & 19 & 0.001 \\
\hline 26 & 0.2 & -6.5 & -11.0 & -6.7 & 0.082 & 0.039 & 0.009 & 0.077 & 0.010 & 0.003 & 0.110 & 0.053 & 0.009 \\
\hline 27 & 0.2 & -6.5 & -11.0 & -7.7 & 0.140 & 0.077 & 0.020 & 0.116 & 0.022 & 0.008 & 0.186 & 0.104 & 0.025 \\
\hline 28 & 2.0 & -4.5 & -13.0 & -5.7 & 0.123 & 0.045 & 0.006 & 0.148 & 0.012 & 0.006 & 0.127 & 46 & 0.006 \\
\hline 29 & 2.0 & -4.5 & -13.0 & -6.7 & 0.156 & 0.057 & 0.008 & 0.174 & 0.014 & 0.008 & 0.137 & 0.048 & 0.010 \\
\hline 30 & 2.0 & -4.5 & -13.0 & -7.7 & 0.157 & 0.059 & 0.008 & 0.166 & 0.014 & 0.008 & 0.121 & 0.040 & 0.011 \\
\hline 31 & 2.0 & -4.5 & -12.0 & -5.7 & 0.110 & 0.039 & 0.010 & 0.132 & 0.013 & 0.006 & 0.118 & 0.050 & 0.012 \\
\hline 32 & 2.0 & -4.5 & -12.0 & -6.7 & 0.137 & 0.052 & 0.016 & 0.152 & 0.018 & 0.010 & 0.128 & 0.066 & 0.026 \\
\hline 33 & 2.0 & -4.5 & -12.0 & -7.7 & 0.135 & 0.054 & 0.016 & 0.142 & 0.018 & 0.011 & 0.113 & 0.064 & 0.029 \\
\hline 34 & 2.0 & -4.5 & -11.0 & -5.7 & 0.125 & 0.059 & 0.013 & 0.081 & 0.014 & 0.004 & 0.121 & 0.067 & 0.013 \\
\hline 35 & 2.0 & -4.5 & -11.0 & -6.7 & 0.198 & 0.104 & 0.024 & 0.121 & 0.027 & 0.009 & 0.217 & 0.132 & 0.031 \\
\hline 36 & 2.0 & -4.5 & -11.0 & -7.7 & 0.204 & 0.111 & 0.027 & 0.123 & 0.028 & 0.009 & 0.230 & 0.144 & 0.033 \\
\hline 37 & 2.0 & -5.5 & -13.0 & -5.7 & 0.088 & 0.025 & 0.005 & 0.127 & 0.010 & 0.005 & 0.129 & 0.051 & 0.006 \\
\hline 38 & 2.0 & -5.5 & -13.0 & -6.7 & 0.097 & 0.030 & 0.006 & 0.136 & 0.012 & 0.006 & 0.139 & 0.058 & 0.010 \\
\hline 39 & 2.0 & -5.5 & -13.0 & -7.7 & 0.132 & 0.044 & 0.007 & 0.164 & 0.014 & 0.007 & 0.149 & 0.057 & 0.010 \\
\hline 40 & 2.0 & -5.5 & -12.0 & -5.7 & 0.081 & 0.026 & 0.008 & 0.113 & 11 & 0.006 & 0.123 & 0.054 & 0.011 \\
\hline 41 & 2.0 & -5.5 & -12.0 & -6.7 & 0.089 & 0.034 & 0.013 & 0.118 & 0.015 & 0.009 & 0.138 & 0.071 & 0.023 \\
\hline 42 & 2.0 & -5.5 & -12.0 & -7.7 & 0.103 & 0.039 & 0.014 & 0.129 & 0.016 & 0.009 & 0.138 & 0.071 & 0.025 \\
\hline 43 & 2.0 & -5.5 & -11.0 & -5.7 & 0.115 & 0.054 & 0.011 & 0.080 & 0.013 & 0.004 & 0.128 & 0.067 & 0.012 \\
\hline 44 & 20 & -5.5 & -11.0 & -6.7 & 0.160 & 0.083 & 0.019 & 0.108 & 0.022 & 0.007 & 0.203 & 0.114 & 0.026 \\
\hline 45 & 2.0 & -5.5 & -11.0 & -7.7 & 0.167 & 0.089 & 0.021 & 0.113 & 0.024 & 0.008 & 0.215 & 0.123 & 0.028 \\
\hline 46 & 2.0 & -6.5 & -13.0 & -5.7 & 0.042 & 0.008 & 0.003 & 0.074 & 0.006 & 0.003 & 0.099 & 0.045 & 0.005 \\
\hline 47 & 2.0 & -6.5 & -13.0 & -6.7 & 0.041 & 0.011 & 0.003 & 0.068 & 0.006 & 0.004 & 0.101 & 0.047 & 0.008 \\
\hline 48 & 2.0 & -6.5 & -13.0 & -7.7 & 0.037 & 0.010 & 0.004 & 0.065 & 0.006 & 0.004 & 0.099 & 0.047 & 0.009 \\
\hline 49 & 2.0 & -6.5 & -12.0 & -5.7 & 0.053 & 0.022 & 0.006 & 0.066 & 0.008 & 0.004 & 0.097 & 0.048 & 0.010 \\
\hline 50 & 2.0 & -6.5 & -12.0 & -6.7 & 0.063 & 0.030 & 0.008 & 0.060 & 0.010 & 0.006 & 0.106 & 0.057 & 0.018 \\
\hline 51 & 2.0 & -6.5 & -12.0 & -7.7 & 0.064 & 0.033 & 0.008 & 0.055 & 0.010 & 0.006 & 0.108 & 0.060 & 0.020 \\
\hline 52 & 2.0 & -6.5 & -11.0 & -5.7 & 0.102 & 0.046 & 0.009 & 0.073 & 0.011 & 0.003 & 0.110 & 0.057 & 0.010 \\
\hline 53 & 2.0 & -6.5 & -11.0 & -6.7 & 0.122 & 0.060 & 0.013 & 0.086 & 0.016 & 0.006 & 0.150 & 0.083 & 0.020 \\
\hline 54 & 2.0 & -6.5 & -11.0 & -7.7 & 0.126 & 0.063 & 0.014 & 0.086 & 0.016 & 0.006 & 0.163 & 0.090 & 0.021 \\
\hline
\end{tabular}


Table C-7. Simulated Flow Direction (degrees east of north) in the

Dewey Lake/Triassic Rocks Near the WIPP Site

\begin{tabular}{|c|c|c|c|c|c|c|c|c|c|c|c|c|c|}
\hline $\begin{array}{l}\text { Rmn } \\
\text { ID. }\end{array}$ & $\begin{array}{c}\vdots \\
\dot{R} \\
(\mathrm{~mm} / \mathrm{yx}) \\
\end{array}$ & $\begin{array}{c}\log \mathrm{K}(\mathrm{m} / \mathrm{s}) \\
\text { Dewey } \\
\text { Lakef } \\
\text { Triassic }\end{array}$ & $\begin{array}{c}\log \mathrm{K}(\mathrm{m} / \mathrm{s}) \\
\text { Alhydinte }\end{array}$ & $\begin{array}{c}\log R(\mathrm{~m} / \mathrm{s}) \\
\text { Dissupted } \\
\text { Region }\end{array}$ & nodel & node2 & nodes & node4 & nodes & node6 & node7 & nodes & node9 \\
\hline 01 & 0.2 & -4.5 & -13.0 & -5.7 & 56 & 70 & 87 & 44 & 59 & 80 & 21 & 45 & 73 \\
\hline 02 & 0.2 & -4.5 & -13.0 & -6.7 & 300 & 293 & 283 & 303 & 297 & 289 & 301 & 296 & 290 \\
\hline 03 & 0.2 & -4.5 & -13.0 & -7.7 & 239 & 236 & 227 & 259 & 252 & 253 & 279 & 270 & 268 \\
\hline 04 & 0.2 & -4.5 & -12.0 & -5.7 & 69 & 90 & 108 & 55 & $\pi$ & 99 & 36 & 65 & 92 \\
\hline 05 & 0.2 & -4.5 & -12.0 & -6.7 & 296 & 280 & 264 & 302 & 292 & 280 & 300 & 293 & 285 \\
\hline 06 & 0.2 & -4.5 & -12.0 & -7.7 & 243 & 235 & 228 & 272 & 262 & 251 & 285 & 278 & 267 \\
\hline 07 & 0.2 & -4.5 & -11.0 & -5.7 & 95 & 130 & 139 & 106 & 128 & 136 & 119 & 131 & 137 \\
\hline 08 & 0.2 & -4.5 & -11.0 & -6.7 & 268 & 256 & 249 & 285 & 276 & 267 & 294 & 286 & 277 \\
\hline 09 & 0.2 & -4.5 & -11.0 & -7.7 & 261 & 257 & 256 & 272 & 272 & 266 & 280 & 281 & 274 \\
\hline 10 & 0.2 & -5.5 & -13.0 & -5.7 & 76 & 100 & 118 & 71 & 101 & 119 & 71 & 110 & 125 \\
\hline 11 & 0.2 & -5.5 & -13.0 & -6.7 & 284 & 274 & 261 & 289 & 281 & 271 & 289 & 282 & 274 \\
\hline 12 & 0.2 & -5.5 & -13.0 & -7.7 & 239 & 236 & 227 & 259 & 252 & 253 & 280 & 270 & 268 \\
\hline 13 & 0.2 & -5.5 & -12.0 & -5.7 & 84 & 107 & 124 & 79 & 106 & 123 & 81 & 113 & 127 \\
\hline 14 & 0.2 & -5.5 & -12.0 & -6.7 & 265 & 254 & 243 & 279 & 269 & 257 & 282 & 274 & 264 \\
\hline 15 & 0.2 & -5.5 & -12.0 & -7.7 & 240 & 235 & 228 & 263 & 256 & 251 & 280 & 270 & 267 \\
\hline 16 & 0.2 & -5.5 & -11.0 & -5.7 & 137 & 146 & 149 & 137 & 145 & 147 & 146 & 147 & 148 \\
\hline 17 & 0.2 & -5.5 & -11.0 & -6.7 & 235 & 232 & 228 & 256 & 247 & 240 & 266 & 258 & 250 \\
\hline 18 & 0.2 & -5.5 & -11.0 & -7.7 & 248 & 249 & 247 & 262 & 262 & 258 & 273 & 274 & 268 \\
\hline 19 & 0.2 & -6.5 & -13.0 & -5.7 & 130 & 142 & 146 & 140 & 146 & 148 & 162 & 155 & 153 \\
\hline 20 & 0.2 & -6.5 & -13.0 & -6.7 & 266 & 262 & 254 & 275 & 269 & 261 & 278 & 272 & 264 \\
\hline 21 & 0.2 & -6.5 & -13.0 & -7.7 & 239 & 236 & 227 & 259 & 251 & 253 & 280 & 270 & 268 \\
\hline 22 & 0.2 & -6.5 & -12.0 & -5.7 & 148 & 152 & 153 & 155 & 155 & 154 & 169 & 160 & 157 \\
\hline 23 & 0.2 & -6.5 & -12.0 & -6.7 & 265 & 257 & 248 & 274 & 266 & 257 & 277 & 270 & 261 \\
\hline 24 & 0.2 & -6.5 & -12.0 & -7.7 & 239 & 235 & 227 & 260 & 254 & 252 & 280 & 270 & 267 \\
\hline 25 & 0.2 & -6.5 & -11.0 & -5.7 & 151 & 155 & 155 & 158 & 157 & 155 & 170 & 162 & 158 \\
\hline 26 & 0.2 & -6.5 & -11.0 & -6.7 & 254 & 246 & 240 & 265 & 257 & 249 & 269 & 262 & 254 \\
\hline 27 & 0.2 & -6.5 & -11.0 & -7.7 & 251 & 246 & 237 & 263 & 259 & 250 & 271 & 271 & 265 \\
\hline 28 & 2.0 & -4.5 & -13.0 & -5.7 & 286 & 277 & 266 & 290 & 283 & 274 & 290 & 284 & 276 \\
\hline 29 & 2.0 & -4.5 & -13.0 & -6.7 & 239 & 236 & 227 & 259 & 250 & 253 & 280 & 270 & 268 \\
\hline 30 & 2.0 & -4.5 & -13.0 & -7.7 & 239 & 239 & 225 & 259 & 239 & 258 & 278 & 270 & 270 \\
\hline 31 & 2.0 & -4.5 & -12.0 & -5.7 & 285 & 276 & 264 & 289 & 282 & 273 & 289 & 283 & 275 \\
\hline 32 & 2.0 & -4.5 & -12.0 & -6.7 & 239 & 236 & 227 & 259 & 251 & 253 & 280 & 270 & 268 \\
\hline 33 & 2.0 & -4.5 & -12.0 & -7.7 & 239 & 239 & 225 & 259 & 239 & 258 & 278 & 270 & 270 \\
\hline 34 & 2.0 & -4.5 & -11.0 & -5.7 & 280 & 269 & 256 & 287 & 278 & 267 & 287 & 280 & 272 \\
\hline 35 & 2.0 & -4.5 & -11.0 & -6.7 & 239 & 236 & 227 & 259 & 251 & 253 & 279 & 270 & 268 \\
\hline 36 & 2.0 & -4.5 & -11.0 & -7.7 & 239 & 239 & 225 & 259 & 239 & 258 & 278 & 270 & 270 \\
\hline 37 & 2.0 & -5.5 & -13.0 & -5.7 & 266 & 263 & 256 & 274 & 269 & 262 & 278 & 272 & 265 \\
\hline 38 & 2.0 & -5.5 & -13.0 & -6.7 & 239 & 236 & 227 & 259 & 250 & 253 & 280 & 270 & 268 \\
\hline 39 & 2.0 & -5.5 & -13.0 & -7.7 & 239 & 239 & 225 & 259 & 239 & 258 & 278 & 270 & 270 \\
\hline 40 & 2.0 & -5.5 & -12.0 & -5.7 & 266 & 262 & 255 & 274 & 269 & 262 & 278 & 272 & 264 \\
\hline 41 & 2.0 & -5.5 & -12.0 & -6.7 & 239 & 236 & 227 & 259 & 251 & 253 & 280 & 270 & 268 \\
\hline 42 & 2.0 & -5.5 & -12.0 & -7.7 & 239 & 239 & 225 & 259 & 239 & 258 & 278 & 270 & 270 \\
\hline 43 & 2.0 & -5.5 & -11.0 & -5.7 & 266 & 261 & 253 & 274 & 268 & 260 & 277 & 271 & 263 \\
\hline 44 & 2.0 & -5.5 & -11.0 & -6.7 & 239 & 236 & 227 & 259 & 251 & 253 & 280 & 270 & 268 \\
\hline 45 & 2.0 & -5.5 & -11.0 & -7.7 & 239 & 239 & 225 & 259 & 239 & 258 & 278 & 270 & 270 \\
\hline 46 & 2.0 & -6.5 & -13.0 & -5.7 & 249 & 256 & 257 & 260 & 261 & 259 & 271 & 266 & 260 \\
\hline 47 & 2.0 & -6.5 & -13.0 & -6.7 & 239 & 236 & 227 & 259 & 250 & 253 & 280 & 270 & 268 \\
\hline 48 & 2.0 & -6.5 & -13.0 & -7.7 & 239 & 239 & 225 & 259 & 239 & 258 & 278 & 270 & 270 \\
\hline 49 & 2.0 & -6.5 & -12.0 & -5.7 & 249 & 256 & 257 & 261 & 261 & 259 & 271 & 265 & 260 \\
\hline 50 & 2.0 & -6.5 & -12.0 & -5.7 & 239 & 236 & 227 & 259 & 250 & 253 & 280 & 270 & 268 \\
\hline 51 & 2.0 & -6.5 & -12.0 & -7.7 & 239 & 239 & 225 & 259 & 239 & 258 & 278 & 270 & 270 \\
\hline 52 & 2.0 & -6.5 & -11.0 & -5.7 & 249 & 256 & 256 & 261 & 261 & 258 & 270 & 265 & 260 \\
\hline 53 & 2.0 & -6.5 & -11.0 & -6.7 & 239 & 236 & 227 & 259 & 251 & 253 & 280 & 270 & 268 \\
\hline 54 & 2.0 & -6.5 & -11.0 & -7.7 & 239 & 239 & 225 & 259 & 239 & 258 & 278 & 270 & 270 \\
\hline
\end{tabular}

C- 11 
Table C-8. Simulated Flow Direction (degrees east of north) in the

Magenta Dolomite Near the WIPP Site

\begin{tabular}{|c|c|c|c|c|c|c|c|c|c|c|c|c|c|}
\hline $\begin{array}{l}\text { Run } \\
\text { D. }\end{array}$ & $\begin{array}{c}R \\
(m+1 / y z)\end{array}$ & $\begin{array}{c}\log \mathrm{K}(\mathrm{m} / \mathrm{s}) \\
\text { Dewrey } \\
\text { Lakel } \\
\text { Triasssic } \\
\end{array}$ & $\begin{array}{c}\log \mathrm{K}(\mathrm{m} / \mathrm{s}) \\
\text { Arhydrite }\end{array}$ & $\begin{array}{c}\log \mathrm{R}(\mathrm{m} / \mathrm{s}) \\
\text { Disrupted } \\
\text { Regian }\end{array}$ & nodel & node2 & node3 & node4 & node5 & node6 & node7 & node8 & node9 \\
\hline 01 & 0.2 & -4.5 & -13.0 & -5.7 & 173 & 161 & 182 & 192 & 203 & 153 & 236 & 276 & 187 \\
\hline 02 & 0.2 & -4.5 & -13.0 & -6.7 & 220 & 220 & 247 & 210 & 234 & 222 & 259 & 284 & 253 \\
\hline 03 & 0.2 & -4.5 & -13.0 & -7.7 & 238 & 233 & 248 & 226 & 242 & 228 & 270 & 286 & 254 \\
\hline 04 & 0.2 & -4.5 & -12.0 & -5.7 & 121 & 132 & 134 & 151 & 162 & 134 & 298 & 317 & 116 \\
\hline 05 & 0.2 & -4.5 & -12.0 & -6.7 & 245 & 237 & 248 & 231 & 226 & 210 & 276 & 284 & 240 \\
\hline 06 & 0.2 & -4.5 & -12.0 & -7.7 & 246 & 237 & 248 & 237 & 228 & 221 & 277 & 282 & 245 \\
\hline 07 & 0.2 & -4.5 & -11.0 & -5.7 & 100 & 130 & 140 & 143 & 147 & 139 & 128 & 131 & 126 \\
\hline 08 & 0.2 & -4.5 & -11.0 & -6.7 & 247 & 245 & 256 & 221 & 238 & 251 & 277 & 281 & 270 \\
\hline 09 & 0.2 & -4.5 & -11.0 & -7.7 & 259 & 251 & 259 & 242 & 250 & 259 & 276 & 280 & 270 \\
\hline 10 & 0.2 & -5.5 & -13.0 & -5.7 & 159 & 147 & 164 & 181 & 179 & 156 & 195 & 215 & 140 \\
\hline 11 & 0.2 & -5.5 & -13.0 & -6.7 & 206 & 207 & 244 & 199 & 222 & 216 & 236 & 267 & 247 \\
\hline 12 & 0.2 & -5.5 & -13.0 & -7.7 & 213 & 216 & 246 & 204 & 230 & 224 & 251 & 277 & 252 \\
\hline 13 & 0.2 & -5.5 & -12.0 & -5.7 & 129 & 131 & 143 & 167 & 164 & 147 & 176 & 171 & 130 \\
\hline 14 & 0.2 & -5.5 & -12.0 & -6.7 & 217 & 219 & 243 & 209 & 217 & 206 & 257 & 273 & 234 \\
\hline 15 & 0.2 & -5.5 & -12.0 & -7.7 & 227 & 227 & 246 & 218 & 223 & 221 & 268 & 278 & 246 \\
\hline 16 & 0.2 & -5.5 & -11.0 & -5.7 & 152 & 159 & 182 & 172 & 175 & 153 & 165 & 159 & 139 \\
\hline 17 & 0.2 & -5.5 & -11.0 & -6.7 & 221 & 228 & 249 & 205 & 223 & 229 & 252 & 264 & 254 \\
\hline 18 & 0.2 & -5.5 & -11.0 & -7.7 & 240 & 242 & 255 & 221 & 240 & 250 & 266 & 274 & 266 \\
\hline 19 & 0.2 & -6.5 & -13.0 & -5.7 & 175 & 156 & 204 & 186 & 187 & 175 & 197 & 215 & 157 \\
\hline 20 & 0.2 & -6.5 & -13.0 & -6.7 & 221 & 224 & 247 & 206 & 225 & 219 & 237 & 263 & 247 \\
\hline 21 & 0.2 & -6.5 & -13.0 & -7.7 & 230 & 232 & 247 & 212 & 232 & 227 & 248 & 271 & 253 \\
\hline 22 & 0.2 & -6.5 & -12.0 & -5.7 & 167 & 157 & 193 & 183 & 185 & 168 & 194 & 205 & 157 \\
\hline 23 & 0.2 & -6.5 & -12.0 & -6.7 & 242 & 241 & 250 & 219 & 223 & 215 & 256 & 271 & 238 \\
\hline 24 & 0.2 & -6.5 & -12.0 & -7.7 & 236 & 235 & 248 & 220 & 225 & 226 & 262 & 276 & 250 \\
\hline 25 & 0.2 & -6.5 & -11.0 & -5.7 & 166 & 168 & 187 & 180 & 182 & 160 & 184 & 179 & 151 \\
\hline 26 & 0.2 & -6.5 & -11.0 & -6.7 & 246 & 244 & 253 & 224 & 233 & 239 & 259 & 264 & 257 \\
\hline 27 & 0.2 & -6.5 & -11.0 & -7.7 & 247 & 244 & 252 & 228 & 239 & 245 & 265 & 271 & 264 \\
\hline 28 & 2.0 & -4.5 & -13.0 & -5.7 & 210 & 211 & 246 & 200 & 224 & 217 & 238 & 268 & 248 \\
\hline 29 & 2.0 & -4.5 & -13.0 & -6.7 & 217 & 221 & 246 & 205 & 231 & 225 & 251 & 278 & 252 \\
\hline 30 & 2.0 & -4.5 & -13.0 & -7.7 & 219 & 223 & 247 & 207 & 232 & 226 & 256 & 282 & 253 \\
\hline 31 & 20 & -4.5 & -12.0 & -5.7 & 243 & 243 & 249 & 221 & 224 & 211 & 264 & 278 & 239 \\
\hline 32 & 2.0 & -4.5 & -12.0 & -6.7 & 235 & 237 & 247 & 218 & 222 & 222 & 267 & 280 & 246 \\
\hline 33 & 2.0 & -4.5 & -12.0 & -7.7 & 235 & 237 & 247 & 217 & 220 & 224 & 268 & 285 & 243 \\
\hline 34 & 2.0 & -4.5 & -11.0 & -5.7 & 260 & 256 & 259 & 231 & 239 & 251 & 272 & 276 & 267 \\
\hline 35 & 2.0 & -4.5 & -11.0 & -6.7 & 241 & 241 & 250 & 220 & 233 & 246 & 272 & 278 & 265 \\
\hline 36 & 2.0 & -4.5 & -11.0 & -7.7 & 239 & 240 & 251 & 218 & 227 & 250 & 273 & 287 & 266 \\
\hline 37 & 2.0 & -5.5 & -13.0 & -5.7 & 223 & 227 & 248 & 205 & 226 & 221 & 237 & 264 & 248 \\
\hline 38 & 2.0 & -5.5 & -13.0 & -6.7 & 232 & 236 & 248 & 212 & 234 & 228 & 250 & 273 & 253 \\
\hline 39 & 2.0 & -5.5 & -13.0 & -7.7 & 225 & 230 & 247 & 208 & 231 & 227 & 250 & 276 & 253 \\
\hline 40 & 2.0 & -5.5 & -12.0 & -5.7 & 246 & 248 & 252 & 221 & 224 & 215 & 259 & 273 & 238 \\
\hline 41 & 2.0 & -5.5 & -12.0 & -6.7 & 242 & 242 & 248 & 222 & 225 & 227 & 265 & 278 & 249 \\
\hline 42 & 2.0 & -5.5 & -12.0 & -7.7 & 239 & 241 & 248 & 218 & 221 & 228 & 265 & 284 & 247 \\
\hline 43 & 2.0 & -5.5 & -11.0 & -5.7 & 259 & 257 & 259 & 231 & 239 & 248 & 267 & 271 & 262 \\
\hline 44 & 2.0 & -5.5 & -11.0 & -6.7 & 245 & 241 & 250 & 226 & 234 & 247 & 271 & 278 & 266 \\
\hline 45 & 2.0 & -5.5 & -11.0 & -7.7 & 243 & 241 & 250 & 223 & 228 & 251 & 271 & 288 & 266 \\
\hline 46 & 2.0 & -6.5 & -13.0 & -5.7 & 248 & 260 & 254 & 213 & 233 & 229 & 239 & 265 & 251 \\
\hline 47 & 2.0 & -6.5 & -13.0 & -6.7 & 256 & 263 & 252 & 221 & 240 & 236 & 248 & 270 & 256 \\
\hline 48 & 2.0 & -6.5 & -13.0 & -7.7 & 262 & 264 & 252 & 228 & 241 & 237 & 254 & 275 & 257 \\
\hline 49 & 2.0 & -6.5 & -12.0 & -5.7 & 251 & 257 & 258 & 223 & 228 & 226 & 257 & 271 & 243 \\
\hline 50 & 2.0 & -6.5 & -12.0 & -6.7 & 250 & 250 & 251 & 227 & 230 & 236 & 263 & 278 & 255 \\
\hline 51 & 2.0 & -6.5 & -12.0 & -7.7 & 252 & 251 & 251 & 228 & 226 & 239 & 265 & 284 & 255 \\
\hline 52 & 2.0 & -6.5 & -11.0 & -5.7 & 252 & 258 & 261 & 227 & 239 & 249 & 261 & 268 & 261 \\
\hline 53 & 2.0 & -6.5 & -11.0 & -6.7 & 246 & 241 & 248 & 232 & 236 & 248 & 269 & 279 & 266 \\
\hline 54 & 2.0 & -6.5 & -11.0 & -7.7 & 248 & 242 & 249 & 233 & 229 & 253 & 270 & 290 & 267 \\
\hline
\end{tabular}


Table C-9. Simulated Flow Direction (degrees east of north) in the

Culebra Dolomite Near the WIPP Site

\begin{tabular}{|c|c|c|c|c|c|c|c|c|c|c|c|c|c|}
\hline $\begin{array}{l}\text { Rum } \\
\text { ID. }\end{array}$ & $\begin{array}{c}\stackrel{f}{R} \\
(\mathrm{~mm} / \mathrm{yr}) \\
\end{array}$ & $\begin{array}{c}\log \mathrm{K}(\mathrm{m} / \mathrm{s}) \\
\text { Dewey } \\
\text { Lakef } \\
\text { Triassie } \\
\end{array}$ & $\begin{array}{c}\log \mathrm{K}(\mathrm{m} / \mathrm{s}) \\
\text { Anhydrite }\end{array}$ & $\begin{array}{c}\log K(\mathrm{~m} / \mathrm{s}) \\
\text { Disuppted } \\
\text { Region } \\
\end{array}$ & nodeI & node2 & nodes & node4 & nodes & node6 & node 7 & node8 & rode9 \\
\hline 01 & 0.2 & -4.5 & -13.0 & -5.7 & 150 & 142 & 179 & 173 & 174 & 177 & 178 & 204 & 167 \\
\hline 02 & 0.2 & -4.5 & -13.0 & -6.7 & 161 & 149 & 201 & 176 & 186 & 190 & 183 & 219 & 238 \\
\hline 03 & 0.2 & -4.5 & -13.0 & -7.7 & 161 & 153 & 213 & 176 & 198 & 201 & 188 & 236 & 256 \\
\hline 04 & 0.2 & -4.5 & -12.0 & -5.7 & 161 & 152 & 207 & 175 & 186 & 187 & 180 & 216 & 190 \\
\hline 05 & 0.2 & -4.5 & -12.0 & -6.7 & 179 & 180 & 236 & 185 & 225 & 219 & 206 & 259 & 264 \\
\hline 06 & 0.2 & -4.5 & -12.0 & -7.7 & 202 & 210 & 241 & 203 & 251 & 230 & 247 & 279 & 268 \\
\hline 07 & 0.2 & -4.5 & -11.0 & -5.7 & 150 & 145 & 181 & 169 & 166 & 163 & 165 & 172 & 116 \\
\hline 08 & 0.2 & -4.5 & -11.0 & -6.7 & 230 & 225 & 255 & 233 & 255 & 250 & 271 & 289 & 273 \\
\hline 09 & 0.2 & -4.5 & -11.0 & -7.7 & 247 & 237 & 255 & 257 & 264 & 254 & 279 & 291 & 272 \\
\hline 10 & 0.2 & -5.5 & -13.0 & -5.7 & 156 & 144 & 182 & 177 & 176 & 177 & 186 & 208 & 164 \\
\hline 11 & 0.2 & -5.5 & -13.0 & -6.7 & 169 & 151 & 202 & 181 & 186 & 188 & 192 & 217 & 220 \\
\hline 12 & 0.2 & -5.5 & -13.0 & -7.7 & 168 & 152 & 207 & 180 & 189 & 192 & 189 & 221 & 239 \\
\hline 13 & 0.2 & -5.5 & -12.0 & -5.7 & 160 & 149 & 199 & 177 & 181 & 181 & 184 & 209 & 160 \\
\hline 14 & 0.2 & -5.5 & -12.0 & -6.7 & 179 & 171 & 230 & 185 & 205 & 205 & 198 & 232 & 251 \\
\hline 15 & 0.2 & -5.5 & -12.0 & -7.7 & 184 & 186 & 235 & 189 & 225 & 217 & 210 & 252 & 262 \\
\hline 16 & 0.2 & -5.5 & -11.0 & -5.7 & 176 & 164 & 224 & 181 & 186 & 180 & 183 & 205 & 133 \\
\hline 17 & 0.2 & -5.5 & -11.0 & -6.7 & 208 & 207 & 249 & 200 & 228 & 227 & 224 & 257 & 264 \\
\hline 18 & 0.2 & -5.5 & -11.0 & -7.7 & 223 & 224 & 252 & 215 & 248 & 242 & 250 & 276 & 270 \\
\hline 19 & 0.2 & -6.5 & -13.0 & -5.7 & 170 & 150 & 196 & 183 & 183 & 182 & 196 & 214 & 183 \\
\hline 20 & 0.2 & -6.5 & -13.0 & -6.7 & 180 & 160 & 211 & 188 & 192 & 192 & 202 & 220 & 229 \\
\hline 21 & 0.2 & -6.5 & -13.0 & -7.7 & 178 & 161 & 214 & 187 & 196 & 196 & 203 & 223 & 242 \\
\hline 22 & 0.2 & -6.5 & -12.0 & -5.7 & 174 & 157 & 211 & 184 & 188 & 186 & 196 & 216 & 182 \\
\hline 23 & 0.2 & -6.5 & -12.0 & -6.7 & 198 & 197 & 237 & 195 & 217 & 212 & 212 & 235 & 255 \\
\hline 24 & 0.2 & -6.5 & -12.0 & -7.7 & 201 & 205 & 238 & 197 & 228 & 218 & 218 & 245 & 261 \\
\hline 25 & 0.2 & -6.5 & -11.0 & -5.7 & 183 & 169 & 224 & 187 & 191 & 183 & 195 & 213 & 148 \\
\hline 26 & 0.2 & -6.5 & -11.0 & -6.7 & 233 & 230 & 252 & 218 & 240 & 235 & 237 & 256 & 265 \\
\hline 27 & 0.2 & -6.5 & -11.0 & -7.7 & 237 & 234 & 251 & 225 & 250 & 238 & 248 & 269 & 268 \\
\hline 28 & 2.0 & -4.5 & -13.0 & -5.7 & 170 & 152 & 202 & 181 & 187 & 188 & 193 & 218 & 223 \\
\hline 29 & 2.0 & -4.5 & -13.0 & -6.7 & 168 & 153 & 207 & 179 & 189 & 192 & 189 & 221 & 240 \\
\hline 30 & 2.0 & -4.5 & -13.0 & -7.7 & 165 & 151 & 207 & 177 & 189 & 193 & 185 & 223 & 245 \\
\hline 31 & 2.0 & -4.5 & -12.0 & -5.7 & 185 & 180 & 234 & 188 & 213 & 212 & 204 & 238 & 257 \\
\hline 32 & 2.0 & -4.5 & -12.0 & -6.7 & 188 & 190 & 237 & 188 & 226 & 218 & 209 & 254 & 263 \\
\hline 33 & 2.0 & -4.5 & -12.0 & -7.7 & 187 & 191 & 237 & 188 & 229 & 220 & 211 & 260 & 264 \\
\hline 34 & 2.0 & -4.5 & -11.0 & -5.7 & 243 & 240 & 257 & 232 & 253 & 250 & 255 & 275 & 271 \\
\hline 35 & 2.0 & -4.5 & -11.0 & -6.7 & 245 & 240 & 252 & 242 & 258 & 244 & 270 & 285 & 270 \\
\hline 36 & 2.0 & -4.5 & -11.0 & -7.7 & 241 & 235 & 252 & 241 & 257 & 246 & 272 & 288 & 271 \\
\hline 37 & 2.0 & -5.5 & -13.0 & -5.7 & 184 & 163 & 212 & 188 & 192 & 192 & 199 & 220 & 229 \\
\hline 38 & 2.0 & -5.5 & -13.0 & -6.7 & 180 & 163 & 215 & 187 & 196 & 196 & 202 & 224 & 242 \\
\hline 39 & 2.0 & -5.5 & -13.0 & -7.7 & 173 & 157 & 211 & 183 & 193 & 194 & 196 & 223 & 242 \\
\hline 40 & 2.0 & -5.5 & -12.0 & -5.7 & 203 & 204 & 239 & 195 & 219 & 214 & 210 & 237 & 257 \\
\hline 41 & 2.0 & -5.5 & -12.0 & -6.7 & 207 & 214 & 240 & 198 & 231 & 220 & 219 & 247 & 262 \\
\hline 42 & 2.0 & -5.5 & -12.0 & -7.7 & 200 & 206 & 239 & 195 & 230 & 219 & 217 & 250 & 262 \\
\hline 43 & 2.0 & -5.5 & -11.0 & -5.7 & 253 & 249 & 257 & 238 & 254 & 247 & 252 & 269 & 270 \\
\hline 44 & 2.0 & -5.5 & -11.0 & -6.7 & 256 & 248 & 252 & 248 & 258 & 243 & 263 & 276 & 270 \\
\hline 45 & 2.0 & -5.5 & -11.0 & -7.7 & 250 & 243 & 252 & 244 & 256 & 245 & 264 & 280 & 270 \\
\hline 46 & 2.0 & -6.5 & -13.0 & -5.7 & 227 & 255 & 233 & 200 & 206 & 200 & 211 & 224 & 240 \\
\hline 47 & 2.0 & -6.5 & -13.0 & -6.7 & 239 & 271 & 238 & 205 & 215 & 206 & 216 & 228 & 250 \\
\hline 48 & 2.0 & -6.5 & -13.0 & -7.7 & 234 & 260 & 236 & 204 & 216 & 207 & 217 & 229 & 252 \\
\hline 49 & 2.0 & -6.5 & -12.0 & -5.7 & 252 & 269 & 249 & 212 & 235 & 223 & 222 & 239 & 259 \\
\hline 50 & 2.0 & -6.5 & -12.0 & -6.7 & 268 & 277 & 248 & 224 & 247 & 227 & 231 & 245 & 263 \\
\hline 51 & 2.0 & -6.5 & -12.0 & -7.7 & 275 & 278 & 249 & 233 & 252 & 228 & 236 & 249 & 264 \\
\hline 52 & 2.0 & -6.5 & -11.0 & -5.7 & 258 & 261 & 259 & 232 & 251 & 245 & 244 & 261 & 268 \\
\hline 53 & 2.0 & -6.5 & -11.0 & -6.7 & 264 & 252 & 250 & 241 & 256 & 240 & 252 & 268 & 269 \\
\hline 54 & 2.0 & -6.5 & -11.0 & -7.7 & 268 & 265 & 251 & 247 & 257 & 244 & 256 & 271 & 269 \\
\hline
\end{tabular}

C- 13 
Table C-10. Simulated Vertical Specific Discharge ( $\mathrm{m} / \mathrm{yr})$ across the top of the Culebra Dolomite Near the WIPP Site

\begin{tabular}{|c|c|c|c|c|c|c|c|c|c|c|c|c|c|}
\hline $\begin{array}{l}\text { Run } \\
\text { D. }\end{array}$ & $\begin{array}{c}R \\
(m \times 1 y x) \\
\end{array}$ & $\begin{array}{l}\text { og K (m/s) } \\
\text { Dewey } \\
\text { Lake' } \\
\text { Tiassic }\end{array}$ & $\begin{array}{c}\log R(m / s) \\
\text { Anhydate }\end{array}$ & $\begin{array}{c}\log \mathrm{K}(\mathrm{m} / \mathrm{s}) \\
\text { Disrupted } \\
\text { Region } \\
\end{array}$ & nodel & node2 & node3 & node4 & node 5 & node6 & node7 & node8 & nodeg \\
\hline 01 & 0.2 & -4.5 & -13.0 & -5.7 & -0.000001 & -0.000001 & -0.000001 & -0.000001 & -0.000001 & -0.000001 & 0.000000 & 0.000000 & -0.000001 \\
\hline 02 & $0 . \dot{2}$ & -4.5 & -13.0 & -6.7 & -0.000003 & -0.000004 & -0.000005 & -0.000002 & -0.000005 & -0.000005 & -0.000002 & -0.000003 & -0.000005 \\
\hline 03 & 0.2 & -4.5 & -13.0 & -7.7 & -0.000006 & -0.000006 & -0.000009 & -0.000004 & -0.000009 & -0.000010 & -0.000004 & -0.000007 & -0.000011 \\
\hline 04 & 0.2 & -4.5 & -12.0 & -5.7 & -0.000024 & -0.000016 & -0.000010 & -0.000012 & -0.000011 & -0.000006 & -0.000007 & -0.000007 & -0.000004 \\
\hline 05 & 0.2 & -4.5 & -12.0 & -6.7 & -0.000063 & -0.000050 & -0.000043 & -0.000039 & -0.000051 & -0.000036 & -0.000037 & -0.000054 & -0.000037 \\
\hline 06 & 0.2 & -4.5 & -12.0 & -7.7 & -0.000111 & -0.000087 & -0.000081 & -0.000076 & -0.000104 & -0.000075 & -0.000081 & -0.000125 & -0.000086 \\
\hline 07 & 0.2 & -4.5 & -11.0 & -5.7 & -0.000041 & -0.000021 & -0.000003 & -0.000008 & -0.000001 & 0.000001 & 0.000006 & 0.000021 & 0.000005 \\
\hline 08 & 0.2 & -4.5 & -11.0 & -6.7 & -0.000320 & -0.000244 & -0.000084 & -0.000221 & -0.000140 & -0.000041 & -0.000233 & -0.000284 & -0.000052 \\
\hline 09 & 0.2 & -4.5 & -11.0 & -7.7 & -0.000491 & -0.000465 & -0.000209 & -0.000368 & -0.000300 & -0.000118 & -0.000413 & -0.000630 & -0.000172 \\
\hline 10 & 0.2 & -5.5 & -13.0 & -5.7 & -0.000001 & -0.000001 & -0.000001 & 0.000000 & -0.000001 & 0.000000 & 0.000000 & 0.000000 & 0.000000 \\
\hline 11 & 0.2 & -5.5 & -13.0 & -6.7 & -0.000003 & -0.000003 & -0.000005 & -0.000002 & -0.000004 & -0.000004 & -0.000002 & 0002 & -0.000004 \\
\hline 12 & 0.2 & -5.5 & & -7.7 & -0.000005 & -0.000005 & -0.000008 & -0.000003 & -0.000007 & -0.000008 & -0.000003 & -0.000005 & -0.000008 \\
\hline 13 & 0.2 & -5.5 & -1 & -5.7 & -0.000016 & -0.000012 & -0.000007 & -0.000007 & -0.000006 & -0.000003 & -0.000003 & -0.000001 & -0.000001 \\
\hline 14 & 0.2 & -5.5 & -12.0 & -6.7 & -0.000058 & -0.000046 & -0.000040 & -0.000033 & -0.000042 & -0.000030 & -0.000027 & 1037 & -0.000027 \\
\hline 15 & 0.2 & 0.5 & & -7.7 & -0.000088 & -0.000071 & -0.000067 & -0.000057 & -0.000080 & -0.000059 & -0.000057 & -0.000087 & -0.000052 \\
\hline 16 & 0.2 & -5.5 & 0 & -5.7 & -0.000085 & -0.000060 & -0.000016 & -0.000035 & -0.000017 & -0.000003 & -0.000008 & 0.000012 & 0.000003 \\
\hline 17 & 0.2 & -5.5 & -11.0 & -6.7 & -0.000278 & -0.000227 & -0.000080 & -0.000170 & -0.000113 & -0.000034 & -0.0 & 171 & -0.000040 \\
\hline 18 & 0 & -5 & & -7.7 & -0.000424 & -0.000406 & -0.000178 & -0.000299 & -0.000243 & -0.000097 & -0.000301 & 0459 & -0.000128 \\
\hline 19 & 0.2 & -6.5 & -1 & -5.7 & -0.000001 & -0.000001 & -0.000001 & -0.000001 & -0.000001 & -0.000001 & 0.000000 & 0.000000 & 0.000000 \\
\hline 20 & 0.2 & -6.5 & -13.0 & -6.7 & -0.000003 & -0.000003 & -0.000004 & -0.000002 & -0.000004 & -0.000004 & -0.000002 & 0002 & 0004 \\
\hline 21 & & $-t$ & & -7.7 & -0.000004 & -0.000004 & -0.000006 & -0.000003 & -0.000006 & -0.000006 & -0.000003 & -0.000004 & -0.000007 \\
\hline 22 & 0.2 & -6.5 & 0 & -5.7 & -0.000013 & -0.000010 & -0.000007 & -0.000007 & -0.000007 & -0.000004 & -0.000004 & -0.000002 & -0.0 \\
\hline 23 & 0.2 & -6.5 & -12.0 & -6.7 & -0.000041 & -0.000034 & -0.000031 & -0.000026 & -0.000035 & -0.000025 & -0.000024 & -0.000034 & -0.000024 \\
\hline 24 & 0 & - & -7 & 7 & -0.000059 & -0.000049 & -0.000050 & -0.000041 & -0.000059 & -0.000045 & -0.000042 & 1065 & -0.0 \\
\hline 25 & 0 & -6.5 & .0 & 7 & -0.000053 & -0.000045 & -0.000012 & -0.000032 & -0.000015 & -0.000003 & -0.000012 & 0.000006 & 0.000002 \\
\hline 26 & 0 & -6.5 & & -6.7 & -0.000194 & -0.000163 & -0.000060 & -0.000132 & -0.000089 & -0.000028 & -0.000120 & -0.000153 & -0.000036 \\
\hline 27 & 0.2 & -6.5 & -11.0 & & -0.000322 & -0.000300 & -0.000127 & -0.000239 & -0.000187 & -0.000072 & -0.000240 & 0358 & -0.00 \\
\hline 28 & 2.0 & -4.5 & -13.0 & -5.7 & -0.000003 & -0.000003 & -0.000005 & -0.000002 & -0.000004 & -0.000004 & -0.000001 & 1002 & -0.000004 \\
\hline 29 & 2.0 & -4.5 & & -6.7 & -0.000004 & -0.000005 & -0.000007 & -0.000003 & -0.000007 & -0.000008 & -0.000003 & 1005 & -0.000008 \\
\hline 30 & 2.0 & -4.5 & -13.0 & -7.7 & -0.000005 & -0.000005 & -0.000008 & -0.000003 & -0.000007 & -0.000008 & -0.00 & 0006 & 009 \\
\hline 31 & 2.0 & -4.5 & -12.0 & -5.7 & -0.000058 & -0.000047 & -0.000042 & -0.000034 & -0.000046 & -0.000033 & -0.000030 & -0.000044 & -0.000031 \\
\hline 32 & 2.0 & -4.5 & & -6.7 & -0.000086 & -0.000071 & -0.000067 & -0.000057 & -0.000080 & -0.000059 & -0.000059 & -0.000090 & -0.000062 \\
\hline 33 & 2.0 & -4.5 & -12.0 & -7.7 & -0.000092 & -0.000075 & -0.000072 & -0.000062 & -0.000085 & -0.000053 & -0.000066 & -0.000103 & 0066 \\
\hline 34 & 2.0 & -4.5 & -11.0 & -5.7 & -0.000356 & -0.000264 & -0.000088 & -0.000239 & -0.000148 & -0.000041 & -0.000235 & 285 & -0.000062 \\
\hline 35 & 2.0 & -4.5 & & -6.7 & -0.000560 & -0.000433 & -0.000160 & -0.000443 & -0.000277 & -0.000090 & -0.000506 & -0.000527 & -0.000131 \\
\hline 36 & 2 & -4.5 & & -7.7 & -0.000605 & -0.000468 & -0.000180 & -0.000475 & -0.000295 & -0.000095 & -0.000549 & -0.000741 & -0.000135 \\
\hline 37 & 2.0 & -5.5 & -13.0 & -5.7 & -0.000002 & -0.000003 & -0.000004 & -0.000002 & -0.000003 & -0.000004 & -0.000001 & 002 & -0.000004 \\
\hline 38 & 2.0 & -5.5 & & -6.7 & -0.000004 & -0.000004 & -0.000006 & -0.000003 & -0.000005 & -0.000006 & -0.000002 & -0.000004 & -0.000006 \\
\hline 39 & 2.0 & -5.5 & -13.0 & -7.7 & -0.000004 & -0.000005 & -0.000007 & -0.000003 & -0.000006 & -0.000007 & -0.000003 & -0.000005 & -0.000007 \\
\hline 40 & 2.0 & -5.5 & -12.0 & -5.7 & -0.000047 & -0.000039 & -0.000036 & -0.000030 & -0.000041 & -0.000029 & -0.000028 & -0.000040 & -0.000028 \\
\hline 41 & 2.0 & -5.5 & -12.0 & -6.7 & -0.000064 & -0.000053 & -0.000053 & -0.000044 & -0.000063 & -0.000048 & -0.000046 & -0.000071 & -0.000050 \\
\hline 42 & 2.0 & -5.5 & -12.0 & -7.7 & -0.000073 & -0.000060 & -0.000059 & -0.000050 & -0.000069 & -0.000052 & -0.000052 & -0.000083 & -0.000053 \\
\hline 43 & 2.0 & -5.5 & -11.0 & -5.7 & -0.000288 & -0.000222 & -0.000076 & -0.000208 & -0.000130 & -0.000037 & -0.000210 & -0.000254 & -0.000056 \\
\hline 44 & 2.0 & -5.5 & -11.0 & -6.7 & -0.000396 & -0.000316 & -0.000125 & -0.000332 & -0.000211 & -0.000074 & -0.000374 & -0.000480 & -0.000102 \\
\hline 45 & 2.0 & -5.5 & & -7.7 & 0.000439 & -0.000349 & -0.000144 & -0.000360 & -0.000226 & -0.000079 & -0.000408 & -0.000580 & -0.000104 \\
\hline 46 & 2.0 & -6.5 & & -5.7 & -0.000001 & -0.000002 & -0.000003 & -0.000001 & -0.000003 & -0.000003 & -0.000001 & -0.000002 & -0.000003 \\
\hline 47 & 2.0 & -6.5 & -13.0 & -6.7 & -0.000001 & -0.000002 & -0.000004 & -0.000001 & -0.000004 & -0.000004 & -0.000001 & -0.000003 & -0.000005 \\
\hline 48 & 2.0 & -6.5 & & -7.7 & -0.000002 & -0.000003 & -0.000004 & -0.000002 & -0.000004 & -0.000005 & -0.000002 & -0.000004 & -0.000005 \\
\hline 49 & 2.0 & -6.5 & -12.0 & -5.7 & -0.000027 & -0.000023 & -0.000025 & -0.000020 & -0.000030 & -0.000021 & -0.000021 & -0.000032 & -0.000023 \\
\hline 50 & 2.0 & -6.5 & -12.0 & -6.7 & -0.000028 & -0.000025 & -0.000031 & -0.000023 & -0.000038 & -0.000031 & -0.000027 & -0.000046 & -0.000033 \\
\hline 51 & 2.0 & -6.5 & -72.0 & -7.7 & -0.000032 & -0.000028 & -0.000034 & -0.000026 & -0.000042 & -0.000033 & -0.000032 & -0.000055 & -0.000035 \\
\hline 52 & 2.0 & -6.5 & -11.0 & -5.7 & -0.000180 & -0.000157 & -0.000059 & -0.000142 & -0.000096 & -0.000030 & -0.000142 & -0.000183 & -0.000042 \\
\hline 53 & 2.0 & -6.5 & -11.0 & -6.7 & -0.000199 & -0.000179 & -0.000083 & -0.000183 & -0.000129 & -0.000054 & -0.000193 & -0.000294 & -0.000066 \\
\hline 54 & 2.0 & -6.5 & -11.0 & -7.7 & -0.000198 & -0.000176 & -0.000090 & -0.000189 & -0.000129 & -0.000055 & -0.000207 & -0.000368 & -0.000063 \\
\hline
\end{tabular}


Table C-11. Simulated Mass Balance in the Magenta Dolomite

Near the WIPP Site

\begin{tabular}{|c|c|c|c|c|c|c|c|c|c|c|c|}
\hline $\begin{array}{c}\text { " } \\
\text { RunID. }\end{array}$ & $\begin{array}{c}R \\
(m m / y z) \\
\end{array}$ & $\begin{array}{l}\log K(m / s) \\
\text { Dewrey } \\
\text { Laked } \\
\text { Thiassic } \\
\end{array}$ & $\begin{array}{c}\log \mathrm{K}(\mathrm{m} / \mathrm{s}) \\
\text { Anlhydite }\end{array}$ & $\begin{array}{c}\log K(\operatorname{m} / s) \\
\text { Disropted } \\
\text { Resion }\end{array}$ & $\begin{array}{r}\text { Total } \\
\text { Flow } \\
\left(\mathrm{m}^{3} / \mathrm{yr}\right) \\
\end{array}$ & $\begin{array}{r}\% \text { Top } \\
\text { In } \\
\end{array}$ & $\begin{array}{r}\% \text { Base } \\
\text { In } \\
\end{array}$ & $\begin{array}{r}\% \text { Side } \\
\text { In } \\
\end{array}$ & $\begin{array}{r}\text { \% Top } \\
\text { Out } \\
\end{array}$ & $\begin{array}{r}\% \text { Base } \\
\text { Out } \\
\end{array}$ & $\begin{array}{r}\% \text { Side } \\
\text { Out } \\
\end{array}$ \\
\hline 01 & 0.2 & -4.5 & -13.0 & -5.7 & 99 & 97.4 & 0.0 & 2.6 & 0.0 & 27.7 & 72.3 \\
\hline 02 & 0.2 & -4.5 & -13.0 & -6.7 & 648 & 97.1 & 0.0 & 2.9 & 0.0 & 20.7 & 79.3 \\
\hline 03 & 0.2 & -4.5 & -13.0 & -7.7 & 1306 & 96.3 & 0.0 & 3.7 & 0.0 & 19.4 & 80.6 \\
\hline 04 & 0.2 & -4.5 & -12.0 & -5.7 & 511 & 87.6 & 0.0 & 12.4 & 0.0 & 76.8 & 23.2 \\
\hline 05 & 0.2 & -4.5 & -12.0 & -6.7 & 2410 & 99.5 & 0.0 & 0.5 & 0.0 & 67.9 & 32.1 \\
\hline 06 & 0.2 & -4.5 & -12.0 & -7.7 & 5048 & 99.3 & 0.0 & 0.7 & 0.0 & 65.1 & 34.9 \\
\hline 07 & 0.2 & -4.5 & -11.0 & -5.7 & 513 & 39.3 & 25.4 & 35.3 & 32.9 & 58.7 & 8.3 \\
\hline 08 & 0.2 & -4.5 & -11.0 & -6.7 & 7056 & 99.9 & 0.0 & 0.1 & 0.0 & 92.5 & 7.5 \\
\hline 09 & 0.2 & -4.5 & -11.0 & -7.7 & 14111 & 99.7 & 0.0 & 0.3 & 0.0 & 89.7 & 10.3 \\
\hline 10 & 0.2 & -5.5 & -13.0 & -5.7 & 84 & 42.0 & 0.0 & 58.0 & 0.0 & 19.8 & 80.2 \\
\hline 11 & 0.2 & -5.5 & -13.0 & -6.7 & 553 & 87.1 & 0.0 & 12.9 & 0.0 & 19.7 & 80.3 \\
\hline 12 & 0.2 & -5.5 & -13.0 & -7.7 & 946 & 95.6 & 0.0 & 4.4 & 0.0 & 20.6 & 79.4 \\
\hline 13 & 0.2 & -5.5 & -12.0 & -5.7 & 284 & 70.6 & 0.0 & 29.4 & 0.9 & 79.2 & 19.9 \\
\hline 14 & 0.2 & -5.5 & -12.0 & -6.7 & 1891 & 99.4 & 0.0 & 0.6 & 0.0 & 71.5 & 28.5 \\
\hline 15 & 0.2 & -5.5 & -12.0 & -7.7 & 3819 & 99.1 & 0.0 & 0.9 & 0.0 & 65.5 & 34.5 \\
\hline 16 & 0.2 & -5.5 & -11.0 & -5.7 & 1095 & 83.1 & 5.4 & 11.5 & 8.4 & 82.1 & 9.5 \\
\hline 17 & 0.2 & -5.5 & -11.0 & -6.7 & 5504 & 99.6 & 0.0 & 0.4 & 0.0 & 91.4 & 8.6 \\
\hline 18 & 0.2 & -5.5 & -11.0 & -7.7 & 11352 & 99.7 & 0.0 & 0.3 & 0.0 & 89.3 & 10.7 \\
\hline 19 & 0.2 & -6.5 & -13.0 & -5.7 & 138 & 30.0 & 0.0 & 70.0 & 0.0 & 16.5 & 83.5 \\
\hline 20 & 0.2 & -6.5 & -13.0 & -6.7 & 519 & 81.1 & 0.0 & 18.9 & 0.0 & 19.3 & 80.7 \\
\hline 21 & 0.2 & -6.5 & -13.0 & -7.7 & 767 & 91.1 & 0.0 & 8.9 & 0.0 & 21.2 & 78.8 \\
\hline 22 & 0.2 & -6.5 & -12.0 & -5.7 & 308 & 72.9 & 0.0 & 27.1 & 0.1 & 69.6 & 30.3 \\
\hline 23 & 0.2 & -6.5 & -12.0 & -6.7 & 1642 & 99.3 & 0.0 & 0.7 & 0.0 & 65.9 & 34.1 \\
\hline 24 & 0.2 & -6.5 & -12.0 & -7.7 & 2934 & 98.9 & 0.0 & 1.1 & 0.0 & 61.7 & 38.3 \\
\hline 25 & 0.2 & -6.5 & -11.0 & -5.7 & 874 & 87.5 & 3.3 & 9.2 & 6.4 & 82.6 & 11.0 \\
\hline 26 & 0.2 & -6.5 & -11.0 & -6.7 & 4369 & 99.5 & 0.0 & 0.5 & 0.0 & 89.4 & 10.6 \\
\hline 27 & 0.2 & -6.5 & -11.0 & -7.7 & 8799 & 99.7 & 0.0 & 0.3 & 0.0 & 88.4 & 11.6 \\
\hline 28 & 2.0 & -4.5 & -13.0 & -5.7 & 564 & 88.8 & 0.0 & 11.2 & 0.0 & 18.8 & 81.2 \\
\hline 29 & 2.0 & -4.5 & -13.0 & -6.7 & 941 & 95.6 & 0.0 & 4.4 & 0.0 & 20.0 & 80.0 \\
\hline 30 & 2.0 & -4.5 & -13.0 & -7.7 & 1047 & 95.8 & 0.0 & 4.2 & 0.0 & 19.9 & 80.1 \\
\hline 31 & 2.0 & -4.5 & -12.0 & -5.7 & 2169 & 99.4 & 0.0 & 0.6 & 0.0 & 67.0 & 33.0 \\
\hline 32 & 2.0 & -4.5 & -12.0 & -6.7 & 3926 & 99.1 & 0.0 & 0.9 & 0.0 & 63.9 & 36.1 \\
\hline 33 & 2.0 & -4.5 & -12.0 & -7.7 & 4280 & 99.1 & 0.0 & 0.9 & 0.0 & ธ3.5 & 36.5 \\
\hline 34 & 2.0 & -4.5 & -11.0 & -5.7 & 7468 & 99.8 & 0.0 & 0.2 & 0.0 & 92.0 & 8.0 \\
\hline 35 & 2.0 & -4.5 & -11.0 & -6.7 & 14351 & 99.8 & 0.0 & 0.2 & 0.0 & 90.0 & 10.0 \\
\hline 36 & 2.0 & -4.5 & -11.0 & -7.7 & 15800 & 99.8 & 0.0 & 0.2 & 0.0 & 89.7 & 10.3 \\
\hline 37 & 2.0 & -5.5 & -13.0 & -5.7 & 534 & 83.3 & 0.0 & 16.7 & 0.0 & 17.2 & 82.8 \\
\hline 38 & 2.0 & -5.5 & -13.0 & -6.7 & 778 & 92.8 & 0.0 & 7.2 & 0.0 & 19.3 & 80.7 \\
\hline 39 & 2.0 & -5.5 & -13.0 & -7.7 & 875 & 94.5 & 0.0 & 5.5 & 0.0 & 20.0 & 80.0 \\
\hline 40 & 2.0 & -5.5 & -12.0 & -5.7 & 1936 & 99.3 & 0.0 & 0.7 & 0.0 & 65.1 & 34.9 \\
\hline 41 & 2.0 & -5.5 & -12.0 & -6.7 & 3157 & 99.0 & 0.0 & 1.0 & 0.0 & 62.1 & 37.9 \\
\hline 42 & 2.0 & -5.5 & -12.0 & -7.7 & 3519 & 99.0 & 0.0 & 1.0 & 0.0 & 62.2 & 37.8 \\
\hline 43 & 2.0 & -5.5 & -11.0 & -5.7 & 6522 & 99.9 & 0.0 & 0.1 & 0.0 & 90.9 & 9.1 \\
\hline 44 & 2.0 & -5.5 & -11.0 & -6.7 & 10924 & 99.8 & 0.0 & 0.2 & 0.0 & 88.2 & 11.8 \\
\hline 45 & 2.0 & -5.5 & -11.0 & -7.7 & 12197 & 99.8 & 0.0 & 0.2 & 0.0 & 88.1 & 11.9 \\
\hline 46 & 2.0 & -6.5 & -13.0 & -5.7 & 452 & 82.9 & 0.0 & 17.1 & 0.0 & 14.4 & 85.6 \\
\hline 47 & 2.0 & -6.5 & -13.0 & -6.7 & 577 & 87.9 & 0.0 & 12.1 & 0.0 & 15.6 & 84.4 \\
\hline 48 & 2.0 & -6.5 & -13.0 & -7.7 & 657 & 91.2 & 0.0 & 8.8 & 0.0 & 16.6 & 83.4 \\
\hline 49 & 2.0 & -6.5 & -12.0 & -5.7 & 1486 & 99.1 & 0.0 & 0.9 & 0.0 & 59.3 & 40.7 \\
\hline 50 & 2.0 & -6.5 & -12.0 & -6.7 & 2028 & 98.6 & 0.0 & 1.4 & 0.0 & 55.0 & 45.0 \\
\hline 51 & 2.0 & -6.5 & -12.0 & -7.7 & 2309 & 98.6 & 0.0 & 1.4 & 0.0 & 54.3 & 45.7 \\
\hline 52 & 2.0 & -6.5 & -11.0 & -5.7 & 4693 & 99.7 & 0.0 & 0.3 & 0.0 & 87.9 & 12.1 \\
\hline 53 & 2.0 & -6.5 & -11.0 & -6.7 & 6578 & 99.6 & 0.0 & 0.4 & 0.0 & 83.8 & 16.2 \\
\hline 54 & 2.0 & -6.5 & -11.0 & -7.7 & 7095 & 99.6 & 0.0 & 0.4 & 0.0 & 83.1 & 16.9 \\
\hline
\end{tabular}

C- 15 
Table C-12. Simulated Mass Balance in the Culebra Dolomite

Near the WIPP Site

\begin{tabular}{|c|c|c|c|c|c|c|c|c|c|c|c|}
\hline Run ID. & $\begin{array}{c}R \\
(\operatorname{mm} / y x) \\
\end{array}$ & $\begin{array}{l}\log \mathrm{K}(\mathrm{m} / \mathrm{s}) \\
\text { Dewey } \\
\text { Lakef } \\
\text { Triassic } \\
\end{array}$ & $\begin{array}{l}\log K(\mathrm{~m} / \mathrm{s}) \\
\text { Anhydrite }\end{array}$ & $\begin{array}{c}\log K(m / s) \\
\text { Dissupted } \\
\text { Region } \\
\end{array}$ & $\begin{array}{r}\text { Total } \\
\text { Flow } \\
\left(\mathrm{m}^{3} / \mathrm{yz}\right)\end{array}$ & $\begin{array}{r}\% \text { Top } \\
\text { In } \\
\end{array}$ & $\begin{array}{r}\% \text { Base } \\
\text { In } \\
\end{array}$ & $\begin{array}{r}\% \text { Side } \\
\text { In } \\
\end{array}$ & $\begin{array}{r}\% \text { Iop } \\
\text { Out }\end{array}$ & $\begin{array}{r}\% \text { Base } \\
\text { Out } \\
\end{array}$ & $\begin{array}{r}\% \text { Side } \\
\text { Out } \\
\end{array}$ \\
\hline 01 & 0.2 & -4.5 & -13.0 & -5.7 & 1076 & 2.5 & 0.4 & 97.0 & 0.0 & 0.8 & 99.2 \\
\hline 02 & 0.2 & -4.5 & -13.0 & -6.7 & 2141 & 6.4 & 1.9 & 91.7 & 0.0 & 0.3 & 99.7 \\
\hline 03 & 0.2 & -4.5 & -13.0 & -7.7 & 2074 & 12.7 & 3.9 & 83.5 & 0.0 & 0.0 & 100.0 \\
\hline 04 & 0.2 & -4.5 & -12.0 & -5.7 & 1550 & 25.3 & 0.6 & 74.2 & 0.0 & 0.8 & 99.2 \\
\hline 05 & 0.2 & -4.5 & -12.0 & -6.7 & 2441 & 67.2 & 2.6 & 30.2 & 0.0 & 0.8 & 99.2 \\
\hline 06 & 0.2 & -4.5 & -12.0 & -7.7 & 3793 & 86.9 & 4.0 & 9.1 & 0.0 & 0.9 & 99.1 \\
\hline 07 & 0.2 & -4.5 & -11.0 & -5.7 & 1413 & 21.4 & 0.3 & 78.4 & 9.3 & 0.9 & 89.8 \\
\hline 08 & 0.2 & -4.5 & -11.0 & -6.7 & 6667 & 97.8 & 1.2 & 1.0 & 0.0 & 1.4 & 98.6 \\
\hline 09 & 0.2 & -4.5 & -11.0 & -7.7 & 13136 & $96: 4$ & 1.6 & 2.0 & 0.0 & 1.4 & 98.6 \\
\hline 10 & 0.2 & -5.5 & -13.0 & -5.7 & 1239 & 1.4 & 0.5 & 98.1 & 0.0 & 0.8 & 99.2 \\
\hline 11 & 0.2 & -5.5 & -13.0 & -6.7 & 2729 & 4.2 & 1.7 & 94.0 & 0.0 & 0.5 & 99.5 \\
\hline 12 & 0.2 & -5.5 & -13.0 & -7.7 & 3225 & 6.4 & 2.4 & 91.2 & 0.0 & 0.3 & 99.7 \\
\hline 13 & 0.2 & -5.5 & -12.0 & -5.7 & 1613 & 13.9 & 0.5 & 85.5 & 0.0 & 0.8 & 99.2 \\
\hline 14 & 0.2 & -5.5 & -12.0 & -6.7 & 3819 & 35.6 & 1.4 & 63.0 & 0.0 & 0.4 & 99.6 \\
\hline 15 & 0.2 & -5.5 & -12.0 & -7.7 & 4595 & 54.7 & 2.7 & 42.6 & 0.0 & 0.5 & 99.5 \\
\hline 16 & 0.2 & -5.5 & -11.0 & -5.7 & 2024 & 44.5 & 0.5 & 55.0 & 3.0 & 1.0 & 96.0 \\
\hline 17 & 0.2 & -5.5 & -11.0 & -6.7 & 6294 & 79.9 & 1.0 & 19.1 & 0.0 & 1.1 & 98.9 \\
\hline 18 & 0.2 & -5.5 & -11.0 & -7.7 & 10647 & 95.2 & 1.5 & 3.2 & 0.0 & 1.4 & 98.6 \\
\hline 19 & 0.2 & -6.5 & -13.0 & -5.7 & 1594 & 1.6 & 0.9 & 97.5 & 0.0 & 0.7 & 99.3 \\
\hline 20 & 0.2 & -6.5 & -13.0 & -6.7 & 2720 & 3.9 & 1.7 & 94.4 & 0.0 & 0.3 & 99.7 \\
\hline 21 & 0.2 & -6.5 & -13.0 & -7.7 & 3125 & 5.6 & 2.3 & 92.1 & 0.0 & 0.1 & 99.9 \\
\hline 22 & 0.2 & -6.5 & -12.0 & -5.7 & 1709 & 12.6 & 0.8 & 86.6 & 0.0 & 0.6 & 99.4 \\
\hline 23 & 0.2 & -6.5 & -12.0 & -6.7 & 3290 & 33.1 & 1.5 & 65.3 & 0.0 & 0.3 & 99.7 \\
\hline 24 & 0.2 & -6.5 & -12.0 & -7.7 & 4328 & 42.2 & 2.4 & 55.4 & 0.0 & 0.4 & 99.6 \\
\hline 25 & 0.2 & -6.5 & -11.0 & -5.7 & 1759 & 41.2 & 0.5 & 58.3 & 1.7 & 0.9 & 97.4 \\
\hline 26 & 0.2 & -6.5 & -11.0 & -6.7 & 5064 & 77.1 & 1.0 & 21.9 & 0.0 & 1.1 & 98.9 \\
\hline 27 & 0.2 & -6.5 & -11.0 & -7.7 & 8824 & 88.2 & 1.4 & 10.4 & 0.0 & 1.2 & 98.8 \\
\hline 28 & 2.0 & -4.5 & -13.0 & -5.7 & 2516 & 4.4 & 1.8 & 93.7 & 0.0 & 0.5 & 99.5 \\
\hline 29 & 2.0 & -4.5 & -13.0 & -6.7 & 3031 & 6.6 & 2.5 & 91.0 & 0.0 & 0.2 & 99.8 \\
\hline 30 & 2.0 & -4.5 & -13.0 & -7.7 & 3132 & 7.0 & 2.5 & 90.5 & 0.0 & 0.1 & 99.9 \\
\hline 31 & 2.0 & -4.5 & -12.0 & -5.7 & 3471 & 42.1 & 1.7 & 56.2 & $0.0^{\circ}$ & 0.4 & 99.6 \\
\hline 32 & 2.0 & -4.5 & -12.0 & -6.7 & 4447 & 56.8 & 2.8 & 40.4 & 0.0 & 0.5 & 99.5 \\
\hline 33 & 2.0 & -4.5 & -12.0 & -7.7 & 4303 & 63.5 & 3.2 & 33.3 & 0.0 & 0.6 & 99.4 \\
\hline 34 & 2.0 & -4.5 & -11.0 & .5 .7 & 7055 & 97.4 & 1.1 & 1.5 & 0.0 & 1.3 & 98.7 \\
\hline 35 & 2.0 & -4.5 & -11.0 & -6.7 & 13270 & 97.3 & 1.2 & 1.5 & 0.0 & 1.2 & 98.8 \\
\hline 36 & 2.0 & -4.5 & -11.0 & -7.7 & 14564 & 97.3 & 1.2 & 1.5 & 0.0 & 1.2 & 98.8 \\
\hline 37 & 2.0 & -5.5 & -13.0 & -5.7 & 2642 & 3.8 & 1.8 & 94.5 & 0.0 & 0.3 & 99.7 \\
\hline 38 & 2.0 & -5.5 & -13.0 & -6.7 & 2969 & 5.5 & 2.3 & 92.2 & 0.0 & 0.1 & 99.9 \\
\hline 39 & 20 & -5.5 & -13.0 & -7.7 & 3075 & 6.1 & 2.5 & 91.4 & 0.0 & 0.2 & 99.8 \\
\hline 40 & 2.0 & -5.5 & -12.0 & -5.7 & 3446 & 36.8 & 1.7 & 61.5 & 0.0 & 0.4 & 99.6 \\
\hline 41 & 20 & -5.5 & -12.0 & -6.7 & 4309 & 45.8 & 2.6 & 51.6 & 0.0 & 0.4 & 99.6 \\
\hline 42 & 2.0 & -5.5 & -12.0 & -7.7 & 4459 & 49.4 & 2.7 & 47.9 & 0.0 & 0.4 & 99.6 \\
\hline 43 & 2.0 & -5.5 & -11.0 & -5.7 & 6484 & 91.5 & 1.1 & 7.4 & 0.0 & 1.2 & 98.8 \\
\hline 44 & 2.0 & -5.5 & -11.0 & -6.7 & 9952 & 96.9 & 1.3 & 1.8 & 0.0 & 1.2 & 98.8 \\
\hline 45 & 2.0 & -5.5 & -11.0 & -7.7 & 11087 & 97.0 & 1.2 & 1.8 & 0.0 & 1.2 & 98.8 \\
\hline 46 & 2.0 & -6.5 & -13.0 & -5.7 & 2140 & 3.4 & 1.8 & 94.8 & 0.0 & 0.1 & 99.9 \\
\hline 47 & 2.0 & -6.5 & -13.0 & -6.7 & 2293 & 4.4 & 2.6 & 93.0 & 0.0 & 0.0 & 100.0 \\
\hline 48 & 2.0 & -6.5 & -13.0 & -7.7 & 2239 & 5.4 & 2.9 & 91.7 & 0.0 & 0.0 & 100.0 \\
\hline 49 & 2.0 & -6.5 & -12.0 & -5.7 & 2742 & 32.4 & 1.9 & 65.7 & 0.0 & 0.3 & 99.7 \\
\hline 50 & 2.0 & -6.5 & -12.0 & -6.7 & 3314 & 34.0 & 2.6 & 63.4 & 0.0 & 0.2 & 99.8 \\
\hline 51 & 2.0 & -6.5 & -12.0 & -7.7 & 3479 & 36.4 & 2.8 & 60.8 & 0.0 & 0.2 & 99.8 \\
\hline 52 & 2.0 & -6.5 & -11.0 & -5.7 & 4987 & 82.7 & 1.1 & 16.1 & 0.0 & 1.1 & 98.9 \\
\hline 53 & 2.0 & -6.5 & -11.0 & -6.7 & 6301 & 87.6 & 1.4 & 11.0 & 0.0 & 1.0 & 99.0 \\
\hline 54 & 2.0 & -6.5 & -11.0 & -7.7 & 6553 & 90.0 & 1.4 & 8.6 & 0.0 & 1.0 & 99.0 \\
\hline
\end{tabular}


APPENDIX D

SELECTED RESULTS FROM TRANSIENT SIMULATIONS

D-1 
This page intentionally left blank

D-2 


\section{Appendix D}

\section{Selected Results from Transient Simulations}

This appendix contains a summary of the mass balance over the reference volumes of the Dewey Lake/Triassic rocks, the Magenta Dolomite, and the Culebra Dolomite at the simulated present time and at 10,000 years in the future. Reference volumes are defined in the introduction of Section 3 of this report. These are the portions of the hydrostratigraphic units that underlie a $6 \mathrm{~km}$ by $6 \mathrm{~km}$ area that approximately corresponds to the WIPP site. The UTM coordinates of the comers of the surface trace of the reference volumes are N3585000, E611000; N3585000,E617000; N3570000, E617000; and $\mathrm{N} 357000$, E611000. The total flow values and the percents in the mass-balance summaries have been truncated to the nearest integer value.

The complete results from these simulations are retained in the WIPP-project central files in electronic form. The corresponding simulation numbers in the central files are:

$\begin{array}{ll}\text { base-case } & 040230 \\ \text { simulation 1 } & 040231 \\ \text { simulation 2 } & 040232 \\ \text { simulation 3 } & 040233 \\ \text { simulation 4 } & 040234 \\ \text { simulation 5 } & 040235 \\ \text { simulation 6 } & 040236 \\ \text { simulation 7 } & 040237 \\ \text { simulation 8 } & 040238 \\ \text { simulation 9 } & 040239 \\ \text { simulation 10 } & 040240 \\ \text { simulation 11 } & 040241 \\ \text { simulation 12 } & 040242 \\ \text { simulation 13 } & 040243 \\ \text { simulation 14 } & 040244 \\ \text { simulation 15 } & 040245 \\ \text { simulation 16 } & 040246\end{array}$


This page intentionally left blank

D-4 
Table D-1. Mass Balance Over the Reference Volumes: Total Flow $\left(\mathrm{m}^{3} / \mathrm{yr}\right)$

Time $=0.0$ Years

Flow in

Flow Out

Top Base Lateral Total Top Base Lateral Total

\begin{tabular}{|c|c|c|c|c|c|c|c|c|c|}
\hline Simulation & bc & & & & & & & & \\
\hline Culebra & & 636 & 69 & 1395 & 2100 & 0 & 0 & -2107 & -2107 \\
\hline Magenta & & 769 & 0 & 15 & 784 & 0 & -590 & -202 & -793 \\
\hline Dewey Lake & & 2122 & 0 & 2893 & 5015 & 0 & -744 & -4458 & -5203 \\
\hline Simulation & 1 & & & & & & & & \\
\hline Culebra & & 84 & 67 & 2017 & 2169 & 0 & 0 & -2173 & -2174 \\
\hline Magenta & & 215 & 0 & 57 & 272 & 0 & -46 & -233 & -279 \\
\hline Dewey Lake & & 2168 & 0 & 2620 & 4789 & 0 & -193 & -4796 & -4990 \\
\hline Simulation & 2 & & & & & & & & \\
\hline Culebra & & 1001 & 80 & 310 & 1392 & 0 & -1 & -1396 & -1398 \\
\hline Magenta & & 1298 & 0 & 21 & 1320 & 0 & -956 & -372 & -1329 \\
\hline Dewey Lake & & 2245 & 0 & 2906 & 5152 & 0 & -1272 & -4044 & -5316 \\
\hline Simulation & 3 & & & & & & & & \\
\hline Culebra & & 134 & 23 & 648 & 807 & -3 & 0 & -807 & -811 \\
\hline Magenta & & 48 & 10 & 113 & 172 & -35 & -121 & -19 & -176 \\
\hline Dewey Lake & & 4553 & 40 & 21321 & 25915 & 0 & -41 & -25925 & -25967 \\
\hline Simulation & 4 & & & & & & & & \\
\hline Culebra & & 993 & 65 & 17678 & 18737 & 0 & 0 & -18744 & -18745 \\
\hline Magenta & & 1122 & 0 & 9 & 1132 & 0 & -941 & -201 & -1143 \\
\hline Dewey Lake & & 2304 & 0 & 2597 & 4902 & 0 & -1093 & -4003 & -5097 \\
\hline Simulation & 5 & & & & & & & & \\
\hline Culebra & & 380 & 60 & 1676 & 2117 & 0 & 0 & -2122 & -2122 \\
\hline Magenta & & 1366 & 0 & 695 & 2061 & 0 & -343 & -1726 & -2070 \\
\hline Dewey Lake & & 2075 & 0 & 3093 & 5169 & 0 & -1346 & -3998 & -5345 \\
\hline Simulation & 6 & & & & & & & & \\
\hline Culebra & & 1400 & 85 & 2138 & 3625 & 0 & -7 & -3620 & -3628 \\
\hline Magenta & & 2011 & 0 & 19 & 2031 & 0 & -1369 & -668 & -2037 \\
\hline Dewey Lake & & 8574 & 0 & 13316 & 21890 & 0 & -1999 & -20069 & -22069 \\
\hline Simulation & 7 & & & & & & & & \\
\hline Culebra & & 798 & 87 & 1547 & 2433 & 0 & 0 & -2441 & -2441 \\
\hline Magenta & & 1010 & 0 & 16 & 1027 & 0 & -737 & -301 & -1039 \\
\hline Dewey Lake & & 2977 & 0 & 4759 & 7737 & 0 & -977 & -7032 & -8009 \\
\hline Simulation & 8 & & & & & & & & \\
\hline Culebra & & 945 & 98 & 1737 & 2781 & 0 & 0 & -2790 & -2790 \\
\hline Magenta & & 1229 & 0 & 19 & 1248 & 0 & -873 & -389 & -1263 \\
\hline Dewey Lake & & 3796 & 0 & 6690 & 10487 & 0 & -1188 & -9652 & -10841 \\
\hline Simulation & 9 & & & & & & & & \\
\hline Culebra & & 1167 & 97 & 371 & 1636 & 0 & -1 & -1642 & -1644 \\
\hline Magenta & & 1550 & 0 & 18 & 1569 & 0 & -1106 & -475 & -1581 \\
\hline Dewey Lake & & 3139 & 0 & 4203 & 7342 & 0 & -1514 & -6072 & -7586 \\
\hline
\end{tabular}

D- 5 
Table D-1. Mass Balance Over the Reference Volumes: Total Flow $\left(\mathrm{m}^{3} / \mathrm{yr}\right)$ Time $=0.0$ Years (continued)

Flow In

Flow Out

Top Base Lateral Total

\begin{tabular}{|c|c|c|c|c|c|c|c|c|c|}
\hline Simulation & 10 & & & & & & & & \\
\hline Culebra & & 1327 & 114 & 441 & 1882 & 0 & -1 & -1891 & -1892 \\
\hline Magenta & & 1792 & 0 & 21 & 1813 & 0 & -1250 & -578 & -1829 \\
\hline Dewey Lake & & 4152 & 0 & 6148 & 10301 & 0 & -1746 & -8887 & -10634 \\
\hline Simulation & 11 & & & & & & & & \\
\hline Culebra & & 636 & 69 & 1395 & 2100 & 0 & 0 & -2107 & -2107 \\
\hline Magenta & & 769 & 0 & 15 & 784 & 0 & -590 & -202 & -793 \\
\hline Dewey Lake & & 2122 & 0 & 2893 & 5015 & 0 & -744 & -4458 & -5203 \\
\hline Simulation & 12 & & & & & & & & \\
\hline Culebra & & 798 & 87 & 1547 & 2433 & 0 & 0 & -2441 & -2441 \\
\hline Magenta & & 1010 & 0 & 16 & 1027 & 0 & -737 & -301 & -1039 \\
\hline Dewey Lake & & 2977 & 0 & 4759 & 7737 & 0 & -977 & -7032 & -8009 \\
\hline Simulation & 13 & & & & & & & & \\
\hline Culebra & & 945 & 98 & 1737 & 2781 & 0 & 0 & -2790 & -2790 \\
\hline Magenta & & 1229 & 0 & 19 & 1248 & 0 & -873 & -389 & -1263 \\
\hline Dewey Lake & & 3796 & 0 & 6690 & 10487 & 0 & -1188 & -9652 & -10841 \\
\hline Simulation & 14 & & & & & & & & \\
\hline Culebra & & 1001 & 80 & 310 & 1392 & 0 & -1 & -1396 & -1398 \\
\hline Magenta & & 1298 & 0 & 21 & 1320 & 0 & -956 & -372 & -1329 \\
\hline Dewey Lake & & 2245 & 0 & 2906 & 5152 & 0 & -1272 & -4044 & -5316 \\
\hline Simulation & 15 & & & & & & & & \\
\hline Culebra & & 1167 & 97 & 371 & 1636 & 0 & -1 & -1642 & -1644 \\
\hline Magenta & & 1550 & 0 & 18 & 1569 & 0 & -1106 & -475 & -1581 \\
\hline Dewey Lake & & 3139 & 0 & 4203 & 7342 & 0 & -1514 & -6072 & -7586 \\
\hline Simulation & 16 & & & & & & & & \\
\hline Culebra & & 1327 & 114 & 441 & 1882 & 0 & -1 & -1891 & -1892 \\
\hline Magenta & & 1792 & 0 & 21 & 1813 & 0 & -1250 & -578 & -1829 \\
\hline Dewey Lake & & 4152 & 0 & 6148 & 10301 & 0 & -1746 & -8887 & -10634 \\
\hline
\end{tabular}

D- 6 
Table D-2. Mass Balance Over the Reference Volumes: Percent of Total Flow Time $=0.0$ Years

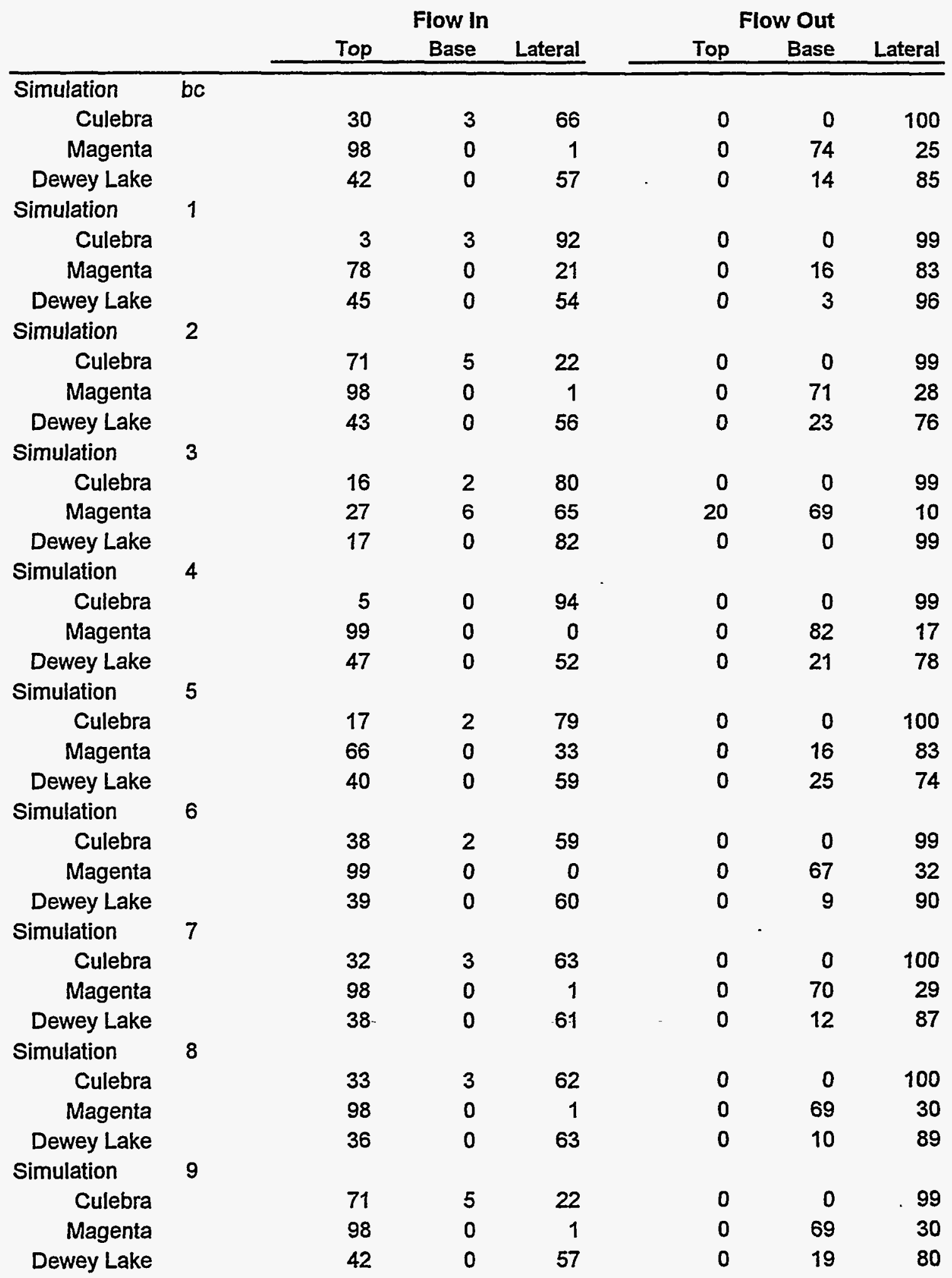


Table D-2. Mass Balance Over the Reference Volumes: Percent of Total Flow Time $=0.0$ Years (continued)

Flow In

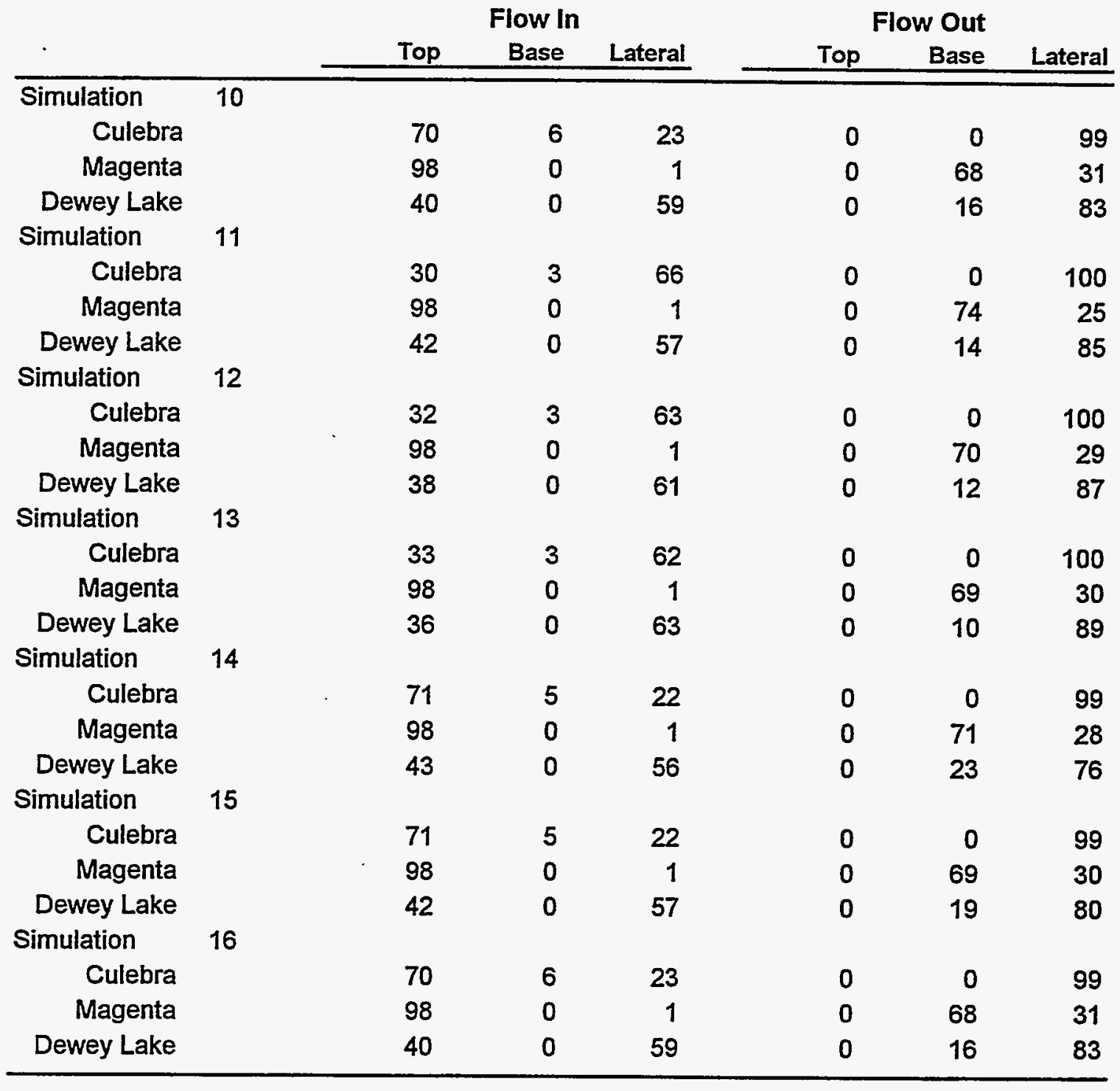

D- 8 
Table D-3. Mass Balance Over the Reference Volumes: Fractions of Base Case Values Time $=0.0$ Years

\begin{tabular}{|c|c|c|c|c|c|c|c|c|c|}
\hline & & & & Flow $\ln$ & & & Flo & N Out & \\
\hline & & Top & Base & Lateral & Total & Top & Base & Lateral & Total \\
\hline Simulation & $\overline{1}$ & & & & & & & & \\
\hline Culebra & & 0.13 & NA & 1.45 & 1.03 & NA & NA & 1.03 & 1.03 \\
\hline Magenta & & 0.28 & NA & 3.82 & 0.35 & NA & 0.08 & 1.15 & 0.35 \\
\hline Dewey Lake & & 1.02 & NA & 0.91 & 0.95 & NA & 0.26 & 1.08 & 0.96 \\
\hline Simulation & 2 & & & & & & & & \\
\hline Culebra & & 1.57 & NA & 0.22 & 0.66 & NA & NA & 0.66 & 0.66 \\
\hline Magenta & & 1.69 & NA & 1.46 & 1.68 & NA & 1.62 & 1.84 & 1.68 \\
\hline Dewey Lake & & 1.06 & NA & 1.00 & 1.03 & NA & 1.71 & 0.91 & 1.02 \\
\hline Simulation & 3 & & & & & & & & \\
\hline Culebra & & 0.21 & NA & 0.46 & 0.38 & NA & NA & 0.38 & 0.38 \\
\hline Magenta & & 0.06 & NA & 7.51 & 0.22 & NA & 0.21 & 0.09 & 0.22 \\
\hline Dewey Lake & & 2.15 & NA & 7.37 & 5.17 & NA & 0.06 & 5.81 & 4.99 \\
\hline Simulation & 4 & & & & & & & & \\
\hline Culebra & & 1.56 & NA & 12.67 & 8.92 & NA & NA & 8.90 & 8.90 \\
\hline Magenta & & 1.46 & NA & 0.65 & 1.44 & NA & 1.59 & 0.99 & 1.44 \\
\hline Dewey Lake & & 1.09 & NA & 0.90 & 0.98 & NA & 1.47 & 0.90 & 0.98 \\
\hline Simulation & 5 & & & & & & & & \\
\hline Culebra & & 0.60 & NA & 1.20 & 1.01 & NA & NA & 1.01 & 1.01 \\
\hline Magenta & & 1.78 & NA & 46.03 & 2.63 & NA & 0.58 & 8.51 & 2.61 \\
\hline Dewey Lake & & 0.98 & NA & 1.07 & 1.03 & NA & 1.81 & 0.90 & 1.03 \\
\hline Simulation & 6 & & & & & & & & \\
\hline Culebra & & 2.20 & NA & 1.53 & 1.73 & NA & NA & 1.72 & 1.72 \\
\hline Magenta & & 2.62 & NA & 1.31 & 2.59 & NA & 2.32 & 3.29 & 2.57 \\
\hline Dewey Lake & & 4.04 & NA & 4.60 & 4.36 & NA & 2.69 & 4.50 & 4.24 \\
\hline
\end{tabular}

D-9 
Table D-4. Mass Balance Over the Reference Volumes: Total Flow $\left(\mathrm{m}^{3} / \mathrm{yr}\right)$

Time $=10,000$ Years

Flow in

Flow Out

Top Base Lateral Total Top Base Lateral Total

Simulation bc

\section{Culebra}

Magenta

Dewey Lake

Simulation

Culebra

Magenta

Dewey Lake

Simulation

Culebra

Magenta

Dewey Lake

Simulation

Culebra

Magenta

Dewey Lake

Simulation

Culebra

Magenta

Dewey Lake

Simulation

Culebra

Magenta

Dewey Lake

Simulation

Culebra

Magenta

Dewey Lake

Simulation

Culebra

Magenta

Dewey Lake

Simulation

Culebra

Magenta

Dewey Lake

Simulation

Culebra

Magenta

Dewey Lake

(a)

1

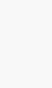

2

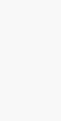

3

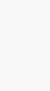

4

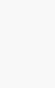

5*

6

7

8
9

4

(2)

1728

$\begin{array}{rrrr}104 & 40 & 2549 & 2694 \\ 448 & 0 & 74 & 522 \\ 8198 & 0 & 9355 & 17554\end{array}$

\begin{tabular}{|c|c|c|c|c|c|c|c|}
\hline 1520 & 53 & 630 & 2203 & 0 & -22 & -2179 & -2202 \\
\hline 2226 & 0 & 8 & 2234 & 0 & -1523 & -709 & -2233 \\
\hline 7932 & 0 & 7530 & 15463 & 0 & -2236 & -13193 & -15429 \\
\hline
\end{tabular}

349

$\begin{array}{rrrr}349 & 12 & 1259 & 1620 \\ 410 & 0 & 40 & 450 \\ 7638 & 0 & 10940 & 18579\end{array}$

\begin{tabular}{|c|c|c|c|c|c|c|c|}
\hline 1571 & 40 & 25417 & 27029 & 0 & -15 & -27013 & -27029 \\
\hline 2070 & 0 & 4 & 2074 & 0 & -1572 & -500 & -2073 \\
\hline 7760 & 0 & 7764 & 15524 & 0 & -2080 & -13400 & -15480 \\
\hline
\end{tabular}

\begin{tabular}{|c|c|c|c|c|c|c|c|}
\hline 690 & 37 & 2245 & 2973 & 0 & -11 & -2960 & -2972 \\
\hline 3243 & 0 & 975 & 4218 & 0 & -690 & -3529 & -4220 \\
\hline 7696 & 0 & 8424 & 16121 & 0 & -3254 & -12819 & -16073 \\
\hline
\end{tabular}

\begin{tabular}{|c|c|c|c|c|c|c|c|}
\hline 1329 & 57 & 2176 & 3564 & 0 & -12 & -3551 & -3564 \\
\hline 1937 & 0 & 12 & 1950 & 0 & -1322 & -627 & -1950 \\
\hline 9087 & 0 & 11161 & 20248 & 0 & -1943 & -18312 & -20256 \\
\hline
\end{tabular}

\begin{tabular}{|c|c|c|c|c|c|c|c|}
\hline 1901 & 79 & 2243 & 4224 & 0 & -21 & -4202 & -4224 \\
\hline 2884 & 0 & 16 & 2901 & 0 & -1894 & -1006 & -2900 \\
\hline 18814 & 0 & 21758 & 40572 & 0 & -2895 & -37670 & -40565 \\
\hline
\end{tabular}

\begin{tabular}{|c|c|c|c|c|c|c|c|}
\hline 2060 & 92 & 2265 & 4418 & 0 & -20 & -4397 & -4418 \\
\hline 3182 & 0 & 22 & 3204 & 0 & -2050 & -1153 & -3204 \\
\hline 28810 & 0 & 31616 & 60426 & 0 & -3196 & -57230 & -60426 \\
\hline
\end{tabular}

\begin{tabular}{|c|c|c|c|c|c|c|c|}
\hline 2255 & 86 & 1173 & 3515 & 0 & -30 & -3484 & -3514 \\
\hline 3408 & 0 & 15 & 3423 & 0 & -2253 & -1169 & -3422 \\
\hline 18312 & 0 & 20465 & 38777 & 0 & -3421 & -35321 & -38742 \\
\hline
\end{tabular}

* This simulation ended prematurely (after about $21 \mathrm{cpu}$ days). The information provided is for 9,200 years in the future.

D- 10 
Table D-4. Mass Balance Over the Reference Volumes: Total Flow $\left(\mathrm{m}^{3} / \mathrm{yr}\right)$ Time $=10,000$ Years (continued)

Flow In

Flow Out

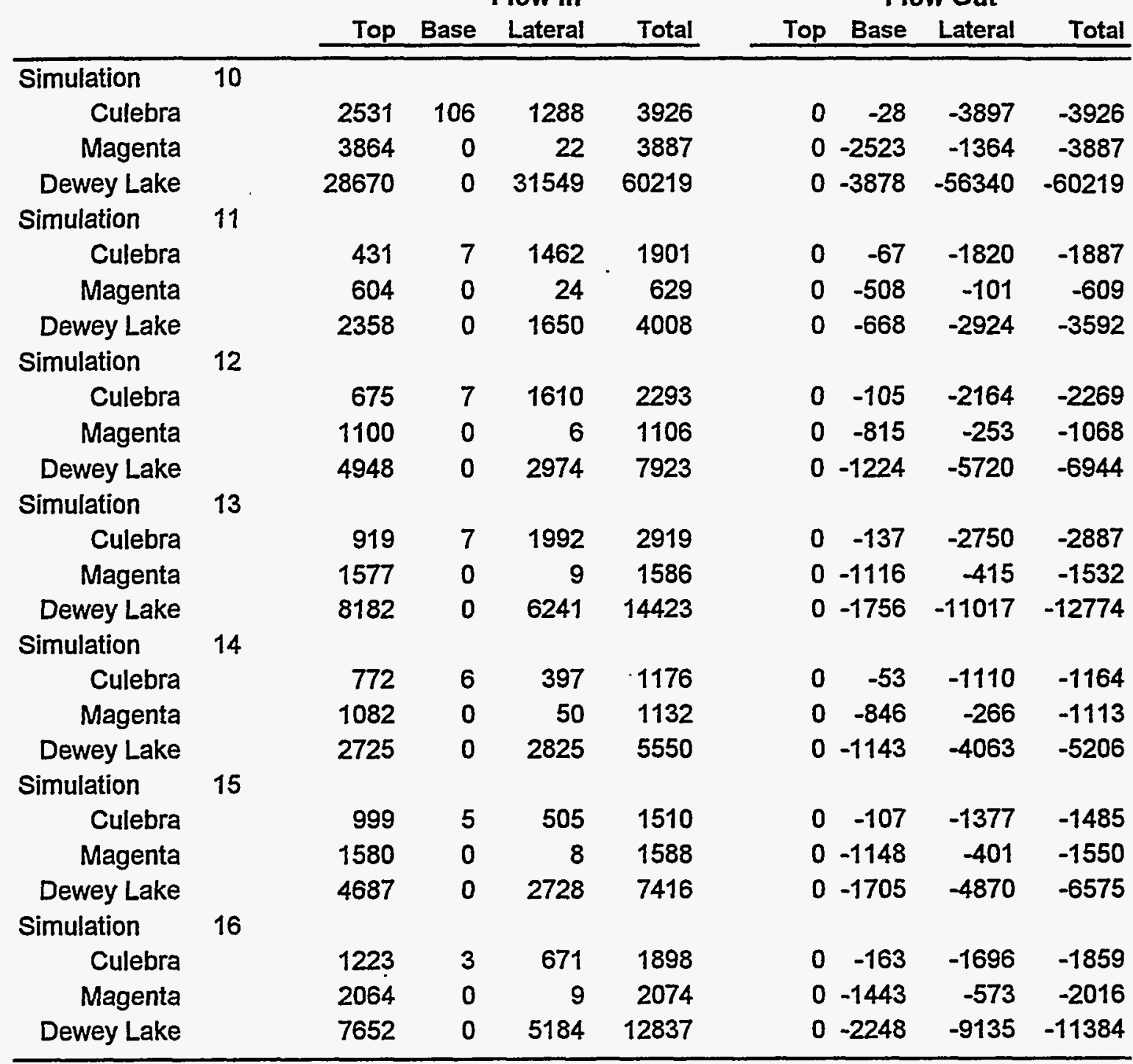


Table D-5. Mass Balance Over the Reference Volumes: Percent of Total Flow Time $=10,000$ Years

Flow in

\begin{tabular}{cccccccrrr} 
& \multicolumn{3}{c}{ Flow In } & & \multicolumn{3}{c}{ Flow Out } \\
& & Top & Base & Lateral & & Top & Base & Lateral \\
\hline Simulation & bc & & & & & & & & \\
Culebra & 35 & 1 & 63 & & 0 & 0 & 99 \\
Magenta & 99 & 0 & 0 & & 0 & 68 & 31 \\
Dewey Lake & 47 & 0 & 52 & & 0 & 10 & 89
\end{tabular}

Simulation

Culebra

Magenta

Dewey Lake

Simulation

Culebra

Magenta

Dewey Lake

Simulation

Culebra

Magenta

Dewey Lake

Simulation

Culebra

Magenta

Dewey Lake

Simulation

Culebra

Magenta

1

Dewey Lake

Simulation

Culebra

Magenta

Dewey Lake

Simulation

Culebra

Magenta

Dewey Lake

Simulation

Culebra

Magenta

Dewey Lake

Simulation

Culebra

Magenta

Dewey Lake

3

$\begin{array}{rrrrrrr}3 & 1 & 94 & & 0 & 0 & 99 \\ 85 & 0 & 14 & & 0 & 20 & 79 \\ 46 & 0 & 53 & & 0 & 2 & 97\end{array}$

2

68

99

51

28

28
0

0

198

$\begin{array}{rr}0 & 0 \\ 0 & 48\end{array}$

68

31

$\begin{array}{llll}48 & 0 & 14 & 85\end{array}$

$21 \quad 0 \quad 77$

$91 \quad 0 \quad 8$

$41 \quad 0 \quad 58$

$0 \quad 99$

$77 \quad 22$

$2 \quad 97$

4

$5 \quad 0 \quad 9$

9900

49

$0 \quad 50$

50

$0 \quad 99$

5*

23

76

47

75

23

52

$75 \quad 24$

6

$\begin{array}{lll}37 & 1 & 61\end{array}$

61

0

99

0

55

13

86

\section{7}

0

$45 \quad 1$

99

46

53

0

53

$\begin{array}{rrr}0 & 0 & 99 \\ 0 & 16 & 83 \\ 0 & 20 & 79\end{array}$

8

46

99

47

0

$\begin{array}{rrr}0 & 0 & 99 \\ 0 & 67 & 32 \\ 0 & 9 & 90\end{array}$

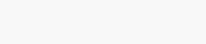


Table D-5. Mass Balance Over the Reference Volumes: Percent of Total Flow

Time $=10,000$ Years (continued)

\begin{tabular}{|c|c|c|c|c|c|c|c|}
\hline & \multicolumn{3}{|c|}{ Flow in } & \multicolumn{3}{|c|}{ Flow Out } \\
\hline & & Top & Base & Lateral & Top & Base & Lateral \\
\hline Simulation & 10 & & & & & & \\
\hline Culebra & & 64 & 2 & 32 & 0 & 0 & 99 \\
\hline Magenta & & 99 & 0 & 0 & 0 & 64 & 35 \\
\hline Dewey Lake & & 47 & 0 & 52 & 0 & 6 & 93 \\
\hline Simulation & 11 & & & & & & \\
\hline Culebra & & 22 & 0 & 76 & 0 & 3 & 96 \\
\hline Magenta & & 96 & 0 & 3 & 0 & 83 & 16 \\
\hline Dewey Lake & & 58 & 0 & 41 & 0 & 18 & 81 \\
\hline Simulation & 12 & & & & & & \\
\hline Culebra & & 29 & 0 & 70 & 0 & 4 & 95 \\
\hline Magenta & & 99 & 0 & 0 & 0 & 76 & 23 \\
\hline Dewey Lake & & 62 & 0 & 37 & 0 & 17 & 82 \\
\hline Simulation & 13 & & & & & & \\
\hline Culebra & & 31 & 0 & 68 & 0 & 4 & 95 \\
\hline Magenta & & 99 & 0 & 0 & 0 & 72 & 27 \\
\hline Dewey Lake & & 56 & 0 & 43 & 0 & 13 & 86 \\
\hline Simulation & 14 & & & & & & \\
\hline Culebra & & 65 & 0 & 33 & 0 & 4 & 95 \\
\hline Magenta & & 95 & 0 & 4 & 0 & 76 & 23 \\
\hline Dewey Lake & & 49 & 0 & 50 & 0 & 21 & 78 \\
\hline Simulation & 15 & & & & & & \\
\hline Culebra & & 66 & 0 & 33 & 0 & 7 & 92 \\
\hline Magenta & & 99 & 0 & 0 & 0 & 74 & 25 \\
\hline Dewey Lake & & 63 & 0 & 36 & 0 & 25 & 74 \\
\hline Simulation & 16 & & & & & & \\
\hline Culebra & & 64 & 0 & 35 & 0 & 8 & 91 \\
\hline Magenta & & 99 & 0 & 0 & 0 & 71 & 28 \\
\hline Dewey Lake & & 59 & 0 & 40 & 0 & 19 & 80 \\
\hline
\end{tabular}

D- 13 
Table D-6. Mass Balance Over the Reference Volumes: Fractions of Base Case Values Time $=10,000$ Years

Flow In

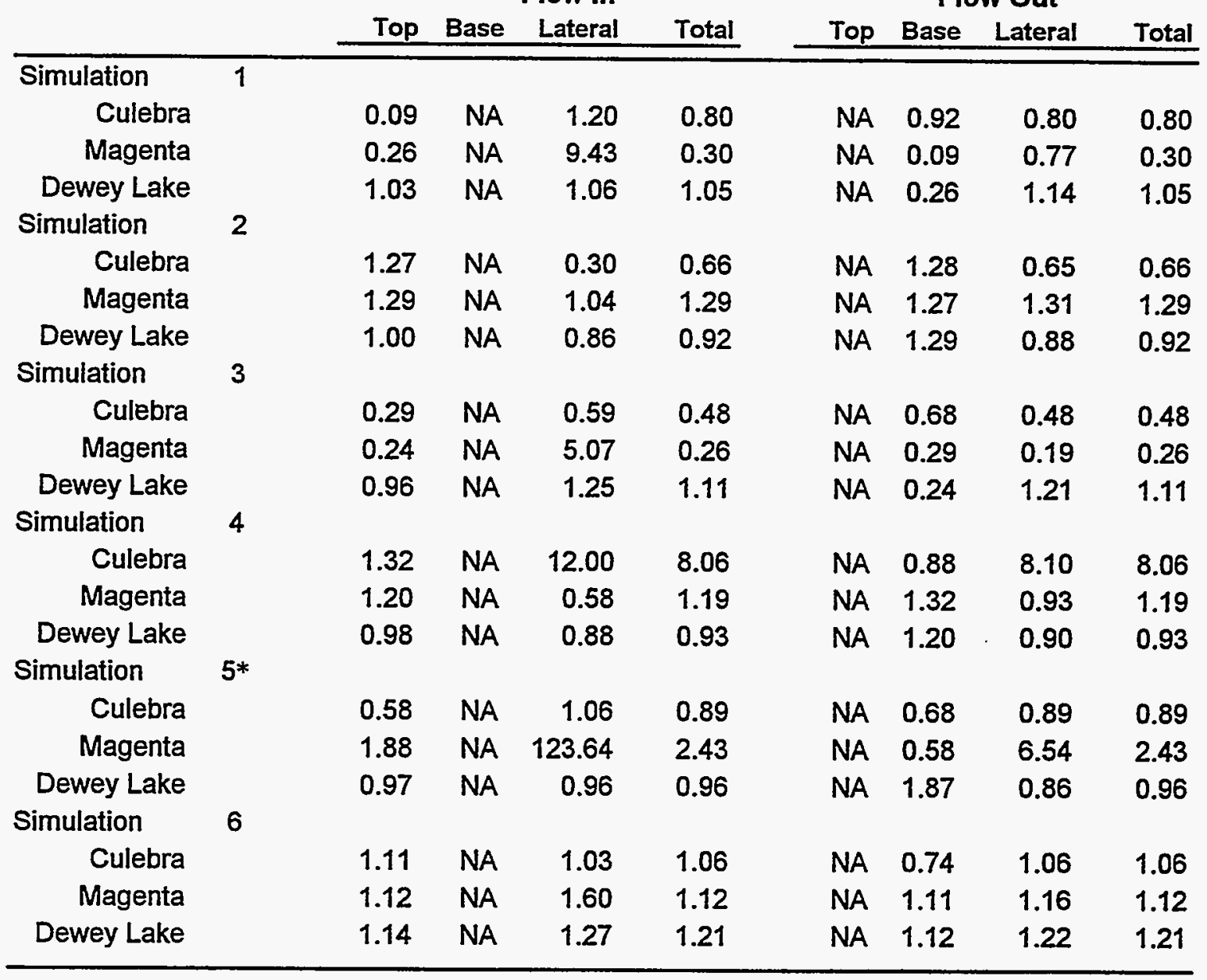

* This simulation ended prematurely (after about $21 \mathrm{cpu}$ days). The fraction of base-case ratio was calculated using a value of total flow at 9,200 years in the future. 
Table D-7. Mass Balance Over the Reference Volumes: Fractions of Time-Zero Values 10,000 Years / 0 years

Flow in

Flow Out

\begin{tabular}{|c|c|c|c|c|c|c|c|c|c|}
\hline & & Top & Base & Lateral & Total & Top & Base & Lateral & Total \\
\hline Simulation & $\overline{b c}$ & & & & & & & & \\
\hline Culebra & & 1.87 & NA & 1.52 & 1.60 & NA & NA & 1.58 & 1.59 \\
\hline Magenta & & 2.25 & NA & 0.52 & 2.21 & NA & 2.02 & 2.66 & 2.19 \\
\hline Dewey Lake & & 3.75 & NA & 3.04 & 3.34 & $N A$ & 2.34 & 3.35 & 3.21 \\
\hline Simulation & 1 & & & & & & & & \\
\hline Culebra & & 1.23 & NA & 1.26 & 1.24 & NA & NA & 1.23 & 1.24 \\
\hline Magenta & & 2.08 & NA & 1.29 & 1.91 & NA & 2.25 & 1.78 & 1.86 \\
\hline Dewey Lake & & 3.78 & NA & 3.57 & 3.67 & NA & 2.37 & 3.55 & 3.51 \\
\hline Simulation & 2 & & & & & & & & \\
\hline Culebra & & 1.52 & NA & 2.03 & 1.58 & NA & NA & 1.56 & 1.58 \\
\hline Magenta & & 1.71 & NA & 0.37 & 1.69 & NA & 1.59 & 1.90 & 1.68 \\
\hline Dewey Lake & & 3.53 & NA & 2.59 & 3.00 & NA & 1.76 & 3.26 & 2.90 \\
\hline Simulation & 3 & & & & & & & & \\
\hline Culebra & & 2.59 & NA & 1.94 & 2.01 & NA & NA & 1.99 & 2.00 \\
\hline Magenta & & 8.52 & NA & 0.35 & 2.61 & NA & 2.87 & 5.28 & 2.55 \\
\hline Dewey Lake & & 1.68 & NA & 0.51 & 0.72 & NA & 9.83 & 0.70 & 0.72 \\
\hline Simulation & 4 & & & & & & & & \\
\hline Culebra & & 1.58 & NA & 1.44 & 1.44 & NA & NA & 1.44 & 1.44 \\
\hline Magenta & & 1.84 & NA & 0.46 & 1.83 & NA & 1.67 & 2.49 & 1.81 \\
\hline Dewey Lake & & 3.37 & NA & 2.99 & 3.17 & NA & 1.90 & 3.35 & 3.04 \\
\hline Simulation & $5 *$ & & & & & & & & \\
\hline Culebra & & 1.81 & NA & 1.34 & 1.40 & NA & NA & 1.39 & 1.40 \\
\hline Magenta & & 2.37 & NA & 1.40 & 2.05 & NA & 2.01 & 2.04 & 2.04 \\
\hline Dewey Lake & & 3.71 & NA & 2.72 & 3.12 & NA & 2.42 & 3.21 & 3.01 \\
\hline Simulation & 6 & & & & & & & & \\
\hline Culebra & & 0.95 & NA & 1.02 & 0.98 & NA & NA & 0.98 & 0.98 \\
\hline Magenta & & 0.96 & NA & 0.64 & 0.96 & NA & 0.97 & 0.94 & 0.96 \\
\hline Dewey Lake & & 1.06 & NA & 0.84 & 0.92 & NA & 0.97 & 0.91 & 0.92 \\
\hline Simulation & 7 & & & & & & & & \\
\hline Culebra & & 2.38 & NA & 1.45 & 1.74 & NA & NA & 1.72 & 1.73 \\
\hline Magenta & & 2.86 & NA & 0.98 & 2.82 & NA & 2.57 & 3.33 & 2.79 \\
\hline Dewey Lake & & 6.32 & NA & 4.57 & 5.24 & NA & 2.96 & 5.36 & 5.06 \\
\hline Simulation & 8 & & & & & & & & \\
\hline Culebra & & 2.18 & NA & 1.30 & 1.59 & NA & NA & 1.58 & 1.58 \\
\hline Magenta & & 2.59 & NA & 1.16 & 2.57 & NA & 2.35 & 2.96 & 2.54 \\
\hline Dewey Lake & & 7.59 & NA & 4.73 & 5.76 & NA & 2.69 & 5.93 & 5.57 \\
\hline Simulation & 9 & & & & & & & & \\
\hline Culebra & & 1.93 & NA & 3.16 & 2.15 & NA & NA & 2.12 & 2.14 \\
\hline Magenta & & 2.20 & NA & 0.81 & 2.18 & NA & 2.04 & 2.46 & 2.16 \\
\hline Dewey Lake & & 5.83 & NA & 4.87 & 5.28 & NA & 2.26 & 5.82 & 5.11 \\
\hline
\end{tabular}

* This simulation ended prematurely (after about $21 \mathrm{cpu}$ days). The fraction of time-zero ratio was calculated using a value of total flow at 9,200 years in the future.

D- 15 
Table D-7. Mass Balance Over the Reference Volumes: Fractions of Time-Zero Values 10,000 Years $/ 0$ years (continued)

Flow In

Flow Out

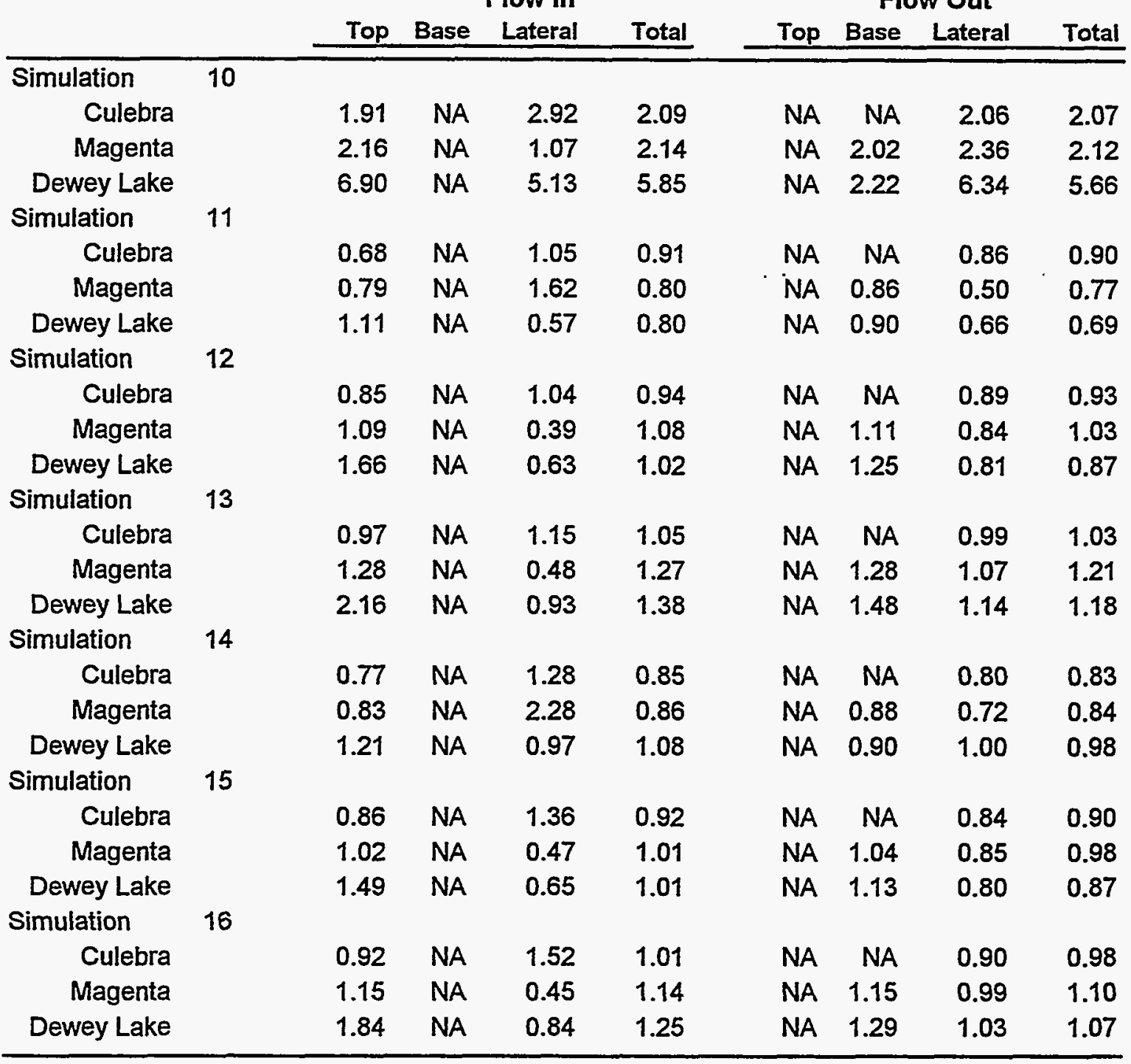


WIPP

UC721 - DISTRIBUTION LIST

SAND96-2133

\section{Federal Agencies}

US Department of Energy (4)

Office of Civilian Radioactive Waste Mgmt.

Attn: Deputy Director, RW-2

Acting Director, RW-10

Office of Human Resources \& Admin.

Director, RW-30

Office of Program Mgmt. \& Integ.

Director, RW-40

Office of Waste Accept., Stor., \& Tran.

Forrestal Building

Washington, DC 20585

Attn: Project Director

Yucca Mountain Site Characterization Office Director, RW-3

Office of Quality Assurance

101 Convention Center Drive, Suite \#P-110

Las Vegas, NV 89109

US Department of Energy

Albuquerque Operations Office

Attn: National Atomic Museum Library

P.O. Box 5400

Albuquerque, NM 87185-5400

US Department of Energy

Research \& Waste Management Division

Attn: Director

P.O. Box E

Oak Ridge, TN 37831

US Department of Energy (5)

Carlsbad Area Office

Attn: G. Dials

D. Galbraith

M. McFadden

R. Lark

J. A. Mewhinney

P.O. Box 3090

Carlsbad, NM 88221-3090

US Department of Energy

Office of Environmental Restoration and

Waste Management

Attn: J. Lytle, EM-30

Forrestal Building

Washington, DC 20585-0002
US Department of Energy (3)

Office of Environmental Restoration and

Waste Management

Attn: M. Frei, EM-34, Trevion II

Washington, DC 20585-0002

US Department of Energy

Office of Envirommental Restoration and Waste Management

Attn: S. Schneider, EM-342, Trevion II

Washington, DC 20585-0002

US Department of Energy (2)

Office of Environment, Safety \& Health

Attn: C. Borgstrom, EH-25

R. Pelletier, EH-231

Washington, DC 20585

US Department of Energy (2)

Idaho Operations Office

Fuel Processing \& Waste Mgmt. Division

785 DOE Place

Idaho Falls, ID 83402

US Environmental Protection Agency (2)

Radiation Protection Programs

Attn: M. Oge

ANR-460

Washington, DC 20460

\section{Boards}

Defense Nuclear Facilities Safety Board

Attn: D. Winters

625 Indiana Ave. NW, Suite 700

Washington, DC 20004

Nuclear Waste Technical Review Board (2)

Attn: Chairman

S. J. S. Parry

1100 Wilson Blvd., Suite 910

Arlington, VA 22209-2297

Distribution - 1 
State Agencies

Attorney General of New Mexico

P.O. Drawer 1508

Santa Fe, NM 87504-1508

Environmental Evaluation Group (3)

Attn: Library

7007 Wyoming NE

Suite F-2

Albuquerque, NM 87109

NM Energy, Minerals, and.Natural

Resources Department

Attn: Library

2040 S. Pacheco

Santa Fe, NM 87505

NM Environment Department (3)

Secretary of the Environment

Attn: Mark Weidler

1190 St. Francis Drive

Santa Fe, NM 87503-0968

NM Bureau of Mines \& Mineral Resources

Socorro, NM 87801

NM Environment Department

WIPP Project Site

Attn: P. McCasland

P.O. Box 3090

Carlsbad, NM 88221

\section{Laboratories/Corporations}

Battelle Pacific Northwest Laboratories Attn: R. E. Westerman, MSIN P8-44

Battelle Blvd.

Richland, WA 99352

INTERA, Inc.

Attn: G. A. Freeze

1650 University Blvd. NE, Suite 300

Albuquerque, NM 87102

INTERA, Inc.

Attn: J. F. Pickens

6850 Austin Center Blvd., Suite 300

Austin, TX 78731

INTERA, Inc.

Attn: W. Stensrud

P.O. Box 2123

Carlsbad, NM 88221
Los Alamos National Laboratory

Attn: B. Erdal, INC-12

P.O. Box 1663

Los Alamos, NM 87544

RE/SPEC, Inc

Attn: Angus Robb

4775 Indian School NE, Suite 300

Albuquerque, NM 87110-3927

$\mathrm{RE} / \mathrm{SPEC}$, Inc

Attn: J. L. Ratigan

P.O. Box 725

Rapid City, SD 57709

Tech Reps, Inc. (3)

Attn: J. Chapman (1)

Loretta Robledo (2)

5000 Marble NE, Suite 222

Albuquerque, NM 87110

Westinghouse Electric Corporation (5)

Attn: Library

J. Epstein

J. Lee

B. A. Howard

R. Kehrman

P.O. Box 2078

Carlsbad, NM 88221

S. Cohen \& Associates

Attn: Bill Thurber

1355 Beverly Road

McLean, VA 22101

National Academy of Sciences, WIPP Panel

Howard Adler

Oxyrase, Incorporated

7327 Oak Ridge Highway

Knoxville, TN 37931

Bob Andrews

Board of Radioactive Waste Management

GF456

2101 Constitution Ave.

Washington, DC 20418

Rodney C. Ewing

Department of Geology

University of New Mexico

Albuquerque, NM 87131

Distribution - 2 
Charles Fairhurst

Department of Civil and Mineral Engineering

University of Minnesota

500 Pillsbury Dr. SE

Minneapolis, MN 55455-0220

B. John Garrick

PLG Incorporated

4590 MacArthur Blvd., Suite 400

Newport Beach, CA 92660-2027

Leonard F. Konikow

US Geological Survey

431 National Center

Reston, VA 22092

Carl A. Anderson, Director

Board of Radioactive Waste Management

National Research Council

HA 456

2101 Constitution Ave. NW

Washington, DC 20418

Christopher G. Whipple

ICF Kaiser Engineers

1800 Harrison St., 7th Floor

Oakland, CA 94612-3430

John O. Blomeke

720 Clubhouse Way

Knoxville, TN 37909

Sue B. Clark

University of Georgia

Savannah River Ecology Lab

P.O. Drawer E

Aiken, SC 29802

Konrad B. Krauskopf

Department of Geology

Stanford University

Stanford, CA 94305-2115

Della Roy

Pennsylvania State University

217 Materials Research Lab

Hastings Road

University Park, PA 16802

David A. Waite

$\mathrm{CH}_{2} \mathrm{M}$ Hill

P.O. Box 91500

Bellevue, WA 98009-2050
Thomas A. Zordon

Zordan Associates, Inc.

3807 Edinburg Drive

Murrysville, PA 15668

Dr. J. Bredehoeft

P.O. Box 352

La Honda, CA 94020

\section{Universities}

University of New Mexico

Geology Department

Attn: Library

141 Northrop Hall

Albuquerque, NM 87131

University of Washington

College of Ocean \& Fishery Sciences

Attn: G. R. Heath

583 Henderson Hall, HN-15

Seattle, WA 98195

Dr. J. Bahr

Department of Geology and Geophysics

University of Wisconsin

1215 West Dayton Street

Madison, WI 53706

\section{Libraries}

Thomas Brannigan Library

Attn: D. Dresp

$106 \mathrm{~W}$. Hadley St.

Las Cruces, NM 88001

Government Publications Department

Zimmerman Library

University of New Mexico

Albuquerque, NM 87131

New Mexico Junior College

Pannell Library

Attn: R. Hill

Lovington Highway

Hobbs, NM 88240

New Mexico State Library

Attn: N. McCallan

325 Don Gaspar

Santa Fe, NM 87503

Distribution - 3 
New Mexico Tech

Martin Speere Memorial Library

Campus Street

Socorro, NM 87810

WIPP Public Reading Room

Carlsbad Public Library

$101 \mathrm{~S}$. Halagueno St.

Carlsbad, NM 88220

\section{Foreign Addresses}

Atomic Energy of Canada, Ltd.

Whiteshell Laboratories

Attn: B. Goodwin

Pinawa, Manitoba, CANADA R0E 1L0

Francois Chenevier (2)

ANDRA

Route de Panorama Robert Schumann

B. P. 38

92266 Fontenay-aux-Roses, Cedex

FRANCE

Claude Sombret

Centre d'Etudes Nucleaires de la Vallee Rhone CEN/VALRHO

S.D.H.A. B.P. 171

30205 Bagnols-Sur-Ceze, FRANCE

Commissariat a L'Energie Atomique

Attn: D. Alexandre

Centre d'Etudes de Cadarache

13108 Saint Paul Lez Durance Cedex

FRANCE

Bundesanstalt fur Geowissenschaften und

Rohstoffe

Attn: M. Langer

Postfach 510153

D-30631 Hannover, GERMANY

Bundesministerium fur Forschung und

Technologie

Postfach 200706

5300 Bonn 2, GERMANY

Institut fur Tieflagerung

Attn: K. Kuhn

Theodor-Heuss-Strasse 4

D-3300 Braunschweig, GERMANY
Gesellschaft fur Anlagen und Reaktorsicherheit (GRS)

Attn: B. Baltes

Schwertnergasse 1

D-50667 Cologne, GERMANY

Shingo Tashiro

Japan Atomic Energy Research Institute

Tokai-Mura, Ibaraki-Ken, 319-11

JAPAN

Netherlands Energy Research Foundation ECN

Attn: J. Prij

3 Westerduinweg

P.O. Box 1

1755 ZG Petten

THE NETHERLANDS

Svensk Karnbransleforsorjning $A B$

Attn: F. Karlsson

Project KBS (Karnbranslesakerhet)

Box 5864

S-102 48 Stockholm

SWEDEN

Nationale Genossenschaft fur die Lagerung

Radioaktiver Abfalle (2)

Attn: S. Vomvoris

P. Zuidema

Hardstrasse 73

CH-5430 Wettingen

SWITZERLAND

AEA Technology

Attn: J. H. Rees

D5W/29 Culham Laboratory

Abington, Oxfordshire OX14 3DB

UNITED KINGDOM

AEA Technology

Attn: W. R. Rodwell

044/A31 Winfrith Technical Centre

Dorchester, Dorset DT2 8DH

UNTTED KINGDOM

AEA Technology

Attn: J.E. Tinson

B4244 Harwell Laboratory

Didcot, Oxfordshire OX11 ORA

UNTTED KINGDOM 


\section{Internal}

\begin{tabular}{|c|c|c|}
\hline$\underline{\text { MS }}$ & Org. & \\
\hline 1324 & 6115 & P. B. Davies \\
\hline 1320 & 6831 & E. J. Nowak \\
\hline 1322 & 6121 & J. R. Tillerson \\
\hline 1324 & 6115 & L. Meigs \\
\hline 1324 & 6115 & A. Lappin \\
\hline 1324 & 6115 & T. Corbet (40) \\
\hline 1328 & 6849 & D. R. Anderson \\
\hline 1328 & 6848 & H. N. Jow \\
\hline 1335 & 6801 & M. Chu \\
\hline 1341 & 6832 & J. T. Holmes \\
\hline 1341 & 6822 & K. Larson \\
\hline 1395 & 6800 & L. Shephard \\
\hline 1395 & 6821 & M. Marietta \\
\hline 1341 & 6832 & L. Brush \\
\hline 1395 & 6841 & V. H. Slaboszewicz \\
\hline 1395 & 6821 & P. Swift \\
\hline 1330 & 6811 & K. Hart (2) \\
\hline 1330 & 4415 & NWM Library (20) \\
\hline 9018 & $8523-2$ & Central Technical Files \\
\hline 0899 & 4414 & Technical Library (5) \\
\hline 0619 & 12630 & $\begin{array}{l}\text { Review and Approval Desk (2) } \\
\text { For DOE/OSTI }\end{array}$ \\
\hline
\end{tabular}

Distribution - 5 